\title{
The Role of Social Security in Respecting and Protecting the Dignity of Lone Mothers in South Africa: Final Report
}

By

Gemma Wright, Michael Noble, Phakama Ntshongwana, David Neves and Helen Barnes 


\section{Acknowledgements}

This project was funded by the UK Department for International Development and the Economic and Social Research Council (ESRC Ref ES/I033130/1). The views expressed herein are those of the authors and not necessarily of the funders. The Human Sciences Research Council is thanked for including questions within the South African Social Attitudes Survey (SASAS). The focus group, in-depth interview, and elite interview participants are thanked for their time and contributions. Members of the Advisory Group are thanked for their time and advice. Veliswa Cebisa, Thandeka Adoro, Danielle Daniels, Jacqueline Tamri, Sibongile Mtini and Joanna Davies are thanked for their assistance with the focus groups and in-depth interviews.

\section{About the authors}

Dr Gemma Wright - Senior Research Fellow, Centre for the Analysis of South African Social Policy (CASASP), Oxford Institute of Social Policy, University of Oxford, UK. She is also a Professor Extraordinarius at the Archie Mafeje Research Institute at the University of South Africa, a Research Associate at Rhodes University, and a Visiting Fellow at the Centre for International Education at the University of Sussex.

Prof Michael Noble - Emeritus Professor, Oxford Institute of Social Policy, University of Oxford, UK. He is also a Director of the Southern African Social Policy Research Institute, an Honorary Fellow at the Human Sciences Research Council and a Visiting Professor at Rhodes University.

Dr Phakama Ntshongwana - Head of Missionvale Campus, Nelson Mandela Metropolitan University, Port Elizabeth, South Africa. She was previously a Research Fellow at CASASP, Oxford Institute of Social Policy, University of Oxford, UK.

David Neves - Senior Researcher, Institute for Poverty, Land and Agrarian Studies, University of the Western Cape, South Africa.

Dr Helen Barnes - Research Fellow at CASASP, Oxford Institute of Social Policy, University of Oxford, UK.

\section{Recommended citation}

Wright, G., Noble, M., Ntshongwana, P., Neves, D. And Barnes, H. (2014) The Role of Social Security in Respecting and Protecting Dignity of Lone Mothers in South Africa: Final Report, Oxford: Centre for the Analysis of South African Social Policy, University of Oxford. 


\section{Table of Contents}

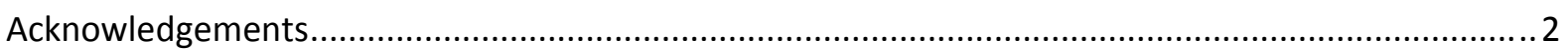

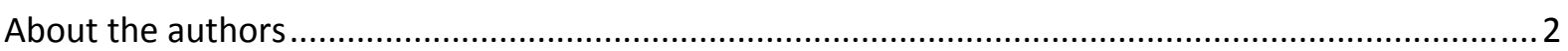

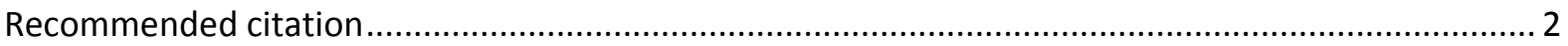

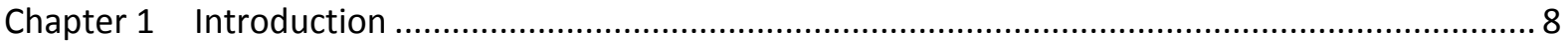

Chapter 2 Research methods and ethical considerations ........................................................... 12

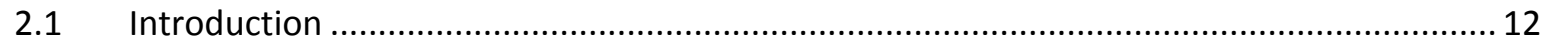

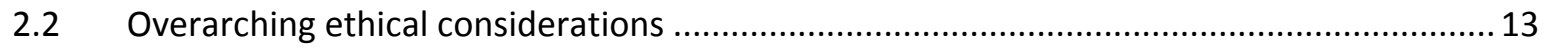

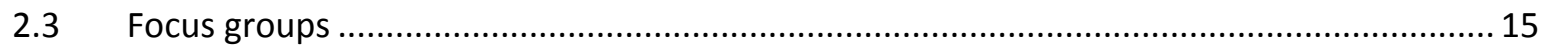

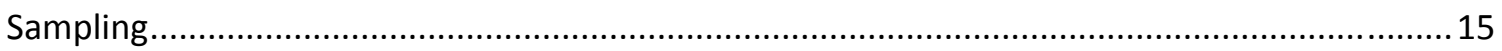

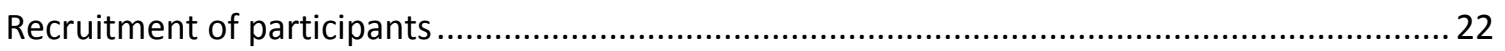

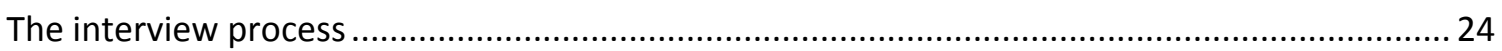

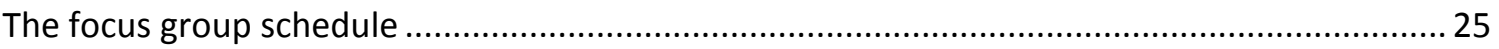

Analysis …

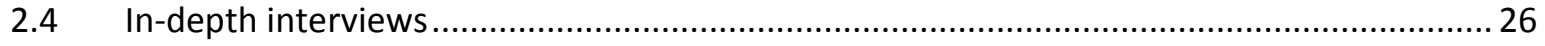

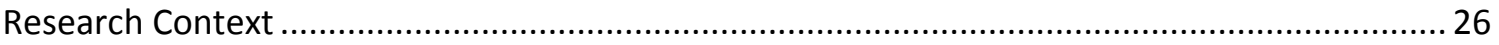

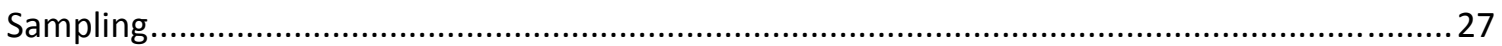

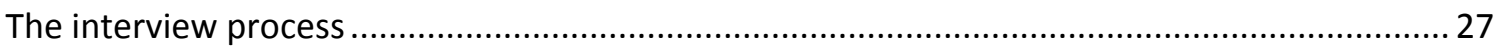

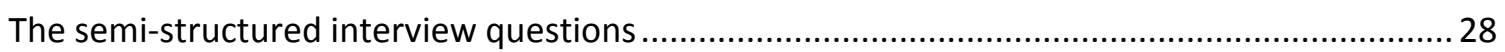

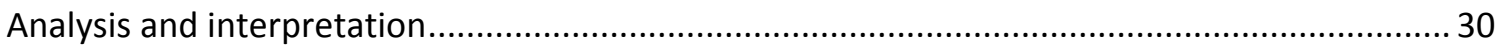

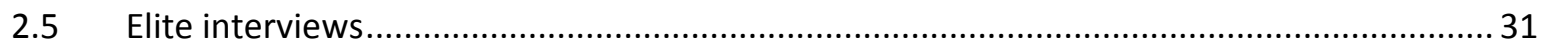

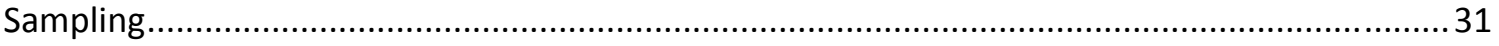

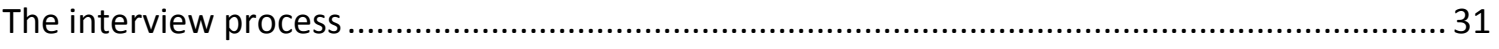

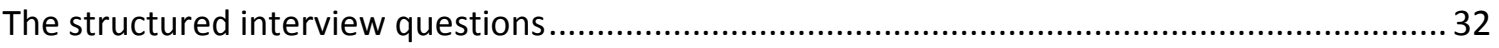

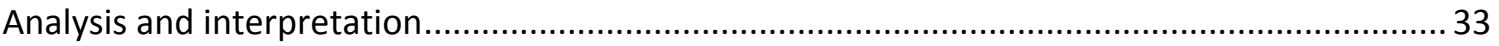

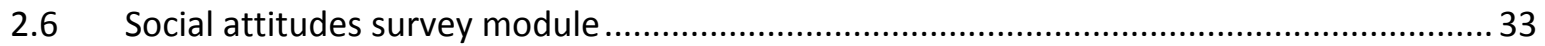

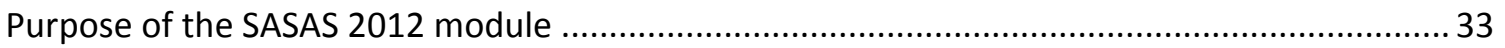

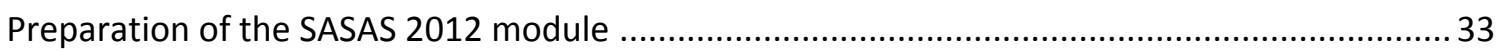

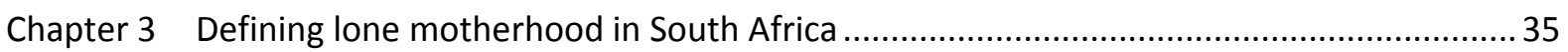

3.1 The terms 'lone mother', 'lone motherhood' and 'lone parent' ........................................... 35

3.2 Routes to lone motherhood in the South African context ................................................. 38

3.3 Towards a working definition of lone mothers in South Africa ............................................. 41

A model of the relational roles of a lone mother to a child ........................................................ 41 
Honing our focus for the project

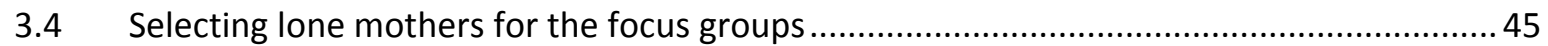

3.5 A profile of lone mothers in South Africa using the General Household Survey 2011.........46

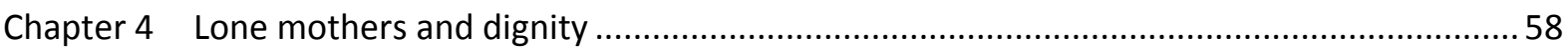

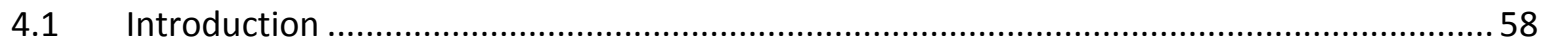

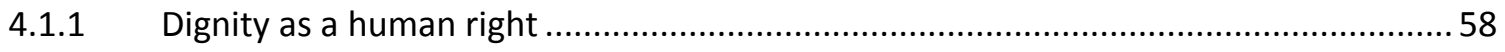

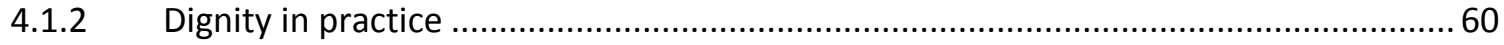

4.2 Dignity and lone mothers: the focus group interviews …................................................. 61

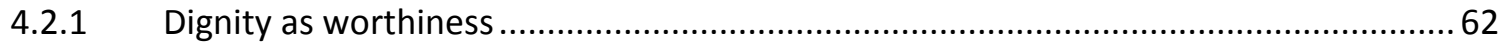

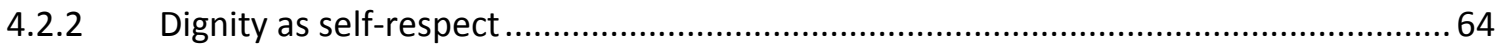

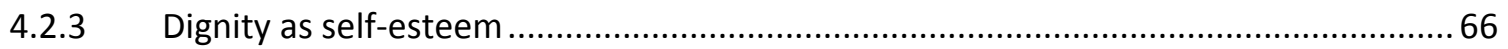

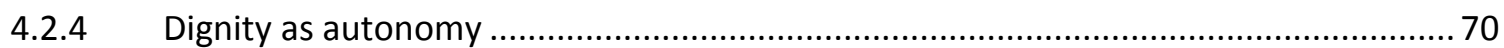

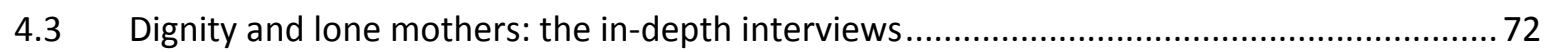

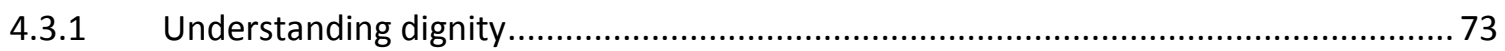

4.3.2 Understanding indignity, impaired or eroded dignity .............................................. 77

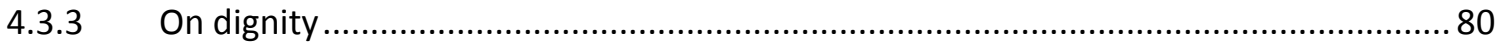

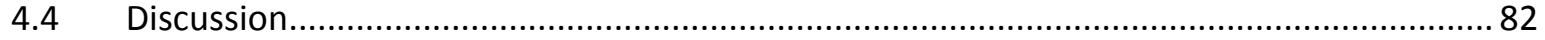

Chapter 5 Lone mothers' experiences of poverty and inequality and their impact on dignity.........84

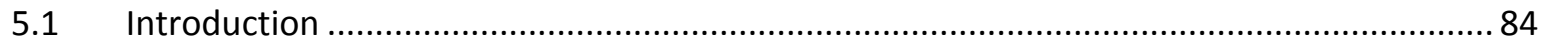

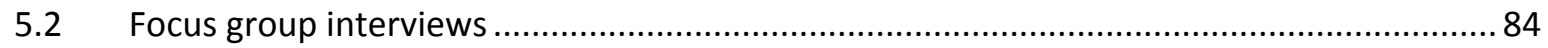

5.2.1 Techniques to survive poverty and their impact on dignity ....................................... 85

5.2.2 Impact of poverty on lone mothers' dignity: strained family relations ........................93

5.2.3 Impact of poverty on lone mothers' dignity: reduced standing within the community 97

5.2.4 Impact of poverty on lone mothers' dignity: the personal toll................................ 100

5.2.5 Impact of inequality on lone mothers' dignity ........................................................ 104

5.3 Lone Mother's practical experience of poverty and inequality, and how these impact on

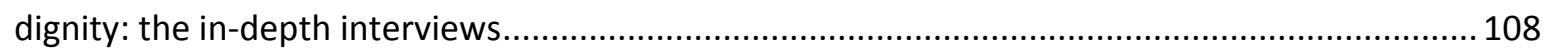

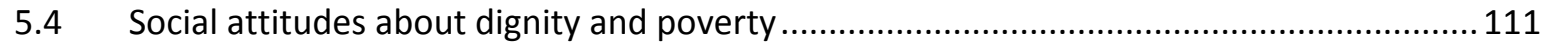

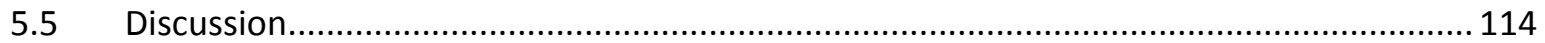

Chapter 6 Social security for lone mothers in South Africa ........................................................... 116

6.1 International commitments to social security as a human right ....................................... 116

6.2 Social security for lone mothers in South Africa - is there any? ........................................ 118

6.2.1 Social assistance for lone mothers in South Africa ................................................... 118 
6.3 Examples of other forms of state or state-governed support in the absence of comprehensive social security

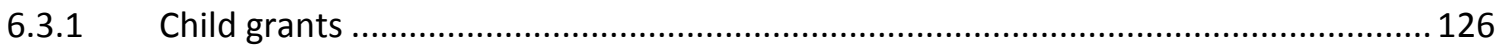

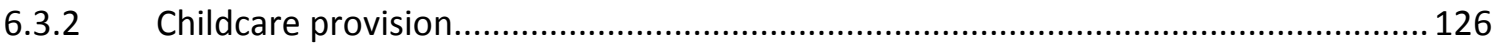

6.3.3 Child support/maintenance from non-resident parents ......................................... 127

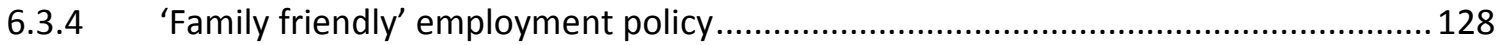

6.4 Dignity and social security policy design: the elite interviews .......................................128

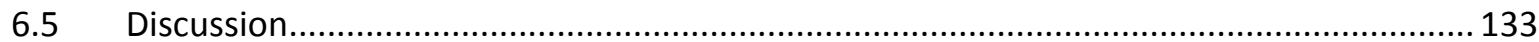

Chapter 7 Lone mothers' accounts of how applying for and collecting the Child Support Grant

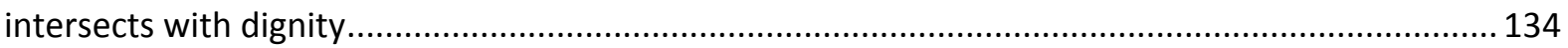

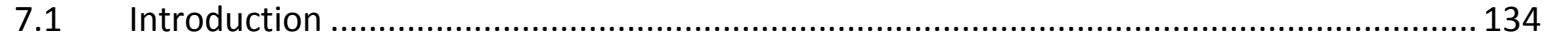

7.2 Applying for the Child Support Grant: the focus group interviews ................................. 135

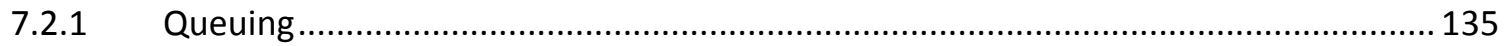

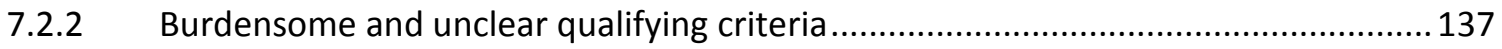

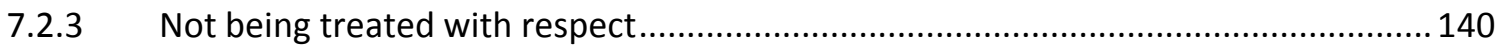

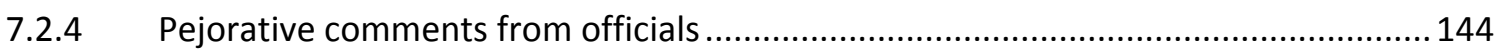

7.2.5 Deferring application - an unaffordable option for most ........................................ 146

7.2.6 Collecting the Child Support Grant: focus group interviews ..................................... 147

7.3 Lone mothers' experiences of applying for and collecting the CSG and its impact on dignity:

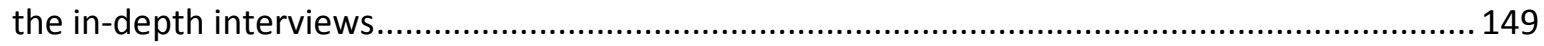

7.4 Dignity and social security policy implementation: the elite interviews ..........................156

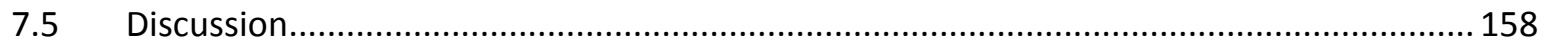

Chapter 8 Lone mothers and how CSG as a source of income, and the status of being a CSG

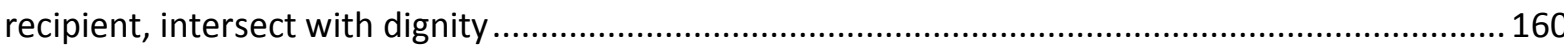

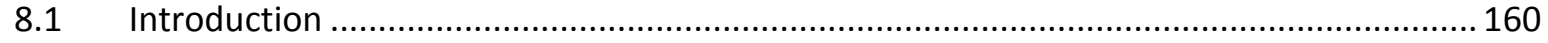

8.2 The CSG as a source of income, and the status of being a CSG recipient: the focus group interviews.

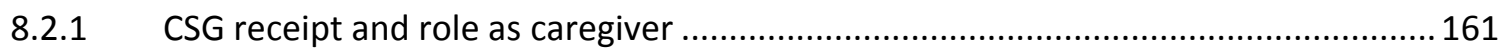

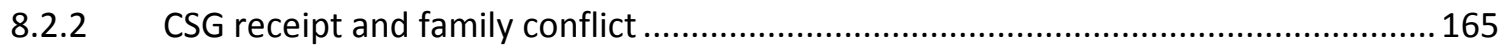

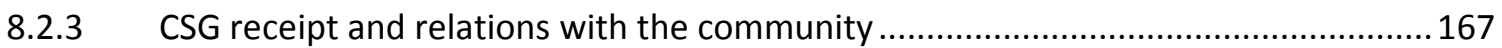

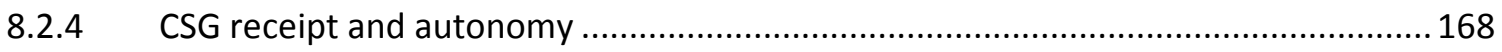

8.3 The CSG as a source of income, and the status of being a CSG recipient: the in-depth interviews. 


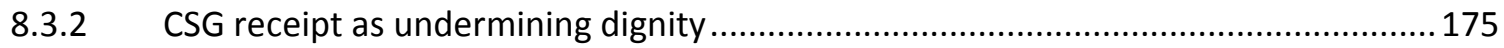

8.3.3 Examining the experience of social grant use.......................................................... 180

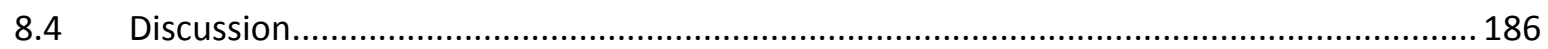

Chapter 9 Social security, traditional forms of social support and Ubuntu .................................189

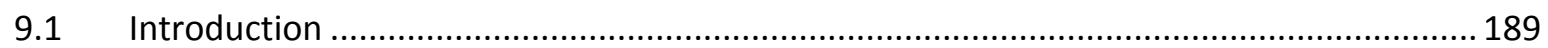

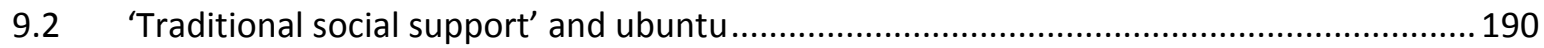

9.3 Understanding social security and 'traditional social support' : the in-depth interviews... 192

9.3.1 Traditional social support and dignity-enhancing dynamics of the CSG ....................192

9.3.2 Traditional social support and dignity-eroding dynamics of the CSG ........................ 195

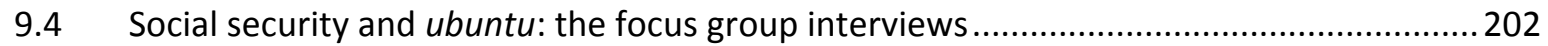

9.5 Social attitudes towards state, community and family support........................................ 204

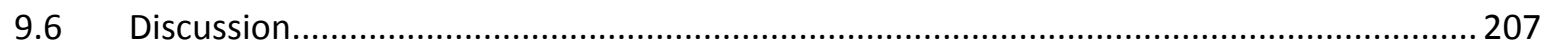

Chapter 10 Social security for lone mothers - if it existed how might it affect recipients' dignity? 209

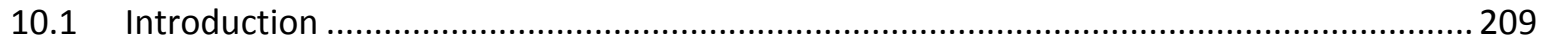

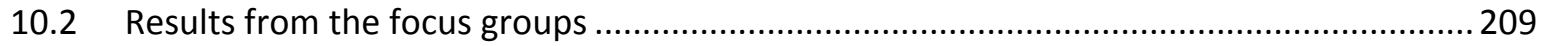

10.2.1 Improved ability to provide for children ................................................................... 210

10.2.2 Improved ability to meet one's own needs ...........................................................212

10.2.3 Concerns about negative or unintended consequences .............................................216

10.3 Social attitudes about social security for single mothers .................................................... 219

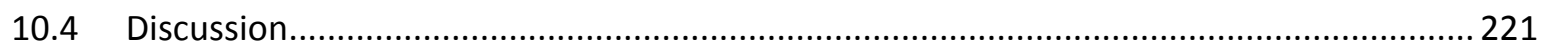

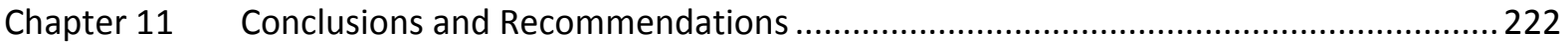

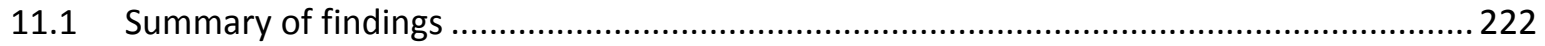

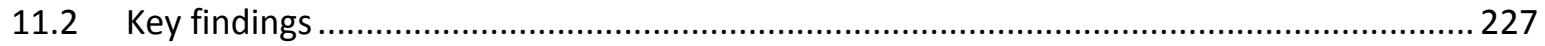

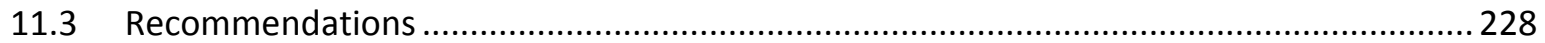

Annex 1: Information and consent form for focus group participants (English, isiXhosa and Afrikaans)

Annex 2: Demographics Questionnaire for focus group and in-depth interview participants

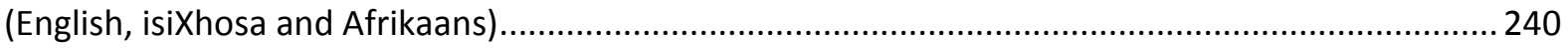

Annex 3: Focus group questionnaire (English, isiXhosa and Afrikaans) ......................................243

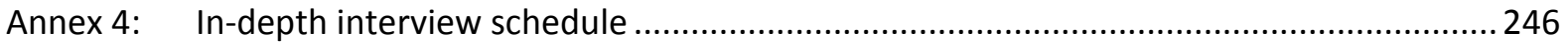

Annex 5: Information and consent form for in-depth interview participants (English and isiXhosa) 247

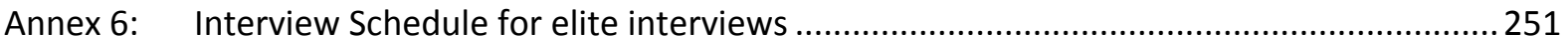

Annex 7: Identifying lone mothers in the GHS 2011............................................................... 252 
Annex 8 Social security for lone mothers elsewhere - some examples.

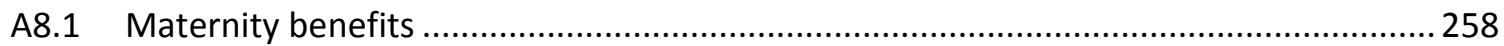

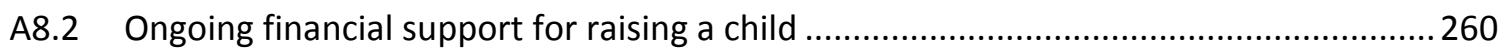

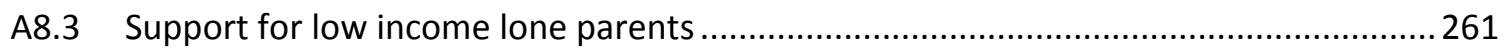

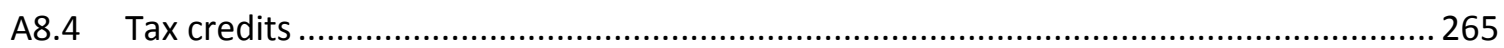

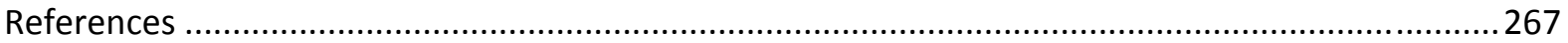

\# 


\section{Chapter 1 Introduction}

This is the final report of a project entitled 'Lone Mothers in South Africa: The role of social security in respecting and protecting dignity'. The project was inspired by research undertaken for the South African Department of Social Development (DSD) about attitudes to employment and social security (e.g. Noble et al., 2008; Ntshongwana, 2010a and 2010b; Surender et al., 2007; Surender et al., 2010). During the fieldwork for that programme of research, participants in focus groups repeatedly made the unprompted point that poverty eroded their sense of dignity. Given that the South African Constitution declares that people have inherent dignity and that dignity should be protected and respected (Republic of South Africa, 1996), we decided to design a project dedicated to exploring the role that social security currently plays in relation to people's sense of dignity. Specifically we hoped to explore whether social assistance, as a financial transfer to low income people, serves to help to protect and respect people's dignity, or conversely whether there are ways in which the country's social security arrangements serve to undermine people's dignity.

Currently, there is no social assistance for low income people of working age unless they are entitled to claim the Disability Grant. There is however a commitment elsewhere in the Constitution to the progressive realisation of access to social assistance for people, and their dependants, who are unable to support themselves (Republic of South Africa, 1996: Chapter 2 section 27). It therefore seemed relevant to explore in addition whether people thought that - in the context of very high levels of unemployment - some additional form of social assistance might be a worthwhile poverty alleviation measure that would help to protect and respect people's sense of dignity, or whether it might serve to further erode people's sense of dignity.

Although the issues around poverty, dignity and social security could be explored with any subgroup of the population, lone mothers (broadly defined, as elaborated in Chapter 3) were selected for several reasons. First, they embody the societal expectations of caregiver and breadwinner - roles which are difficult to reconcile even if there is financial support from the state (e.g. Lewis, 2010; Mokomane, 2009). Second, as lone mothers typically have a low level of educational qualifications and in the context of high unemployment, any paid work is likely to be insecure and poorly paid. Third, if employment opportunities are available, state provided childcare facilities are inadequate in many areas, and even if private provision is physically accessible it is usually unaffordable for low income families (Goldblatt, 2001; Dawes et al., 2010; Ntshongwana, 2010b; Richter et al., 2012), and so challenges are faced at every turn whether in work or not in work. Recent research indicates that lone mothers in South Africa experience particularly high levels of poverty, and suffer financial (and often physical) insecurity which is compounded by a lack of autonomy (e.g. Ntshongwana, 2010a and 2010b). In addition this group internationally and within South Africa are often the focal point for debates around the undeserving poor, 
dependency culture, perverse incentives and the unsustainability of the social security budget, and are often the object of negative sentiment in the media.

In order to explore the role of social security in respecting and protecting the dignity of lone mothers, the project had six subsidiary research questions which are considered in this report:

Q1: Given the importance accorded to dignity in the Constitution and elsewhere, how do lone mothers interpret its meaning in the context of their own lives?

Q2: How do lone mothers' lived experiences of poverty and inequality impact on their dignity?

Q3: To what extent do lone mothers regard social grants as respecting and protecting their dignity?

Q4: How does the actual experience of claiming CSG intersect with lone mothers' sense of dignity?

Q5: To what extent do policy makers take into account people's dignity in the process of social security design and implementation?

Q6: What is the relationship between dignity, social security and ubuntu ${ }^{1}$ ?

A range of methodological approaches were used to explore the research questions including 30 focus groups and 16 in-depth interviews which were undertaken in the Eastern Cape and the Western Cape provinces in South Africa, as well as social attitudes survey data, and elite interviews with senior members of government. The methodological approaches and ethical considerations are described in Chapter 2.

Lone motherhood is rarely used as an analytical category in South Africa and so great care was taken to explore the term (Chapter 3 ) including consideration of the varied routes to lone motherhood in the South African context, and undertaking a profile of lone mothers in South Africa using the General Household Survey.

Before considering issues relating to dignity and social security in Chapters 6-10, Chapter 4 presents analysis from the focus groups and in-depth interviews of lone mother's portrayals of dignity, and Chapter 5 focuses broadly on the impact of poverty and inequality on the dignity of lone mothers. These provide the context for considering the role of social security.

In Chapter 6 the South African social security system is reviewed and the extent to which lone mothers are currently excluded from provision (along with most other unemployed working age people) is articulated. Although in their own right they are mainly excluded (unless disabled), many lone mothers do intersect with the social security system as recipients of the Child Support Grant which is social assistance for children with low

\footnotetext{
${ }^{1}$ For a full discussion on the meaning of ubuntu please see chapter 9.
} 
income caregivers. ${ }^{2}$ Chapter 6 also contains an analysis of the elite interviews on the extent to which dignity is taken into account as part of the social security policy design and Chapter 7 contains analysis of the elite interviews in respect of dignity and social security policy implementation.

In relation to the current social security arrangements, Chapters 7 and 8 explore ways in which the CSG intersects with lone mothers' dignity, looking first at the application and receipt process (Chapter 7 ) and then at the consequence of receipt, namely having and using the CSG, and being a CSG recipient (Chapter 8).

In Chapter 9 the intersections and tensions between traditional forms of social support and the formal provision of social security are considered. The concept of ubuntu is considered. In addition to in-depth interview material, social attitudes survey data is also drawn upon, to explore the extent to which the qualitative findings resonate with nationally representative survey data. In Chapter 10 lone mothers' views are explored about the introduction of a new grant for their own needs. Focus group material is presented, as well as social attitudes survey data. Lastly in Chapter 11 the findings are discussed, a number of policy recommendations are made, and issues are raised that would merit further exploration.

Dignity is a complex and socially embedded concept, which may have varied meanings across different groups, cultures and languages. This was acknowledged at the outset of the project, and varied attempts using different methodological approaches were used to try to shed light on how it is understood and experienced in practice. It was also acknowledged from the outset that issues relating to dignity encompass aspects of life that fall wholly outside the realm of social security.

In relation to social security, and as will be elaborated in Chapter 6, although lone mothers used to be eligible for social assistance this was phased out between 1998 and 2001 and there is currently no social assistance for lone mothers of working age unless they are disabled. This report therefore spans the various situations of past provision (referred to by a small number of focus group participants), current absence of provision (ch5 and 6), current provision of social assistance for children in low income families (ch6-9), and prospective provision of social assistance for caregivers (ch10).

Every attempt was made to make no prior assumptions about the function of past/current/future social security arrangements with respect to their impact on lone mothers' dignity. Accordingly, the material was analysed to explore whether there were dignity protecting/respecting elements, and dignity eroding elements associated with current arrangements and (in Chapter 10) a hypothetical grant for caregivers. It proved useful to distinguish different aspects of social security provision as they yielded quite different results. These can be summarised as follows:

\footnotetext{
${ }^{2}$ In this report reference is made to the Child Support Grant (CSG) being received by adult (female) recipients. Child Support Grant recipients collect the CSG on behalf of beneficiary children, hence the respective descriptors of 'recipients' and 'beneficiaries' are used.
} 
- The experience of having no social security for own material needs [Ch5]

- The experience of claiming and collecting the CSG [Ch7]

- The experience of using the CSG [Ch8 and Ch9]

- The experience of categorically 'being' a CSG recipient [Ch8]

- The prospect of having social security for own material needs [Ch10]

Each of these experiences could serve to respect and protect dignity, or could be 'neutral' in respect of dignity, or could be erosive of dignity, on a continuum. 


\section{Chapter 2 Research methods and ethical considerations}

Summary: This chapter provides details about the research methods that were used in the project as well as the principles of ethical research that informed each stage of the project. Details are provided about the focus groups, in-depth interviews, elite interviews, and modules in the South African Social Attitudes Survey 2006, 2007 and 2012.

\section{$2.1 \quad$ Introduction}

This chapter provides details about the research methods that were used in the project as well as the principles of ethical research that informed each stage of the project. Any practical or ethical challenges encountered during the fieldwork and analysis are also presented here. A range of very different methodological approaches were employed in order to explore the research questions: focus groups, in-depth interviews, elite interviews, a module in a social attitudes survey, and secondary analysis of existing datasets. Different methods were used to approach the project's six key research questions and these are summarised in Table 2.1.

Table 2.1 Summary of method of enquiry by research question

\begin{tabular}{|c|c|c|c|c|c|}
\hline Research Questions & $\begin{array}{l}\text { Focus } \\
\text { groups }\end{array}$ & $\begin{array}{l}\text { In-depth } \\
\text { interviews }\end{array}$ & $\begin{array}{c}\text { Elite } \\
\text { interviews }\end{array}$ & $\begin{array}{l}\text { Social } \\
\text { Attitudes } \\
\text { Survey }\end{array}$ & $\begin{array}{l}\text { Other } \\
\text { 2ndary data } \\
\text { analysis }\end{array}$ \\
\hline $\begin{array}{l}\text { Q1: Given the importance accorded to dignity } \\
\text { in the Constitution and elsewhere, how do lone } \\
\text { mothers interpret its meaning in the context of } \\
\text { their own lives? [Chapter 4] }\end{array}$ & $\checkmark$ & $\checkmark$ & - & $\checkmark$ & - \\
\hline $\begin{array}{l}\text { Q2: How do lone mothers' lived experiences of } \\
\text { poverty and inequality impact on their dignity? } \\
\text { [Chapter } 5]\end{array}$ & $\checkmark$ & $\checkmark$ & - & $\checkmark$ & - \\
\hline $\begin{array}{l}\text { Q3: To what extent do lone mothers regard } \\
\text { social grants as respecting and protecting their } \\
\text { dignity? [Chapters 7-10] }\end{array}$ & $\checkmark$ & $\checkmark$ & - & - & - \\
\hline $\begin{array}{l}\text { Q4: How does the actual experience of } \\
\text { claiming CSG intersect with lone mothers' } \\
\text { sense of dignity? [Chapter 7] }\end{array}$ & $\checkmark$ & $\checkmark$ & - & - & - \\
\hline $\begin{array}{l}\text { Q5: To what extent do policy makers take into } \\
\text { account people's dignity in the process of } \\
\text { social security design and implementation? } \\
\text { [Chapters 6-7] }\end{array}$ & - & - & $\checkmark$ & - & - \\
\hline $\begin{array}{l}\text { Q6: What is the relationship between dignity, } \\
\text { social security and ubuntu? [Chapter 9] }\end{array}$ & $\checkmark$ & $\checkmark$ & - & $\checkmark$ & - \\
\hline $\begin{array}{l}\text { Context setting e.g. profile of lone mothers } \\
\text { (GHS) [Chapter 3]; selection of focus group } \\
\text { locations (Census of Population) [Chapter 2]; } \\
\text { social attitudes to social security (SASAS). } \\
\text { [Chapter 10] }\end{array}$ & - & - & - & $\checkmark$ & $\checkmark$ \\
\hline
\end{tabular}


The focus groups and in-depth interviews were the primary sources for questions 1-4; question 5 was explored using elite interviews; and for question 6 we used material from the focus groups and in-depth interviews as well as a dedicated module in the South African Social Attitudes Survey (SASAS) 2012. Contextual analysis was undertaken using a number of other data sources, particularly the General Household Survey, the Census of Population, and earlier years of SASAS.

\subsection{Overarching ethical considerations}

The project team gave serious consideration to the ethics of all aspects of the research, and these were scrutinised and approved by the University of Oxford's ethics procedure. The components of research undertaken by the University of the Western Cape (in particular the in-depth interviews) and the Human Sciences Research Council (piloting and implementing the 2012 South African Social Attitudes Survey for which the team had designed a dedicated module) were additionally scrutinised and approved by their respective ethics committees.

The University of Oxford's ethics procedure requires all research projects involving human participants to be submitted first to the Departmental Research Ethics Committee and then to the Interdisciplinary Research Ethics Committee, which includes independent lay members with specialist research ethics expertise and experience (www.admin.ox.ac.uk/curec). Additionally, all research is expected to adhere to the standards set out in ethics guidelines published by relevant bodies including the Economic and Social Research Council (e.g. ESRC, 2012) and the Social Research Association (e.g. SRA 2003 and 2008). ESRC's six key principles of ethical research are presented in Figure 1.

\section{Figure 1: The Economic and Social Research Councils' six key principles of ethical research}

1. Research should be designed, reviewed and undertaken to ensure integrity, quality and transparency.

2. Research staff and participants must normally be informed fully about the purpose, methods and intended possible uses of the research, what their participation in the research entails and what risks, if any, are involved.

3. The confidentiality of information supplied by research participants and the anonymity of respondents must be respected.

4. Research participants must take part voluntarily, free from any coercion.

5. Harm to research participants and researchers must be avoided in all instances.

6. The independence of research must be clear, and any conflicts of interest or partiality must be explicit.

Source: ESRC, 2012 pp.2-3. 
The University of Oxford's ethics procedures require consideration of the purpose of the research; the selection of participants; information and consent; privacy, anonymity and confidentiality of data; risks and benefits of the research (to researchers, participants or third parties); methods to be used; the use to which the results will be put; and dissemination, including feedback of the research to participants.

In seeking ethical approval from different organisations (University of Oxford in the UK, and in South Africa the University of the Western Cape and the Human Sciences Research Council) we strove to ensure a protective research experience for all researchers, participants and third parties. Nevertheless we did face some challenges and these are described in the relevant sections below, but two overarching issues are summarised here.

First, the Principal Investigator and lead institution are required by the ESRC to accept responsibility for the ethical aspects of the entire project. This required subcontracted organisations to not only go through their own ethical scrutiny processes for their components of the project, but also for their components of the project to be scrutinised by the lead organisation; as such this sets up an 'ethics power imbalance' to which it was important to be sensitive. Fortunately, for this project, there were no conflicting requirements across the organisations and so this was simply noted as being a sensitive issue (particularly with the lead institution being located in the northern hemisphere and sub-contracting two southern hemisphere institutions) rather than an impediment to the collaborative research.

Second, this research project considers a very sensitive and personal issue (that of dignity) in the context of the lives of low income women. The ESRC's guidelines actually refer to dignity explicitly, stating - perhaps even more forcefully than the South African constitution on the subject of dignity - that "Research should be designed in a way that the dignity and autonomy of research participants is protected and respected at all times." (ESRC, 2012: 3). This raised issues for self-reflection for the team as to how to approach such a group of women about such a personal issue as dignity in a sensitive way, so as to actively protect and respect their dignity. As part of this process we reflected on issues of difference, both within the team as well as between the team and the women being interviewed. As a team we reflected on the way in which some of us are women and some not, some are parents and some not, some have experienced lone parenthood and some not, some of us are South African and some not, some of us are black but most not, some of us speak the same mother tongue(s) as the women being researched but many of us do not, some of us would be older than the women being interviewed and some not, and all of us would be wealthier than the women under consideration. We discussed how such differences both within the team, and between the team and the women under consideration (e.g. gender, age, racial, cultural, economic) could best be taken into account when designing the research on the sensitive subject of dignity. In addition we drew from the ethics guidelines cited above; knowledge acquired from previous experiences in the field (e.g. du Toit and Neves, 2009a and 2009b; Neves et al., 2009; Surender et al., 2007 and 2010); and from current local debates on these issues (e.g. Hochfield and Graham, 2012; 
Swartz, 2011). These deliberations resulted in varying approaches being selected (variously principled and pragmatic).

\subsection{Focus groups}

\section{Sampling}

The focus groups and in-depth interviews were undertaken in two of South Africa's nine provinces: the Eastern Cape and the Western Cape. Based on analysis of the GHS (see chapter 3) almost a quarter of lone mothers who are living with their children live in these two provinces (23\%). These two provinces were selected for a number of reasons.

First, of the nine provinces in South Africa the Eastern Cape and the Western Cape are (or are among, depending on how it is measured) the most and least deprived provinces respectively. These two provinces therefore provided opportunities to undertake research in areas that were fairly homogenously deprived in the Eastern Cape, particularly in the highly deprived areas in the former homeland areas of the Transkei and Ciskei (e.g. Noble and Wright, 2013a), as well as in areas that are in closer proximity to less deprived areas. High levels of deprivation occur in rural farming communities and in townships on the outskirts of cities in both provinces, but in the Western Cape there are also areas of great affluence which might have an impact on low income people's attitudes on relevant issues (e.g. Noble and Wright, 2013b).

Second, these two provinces have distinct and long-standing patterns of migration which intersect with the issues of work-seeking and social security claiming patterns, and the research team have extensive experience of working in these areas previously (e.g. Du Toit and Neves, 2009a; Ntshongwana, 2010a and 2010b; Surender et al., 2007). The selection of these two sites therefore captures an important dimension of the rural urban poles, along which many households extend.

Third, by restricting the focus groups to these two provinces, the project only needed to employ three of South Africa's eleven official languages. Although English is the language of South African government, according to the 2011 Census the main language spoken by people in the Eastern Cape is isiXhosa (79\%) followed by Afrikaans (11\%), and the main language spoken by people in the Western Cape is Afrikaans (50\%) followed by isiXhosa (25\%) (Statistics South Africa, 2012c). The use of multiple languages greatly increases the complexity of qualitative and quantitative research (e.g. attempts to achieve conceptual harmony across languages, costs of translation) and by limiting the languages to three the issue could be contained.

Finally, given the large geographical size of country, the logistical costs of undertaking fieldwork (e.g. flights, car hire, accommodation) were also contained by focusing on two provinces.

The areas for the focus groups within these two provinces were selected in a twostage process using the municipality-level South African Index of Multiple Deprivation 2007 
(SAIMD 2007) (Wright and Noble, 2009) and the datazone-level SAIMD 2001 (Noble et al., 2009), and these are summarised below.

\section{South African Index of Multiple Deprivation 2007 (SAIMD 2007) at municipality-level}

The municipality-level SAIMD 2007 is an index comprising four dimensions of deprivation experienced by people in South Africa: income and material deprivation, employment deprivation, education deprivation and living environment deprivation (for details see Wright and Noble 2009). The SAIMD 2007 was constructed using data from Statistics South Africa's Community Survey 2007. The municipalities are ranked in order to identify the most deprived areas, with the most deprived having a rank of 1 and the least deprived a rank of 237. According to the overall multiple deprivation score Intsika Yethu municipality in the Eastern Cape was ranked as the most deprived municipality nationally.

Figure 2 shows the geography of deprivation across South Africa based on the SAIMD 2007. The municipalities have been divided into national quintiles of deprivation - five equal groups. On the map the thin grey line depicts the municipality boundaries. The most deprived $20 \%$ of municipalities nationally are shaded in a deep blue colour and the least deprived $20 \%$ of municipalities are shaded in a bright yellow (areas left white are municipalities that were excluded due to small numbers). As can be seen, the Eastern Cape contains many of the most deprived municipalities in South Africa, whereas in relative terms the Western Cape contains many of the least deprived municipalities.

Figure 2: South African Index of Multiple Deprivation 2007 (municipality level)

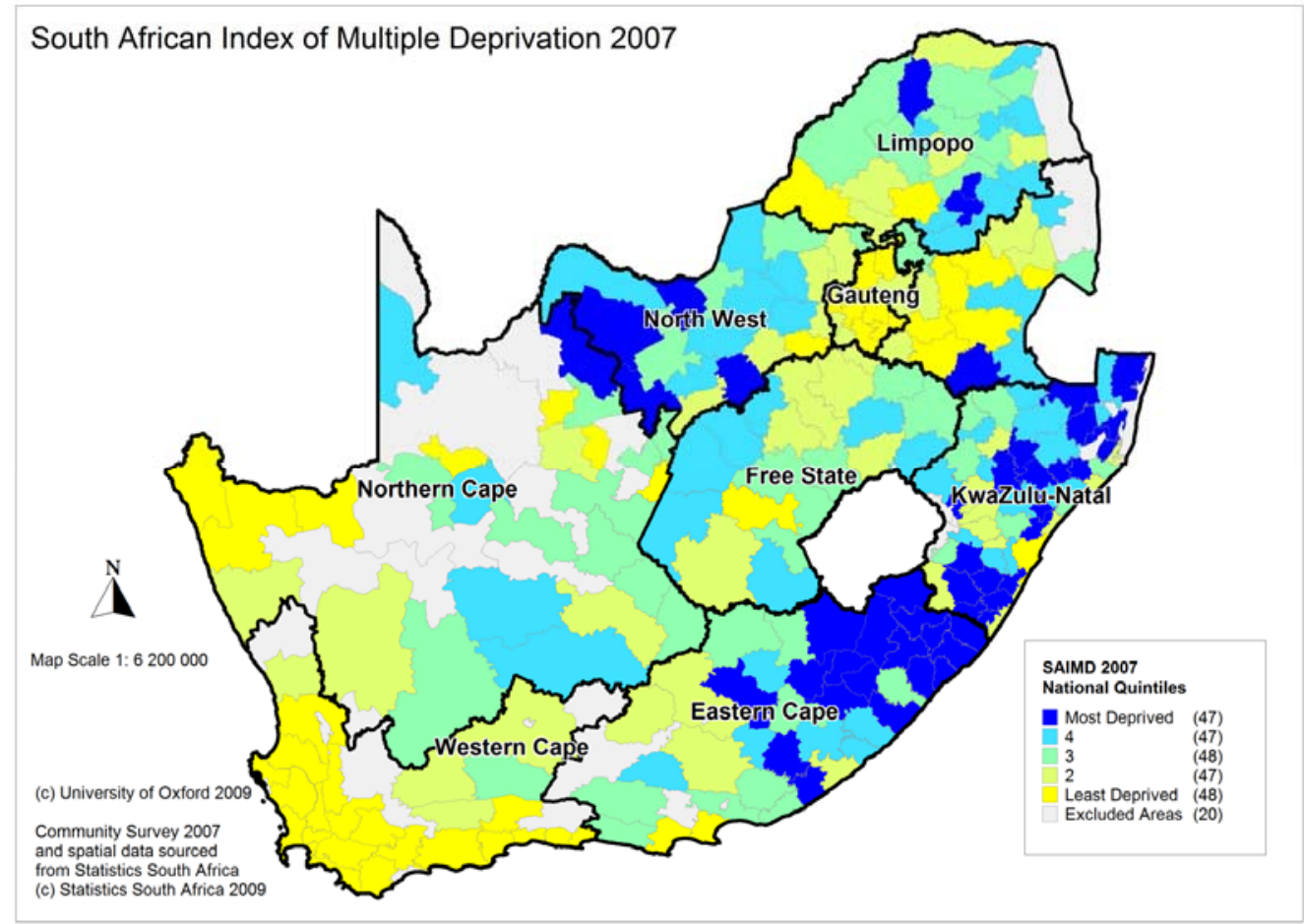




\section{South African Index of Multiple Deprivation 2001 (SAIMD 2001) at datazone-level}

The datazone-level SAIMD 2001 was constructed using similar methodology to the municipality-level SAIMD 2007, but additionally contained a health deprivation domain (Noble et al., 2009). Although based on older data (the 2001 Census of Population) it is much more fine-grained as it was constructed at datazone level. Datazones are small areas containing approximately the same number of people (on average 2,000 people). The datazone-level SAIMD 2001 therefore provides a fine-grained profile of deprivation in South Africa and enables pockets of deprivation to be identified.

As an example, Figure 3 shows a map of datazone level SAIMD 2001 for the Eastern Cape Province. The datazones have been divided into national deciles of deprivation - ten equal groups. The most deprived $10 \%$ of datazones (decile 10 ) are shaded in a deep blue colour and the least deprived $10 \%$ of datazones (decile 1 ) are shaded in yellow. The boundaries of the Former Transkei and Former Ciskei are marked in red, clearly portraying the high levels of deprivation in these two former homeland areas.

Returning to the issue of area selection, the municipality level SAIMD 2007 was used to select deprived municipalities. In the Western Cape, however, this was too large a geographical level as the City of Cape Town metropolitan area comprises highly deprived areas which are disguised by more affluent areas when profiled at this level of aggregation. The datazone level SAIMD 2001 was therefore additionally used for the selection of areas within municipalities.

It was important to include a range of area types in the qualitative fieldwork, including former homeland areas which are known to be disproportionately deprived. As seen in Figure 3, deprivation in the Eastern Cape is concentrated in the former homeland areas, and so most of the areas selected for fieldwork in the Eastern Cape were located in the Former Transkei or Former Ciskei. Additionally, we selected sites so as to include areas with formal and informal housing, peri-urban townships and rural farming areas. There is not an official urban/rural classification of areas, however, based on knowledge of areas and analysis of SAIMD which show how densely an area is populated we were able to classify areas we were able to ensure that urban and rural areas were captured. Consideration was also given to selecting areas located close to wealthier areas as views about dignity may be impacted by lived experiences of inequality.

Figure 4 shows a map of the focus groups in the Western Cape (apart from two near Paarl, further to the East). The focus groups are overlaid on national deciles of the SAIMD 2001. As can be seen, the selected sites are in the more deprived parts of Cape Town (shaded in blues) yet are located close to less deprived areas (in yellow). Figure 5 shows a map of the focus groups in the Eastern Cape, again overlaid on national deciles of the SAIMD 2001. 
Figure 3: Deprivation in the Eastern Cape (Datazone level SAIMD 2001)

South African Index of Multiple Deprivation 2001 at Datazone Level - Eastern Cape with boundaries of Former Ciskei and Former Transkei

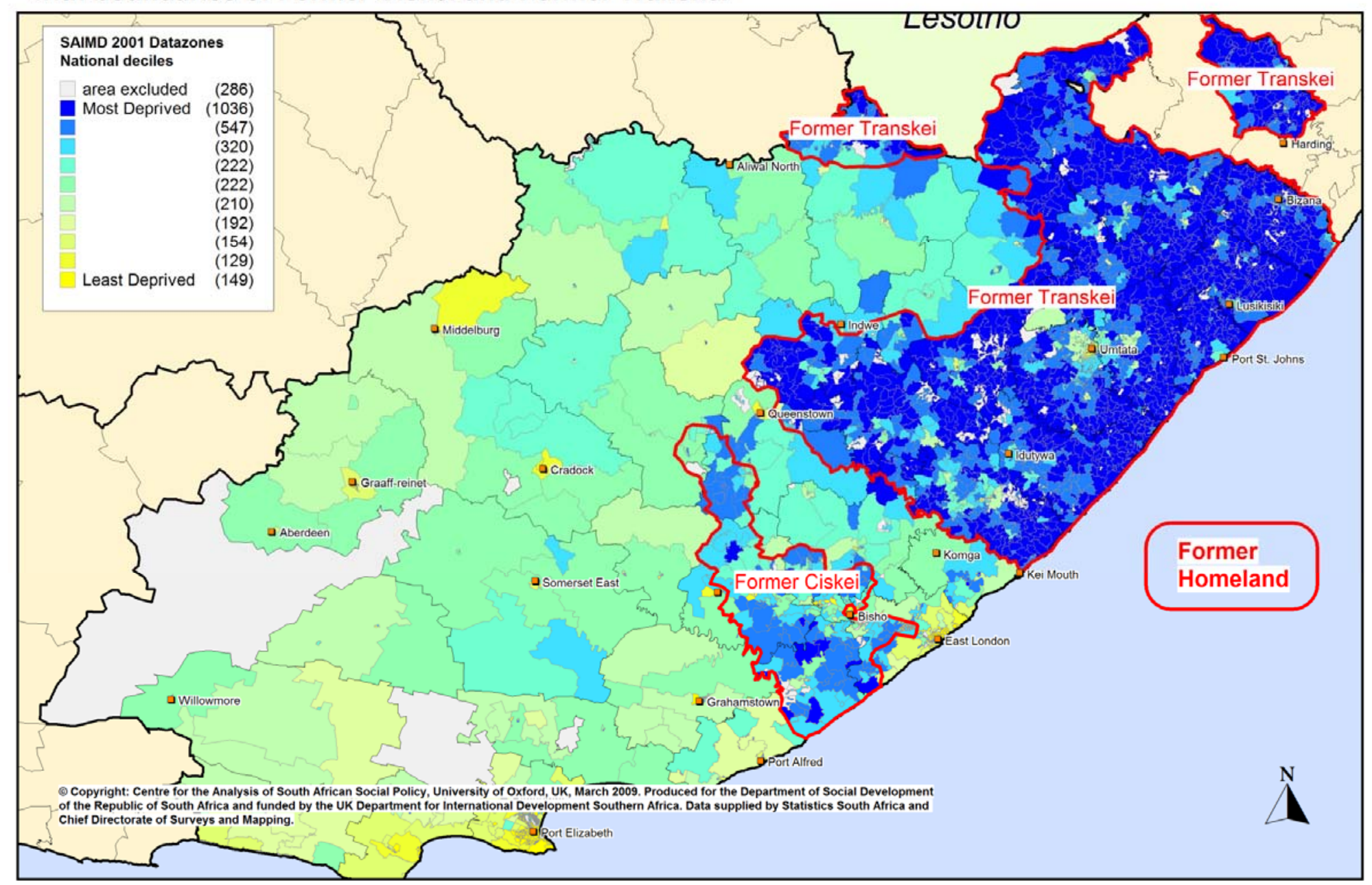


Figure 4: Location of focus groups in the Western Cape (Paarl not shown)

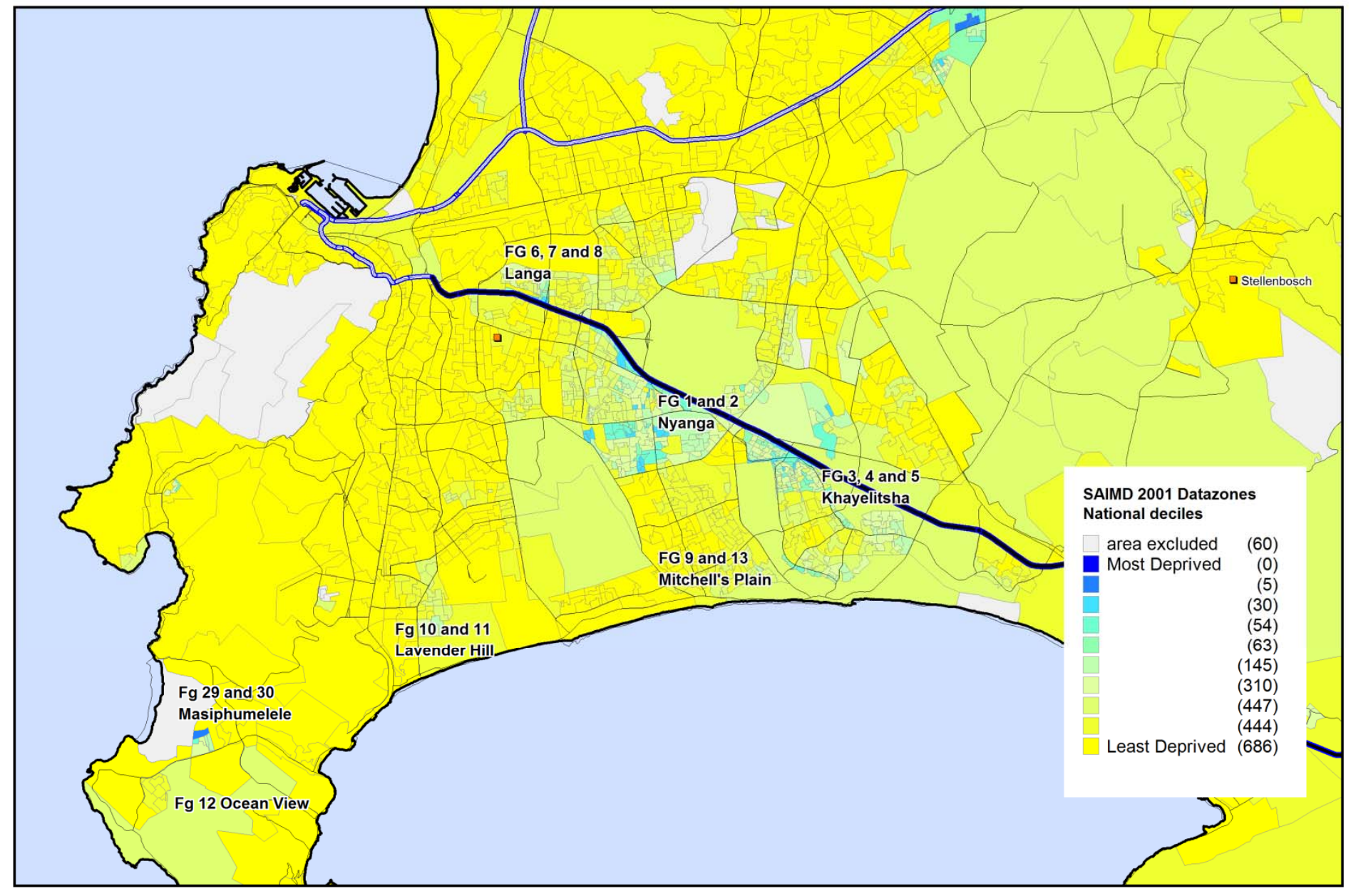

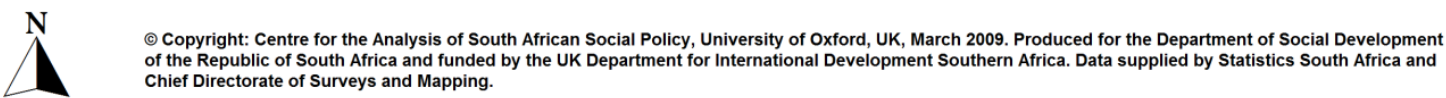


Figure 5: Location of focus groups in the Eastern Cape

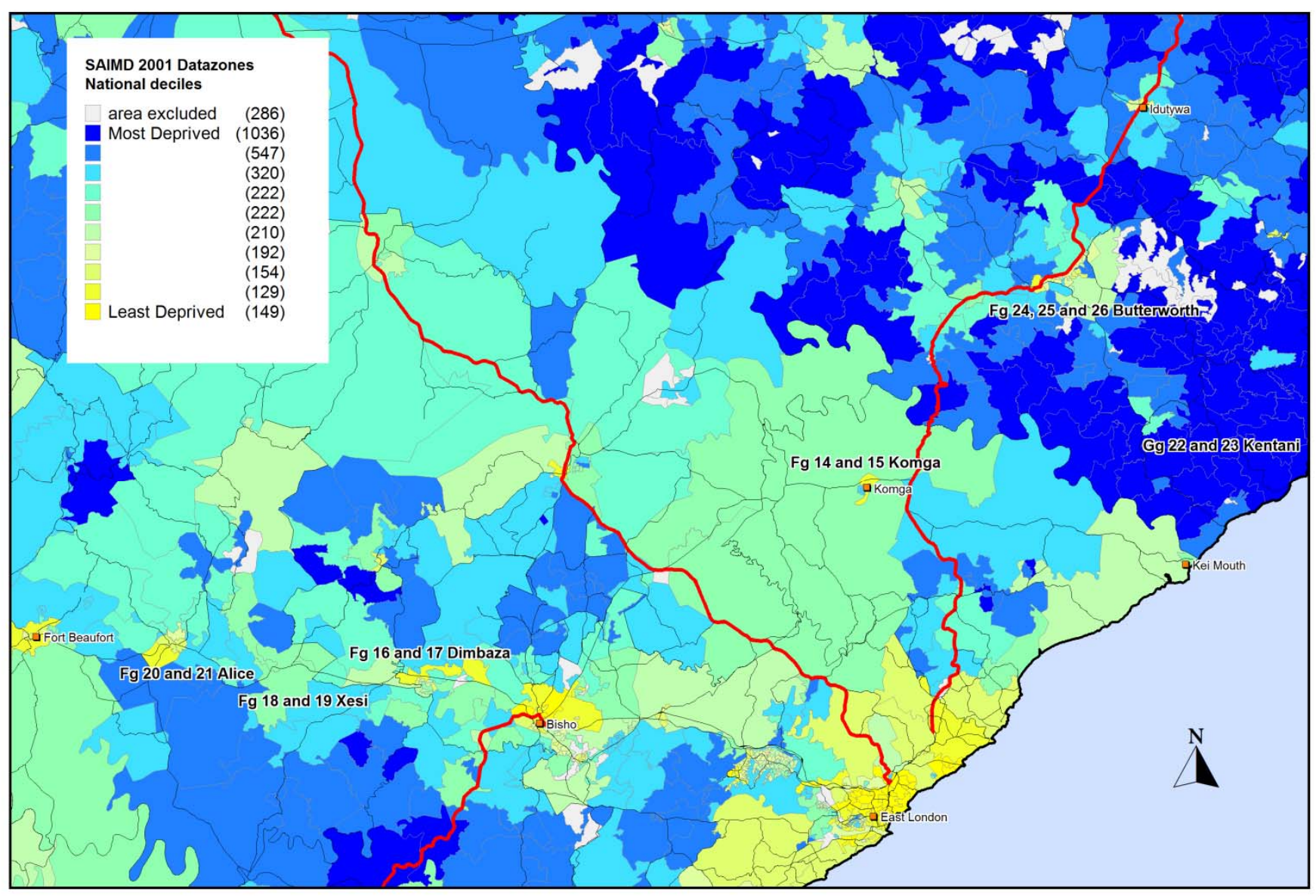

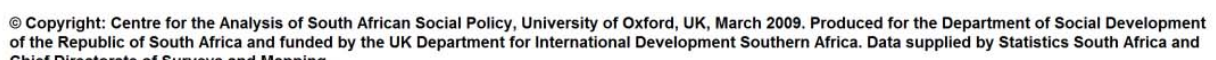

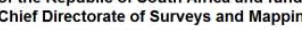


Table 2.2 summarises details about the locations of the 30 focus groups that were undertaken, as well as the language that was used for each focus group (final column). Seventeen were undertaken in the Western Cape and 13 in the Eastern Cape. Twelve were undertaken in peri-urban townships, five were undertaken in townships in more rural areas (which will include farm workers, particularly in Paarl), and 13 were undertaken in rural former homeland areas. In terms of the main type of housing in the area of each focus group, 12 of the focus groups were undertaken in areas that comprised mainly formal dwellings, 3 that were mainly informal, 13 that were a mixture of mainly formal and traditional dwellings, and 2 that were a mix of formal and informal dwellings.

An additional consideration as part of the sampling process was that of population group. As will be seen in the profile of lone mothers in chapter 3 , of the lone mothers identified $91 \%$ were black African, and $7 \%$ were coloured, with the remaining $2 \%$ being white and Indian/Asian. Most focus groups were in predominantly black African areas and were undertaken in isiXhosa and five focus groups were organised in predominantly coloured areas and undertaken in Afrikaans (though the sample was not intended to be a quota sample. The focus groups in Afrikaans took place in the Western Cape as more than half of the South African coloured population lives in this province.

Table 2.2: Area characteristics for the $\mathbf{3 0}$ focus group locations

\begin{tabular}{|c|c|c|c|c|c|c|}
\hline $\begin{array}{l}\text { FG } \\
\text { No }\end{array}$ & Province & Area & $\begin{array}{l}\text { semi } \\
\text { urban/rural/former } \\
\text { homeland }\end{array}$ & $\begin{array}{l}\text { Housing } \\
\text { type in area }\end{array}$ & Language & $\begin{array}{l}\text { SAIMD } \\
\text { range }\end{array}$ \\
\hline F1 & WC & $\begin{array}{l}\text { Nyanga } \\
\text { (Gugulethu) }\end{array}$ & peri-urban townships & formal & isiXhosa & 3 to 8 \\
\hline $\mathrm{F} 2$ & WC & $\begin{array}{l}\text { Nyanga } \\
\text { (Gugulethu) }\end{array}$ & peri-urban townships & formal & isiXhosa & 3 to 8 \\
\hline F3 & WC & $\begin{array}{l}\text { Khayelitsha } \\
\text { (Lingelethu) }\end{array}$ & peri-urban townships & informal & isiXhosa & 4 to 8 \\
\hline $\mathrm{F} 4$ & WC & $\begin{array}{l}\text { Khayelitsha } \\
\text { (Site C) }\end{array}$ & peri-urban townships & informal & isiXhosa & 4 to 8 \\
\hline F5 & WC & $\begin{array}{l}\text { Khayelitsha } \\
\text { (Site C) }\end{array}$ & peri-urban townships & informal & isiXhosa & 4 to 8 \\
\hline F6 & WC & Langa & peri-urban townships & formal & isiXhosa & 2 to 8 \\
\hline F7 & WC & Langa & peri-urban townships & formal & isiXhosa & 2 to 8 \\
\hline F8 & WC & Langa & peri-urban townships & formal & isiXhosa & 2 to 8 \\
\hline F9 & WC & Mitchells Plain & peri-urban townships & formal & Afrikaans & 2 to 5 \\
\hline F10 & WC & Lavender Hill & peri-urban townships & formal & Afrikaans & 2 to 5 \\
\hline F11 & WC & Lavender Hill & peri-urban townships & formal & Afrikaans & 2 to 5 \\
\hline F12 & WC & Ocean View & $\begin{array}{l}\text { Township in rural } \\
\text { area }\end{array}$ & formal & Afrikaans & 2 \\
\hline F13 & WC & Mitchells Plain & peri-urban townships & formal & Afrikaans & 2 to 5 \\
\hline F14 & $\mathrm{EC}$ & $\begin{array}{l}\text { Komga } \\
\text { (Qumrha) }\end{array}$ & $\begin{array}{l}\text { former homeland } \\
\text { rural }\end{array}$ & $\begin{array}{l}\text { formal/ } \\
\text { traditional }\end{array}$ & isiXhosa & 8 \\
\hline F15 & $\mathrm{EC}$ & $\begin{array}{l}\text { Komga } \\
\text { (Qumrha) }\end{array}$ & $\begin{array}{l}\text { former homeland } \\
\text { rural }\end{array}$ & $\begin{array}{l}\text { formal/ } \\
\text { traditional }\end{array}$ & isiXhosa & 8 \\
\hline
\end{tabular}




\begin{tabular}{|c|c|c|c|c|c|c|}
\hline F16 & EC & Dimbaza & $\begin{array}{l}\text { former homeland } \\
\text { rural }\end{array}$ & $\begin{array}{l}\text { formal/ } \\
\text { traditional }\end{array}$ & isiXhosa & 7 to 10 \\
\hline F17 & EC & Dimbaza & $\begin{array}{l}\text { former homeland } \\
\text { rural }\end{array}$ & $\begin{array}{l}\text { formal/ } \\
\text { traditional }\end{array}$ & isiXhosa & 7 to 10 \\
\hline F18 & EC & Xesi, Middledrift & $\begin{array}{l}\text { former homeland } \\
\text { rural }\end{array}$ & $\begin{array}{l}\text { formal/ } \\
\text { traditional }\end{array}$ & isiXhosa & 6 to 9 \\
\hline F19 & EC & Xesi, Middledrift & $\begin{array}{l}\text { former homeland } \\
\text { rural }\end{array}$ & $\begin{array}{l}\text { formal/ } \\
\text { traditional }\end{array}$ & isiXhosa & 6 to 9 \\
\hline F20 & EC & Alice & $\begin{array}{l}\text { former homeland } \\
\text { rural }\end{array}$ & $\begin{array}{l}\text { formal/ } \\
\text { traditional }\end{array}$ & isiXhosa & 3 to 9 \\
\hline F21 & EC & Alice & $\begin{array}{l}\text { former homeland } \\
\text { rural }\end{array}$ & $\begin{array}{l}\text { formal/ } \\
\text { traditional }\end{array}$ & isiXhosa & 3 to 9 \\
\hline $\mathrm{F} 22$ & EC & $\begin{array}{l}\text { Kentani } \\
\text { (Thafalofefe) } \\
\end{array}$ & $\begin{array}{l}\text { former homeland } \\
\text { rural }\end{array}$ & $\begin{array}{l}\text { formal/ } \\
\text { traditional }\end{array}$ & isiXhosa & 8 to 10 \\
\hline F23 & EC & Kentani & $\begin{array}{l}\text { former homeland } \\
\text { rural }\end{array}$ & $\begin{array}{l}\text { formal/ } \\
\text { traditional }\end{array}$ & isiXhosa & 8 to 10 \\
\hline F24 & EC & $\begin{array}{l}\text { Butterworth } \\
\text { (Cegcuwana) }\end{array}$ & $\begin{array}{l}\text { former homeland } \\
\text { rural }\end{array}$ & $\begin{array}{l}\text { formal/ } \\
\text { traditional }\end{array}$ & isiXhosa & 8 to 10 \\
\hline F25 & EC & $\begin{array}{l}\text { Butterworth } \\
\text { (Mission) }\end{array}$ & $\begin{array}{l}\text { former homeland } \\
\text { rural }\end{array}$ & $\begin{array}{l}\text { formal/ } \\
\text { traditional }\end{array}$ & isiXhosa & 8 to 10 \\
\hline F26 & EC & $\begin{array}{l}\text { Butterworth } \\
\text { (Mission) }\end{array}$ & $\begin{array}{l}\text { former homeland } \\
\text { rural }\end{array}$ & $\begin{array}{l}\text { formal/ } \\
\text { traditional }\end{array}$ & isiXhosa & 8 to 10 \\
\hline F27 & WC & $\begin{array}{l}\text { Paarl } \\
\text { (Mbekweni) }\end{array}$ & $\begin{array}{l}\text { Township in rural } \\
\text { area }\end{array}$ & formal & isiXhosa & 4 to 8 \\
\hline F28 & WC & $\begin{array}{l}\text { Paarl } \\
\text { (Mbekweni) }\end{array}$ & $\begin{array}{l}\text { Township in rural } \\
\text { area }\end{array}$ & formal & isiXhosa & 4 to 8 \\
\hline F29 & WC & Masiphumelele & $\begin{array}{l}\text { Township in rural } \\
\text { area }\end{array}$ & $\begin{array}{l}\text { formal/ } \\
\text { informal }\end{array}$ & isiXhosa & 4 to 9 \\
\hline $\mathrm{F} 30$ & WC & Masiphumelele & $\begin{array}{l}\text { Township in rural } \\
\text { area }\end{array}$ & $\begin{array}{l}\text { formal/ } \\
\text { informal }\end{array}$ & isiXhosa & 4 to 9 \\
\hline
\end{tabular}

The final column in Table 2.2 gives an 'SAIMD 2001 decile range' for each focus group location. This summarises the range of datazones (with decile 10 being the most deprived, and decile 1 being the least deprived) for the datazone in which the focus group took place as well as neighbouring datazones. So for example a range of ' 8 to 10 ' indicates that the datazones surrounding the venue were concentrated at the most deprived end of the national distribution, where as a range of ' 3 to 9 ' indicates that the venue was surrounded by datazones with a wider range of deprivation.

\section{Recruitment of participants}

Another important consideration when selecting areas was the practicalities of recruiting participants in those areas. Originally it was intended that the recruitment of participants would be achieved through local community organisations. However this carries a certain amount of bias by excluding women who do not use these particular services, and areas which lack these services. It was therefore decided very early on in the project that women would instead be recruited at social security paypoints on the payment days for the Child 
Support Grant. This method had been used successfully by members of the team previously (e.g. Surender et al., 2007).

Paypoints are distributed across South Africa, and are organised for set times during a month and use various buildings such as community halls, church halls, and in smaller areas local shops are sometimes used. The paypoint manager along with other staff members set up what are essentially portable cash machines. Recipients queue up and identify themselves with a finger or thumbprint in conjunction with an ID card and their money is dispensed.

Paypoints are organised by the South African Social Security Agency (SASSA) on behalf of the national government Department of Social Development. Special permission to both access the paypoint sites and recruit women to participate in the research was sought and obtained from the provincial heads of SASSA in the Eastern Cape and Western Cape. SASSA in turn notified the private companies contracted by SASSA to implement the payments so that they would expect the researchers on specific dates.

Each paypoint location is active (i.e. set up to pay recipients their grant money) on between one to five days each month, so recruitment in a particular area could only take place on these specified days. Therefore logistical considerations about when and where it was possible to recruit women for the focus groups was a consideration when selecting areas.

Once a paypoint was identified, the research team arrived early at each selected venue, made themselves known to the paypoint manager, and approached women to ask whether they would be willing to take part in a focus group. Whilst at the outset the intention was to allow women to decide overnight about whether to participate (i.e. recruit on one day, and run the focus group the following day) this caused great difficulties for the participants who were unable to take time out to visit a paypoint on two days in a row. This requirement was therefore dropped and instead the focus groups mainly took place later on the same day.

If someone was interested in participating, then they were fully informed about the purpose of and benefits of the research, why and how they have been selected, what they would have to do, how the results would be used, what to do if they do not want to take part (emphasising that they could withdraw at any time without any negative consequences), and how their responses would be kept confidential and anonymous. They were also given details about the project and a copy of the information and consent form (see Annex 1) in their preferred language. They also took part in a brief screening questionnaire to ensure that they fell within the group of women whom we were seeking to interview. The screening questionnaire is described in detail in Chapter 3 and so is not repeated here (see Annex 2).

Paypoints are very carefully guarded, and the payment agencies tend to contract armed security services to accompany them and ensure that the venues are secure on payout days, and there is often a high police presence at paypoint venues too. In terms of the security of the researchers, the high presence of security guards had the advantage that 
they could recruit participants in areas that might otherwise be more dangerous to visit; conversely the paypoints brought with them the disadvantage that due to the prevalence of cash at the venue there is a risk of criminal activity and there have been some incidents where people have been robbed around paypoints, or the cash machines at the paypoints have been stolen. On balance, however, recruiting in a heavily guarded venue was thought to be better than not doing so.

Three significant changes to the administration of grant payments took place towards the end of the focus group fieldwork phase of the project which impacted in different ways on the recruitment process. First, on 17 Feb 2012 the Minister of Social Development announced that all beneficiaries would be required to re-register with SASSA in order to reduce the number of fraudulent claims being made. Second, SASSA readvertised for the role of distributing social security payments to beneficiaries and appointed a new contractor which was contested in court by the existing contractors this caused us difficulties trying to contact paypoint managers who were unsure whether they were about to lose their jobs, making it difficult (not only for the team but more importantly also for the grant beneficiaries) to ascertain which day the payments would be made during that period. Third, as a consequence of the appointment of a new contractor, SASSA began the roll-out of a new payment method which involved a dedicated payment card - the 'SASSA' branded Smart Card.

The card enables people to withdraw the CSG from a bank or certain chains of large supermarkets (e.g. Boxer, Pick \& Pay, Checkers, Shoprite, Spar). Although some CSG recipients already had their grant money paid directly into a bank account, most still received payment through paypoints although exact figures were not readily available. SASSA has committed to keep existing paypoints in operation whilst usage of the cards is monitored, but there is an expectation that the number of paypoints may be reduced in future, and so it is likely that paypoints will cease to be viable recruitment venues in future.

\section{The interview process}

At the start of each focus group the participants were told about the project, and a number of 'ground rules' were articulated: that the focus group would be recorded so that the material could be analysed but any details would be anonymised if used as part of the research so as to ensure that no individual could ever be identified; that any issues discussed by participants should be respected and should not be repeated outside the focus group; that participants could leave at any time without penalty; that their participation had no bearing on their receipt of the CSG (i.e. what they said would not jeopardise their receipt of the CSG) and that the research team did not comprise members of SASSA or DSD; that there were no right or wrong answers, and that different and differing opinions are fine. This introductory stage was also used to ensure that none of the participants were related to each other, and that nobody felt that they were there under duress. Once it was certain that everyone understood and was happy to proceed, the participants were then given a copy of the information and consent form to sign. 
The participants were provided with refreshments (soft drinks, biscuits and crisps) as well as a payment in acknowledgement of their time of R100. In addition to signing the consent forms, each woman also signed a document acknowledging receipt of the payment.

Each focus group was attended by at least two members of the research team. One person undertook the focus group facilitation, and the other person ensured that the recording was operational, took notes, and dealt with any logistical issues during the course of the session. On occasions a third member attended and took part in the debriefing of participants at the end of the focus group.

As the focus group schedule comprised a number of direct questions relating to dignity, the team were anxious to ensure that the participants would feel sufficiently at ease discussing such sensitive issues (see 'overarching ethical considerations' above). Accordingly, the focus groups were only facilitated by female members of the team, and only female researchers or research assistants attended the focus groups as it was felt within the team that the presence of a man would make the participants uncomfortable and reluctant to speak. For each focus group the facilitator was fluent in the mother tongue of the participants.

\section{The focus group schedule}

Annex 3 contains the English, isiXhosa and Afrikaans versions of the focus group schedule. At the start of each focus group participants were read the section of the South African constitution which states that 'Everyone has inherent dignity and the right to have their dignity respected and protected'. The versions in isiXhosa and Afrikaans were taken directly from the official translations of the Constitution, which respectively translated dignity as isidima and menswaardigheid. The focus group schedule was contoured around direct questions about dignity (Q1-5 and 10) and social security (Q6-9).

\section{Analysis}

The focus group interviews were translated and transcribed into English. The transcripts were then analysed in Nvivo.

The screening questionnaire was used to profile the participants. At total of 198 women took part in the focus groups, all under the age of 60 . The vast majority of the women (81\%) were 'single, never been married'. The next largest group (6\%) were widowed, with a small percentage ( $4 \%$ each) being separated, or divorced, or married with husband mainly living elsewhere.

When asked, as part of the demographics questionnaire, whether they are mainly raising their children alone, $97 \%$ said 'yes', the remaining few specifying that their mother helps with raising the child, and one referring to the father of the child. The respondents lived with an average of 1.8 children: $42 \%$ lived with one child, $37 \%$ with two children, $16 \%$ with three children, $4 \%$ with four children, and $1 \%$ with six children.

In terms of their home language, $84 \%$ spoke isiXhosa, $10 \%$ spoke Afrikaans, and $6 \%$ spoke English. Eighty-six percent of the participants were unemployed, with the remainder mainly being in part-time employment and only four women being full-time employed. 


\section{$2.4 \quad$ In-depth interviews ${ }^{3}$}

\section{Research Context}

In order to understand the empirical material that is presented and discussed, it is useful to have a sense of the research context. The in-depth interview participants were recruited in the Eastern Cape (villages in the former communal area homelands of the ex Ciskei and Transkei) and urban Western Cape ('township's in metropolitan Cape Town, and the rural service-centre town of Paarl). The informants were Xhosa-speaking lone mothers, Child Support Grant recipients, variously the mothers, aunts or grandmothers of beneficiary children. Their demographic details, residence in zones of widespread poverty and status as CSG recipients meant each was vulnerable and economically marginalized.

Contemporary impoverished livelihoods in South Africa are located within migratory dynamics that link urban and rural areas. In the focal area of the current inquiry, these often link the rural Eastern Cape, to urban centres in the Western Cape. These two sites are often the locales of households geographically 'stretched' between urban and rural, and typically sustained by complex repertoires of livelihood supporting activities. These acts of survivalist improvisation include drawing on modest land-based endowments (some market gardening, resource harvesting), low levels of remittances from scarce employment, informal sector self-employment and finally receipt of state cash transfers (social grants). Impoverished livelihoods have therefore long been constituted within practices of mobility and migration, whereby low cost rural living is often combined with attempts to access the labour markets, or superior social and infrastructural services of urban areas.

The dynamics of South Africa's enduring poverty and globally leading levels of inequality, do not simply have economic dimensions, they are inextricably bound up with cultural mores and social dynamics. The decades old collapse of formal male labour migration has altered patterns of rural back investment, accumulation and subsequent practices of household formation. Limited prospects for unskilled male migrant employment have fed into changes in the material base of households and contributed to a changing gender relations and conjugal contract. Contrary to general demographic trends, declining rates of formal marriage amongst black African people have however not seen a commensurate increase in the numbers of co-resident male partners. Much of these larger dynamics are evident elsewhere, for instance in the evidence that well over half of South African children have no contact with their fathers (Posel and Devey, 2006), and demographic evidence of a move towards smaller household sizes (Pillay, 2008) - increased number of households but with a lower mean household size. In this way receipt of the Child Support Grants, and the dynamics surrounding it household making and childrearing, often play themselves out in a social landscape, where men are absent and gender relations potentially contested. This context of poverty, inequality, and spatially extensive

\footnotetext{
${ }^{3}$ The in-depth interviews were undertaken by collaborators at UWC. Transcripts of the case studies in this report can be provided in the original language of the in-depth interviews (mainly isiXhosa) on request.
} 
households, where men are absent, all set the scene of the data presented in the chapters that follow.

\section{Sampling}

The in-depth qualitative interviews were an adjunct to the focus group interviews and the quantitative module administered as part of the larger study. A total of 16 predominantly isiXhosa-speaking female research participants were sampled. ${ }^{4}$ All were Child Support Grant (CSG) recipients who had participated in the focus group interviews of the preceding phase. They were evenly divided between being rural and urban resident. Rural informants were sampled in the Eastern Cape Provinces, former Ciskei and Transkei communal area homelands (in the Alice and Centani districts). Urban informants from two Western Cape townships: metropolitan Cape Town's Masiphumelele and Mbekweni, outside the rural town of Paarl, respectively. Each informant was in receipt of a Child Support Grant for a beneficiary child, grandchild, nephew or niece. The vast majority received the grant for their beneficiary children at the cash pay point, the focus groups also included very small numbers of recipients who received a CSG into a bank account, one such recipient was included in the interview sample.

\section{The interview process}

Qualitative inquiry offers up distinct strengths and weaknesses as a mode of inquiry, but does not make recourse to the same circumscribed parameters of statistical inquiry. For this reason, and to provide sufficient context, to sustain claims of the 'transferential validity' of the findings (Smaling, 1992), the research process is explicated in detail below.

A number of research sites, evenly split between the urban and rural locales were selected. Once initial contact was established with random selection of potential research participants included in the previous focus groups, arrangements were made to conduct the research interviews at participant's homes, by the small three-person research team. An experienced isiXhosa speaking female interviewer conducted most of the interview, while another isiXhosa speaking fieldworker (who had been involved in the focus group interviews) simultaneously interpreted in parallel (in a low voice, with as little disruption as possible) for the third team member, the English speaking male researcher who took field notes. This particular arrangement, honed during previous research, has a number of advantages (Du Toit \& Neves, 2008a; Neves \& Du Toit, 2012)

It is a modality that keeps the interview relatively naturalistic in terms of everyday conversational conventions. The informant largely converses with a single interviewer, and the pace of the discourse is not slowed by laborious to and fro interpretation for the researcher. Occasionally the researcher or fieldworker/interpreter would offer up a query, but these were kept to a minimum and generally deferred towards the conclusion of the

\footnotetext{
${ }^{4}$ Several had English and Afrikaans conversational skills, but isiXhosa was the mother tongue of all the research participants.
} 
interview. The exception to this arrangement was if the respondent wished to respond in English, or spontaneously did so, or preferred to have the questions posed in English while she respond in isiXhosa. Informants were given the opportunity to pose questions about the research at any time, an offer that was explicitly reiterated at the conclusion of the interview. In the interviews the respondents are typically the lone mother CSG recipients, but in more than one case other members of kin spontaneously participated in the interview and their contribution was recorded and transcribed. The older women interviewed were on occasion Old Age Grant (OAG) beneficiaries.

The interviews drew on a semi-structured interview schedule, which was discussed, revised and carefully practiced with the small research team prior to the interview. This was an important undertaking as the isiXhosa speaking fieldworker conducting the interview needed to understand its logic, in order to make instantaneous decisions about how to steer the conversation. The content of the semi-structured instrument is discussed here, in order to explicate the logic of the inquiry and frame the data that was gathered.

\section{The semi-structured interview questions}

In broad terms the interviews followed a three part structure of firstly, eliciting basic information about household composition and respondent's life history, followed secondly by a series of questions on grant receipt, and thirdly, concluded with discussion of community perceptions of grants receipt and grant recipients more generally (see Annexes 4 and 5).

The first component, a series of questions concerning the household were relatively unthreatening to informants. These were useful to elicit a sense of household composition, including household members who normally reside elsewhere. Against the backdrop of widespread migration and spatially extended households within South Africa (Spiegel, 1996; Ross, 1996), it is important to capture these details in order to adequately understand the focal household. This section enquires about activities household members engage in order to 'survive' and seeks to gain a cursory sense of those that the household 'helps', and from whom it relies on for assistance. The studied vagueness of asking after activities informants engage in in order to 'survive' (rather than work), and 'help' (rather than resources) they receive serves to cue informants to the expansiveness of the information sought. The objective of this component of the interview is to glean a sense of the informant, their household's labour market history, and linkages to others (even geographically distant, or in the temporal past), particularly as these factors are typically key determinants of vulnerability in the South African context (Du Toit and Neves, 2012).

Once the household had been a contextualized, and the narrative momentum picked up, research participants were asked to narrate the 'story' of how they applied for their grant. Following which the questioning sought to gain a sense of the sorts of expenditure to which grant income was directed. Contrastively, it was also useful to ask informants how they survived prior to getting the grant. Understanding grant receipt and expenditure was, 
in the context of the interviews, often aided by inviting informants to imagine and narrate a routine or past grant payout day.

Even with the constraints of time, it was useful to enquire about grant expenditure because it is a clue to key household and social dynamics, including the degree of intrahousehold pooling, individual and household 'life projects' and survival strategies. For example within the research a strata of informants' directed CSG income not to food or basic consumption, but rather to comparatively higher quality schooling. This suggested something of their slightly different vulnerability relative to others, and the kinds of livelihood making objectives to which their households were orientated. In the interviews a final question concerned how the process of collecting their monthly CSG made them feel. Informants' accounts of the subjective experience and affective components of grant receipt were therefore located in a grounded narrative of what typically happened, rather than simply being an abstract reflection thereon.

The third and final component of the interview, built on the rapport that had been built up to this point and the research team's understanding of the context and household structure. It entailed posing a range of questions concerning perceptions of grant recipients. These included questions concerning community perceptions of grant recipients, and how receiving the CSG made informants feel (questioning including some prompts, if they were unsure or reticent). This line of inquiry encouraged informants to move from general assessment of community responses, to reflecting on how they believe they were viewed.

Here the various dimensions of dignity were frequently cast in the rubric of gossip, esteem and respectability ('intloniphlo'). The isiXhosa speaking fieldworkers readily identified the term 'isidima' as a vernacular synonym for dignity, but the research team remained attentive to the emergence of alternative accounts of dignity, even thought it was frequently operationalised in terms of, its converse, the rubric of jealousy 'umona' and gossip 'ukuhlemba' and disrespect more generally ('ukunga hloniphi'). It is important to stress that research informants accounts of dignity, entailed moving from a general to individual account, from 'what do people say about social grant recipients in this community?' to 'what do they say about you?". Questions around gossip were useful because, they allowed an easy transition from general question about the nature of gossip to a focus on the informant and their position. These accounts of gossip and stigma were probed with the research team enquiring about its origins (i.e. from whom did it emanate), including the demographic differentials such as male/female, young/old, unemployed/employed and poor/rich. Throughout the research team remained attentive to the way in which dignity was a lightning rod for larger issues of social exclusion, adverse gender dynamics, and vulnerability.

A final, concluding question concerned the hypothetical scenario of what the informant would do if the grant were to stop being paid. This was potentially sensitive question, as it could be distressing if misunderstood. Hence the research team was scrupulous to preface the question by indicating their status and inability to stop (or award) 
social grants and none of the informants seemed concerned about this. However it was a useful summing up question, which encouraged informants to reflect on other sources of support and entitlements they potentially exercise, and to clarify the place of the CSG in their lives.

It is important to be clear on the nature of the data that were elicited. Although randomly selected from the large sub-set of focus group recipients, this qualitative data can make no assertion to being representative of CSG recipients generally. An in-depth qualitative inquiry with a diminutive data set can make no claims to be statistically representative. Nor do the highly individual and located narratives represent the kind of intersubjective exposition of phenomena that would be a characteristic of focus group inquiry. Focus groups are suited to eliciting the breadth of perceptions of the dignity in relation to social grants, probed the inter-subjective consensus (and strength of the consensus) between informants on particular aspects and highlighted the differences and tensions between component parts of the research problematic (Kvale, 1996). Instead each of the in-depth interview narratives was highly individual and profoundly 'subjective' or perspectival. Although some commonalities and convergences emerged over the sixteen case studies, they should not even be read to represent inveterate 'types' of social grant recipients. Instead, the case studies illustrate key dynamics and salient relationships between the various phenomena - social grants and dignity - under study. They also offer the potential to illustrate the complexity and nuances of these dynamics. Therein lies their analytic value.

Axiomatic to this approach is approaching the notion of dignity with an interpretative openness, allowing the precise contours of the concept to be defined in an inductive and 'emic' fashion, and not imposing a rigid concept of dignity it a priori. Accordingly the researchers did not define it rigidly but instead sought to create the discursive space for accounts of 'dignity' to emerge narratively, out of the context of the respondent's history and the account of their everyday life experiences. In this process the research team neither enquired too directly after dignity, nor framed it too emphatically or as the sole concern of the research, particularly in the initial stages of the interview. This imperative shaped not only the data collection but also the process of analysis and interpretation.

\section{Analysis and interpretation}

This process of analysis demanded being attentive to the nuance of informant's narratives including the contestation these referenced, and contradiction they contained. In this research participant's accounts were not simply viewed as objective truths, as dispassionate answers to the sequence of interview questions. Instead informants' accounts were treated as discursive formulations, embedded in the social exchange of the interview, where their 'performative' function - the rhetorical work they did - was no less valid or interesting than their content (Potter \& Wetherell, 1987). How informants' accounts constructed grant receipt, their social context and sense of personal agency, were as important as the 
objective 'facts' of the narrative they proffered. Each interview therefore offered a fundamentally perspectival glimpse into how dignity works, in relation to the specificity of the informants' life and context. Quite apart from the objective facts elicited, each interview contained this individual and psychological truth, which had a veracity of its own. Many of these findings were surfaced and clarified in the debrief session with members of the research team at the conclusion of each working day.

In this manner the in-depth interviews elicited distinctive and perspectival data of the larger phenomenon under study (viz. dignity). This process of understanding dignity also demanded being attentive to its antithesis of dignity: namely instance of indignity, or what serves to erode or impair dignity. It included being attentive to a range of issues gossip, stigma and vulnerability, which are consequences, proxies and manifestations of the loss, or absence of, dignity.

The analysis drew on the data (both field notes and audio-recorded interviews) at two very different scales. The first are data at a micro scale, the fine-grained discursive extracts of informants' illocutions translated from the vernacular isiXhosa in to English. The second variety of data are far more expansive and larger-scale case study vignettes, interpreted and synthesized from the interviews. Both are used in the analysis that follows, as it moves between these two scales. This allows close rendering of respondents' 'voices', but also the complexity of their lives and context.

\section{$2.5 \quad$ Elite interviews}

\section{Sampling}

For the elite interviews, purposive sampling was used. Key informants were identified at the time of writing the proposal and were contacted directly by the research team due to their specialist knowledge on the subject of South African social security policy.

\section{The interview process}

Potential interviewees were contacted in person or by phone or email by a member of the team who invited them to take part in the interview and broadly described the project and the purpose of these elite interviews. They were then emailed a summary of the project and a description of how the interview would take place. If after this they agreed to proceed then a suitable time was arranged, with prioritization given to in-person interviews rather than telephone interviews.

A total of ten people were interviewed: four in Pretoria, three in Cape Town, one in East London, and two by Skype. Seven of the interviewees were male and three were female. They were all in - or recently in - senior positions that directly intersected with social security policy in South Africa (see Annex 6).

At the outset of the meeting the interviewer introduced the project again and explained the purpose of the interview. People were asked whether they would be happy 
for the interview to be recorded so that it could be transcribed. It was explained that the interviews would not be passed on to anyone outside of the research team. It was further undertaken that if the team wished to directly quote anything that they said in the interview in a project output, they would be contacted again for their permission and to ascertain whether they would be happy for it to be attributed to them personally (showing name and job title), or just in terms of their job title, or an anonymised job title. All interviewees appreciated this degree of consideration and agreed to being recorded. One interviewee asked to see the surrounding text to ensure that she was not being misrepresented as they had had experience of being quoted out of context and being misrepresented in publications in the past. Notes were also taken at the time of the interview as a back-up and aide-memoire. Each interview lasted about 45 minutes.

\section{The structured interview questions}

The interviewees were asked four questions and were then invited to comment briefly on two themes that were emerging from the focus group material that had been collected at an earlier stage of the project. The interview schedule is included in Annex 7.

In relation to social security policy design, the interviewee was reminded of South Africa's constitutional commitment to respect and protect people's dignity as well as Section 27 of the Bill of Rights which states that everyone has the right to have access to social security, including, if they are unable to support themselves and their dependants, appropriate social assistance. They were then invited to reflect on the extent to which the concept of dignity plays a role, if at all, when social security policies are designed; and whether they had encountered any practical difficulties or contradictions in the policy design process that might compromise people's sense of dignity.

These two questions were then repeated, this time with a focus on implementation rather than policy design. So the interviewees were asked about the extent to which the concept of dignity plays a role, if it all, when social security policies are implemented, i.e. when people register for and claim for a grant; and whether they had encountered any practical difficulties and or contradictions in the policy implementation process that might compromise people's sense of dignity.

In the final part of the interview, two themes that had emerged from the focus groups were introduced and comments invited. The point was first made that many of the focus group participants stressed their appreciation of government in providing the Child Support Grant, and were fully aware that the grant is intended for the child. The two emerging themes related to the adequacy of the CSG: first in terms of it being insufficient for meeting the needs of the child; and second because the CSG is not intended for the material needs of the mother and so they find themselves in situations that compromise their dignity (e.g. poverty, hunger, abusive relationships with men, prostitution, begging). 


\section{Analysis and interpretation}

The interviews were downloaded from the portable recorder and then transcribed. The transcriptions were imported into NVIVO for analysis. Key emerging themes were identified and written up as part of Chapter 6 .

\subsection{Social attitudes survey module}

The South African Social Attitudes Survey (SASAS) is a nationally representative social survey of people aged 16 and older which has been run annually by the Human Sciences Research Council (HSRC) since 2003 (Pillay et al., 2006; Roberts et al., 2010) and is similar in design to the British Social Attitudes Survey. As part of this project we drew from two existing modules in the SASAS series and designed one new module.

In 2006, SASAS contained a module on attitudes to work and social security (see Noble et al., 2008), and SASAS 2007 contained a module on attitudes about lone mothers, employment and childcare; both modules had been designed by members of the research team and they were both drawn upon as part of the secondary analysis undertaken for this project.

Table 2.3 Summary of usage of social attitude survey modules

\begin{tabular}{|l|l|l|}
\hline Year & Module & Referred to in this report \\
\hline SASAS 2006 & Work and social security & Ch8, 9 \& 10 \\
\hline SASAS 2007 & Lone mothers, employment and childcare & Ch3 \& 10 \\
\hline SASAS 2012 & Dignity, poverty and social grants & Ch5 \& 9 \\
\hline
\end{tabular}

\section{Purpose of the SASAS 2012 module}

Previous versions of SASAS had not contained questions that explicitly addressed the relationship between social security and dignity. We therefore designed a new module for SASAS 2012 with the intention of exploring the project's sixth research question which does not focus on lone mothers in particular but rather considers broadly the relationship between dignity, social security and ubuntu.

The intention was that - in addition to the focus group and in-depth interview materials - the module would enable us to explore popular concerns about the role of social security in alleviating poverty in terms of whether it jeopardises traditional forms of social solidarity, or whether social security can itself be seen as a manifestation of social solidarity. Whilst possible to analyse the responses of lone mothers (by constructing a lone mother flag' from questions in the survey) the main intention was to look at the whole population and broader subgroups, e.g. those living in a households that receive social assistance.

\section{Preparation of the SASAS 2012 module}

We constructed most of the questions as statements about which the respondent is asked to agree or disagree across a spectrum of five options (using a Lickert scale). Some of the 
questions were inspired by the Kankaras and Moors (2009) analysis of solidarity attitudes in Europe which was based on the third wave of the European Values Study (Halman, 2001). The design of the module was also informed by material arising from the first set of focus groups which were undertaken prior to drafting the module. The questions were then tested within the team and consulted upon within the advisory group.

We worked closely with HSRC on issues of translation. In the same way as for the focus groups, the translation of 'dignity' was informed by the translations of Section 10 of the Bill of Rights at http://www.constitutionalcourt.org.za/site/theconstitution/thetext.htm. HSRC piloted the module and no changes were required. The full SASAS 2012 questionnaire was translated into seven of the eleven official languages and went into the field in November and early December 2012, having first been approved by the HSRC's ethics committee. HSRC's themed focus for SASAS 2012 was 'Family Policy and Public Attitudes in South Africa', supported by the Department of Science and Technology (Roberts et al., 2013). As such, our questions which explored attitudes about the role of the family, household, community and the state in supporting people in poverty - and how this intersects with dignity - were synergistic and complementary.

The target population for the survey was individuals aged 16 and over, excluding those living in special institutions such as hospitals or prisons, and a total of 2,547 people aged 16 and over were interviewed. (Roberts et al., 2013). A dataset containing the responses to the module was supplied to the research team by HSRC complete with a set of survey weights and demographic variables. 


\section{Chapter 3 Defining lone motherhood in South Africa}

Summary: This chapter provides a working definition of lone motherhood which was developed at the outset of the project and informed the recruitment process for the focus groups and in-depth interviews. Section 3.2 considers routes to lone motherhood in the South African context. A profile of lone mothers who live with their children is presented in section 3.5 using data from the General Household Survey 2011.

\subsection{The terms 'lone mother', 'lone motherhood' and 'lone parent'}

We use the term 'lone mother' as a socially constructed, descriptive term for lone parents who are female, and use 'lone motherhood' as a term that describes the varying states of being in the role of a lone mother.

There is an extensive literature on the social construct of lone motherhood and different terms have been used and critiqued over time. Vanessa May (2010) argues that 'we cannot assume that lone motherhood is experienced as a basis for identity nor that lone mothers constitute a self-defined group' (May, 2010: 429). She further cautions against 'interpreting a woman's life or identity through the homogenizing, totalizing and (at times) oppressive lens of lone motherhood' and recommends using a biographical approach in order to explore 'the place of lone motherhood in a woman's self-understanding' (May, 2010: 430). ${ }^{5}$ Nevertheless she maintains that 'because 'lone mother' is a category that has significant impact on the lives of women categorized as 'lone mothers', it remains important for sociologists to offer theoretical and practical tools to counter the social and material inequalities that many lone mothers do face' (May, 2010: 433). In this report we try to tread that fine line.

We use the term 'lone parent' to refer to people who both (1) either do not have a partner or spouse or who do not co-habit with their partner or spouse and (2) are the main caregiver for a child under the age of 18 . Such a broad definition encompasses a heterogeneous group of people. For example, in the same way as a parent may or may not be a biological parent, so too a mother may or may not be the biological mother and it is not assumed that a lone mother is a biological parent.

The UK's Department for Work and Pensions (DWP) has commissioned a large number of studies on social security and lone parents. The so-called 'generic definition' of lone parents in these studies is as follows: 'Parent or guardian with a dependent child under 16 who is not in a co-habiting relationship.' (Sims et al., 2010: xiii; Lane et al., 2011: xi; Griffiths, 2011: xiii). Coleman and Lanceley use a slightly broader definition: 'Lone parent -

\footnotetext{
${ }^{5}$ For a recent example of such an exploration (more broadly on the subject of motherhood and inspired by the work of Walker (1995)) see Moore (2013) in which she argues that that 'more research is required to examine how state policy concerning women, work and childcare, or 'political motherhood', affects the way mothering is constructed in the everyday experiences of individuals' ( $p 170)$.
} 
generic definition - Parent or guardian who is not in a co-habiting relationship and who has care of a dependent child under 16, or under 18 if in full-time education' (Coleman and Lanceley, 2011: xv). However, in relation to who qualifies as a lone parent for Income Support, DWP provides many pages of technical detail in a guidance document called 'The Decision Makers Guide' issued by the Secretary of State for officials who make decisions about claims (DWP, 2013). Concepts are defined in great detail in Chapter 22 of the guide in relation to marital status (with detailed definitions of couple, lone parent, partner and polygamous relationships), having a child of eligible age", and 'being the person responsible for the child', with examples provided.

The term 'lone mother' is not widely used in South Africa. Indeed, on one occasion when the project title was referred to, 'lone mother' was understood by the South African person who heard it to mean 'loan mother' (i.e. a mother who offers cash loans to people), in the same vein as a 'loan shark' (i.e. someone who lends money to people at a high rate of interest).

In the South African academic literature researchers make regular use of 'femaleheaded households' as a category of analysis (e.g. Dungumaro, 2008; Posel and Rogan, 2012). For example, Rogan (2012) disaggregates the category into three non-overlapping classifications: de jure female-headed households (never married, widowed or divorced/separated - the fastest growing type of female-headed household), de facto female-headed households (married but not living with husband or partner - the group at most risk of poverty) and co-resident female-headed households (living with partner or spouse). However, this categorisation also has its challenges and Budlender (2003) cautions against its use. Posel (2001a) highlights that 'household head' may be differently interpreted across cultures, and that the term presupposes that households are hierarchical, and is based on an assumption that household heads have primary control over decision-making and resources within the household (Posel, 2001a). It could also be argued that - even though Statistics South Africa makes explicit that it does not presume this to be the case ${ }^{7}$ the expression 'female headed household' could be inferred by some to mean that households can only be headed by a woman if there are no men (particularly a spouse or partner) present, thereby preserving a sexist and hierarchical notion that men should head the household if they are present, and that women should defer to that social order. Indeed, according to Rogan (2012), in 2006 only 8\% of female heads of household lived with a spouse or partner whereas $62 \%$ of male heads of household lived with a spouse or partner. In any event, for the purposes of our study, information on the self-identified head

\footnotetext{
${ }^{6}$ This decreased to 5 in May 2012 for people qualifying as a lone parent for Income Support.

${ }^{7}$ Statistics South Africa defines a household head as 'A person recognised as such by household, usually the main decision-maker, or the person who owns or rents the dwelling, or the person who is the main breadwinner. The head can be either male or female. If two people are equal decision-makers, or in a household of totally unrelated persons, the older or oldest can be named as the household head.' (Statistics South Africa, 2012a: 13)
} 
of household does not aid the process of trying to identify the group of interest as the women may or may not identify themselves, or be identified, as heads of household. More colloquially, reference is made in speech and the media to 'single-parent' households, but this is a rarely used term in the academic literature, though see p49 of Amoateng et al. (2007) for a chart showing numbers of single parent households (with and without relatives) in 1996 and 2001 by race of head of household (though 'single-parent' is not defined). In a paper on single motherhood in Ethiopia, Kenya, Tanzania, Malawi and Zimbabwe, Clark and Hamplová (no date) argue that single motherhood may be a more useful focus for research than female headed households. In the UK the established convention is to use the term 'Ione mother' instead of 'single mother' which was seen as being too linked (as the counterpoint) to marriage. It was argued that the term 'single mother' implied that the woman was either 'single never married' or 'single following divorce or widowhood', whereas in a context where partnerships do not necessarily involve marriage, there was a need for a term that was broader than the maritally-oriented term 'single', and so the expression 'lone' was introduced. For example, Bradshaw and Millar wrote in the early 1990s: 'The general description "single-parent families" leads to confusion because one category of lone parents are single lone parents' (Bradshaw and Millar, 1991: 1). Although 'single mother' is a commonly used expression colloquially in South Africa we have chosen not to use it for this same reason. ${ }^{8}$

A risk, however, of using the term 'lone mother' in the South African context is that it is interpreted as meaning that the mother is 'alone', implying that the lone mother is not only the sole adult in the household but also that she is the sole person that provides care for the child and that she exists and brings up the child in an atomised environment with no social networks or other forms of support. Such an interpretation became apparent in the project's advisory group inception meeting. This highlighted to us the importance of trying to be as explicit and transparent as possible about the group of interest in terms of how lone mothers are defined for the purposes of the qualitative and quantitative analysis and when presenting the findings. Some studies do define lone motherhood as situations where women live in households with children but not with other adults. For example, a recent 18country study identified lone mothers as female-headed households where the women were not married or cohabiting, with children present but no other adults present (Brady and Burroway, 2012: 724). However in our definition we would include women who live with other adults (but do not cohabit with a partner or spouse). Also - as elaborated further in section 3.3-our definition of lone motherhood takes into account that in principle many different people contribute in varying ways to raising a child and for this reason, we would not wish to go so far as to use the term 'sole parent', as favoured by the OECD (e.g. OECD, 2007 and 2011). That is, our working definition of lone parenthood is driven more by consideration of cohabitation (and presence of a child) than by a distinction between 'lone' and 'shared' parenting which is not separable by a fine line (Payne and Range, 1998).

\footnotetext{
${ }^{8}$ See also Moyo and Kawewe (2009) which uses 'lone motherhood' as an analytical concept in the Zimbabwean context to great effect.
} 
The concept of lone motherhood is nevertheless beset with challenges. Household structures are fluid and both cohabitation (with partners or spouses) and co-residence (with children) is not necessarily clear-cut. There is also the challenge of countering a dominant ideology of the nuclear family'. As May (2008) highlights: 'A lone mother family by definition breaches the ideal nuclear family of two parents and their biological children. Lone mothers face prejudice, stigma and doubts over their ability to bring their children up 'properly" (May, 2008: 479). The negative connotations associated in South Africa and internationally with the term 'lone motherhood' require the term to be used critically.

At the risk of being tautological the next section presents a range of routes to lone motherhood. This sets the context for section 3.3 which makes explicit how we define what is meant by 'lone mother' for the purposes of this research project.

\subsection{Routes to lone motherhood in the South African context}

There are many routes to lone motherhood status if, as suggested in the section above, a lone mother is defined as a woman who does not live with a partner or spouse and who is the main caregiver for a child under the age of 18. Perceived moral hierarchies associated with different subgroups of lone mothers reflect ideological positions about gender, sexuality and family (May, 2010).

Amoateng et al. (2007) identify four main household types in South Africa: single person, nuclear (household head, spouse and children), extended (nuclear family plus other relatives) and complex households (containing members that are not related to the household head). The percentages of people living in each type in 2011, using GHS data, are $5 \%, 35 \%, 57 \%$ and $3 \%$ respectively (Statistics South Africa, 2012b: 10). In theory, a lone mother may be found in any of these household types.

A widow with children is an archetypal type of lone mother. Statistics South Africa defines a widow as 'a woman whose husband has died and who has not married again' (Statistics South Africa, 2012a: 21). A South African study on resilience in 'single-parent families' focuses only on parents who have been widowed and are not in a relationship (Greeff and Ritman, 2005). This group tends to rank highest in the 'moral hierarchy' of lone mothers (Ntshongwana, 2010) and - unlike many of the other types of lone mother -fault is less likely to be attributed to the woman for her status. In countries with more comprehensive social security provision than South Africa such favour has often been translated to better social security provision for widows than other groups of lone mothers (Kiernan et al., 1998).

\footnotetext{
${ }^{9}$ In this report we use the word 'family' to denote a group of household members who are related to each other. In most cases this will be all household members but note Amoateng's 'complex households' mentioned below. That is, the word 'family' is used to include extended families within a household, lone parent families within a household as well as nuclear families.
} 
Lone mothers may also comprise women who have had a child with a partner or spouse but subsequently become separated or divorced, or less formally as a result of having abandoned or been abandoned by the partner or spouse. These women are sometimes regarded as at fault due to their 'failure to retain' the father of the child (Ntshongwana, 2010).

Some lone mothers may never have cohabited with a partner or spouse. ${ }^{10}$ Such women, especially if they are young are often positioned at the other end of the moral hierarchy than widows. There is an ongoing popular debate in South Africa about whether young women are becoming pregnant in order to gain access to the Child Support Grant (CSG). Although Makiwane et al. (2006) have demonstrated that teenage pregnancies are not on the rise, it is a prominent theme in the press that the numbers are increasing and that the CSG provides young women with a 'perverse incentive' to become pregnant. The media focuses on low income lone mothers but not on high income lone mothers. Another route to lone motherhood includes the (formal or informal) adoption or fostering of a child whilst not in a cohabiting relationship. The broad working definition of lone motherhood that we are moving towards (see next section) will include women who are living with and caring for children other than their own, e.g. aunts and grandmothers ${ }^{11}$ of children who - if not cohabiting with a partner or spouse - will be captured as 'de facto' lone mothers.

The structure of families cannot be ascribed to personal choice alone, but also reflects complex historical and societal dynamics including legacies of apartheid and colonialism, patterns of migration and urbanisation, high levels of poverty, unemployment, ill-health (including the HIV/AIDS pandemic) and premature mortality, and changing cultural norms and household structures (e.g. Amoateng et al., 2007; Bak, 2008; Moore, 2013; Pirouz, 2005; Posel and van der Stoep, 2008; Russell, 2003a and 2003b). So for example, family structures have been extensively influenced by the migrant labour system which as Posel writes 'cannot be explained outside of the context of forced labour, racial segregation and alienation of land' (Posel, 2001b p168). Urban-bound migration led to an absence of black African men residing permanently in rural areas as they dominated the migratory labour system. Influx control regulations prohibited permanent settlement of many black African families in urban areas and so promoted patterns of migration that were circular or temporary (Posel and van der Stoep, 2008). Unaccompanied formal male labour migration shaped the social practices and material basis of matrimony and household formation for much of the twentieth century. However rising unemployment amongst unskilled black Africans since the 1970s served to erode the material basis of the conjugal contract leading to either the postponement or complete avoidance of marriage among black Africans. More recently, Posel et al. (2011) suggest that the unaffordability of lobola contributes to the reduction in marriage rates among black African women. In addition to declining marriage

\footnotetext{
${ }^{10}$ Table A1 in Annex 2 shows that $63 \%$ of the women that we identify in the GHS as lone mothers living with their children, are 'single and have never married or lived together with someone before'.

${ }^{11}$ Households with a 'missing generation' are referred to as 'skip-generation' households by Statistics South Africa (e.g. Statistics South Africa, 2012b).
} 
rates, the rates of co-habiting partnerships have also fallen over time (Hall and Posel, 2012). This contributes to dynamics such as female-headed households, out of wedlock births and unstable and fluid household composition, and is also reflected in demographic evidence of declines in average household size (Pillay, 2008).

Internal migration is still extensive and female labour migration is on the increase (Posel and Casale, 2006). Often, however, women with children do not migrate together as explained here: 'Although mothers can now move permanently with their families to places of employment, there are a number of reasons why they may be choosing to migrate without their children. The precarious nature of employment, a higher cost of living [including unaffordable childcare], and the accessibility and quality of accommodation at places of employment would discourage migration with children [...] At the same time, extended family structures in households of origin may provide care and support of children, making it possible for women to leave their children "behind"' (Posel and van der Stoep, 2008: 6). Lone mothers therefore often have to confront the invidious choice of living with their children or finding paid work. Indeed in their review of motherhood and coresidence in South Africa, Posel and van der Stoep (2008) found that mothers who were notco-resident with their children were more likely to be in employment than mothers who were co-resident. This difficult choice serves to undermine one of the articles in the African Charter on the Rights and Welfare of the Child: 'Every child shall be entitled to the enjoyment of parental care and protection and shall, whenever possible, have the right to reside with his or her parents. No child shall be separated from his parents against his will, except when a judicial authority determines in accordance with the appropriate law, that such separation is in the best interest of the child.' (Organisation of African Unity, 1999: Article 19.1)

There is also a growing body of work on the migratory patterns of children (e.g. Hall and Posel, 2012; Madhavan et al., 2012), which serves to further shed light on the fluid household arrangements that exist.

The combined impact of these and other factors means that the nuclear family (containing two generations, co-resident parents and biological children) is most certainly not the local norm (Budlender, 2010). Social mores concerning fertility, descent and family structure are complex and Russell has argued that black African households are not nuclear, and that with rising affluence and influence of Western modernity, black African households are additionally not becoming more nuclear (Russell, 2003a).

Statistics South Africa reported recently that only a third of South African children consistently lived with both their biological parents, almost a quarter (24\%) lived with neither of their biological parents, almost two-fifths (39\%) lived with their mothers, and $4 \%$ lived with their fathers. Of the children who lived with neither of their biological parents, $59 \%$ still had both their parents alive, while only $16 \%$ were double orphans (Statistics South Africa, 2012b). It has been well documented that child-headed households are very small in 
number (Meintjes et al., 2009) ${ }^{12}$ and thus people who are not biological parents are playing a significant role in raising children. So for example, in their analysis of women living with children who are not their biological children (in which they demonstrate that the labour market activity of women who are not biological mothers yet live with other children in the household is negatively and significantly related to labour force participation) Posel and van der Stoep suggest that this adverse impact on participation in the labour market means that 'the "effects" of motherhood are not borne by mothers alone' (Posel and van der Stoep, 2008: 18).

Finally, there are also examples of lone motherhood being hidden. In some instances in black African families when a young woman has a child, the child is assimilated into the grandmother's family as a sibling to the mother and the child is given the mother's surname. The 'protected' young lone mothers are seen to have had an 'accident', coined a 'fall' and are 'helped up' by their parents or extended family members so as to continue with their lives as 'normally' as possible, in particular attending to their education (Ntshongwana, 2010). In many such occasions the grandmother would become the primary caregiver while the young mother continued with her education if she was still undergoing secondary schooling.

Whether hidden or not, notions of lone motherhood remain value laden and gender biased. Very little focus, negative or positive, has been placed on non-resident fathers. Although non-resident fathers are required to pay maintenance (Maintenance Act, 1998) this is not tightly enforced and in any event due to the high unemployment rates a considerable number of non-resident fathers are unable to financially support their children. ${ }^{13}$

\subsection{Towards a working definition of lone mothers in South Africa}

\section{A model of the relational roles of a lone mother to a child}

One way of approaching the definition of lone motherhood is to start with the distinguishing feature that there is a child involved and that the woman plays a role in relation to that child. If we consider lone motherhood in relation to the provision of care for that child, a lone mother's roles (as for any parent or caregiver) could be divided very crudely and in no order into three groups: (A) affective allegiances to the child or 'wishing the best for the

\footnotetext{
${ }^{12}$ See also http://www.childrencount.ci.org.za/indicator.php?id=1\&indicator=17 .

${ }^{13}$ According to South Africa's Maintenance Act parents are required to give their children a 'proper living and upbringing' with 'the provision of food, clothing, accommodation, medical care and education. The parents' respective shares of such obligation are apportioned between them according to their respective means, and the duty exists, irrespective of whether a child is born in or out of wedlock or is born of a first or subsequent marriage' (Republic of South Africa, 1998:14).
} 
child'; (B) providing materially (i.e. financially and in-kind) for the child; and (C) physical presence with and physical care of the child.

Such an approach is different from the more prominent focus on the child as the unit of analysis (for a review of recent child-focussed research on poverty and deprivation see Barnes et al., 2011) as the lone mother is here 'centre-stage' and there are various ways in which she may have a role in relation to a child including, as we have seen in the previous section, living away from the child in order to earn a living.

There are many combinations of these three roles and the prominence and adequacy of the roles may change over time (e.g. varying extents of wider family, community and state provision of support and changing employment, household and financial situations).

\section{Figure 6: Relational roles of a lone mother to a child}

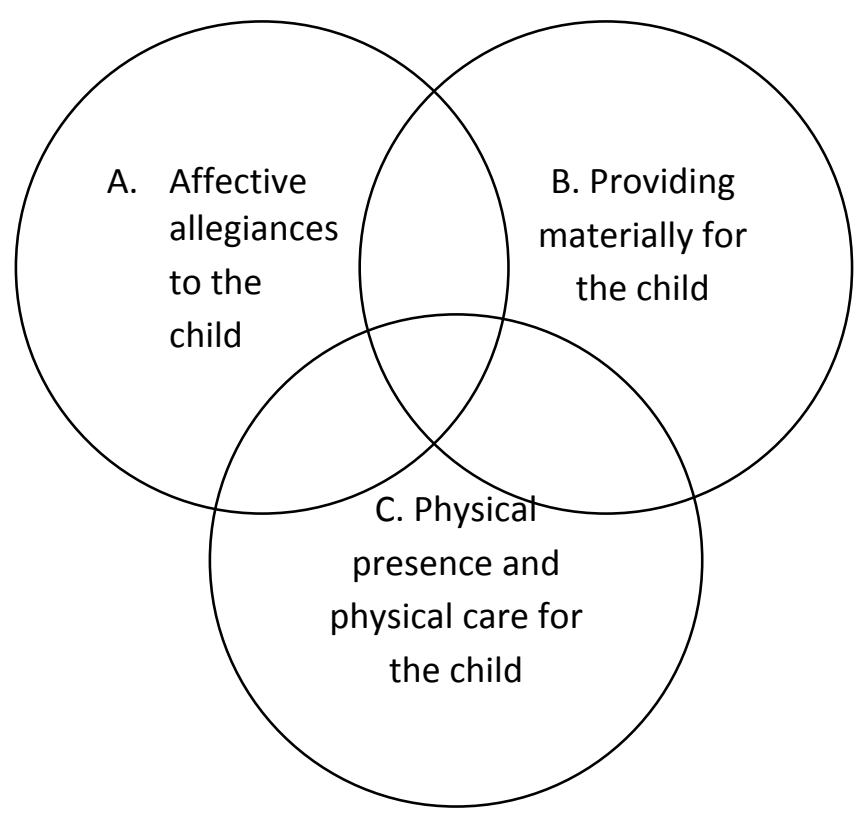

Examples of combinations of the relational roles include:

'ABC': A lone mother might play all three roles.

'AC': A lone mother might live with her child and have affective allegiances to the child but not provide materially for the child (e.g. she has no income, and the financial support is provided by another member of the household or by the absent father in the form of child maintenance or in-kind payments).

' $A B$ ': A lone mother may have affective allegiances to the child and provide materially for the child but not live with or providing physical care for the child (e.g. in order to get 
employment, she works away from her child and remits funds to the person who cares for the child in practice).

'BC': A lone mother may live with the child and provide materially for the child but not have affective allegiances to the child (e.g. other children in the household may be prioritised for whatever reason, or the mother for varying reasons may be unable or unwilling to care for the child).

We are not suggesting that lone mothers live in an isolated bubble, nor that a family's circumstances or arrangements never change. In practice, many people may have affective allegiances to the child, provide materially for her, and provide her with physical presence and care, and the individuals who provide these may change over time. Rather, our interest is on the policy question of whether social security could potentially play a role in respecting and protecting dignity amongst low income female primary caregivers who have to balance the competing needs and expectations around paid work and unpaid care.

The sections above attempt to set the context for the following sub-section which describes in more detail the group of interest for this project.

\section{Honing our focus for the project}

Income

The issue of dignity is relevant for all people regardless of their income status. However, because the prior study had raised such a strong message about the detrimental impact of poverty on people's sense of dignity we wanted to narrow the focus of the study to only include people living on a low income. For the purposes of this study we selected people whose income falls below the means test of the CSG (currently ${ }^{14}$ R33,600 per year for a single person).

\section{Age}

The study could have considered low income people of all ages. However, a group of particular interest for our purposes in relation to social assistance provision comprise those of working age, as there is no income maintenance provision for people in this age group who are not disabled. Low income people aged 60 and over are eligible for the Old Age Grant and are not expected to seek work. However, people below this age threshold are expected to obtain employment. South Africa has very high levels of unemployment and so this expectation is often impossible to meet in practice. Although unemployment is often recognised as being a structural issue, there is no structural provision of income maintenance for people of working age who are unemployed (other than the Unemployment Insurance Fund which is time-limited and requires one to have made prior contributions within the formal sector).

\footnotetext{
${ }^{14}$ As at 31 March 2013.
} 


\section{Caregiver status}

Having identified that we are interested in low income people of working age, we additionally wanted to narrow the focus to include people with dependent children aged 017 inclusive. Caregivers - whether biological parents or not - have the burden of not only meeting their own financial needs but also the needs of the children whom they are raising. Although there is no social assistance for low income adults with children, the government does provide support for their children in the form of the means-tested CSG. In addition, although the Foster Child Grant (FCG) is not means-tested, low income recipients of FCG would also fall within our group of interest but are not included.

\section{Gender}

The study - like the earlier project for DSD - could have considered men and women. However, we were keen to explore the issue of dignity and social security with women as they most commonly have primary responsibility for raising children and in gendered analyses of poverty are more likely to be poor.

\section{Marital status}

All low income parents face great challenges in trying to make ends meet, regardless of their marital status. However, we wanted to narrow the focus to include low income working age mothers who are, for whatever reason, raising their child without a partner present. This would include women who are single never married never having lived with a partner, women who are single never married separated from a partner, and women who are widowed, separated and divorced having been married. We decided to broaden the definition to additionally include women who, though married or with a partner, are mainly living apart from their husband or partner (e.g. due to the other person being a migrant labourer, sick, imprisoned, absent for other reasons).

\section{Household structure}

Having said that such women are balancing these two roles (caregiver, breadwinner) without a co-resident partner or spouse, they may live in a range of household structures. In addition to the child or children they may live with people of an older generation, with siblings, with other adults, or on their own. It will be part of the project to explore this issue. Household structure is not a determining feature of our working definition of lone motherhood. 


\section{Summary}

So far, then, we have narrowed the focus of the project to include a diverse group of people who are:

1) Female

2) A biological or foster or de facto caregiver of one or more children under the age of 18

3) Not co-resident with a husband or partner

4) Aged 16-59 inclusive

5) Low income (below CSG means test)

Only the first three criteria relate to lone motherhood. The latter two criteria are not distinguishing features of lone motherhood per se, as lone mothers could be of any age and any income status.

To what extent does this working definition map onto Figure 6? Using a definition such as this we would capture groups ' $A B C$ ', ' $A C$ ' and ' $B C$ '. The ' $A B$ ' group is harder to capture in survey data as the mothers are not living with the children and therefore will not be co-resident with the children. In the focus groups some women refer to previous occasions when they worked away from their children as domestic workers and so this enables insights to be obtained from the ' $A B$ ' group.

\subsection{Selecting lone mothers for the focus groups}

On the basis of the points above, we devised a multi-stage process to recruit lone mothers for the focus groups. Annex 2 contains the demographic questionnaire for the focus group participants for this study, which was filled in at the time of recruitment. The first three questions serve as screening questions.

Income - By recruiting at paypoints on CSG pay-day we know that people are low income. Gender - By recruiting in person we can identify women. The prospects of sampling women are high as, for example, Williams (2007) and Delany et al. (2008) report that over $90 \%$ of caregivers receiving the CSG are female.

Marital status - Using the categories shown in Q1 in Annex 2 we ask people their marital status and exclude people who are both (1) married or living as married and (2) living with their husband or partner most of the time.

Age - We then exclude people aged 60 and over.

Caregiver status - In recognition that a number of people may care for the child of the women selected, we then ask if they mainly raise their child/ren alone. Those who say 'yes' are automatically included. Those who say 'no' are also included (unless their answer reveals that they are in fact living with a partner or spouse) and could include for example a woman living with her child but the child is mainly looked after by someone else whilst she works or seeks work. 


\subsection{A profile of lone mothers in South Africa using the General Household Survey 2011}

The General Household Survey (GHS) 2011 is the latest available survey in a series of annual household surveys carried out by Statistics South Africa since 2002. The GHS is designed to measure living conditions, social development and service delivery in South Africa. Six broad areas are covered: education, health and social development, housing, household access to services and facilities, food security, and agriculture (Statistics South Africa, 2011: 1).

An analysis of the GHS 2011 is used here to build a profile of lone mothers in South Africa. Focusing on key demographic and socio-economic characteristics, the analysis is intended to develop a clearer understanding of the challenges faced by lone mothers. Details of the approach to identifying lone mothers in the data are contained in Annex 8 . For the purposes of this analysis, a lone mother is defined as a mother living in the same household as her dependent (aged 0-17 inclusive) biological or non-biological children and not living with a spouse or partner. Linking back to Figure 6, therefore, we could in theory capture women in the diagram that relate to the groups ' $A B C$ ', ' $A C$ ' and ' $B C$ '. We will not capture the 'AB' women - those who do not live in the same household as their child. ${ }^{15}$ This will be a sizeable group, and so the analysis in this section should be regarded as a profile of lone mothers in South Africa who were living in the same household as their child at the time of the GHS 2011. Furthermore, as a number of iterative assumptions had to be made (Annex 8 ) the figures should be regarded as estimates of the number of lone mothers living with their children.

Before moving on to the profile of lone mothers using the GHS, a further note on the definition process may be instructive. The South African Social Attitudes Survey (SASAS) can help to further elaborate on the methods for identifying lone mothers. SASAS 2007 asks the respondents whether they are a 'single parent'. Other questions in SASAS 2007 enable us to operationalise our working definition outlined in the previous section ${ }^{16}$, and therefore enable a comparison of a self-defined 'single parent' status with our working definition. Analysis of SASAS 2007 shows that of those women aged 16-59 who define themselves as a single parent, $92 \%{ }^{17}$ are captured by our working definition. Conversely, $81 \%$ of those included using our working definition also define themselves as a single parent. This analysis only includes lone mothers who state that they have a child or children living with them at home. Analysis of SASAS 2007 also reveals that 5\% of those women aged 16-59 who define

\footnotetext{
${ }^{15}$ This means that in theory there could be two lone mothers per child (e.g. an unmarried non-biological mother living with the child whilst the biological mother works elsewhere). This is not problematic for our purposes and in any event there will not be any double-counting in this chapter as we are only capturing women living with dependent children.

${ }^{16}$ Namely 'Are you the parent or caregiver of any children under the age of 18 ?', 'Are you currently living with your husband/wife?', 'Do you live together with a partner?', 'Do you have children living at home with you?' (and gender and age of respondent).

${ }^{17}$ Survey weights were not applied in this analysis of SASAS 2007.
} 
themselves as a single parent do not have any children living with them at home, thus perhaps shedding some light on the group of ' $A B$ ' women (i.e. those who do not live in the same household as their child).

\section{Demographics}

Based on our analysis of the GHS 2011 using this broad definition, there are over 5 million lone mothers in South Africa, and of these, the majority (79\%) are caring for a biological child. ${ }^{18}$ A further $1 \%$ of lone mothers (approximately 48,000 ) are caring for a step or adopted child. ${ }^{19}$ Approximately 1 million lone mothers are de facto lone mothers caring alone for a non-biological child (see Annex 8 for more information about how de facto lone mothers are defined). ${ }^{20}$

Of the de facto lone mothers, $42 \%$ are known from the survey data to be the grandmother of the child. This amounts to over 425,000 grandmothers (who are not cohabiting with a partner or spouse) caring for grandchildren. ${ }^{21}$ The actual figure may be higher than this as grandmother status can only be determined where the lone mother is the head of the household and the child they care for is the 'grandchild/great grandchild' of the head of household. ${ }^{22}$

Table 3.1 shows the proportion of mothers across three age categories. The vast majority of mothers are aged 16-59 years inclusive ${ }^{23}$ and there is very little difference between lone mothers and non-lone mothers in the age breakdown.

Table 3.1: Mothers by age group

\begin{tabular}{|l|r|r|r|}
\hline Age group & All mothers (\%) & Lone mothers (\%) & Non-lone mothers (\%) \\
\hline Under 16 & 1 & 1 & $0 *$ \\
\hline $16-59$ & 95 & 93 & 97 \\
\hline 60 and over & 4 & 5 & 3 \\
\hline Total & 100 & 100 & 100 \\
\hline N & $8,549,605$ & $5,027,907$ & $3,521,698$ \\
\hline Actually 0.01 & \multicolumn{3}{|}{}
\end{tabular}

\footnotetext{
${ }^{18}$ This may be in addition to non-biological children, but the status as a biological mother is prioritised.

${ }^{19}$ In total $1.6 \%$ of lone mothers are mothers of a step or adopted child. Approximately two fifths of these are also a biological mother to another child (and therefore identified as a biological mother).

${ }^{20}$ In addition, there are approximately 500,000 lone fathers (74\% of the total number of male carers identified in cases where a female carer could not be identified). Of these lone fathers, $74 \%$ are biological fathers, $2 \%$ are step/adoptive fathers and $24 \%$ are de facto fathers.

${ }^{21}$ These non-cohabiting grandmothers are most prominent in provinces containing rural former homelands: $26 \%$ of them live in KwaZulu-Natal, $20 \%$ in the Eastern Cape, $16 \%$ in Limpopo, $11 \%$ in Gauteng, $8 \%$ in Mpumalanga, 7\% in North West, 6\% in Free State, 4\% in the Western Cape and 2\% in the Northern Cape.

${ }^{22}$ See also Annex 2 for details of how grandmother carers may be undercounted in the process of identifying the main carer.

${ }^{23}$ This differs from the definition of working age used in official statistics which is 15 to 64 years inclusive (e.g. Statistics South Africa, 2008). Our age bracket of 16-59 years inclusive takes into account, at the lower end, the age at which children should have completed compulsory schooling (i.e. 15 years), and at the upper end, the age at which adults become eligible for the state Old Age Grant (i.e. 60 years for men and women from 2010).
} 
Table 3.1 also reveals that there are more lone mothers than non-lone mothers: based on this definition, $59 \%$ of all mothers in South Africa are lone mothers. ${ }^{24}$

The 16-59 age category is of course quite wide in terms of ages captured, and will partly be influenced by the prioritisation of working age women in the identification of the main female carer (see Annex 8). Table 3.2 breaks down this age category into five subgroups. Approximately $65 \%$ of lone mothers are aged between 20 and 39, while for nonlone mothers almost $70 \%$ are aged between 30 and 49 . This pattern is reflected in the average age: the mean age for lone mothers is 37 and the median is 35 , while the mean and median ages for non-lone mothers are both 40 .

Table 3.2: Lone and non-lone mothers aged $16-59$ by age subgroup

\begin{tabular}{|l|r|r|}
\hline Age group & \multicolumn{1}{|c|}{ Lone mothers (\%) } & \multicolumn{1}{|c|}{ Non-lone mothers (\%) } \\
\hline$>=16 \&<=19$ & 5 & 1 \\
\hline$>=20 \&<=29$ & 34 & 18 \\
\hline$>=30 \&<=39$ & 31 & 39 \\
\hline$>=40 \&<=49$ & 18 & 28 \\
\hline$>=50 \&<=59$ & 11 & 14 \\
\hline Total & 100 & 100 \\
\hline N & $4,696,933$ & $3,412,939$ \\
\hline
\end{tabular}

When lone mothers are broken down into biological, step/adoptive, and de facto status (as defined above and in Annex 8 ) there is a substantial difference in the mean and median ages: 34 and 33 respectively for biological mothers; 46 and 45 respectively for step/adopting lone mothers; and 47 and 51 respectively for de facto lone mothers.

In terms of the presence of other adults in the household, on average lone mothers live with 2.19 other adults (people aged 18 and over), which is slightly higher than the figure for non-lone mothers (2.01) and the average for all mothers (2.12). The average number of children in lone mother households is 2.95 , again slightly higher than the figure for non-lone mother households (2.28) and all mothers (2.68).

Table 3.3 shows the racial breakdown of lone mothers as a whole and across the three age categories. Over $90 \%$ of all lone mothers in South Africa are black African. The

\footnotetext{
${ }^{24}$ In terms of head of household analysis, $63 \%$ of all households were headed by a male and $38 \%$ were headed by a female. In households in which there is one or more child, $54 \%$ were headed by a male and $46 \%$ were headed by a female. As the number of children in the household increases, the proportion of households headed by a female increases incrementally, up to 7 children: $42 \%$ of households containing 1 child have a female household head, compared with $43 \%$ of households with 2 children, $50 \%$ of households with 3 children, $55 \%$ of households with 4 children, $57 \%$ of households with 5 children, $59 \%$ of households with 6 children, and $71 \%$ of households with 7 children (after this point the incremental relationship ceases, with $57 \%$ of households containing 8 or more children having a female household head). Forty-seven percent of the women identified here as lone mothers were also the head of household, whereas only $5 \%$ of non-lone mothers were household heads.
} 
remainder are mainly coloured, with only a small percentage of white or Indian/Asian lone mothers. A much higher proportion of lone mothers than non-lone mothers are black African (91\% and $70 \%$ respectively). Indeed, given that only $82 \%$ of all mothers are black African, lone mothers are disproportionately represented amongst this population group. There is little difference between the age groups in the racial breakdown: a slightly higher proportion of under 16 lone mothers are white than in the other age groups, while a slightly higher proportion of lone mothers aged 16-59 are coloured than in the other age groups.

Table 3.3: Lone mothers by population group

\begin{tabular}{|c|c|c|c|c|c|}
\hline Population group & $\begin{array}{c}\text { All lone } \\
\text { mothers (\%) }\end{array}$ & $\begin{array}{l}\text { Lone mothers } \\
\text { under } 16(\%)\end{array}$ & $\begin{array}{l}\text { Lone mothers } \\
\text { aged } 16-59 \\
\text { (\%) }\end{array}$ & $\begin{array}{l}\text { Lone mothers } \\
\text { aged } 60 \text { and } \\
\text { over (\%) }\end{array}$ & $\begin{array}{c}\text { Non-lone } \\
\text { mothers (\%) }\end{array}$ \\
\hline Black African & 91 & 90 & 91 & 93 & 70 \\
\hline Coloured & 7 & 4 & 7 & 4 & 13 \\
\hline Indian/Asian & 1 & 0 & 1 & 1 & 5 \\
\hline White & 2 & 6 & 2 & 3 & 12 \\
\hline Total & 100 & 100 & 100 & 100 & 100 \\
\hline $\mathrm{N}$ & $5,027,907$ & 73,395 & $4,696,933$ & 257,579 & $3,521,698$ \\
\hline
\end{tabular}

\section{Geographical location}

Table 3.4 shows the proportion of lone mothers in each of the provinces. KwaZulu-Natal has the highest proportion of lone mothers (23\%), while Gauteng has the highest proportion of non-lone mothers (26\%). The highest proportion of younger lone mothers is in Gauteng however (24\%), whereas the highest proportion of older lone mothers is in KwaZulu-Natal, followed closely by the Eastern Cape (both 25\%). As demonstrated in the section just above this one, both KwaZulu-Natal and the Eastern Cape contain large former homeland areas where 'skip-generation' households (containing a grandmother and grandchildren) are particularly prevalent.

Table 3.4: Lone mothers by province

\begin{tabular}{|c|c|c|c|c|c|}
\hline Province & $\begin{array}{c}\text { All lone } \\
\text { mothers (\%) }\end{array}$ & $\begin{array}{l}\text { Lone mothers } \\
\text { under } 16(\%)\end{array}$ & $\begin{array}{l}\text { Lone mothers } \\
\text { aged } 16-59 \\
\text { (\%) }\end{array}$ & $\begin{array}{l}\text { Lone mothers } \\
\text { aged } 60 \text { and } \\
\text { over (\%) }\end{array}$ & $\begin{array}{l}\text { Non-lone } \\
\text { mothers } \\
(\%)\end{array}$ \\
\hline Western Cape & 7 & 12 & 8 & 3 & 15 \\
\hline Eastern Cape & 16 & 9 & 15 & 25 & 10 \\
\hline Northern Cape & 2 & 2 & 2 & 2 & 2 \\
\hline Free State & 6 & 6 & 6 & 6 & 6 \\
\hline KwaZulu-Natal & 23 & 18 & 23 & 25 & 17 \\
\hline North West & 7 & 4 & 8 & 6 & 7 \\
\hline Gauteng & 16 & 24 & 16 & 13 & 26 \\
\hline Mpumalanga & 8 & 9 & 8 & 5 & 7 \\
\hline Limpopo & 14 & 17 & 14 & 15 & 9 \\
\hline Total & 100 & 100 & 100 & 100 & 100 \\
\hline $\mathrm{N}$ & $5,027,907$ & 73,395 & $4,696,933$ & 257,579 & $3,521,698$ \\
\hline
\end{tabular}


In most provinces lone mothers outnumber non-lone mothers (Table 3.5). So for example, in the Eastern Cape and Limpopo 69\% of all mothers are lone mothers. The exceptions are the Western Cape and Gauteng where the proportion of lone mothers is lower than the proportion of non-lone mothers at $41 \%$ and $47 \%$ respectively.

Table 3.5: Lone mothers and non-lone mothers by province

\begin{tabular}{|l|r|r|}
\hline Province & Lone mothers (\%) & $\begin{array}{c}\text { Non-lone mothers } \\
(\%)\end{array}$ \\
\hline Western Cape & 41 & 59 \\
\hline Eastern Cape & 69 & 31 \\
\hline Northern Cape & 60 & 40 \\
\hline Free State & 57 & 43 \\
\hline KwaZulu-Natal & 66 & 34 \\
\hline North West & 60 & 40 \\
\hline Gauteng & 47 & 53 \\
\hline Mpumalanga & 62 & 38 \\
\hline Limpopo & 69 & 31 \\
\hline South Africa & 59 & 41 \\
\hline
\end{tabular}

The proportion of lone mothers in urban formal areas is lower than the proportion of nonlone mothers ( $43 \%$ and $63 \%$ respectively). Conversely, a higher proportion of lone mothers live in areas defined as 'tribal' (i.e. former homeland communal areas) than non-lone mothers ( $48 \%$ and $25 \%$ respectively). Half the young lone mothers live in urban formal areas, a higher percentage than for the other age groups. Over $60 \%$ of older lone mothers live in 'tribal' areas, compared to less than $50 \%$ of young and $16-59$ year old lone mothers.

Table 3.6: Lone mothers and non-lone mothers by area type

\begin{tabular}{|c|c|c|c|c|c|}
\hline Geography type & $\begin{array}{c}\text { All lone } \\
\text { mothers (\%) }\end{array}$ & $\begin{array}{l}\text { Lone mothers } \\
\text { under } 16(\%)\end{array}$ & $\begin{array}{c}\text { Lone } \\
\text { mothers } \\
\text { aged } 16-59 \\
(\%)\end{array}$ & $\begin{array}{l}\text { Lone mothers } \\
\text { aged } 60 \text { and } \\
\text { over (\%) }\end{array}$ & $\begin{array}{c}\text { Non-lone } \\
\text { mothers (\%) }\end{array}$ \\
\hline Urban formal & 43 & 50 & 43 & 31 & 63 \\
\hline Urban informal & 7 & 3 & 7 & 6 & 8 \\
\hline $\begin{array}{l}\text { Communal land } \\
\text { administered under } \\
\text { traditional authority }\end{array}$ & 48 & 44 & 47 & 62 & 25 \\
\hline Rural formal & 3 & 3 & 3 & 1 & 5 \\
\hline Total & 100 & 100 & 100 & 100 & 100 \\
\hline $\mathrm{N}$ & $5,027,907$ & 73,395 & $4,696,933$ & 257,579 & $3,521,698$ \\
\hline
\end{tabular}




\section{Education}

Table 3.7 shows the highest educational level successfully completed by lone mothers. The proportion of lone mothers aged 16-59 who have completed post compulsory education $(54 \%)$ is much higher than the proportion of older lone mothers (7\%). Conversely, the proportion of older lone mothers who do not have any schooling is much higher (39\%) than the proportion of lone mothers aged 16-59 (5\%). These patterns reflect the discriminatory apartheid education system which would have been in place during their schooling. Post compulsory education is usually completed after the age of 15 , which explains the low post compulsory completion rate for the under 16 group. Although a surprisingly high $13 \%$ of lone mothers aged under 16 reported that they had had no schooling, over $90 \%$ of this group reported elsewhere in the survey that they were currently attending school. The finding that $65 \%$ of lone mothers under 16 had completed primary (but had not completed any secondary) level grades may also in part reflect repeated years of schooling.

When all lone mothers are compared to non-lone mothers, the main difference is in the proportion with higher education. A higher proportion of non-lone mothers (14\%) than lone mothers (6\%) have completed some form of higher education.

Table 3.7: Lone mothers and non-lone mothers by highest level of education successfully completed

\begin{tabular}{|c|c|c|c|c|c|}
\hline Education level & $\begin{array}{c}\text { All lone } \\
\text { mothers (\%) }\end{array}$ & $\begin{array}{l}\text { Lone mothers } \\
\text { under } 16(\%)\end{array}$ & $\begin{array}{l}\text { Lone mothers } \\
\text { aged } 16-59(\%)\end{array}$ & $\begin{array}{l}\text { Lone mothers } \\
\text { aged } 60 \text { and } \\
\text { over (\%) }\end{array}$ & $\begin{array}{c}\text { Non-lone } \\
\text { mothers (\%) }\end{array}$ \\
\hline No schooling & 7 & 13 & 5 & 39 & 5 \\
\hline Primary & 19 & 65 & 17 & 36 & 18 \\
\hline Secondary & 17 & 17 & 17 & 13 & 14 \\
\hline Post compulsory & 51 & 2 & 54 & 7 & 48 \\
\hline Higher & 6 & 0 & 7 & 2 & 14 \\
\hline Missing & 1 & 2 & 1 & 1 & 1 \\
\hline Total & 100 & 100 & 100 & 100 & 100 \\
\hline $\mathrm{N}$ & $5,027,907$ & 73,395 & $4,696,933$ & 257,579 & $3,521,698$ \\
\hline
\end{tabular}

Levels of literacy ${ }^{25}$ follow a similar pattern with regard to differences between lone mothers of different ages (Table 3.8). A higher proportion of older lone mothers are illiterate (41\%) compared to younger lone mothers (20\%) and lone mothers aged $16-59$ (6\%).

\footnotetext{
${ }^{25}$ Illiteracy is defined as having a lot of difficulty or being unable to read (e.g. newspapers, magazines, religious books) or write a letter in at least one language.
} 
Table 3.8: Lone mothers by literacy

\begin{tabular}{|c|c|c|c|c|c|}
\hline Literacy & $\begin{array}{c}\text { All lone } \\
\text { mothers (\%) }\end{array}$ & $\begin{array}{l}\text { Lone mothers } \\
\text { under } 16(\%)\end{array}$ & $\begin{array}{l}\text { Lone mothers } \\
\text { aged 16-59 (\%) }\end{array}$ & $\begin{array}{l}\text { Lone mothers } \\
\text { aged } 60 \text { and } \\
\text { over }(\%)\end{array}$ & $\begin{array}{c}\text { Non-lone } \\
\text { mothers (\%) }\end{array}$ \\
\hline Literate & 91 & 79 & 93 & 55 & 93 \\
\hline Illiterate & 8 & 20 & 6 & 41 & 6 \\
\hline Missing & 2 & 1 & 1 & 4 & 1 \\
\hline Total & 100 & 100 & 100 & 100 & 100 \\
\hline $\mathrm{N}$ & $5,027,907$ & 73,395 & $4,696,933$ & 257,579 & $3,521,698$ \\
\hline
\end{tabular}

\section{Employment}

Table 3.9 shows the employment status of lone mothers with regard to work activity in the last week, for those aged $16-59 .{ }^{26}$ Lone mothers have a similar employment profile to all women in this age group: a little over one third worked in the past week (or had a job to return to), while just under two thirds did not. A higher proportion of non-lone mothers of aged 16-59 (45\%) worked in the past week (or had a job to return to).

Table 3.9: Lone mothers by work activity in the past week

\begin{tabular}{|l|r|r|r|}
\hline Employment status & $\begin{array}{c}\text { Lone mothers aged } \\
16-59(\%)\end{array}$ & $\begin{array}{c}\text { Non-lone mothers } \\
\text { aged 16-59 (\%) }\end{array}$ & $\begin{array}{c}\text { All women aged 16- } \\
\text { 59 (\%) }\end{array}$ \\
\hline Work & 36 & 45 & 37 \\
\hline No work & 63 & 54 & 62 \\
\hline Missing & 1 & 1 & 1 \\
\hline Total & 100 & 100 & 100 \\
\hline N & $4,696,933$ & $3,412,939$ & $15,495,677$ \\
\hline
\end{tabular}

\section{Health}

There is little difference between lone mothers and non-lone mothers with regard to suffering from illness or injury over the past month (Table 3.10). However, a higher proportion of lone mothers aged 60 and over suffered illness or injury than lone mothers in the younger age bands.

Table 3.10: Lone mothers by health status over the past month

\begin{tabular}{|l|r|r|r|r|r|}
\hline Health status & $\begin{array}{c}\text { All lone } \\
\text { mothers (\%) }\end{array}$ & $\begin{array}{c}\text { Lone mothers } \\
\text { under 16 (\%) }\end{array}$ & $\begin{array}{c}\text { Lone mothers } \\
\text { aged 16-59 (\%) }\end{array}$ & $\begin{array}{c}\text { Lone mothers } \\
\text { aged 60 and } \\
\text { over (\%) }\end{array}$ & $\begin{array}{c}\text { Non-lone } \\
\text { mothers (\%) }\end{array}$ \\
\hline Suffer illness or injury & 10 & 5 & 9 & 20 & 12 \\
\hline N & 494,087 & 4,030 & 438,509 & 51,548 & 418,897 \\
\hline
\end{tabular}

\footnotetext{
${ }^{26}$ This includes working for a wage, salary, commission or payment in kind, or running any kind of business big or small, even for 1 hour per week, or a job or business to return to.
} 


\section{Housing}

The majority (69\%) of lone mothers live in a dwelling/house or brick/concrete block structure on a separate stand or yard or on farm. This is a similar proportion to non-lone mothers (71\%). However, a much higher proportion of lone mothers than non-lone mothers live in a traditional dwelling/hut/structure made of traditional materials ( $17 \%$ and $8 \%$ respectively). This corresponds with the higher proportion of lone mothers living on communal land administered under traditional authority. A relatively small proportion of both lone mothers and non-lone mothers live in informal dwellings.

Key differences between lone mothers of different ages are that a higher proportion of older lone mothers live in traditional dwellings ( $28 \%$ compared to $16 \%$ for 16 59s and under 16s). Also, a higher proportion of lone mothers who are under 16 and 16-59 live in informal dwellings (7-8\% compared) than for older lone mothers (3\%). A higher proportion of younger lone mothers live in a flat or apartment $(10 \%$ compared to less than $1 \%$ for lone mothers aged $16-59$ and 60 and over).

Table 3.11: Lone mothers by dwelling type

\begin{tabular}{|c|c|c|c|c|c|}
\hline Dwelling type & $\begin{array}{c}\text { All lone } \\
\text { mothers (\%) }\end{array}$ & $\begin{array}{c}\text { Lone } \\
\text { mothers } \\
\text { under } 16(\%)\end{array}$ & $\begin{array}{c}\text { Lone } \\
\text { mothers } \\
\text { aged } 16-59 \\
(\%)\end{array}$ & $\begin{array}{c}\text { Lone } \\
\text { mothers } \\
\text { aged } 60 \text { and } \\
\text { over }(\%)\end{array}$ & $\begin{array}{c}\text { Non-lone } \\
\text { mothers (\%) }\end{array}$ \\
\hline $\begin{array}{l}\text { Dwelling/house or } \\
\text { brick/concrete block structure } \\
\text { on a separate stand or yard or } \\
\text { on farm }\end{array}$ & 69 & 59 & 70 & 64 & 71 \\
\hline $\begin{array}{l}\text { Traditional } \\
\text { dwelling/hut/structure made } \\
\text { of traditional materials }\end{array}$ & 17 & 16 & 16 & 28 & 8 \\
\hline $\begin{array}{l}\text { Flat or apartment in a block of } \\
\text { flats }\end{array}$ & 2 & 5 & 2 & 0* & 3 \\
\hline $\begin{array}{l}\text { Town house (semi-detached } \\
\text { house in complex) }\end{array}$ & 0* & 10 & $0 *$ & 0* & 1 \\
\hline $\begin{array}{l}\text { Dwelling/house/flat/room in } \\
\text { backyard }\end{array}$ & 1 & 0* & 1 & 1 & 2 \\
\hline $\begin{array}{l}\text { Informal dwelling/shack in } \\
\text { backyard }\end{array}$ & 2 & 2 & 2 & 1 & 4 \\
\hline $\begin{array}{l}\text { Informal dwelling/shack not in } \\
\text { backyard, e.g. in an } \\
\text { informal/squatter settlement } \\
\text { or on farm }\end{array}$ & 5 & 6 & 5 & 2 & 6 \\
\hline Other & 2 & 1 & 1 & 2 & 4 \\
\hline Missing & 2 & 1 & 3 & 2 & 1 \\
\hline Total & 100 & 100 & 100 & 100 & 100 \\
\hline $\mathrm{N}$ & $5,027,907$ & 73,395 & $4,696,933$ & 257,579 & $3,521,698$ \\
\hline
\end{tabular}


Table 3.12 shows the amenities available in the households in which lone mothers reside. Over half of lone mothers do not have access to a flush toilet, and almost two fifths do not have piped water in the dwelling or yard. These figures are much higher than for non-lone mothers. Older lone mothers experience greater deprivation of these household amenities, with almost two thirds not having access to a flush toilet and almost half not having piped water in the dwelling or yard.

The proportion of lone mothers living in a household without mains electricity, or without a telephone is not substantially higher than the proportion of non-lone mothers. Similarly, the proportion of lone mothers living in an overcrowded household is only slightly higher than the proportion of non-lone mothers. However, there are differences between age groups for all three indicators. For example, the proportion of older lone mothers living in a household without a telephone is over three times higher than the proportion of lone mothers aged less than 16 and 16-59, while the proportion of lone mothers aged 16-59 living in an overcrowded household is almost twice that of older lone mothers and over three times that of younger lone mothers.

These findings again correspond with findings on the geographical location of lone mothers. A higher proportion of older lone mothers live on communal land administered under traditional authority, which in turn suffer from poor provision of infrastructural services. It is unsurprising, therefore, that a higher proportion of older lone mothers than other lone mothers should lack the different household amenities.

Table 3.12: Lone mothers by household amenities

\begin{tabular}{|c|c|c|c|c|c|}
\hline Household amenity & $\begin{array}{c}\text { All lone } \\
\text { mothers (\%) }\end{array}$ & $\begin{array}{l}\text { Lone mothers } \\
\text { under } 16(\%)\end{array}$ & $\begin{array}{c}\text { Lone mothers } \\
\text { aged } 16-59 \\
\text { (\%) }\end{array}$ & $\begin{array}{l}\text { Lone mothers } \\
\text { aged } 60 \text { and } \\
\text { over (\%) }\end{array}$ & $\begin{array}{c}\text { Non-lone } \\
\text { mothers (\%) }\end{array}$ \\
\hline $\begin{array}{l}\text { No piped water in dwelling } \\
\text { or yard }\end{array}$ & 38 & 32 & 38 & 48 & 23 \\
\hline $\begin{array}{l}\text { No mains electricity supply } \\
\text { to the house }\end{array}$ & 15 & 16 & 15 & 18 & 12 \\
\hline No access to flush toilet & 53 & 50 & 52 & 65 & 31 \\
\hline $\begin{array}{l}\text { No telephone (landline or } \\
\text { cell phone) }\end{array}$ & 6 & 5 & 5 & 18 & 4 \\
\hline Overcrowded household* & 19 & 6 & 20 & 11 & 17 \\
\hline
\end{tabular}

*A household with 2 or more people per room

\section{Poverty}

In the GHS, receipt of a grant is recorded against those for whom the grant is intended, rather than those who actually receive it and so receipt of the CSG is recorded against the child rather than the primary caregiver.

Nevertheless, it is possible to examine grant receipt in the households in which lone mothers live (Table 3.13 ). The vast majority (84\%) of lone mothers live in a household where 
at least one grant is received. For older lone mothers the proportion is $96 \%$, while for younger lone mothers the proportion is much lower at $56 \%$. Over three quarters of lone mothers live in a household where at least one CSG is received. A higher proportion of lone mothers aged 16-59 (78\%) than lone mothers under 16 (50\%) or older lone mothers (63\%) live in CSG households. Conversely, a higher proportion of older lone mothers (90\%) live in households where there is an old age grant (OAG) recipient, compared to lone mothers aged 16-59 (25\%) and younger lone mothers (8\%). Disability grant receipt in the household is higher amongst lone mothers aged 16-59 (12\%) than younger and older lone mothers (3\% and $4 \%$ respectively $)^{27}$. Although not shown in the table, $7 \%$ of lone mothers live in a household in which Foster Child Grant is received, and this rises to $13 \%$ for lone mothers aged 60 and over.

The proportion of non-lone mothers living in a household where one or more grants are received is much lower, both for any grant (56\%) and for each grant type.

Table 3.13: Lone mothers by grant receipt in household

\begin{tabular}{|c|c|c|c|c|c|}
\hline Grant type & $\begin{array}{c}\text { All lone } \\
\text { mothers (\%) }\end{array}$ & $\begin{array}{l}\text { Lone mothers } \\
\text { under } 16(\%)\end{array}$ & $\begin{array}{l}\text { Lone mothers } \\
\text { aged } 16-59 \\
(\%)\end{array}$ & $\begin{array}{c}\text { Lone } \\
\text { mothers } \\
\text { aged } 60 \text { and } \\
\text { over (\%) }\end{array}$ & $\begin{array}{c}\text { Non-lone } \\
\text { mothers (\%) }\end{array}$ \\
\hline Any grant & 84 & 56 & 84 & 96 & 56 \\
\hline Old age grant & 28 & 8 & 25 & 90 & 13 \\
\hline Disability grant & 11 & 3 & 12 & 4 & 8 \\
\hline Child support grant & 76 & 50 & 78 & 63 & 50 \\
\hline
\end{tabular}

Other indicators of low income that can be measured in the GHS include food poverty, income poverty and material deprivation.

Table 3.14 shows three different measures of food poverty. A higher proportion of lone mothers than non-lone mothers live in a household that experienced these types of food poverty. So for example, $30 \%$ of lone mothers live in a household that ran out of money to buy food in the last year, while this applied to $21 \%$ of non-lone mothers. A higher proportion of lone mothers than non-lone mothers also reported that the household had insufficient food 'always', 'often' or 'sometimes' (for adults and children separately). A lower proportion of younger lone mothers than other groups of lone mothers experienced the different types of food poverty. This is possibly because they are mainly not lone mothers living by themselves, but are instead living in households where there are other adult household members and different income streams.

\footnotetext{
${ }^{27}$ The Disability Grant is paid to disabled people aged 18-59 only.
} 
Table 3.14: Lone mothers by food poverty

\begin{tabular}{|c|c|c|c|c|c|}
\hline Food poverty in last 12 months & $\begin{array}{l}\text { All lone } \\
\text { mothers } \\
(\%)\end{array}$ & $\begin{array}{c}\text { Lone } \\
\text { mothers } \\
\text { under } 16 \\
(\%)\end{array}$ & $\begin{array}{c}\text { Lone } \\
\text { mothers } \\
\text { aged } 16-59 \\
\text { (\%) }\end{array}$ & $\begin{array}{c}\text { Lone } \\
\text { mothers } \\
\text { aged } 60 \\
\text { and over } \\
(\%)\end{array}$ & $\begin{array}{l}\text { Non-lone } \\
\text { mothers } \\
(\%)\end{array}$ \\
\hline Ran out of money to buy food & 30 & 17 & 31 & 26 & 21 \\
\hline $\begin{array}{l}\text { Insufficient food for adults } \\
\text { (always/often/ sometimes) }\end{array}$ & 15 & 8 & 15 & 14 & 10 \\
\hline $\begin{array}{l}\text { Insufficient food for children } \\
\text { (always/ often/sometimes) }\end{array}$ & 14 & 9 & 14 & 12 & 9 \\
\hline
\end{tabular}

The Hoogeveen and Özler (2006) lower bound and upper bound poverty lines have been used regularly to measure income poverty in South Africa in the absence of an official poverty line. The poverty lines are R604 and R1,113 per capita per month respectively (2011 prices). Two thirds of lone mothers are poor on the lower bound measure, and over four fifths are poor on the upper bound measure. A higher proportion of older lone mothers (90\%) are poor on the upper bound compared to lone mothers under 16 and 16-59. The poverty rates using each of the poverty lines are lowest for lone mothers under 16 . The poverty rates for non-lone mothers are lower than for any of the lone mother age groups.

Table 3.15: Lone mothers by income poverty

\begin{tabular}{|l|r|r|r|r|r|}
\hline & \multicolumn{1}{|c|}{$\begin{array}{c}\text { All lone } \\
\text { mothers (\%) }\end{array}$} & $\begin{array}{c}\text { Lone mothers } \\
\text { under 16 (\%) }\end{array}$ & $\begin{array}{c}\text { Lone mothers } \\
\text { aged 16-59 } \\
(\%)\end{array}$ & $\begin{array}{c}\text { Lone } \\
\text { mothers } \\
\text { aged 60 and } \\
\text { over (\%) }\end{array}$ & $\begin{array}{c}\text { Non-lone } \\
\text { mothers (\%) }\end{array}$ \\
\hline Poor on lower bound & 67 & 50 & 67 & 63 & 37 \\
\hline Poor on upper bound & 82 & 63 & 82 & 90 & 53 \\
\hline
\end{tabular}

Poverty lines of R604 (lower bound) and R1,113 (upper bound) in 2011 prices

Finally, two indicators of material deprivation can be measured in the GHS: not owning a refrigerator and not owning a TV or radio. As with the previous poverty measures, the proportion of non-lone mothers lacking the items is lower than the proportion of lone mothers (Table 3.16). Thus, $24 \%$ of lone mothers live in a household that does not have a refrigerator, compared to $15 \%$ of non-lone mothers, and $10 \%$ of lone mothers live in a household that does not have a TV or radio, compared to $5 \%$ of non-lone mothers. A lower proportion of lone mothers aged 16-59 lacked these material items than the younger and older lone mothers. 
Table 3.16: Lone mothers by material deprivation

\begin{tabular}{|l|r|r|r|r|r|}
\hline & $\begin{array}{c}\text { All lone } \\
\text { mothers (\%) }\end{array}$ & $\begin{array}{c}\text { Lone mothers } \\
\text { under 16 (\%) }\end{array}$ & $\begin{array}{c}\text { Lone mothers } \\
\text { aged 16-59 } \\
(\%)\end{array}$ & $\begin{array}{c}\text { Lone } \\
\text { mothers } \\
\text { aged 60 and } \\
\text { over (\%) }\end{array}$ & $\begin{array}{r}\text { Non-lone } \\
\text { mothers (\%) }\end{array}$ \\
\hline No refrigerator & 24 & 30 & 23 & 30 & 15 \\
\hline No TV or radio & 10 & 12 & 10 & 17 & 5 \\
\hline
\end{tabular}




\section{Chapter 4 Lone mothers and dignity}

Summary: This chapter seeks to explore what dignity means to South African lone mothers in practice. By way of introduction, Section 4.1 considers interpretations of dignity 'as principle' and experiences of dignity 'in practice'. Section 4.2 presents analysis of the focus group findings contoured around four dimensions of dignity: worthiness, self-esteem, self-respect and autonomy. These findings highlight ways in which dignity intersects with issues of racism, sexism, relations with the community and family, caregiver status and employment status. Section 4.3 presents analysis of the in-depth interviews and findings are presented on the diversity of experiences and dynamics that underpin dignity, as well as examples of eroded or impaired dignity.

\subsection{Introduction}

A key objective of the project was to explore what 'dignity' means to low income lone mothers in South Africa in the context of their lives. This provides a framework for the following chapter which examines lone mothers' accounts of the impact of poverty and inequality on their dignity. Inevitably, the issues of poverty, inequality and social security arise in this chapter but the primary focus is on dignity per se.

This chapter presents analysis of the focus groups (section 4.2) and in-depth interviews (section 4.3) which used very different approaches to explore what dignity means to the participants. Each focus group began with a quotation from the Bill of Rights in the South African Constitution, and so the notion of 'dignity as principle' was explicitly enunciated at the outset. In contrast, the in-depth interviews approached the subject of dignity less directly, although the in-depth interviewees had previously taken part in one of the focus groups.

The remainder of this introductory section considers 'dignity as principle' and 'dignity in practice' in more detail. As will be seen, the notion of 'dignity as principle' is prominent within the jurisprudence literature wherein dignity is regarded as indefeasible human worth. However, dignity can also be considered as a psycho-social phenomenon 'dignity in practice' (e.g. Budowski, 2005). At times these two notions of dignity can seem disconnected (e.g. Phillips, 2011), but the material presented in this chapter enables consideration of the extent to which the two intersect.

\subsubsection{Dignity as a human right}

The Universal Declaration of Human Rights refers to dignity on five occasions including in the first words of the preamble which states that in order for there to be freedom, justice and peace in the world, people's inherent dignity must first be recognised: 
'Whereas recognition of the inherent dignity and of the equal and inalienable rights of all members of the human family is the foundation of freedom, justice and peace in the world'. (UN, 1948, Preamble)

As well as dignity being inherent, the Universal Declaration of Human Rights states that people are born with equal amounts of dignity: 'All human beings are born free and equal in dignity and rights' (UN, 1948 Article 1).

Later, in Article 22, it is stated inter alia that everyone 'is entitled to realization [...] of the economic, social and cultural rights indispensable for his dignity..' (UN, 1948 Article 22). The notion that a person's dignity requires that certain rights be realised can be interpreted as implying that the absence of those rights would be detrimental to dignity. Even at this high level, there is therefore an acknowledgement that dignity could be compromised.

The Convention on the Elimination of All Forms of Discrimination against Women which was adopted in 1979 by the United Nations General Assembly is sometimes referred to as a Bill of Rights for women, and also sets dignity in centre stage (UN, 1979). This was signed by South Africa in January 1993 and ratified in December 1995.

Dignity features very prominently within the South African Constitution. The chapter on founding provisions begins with the following:

'The Republic of South Africa is one, sovereign, democratic state founded on the following values: (a) Human dignity, the achievement of equality and the advancement of human rights and freedoms..' (RSA, 1996 Ch1s1a).

As such, dignity is recognised as a foundational value and is highly entrenched: any amendment to this section of the constitution requires approval by a larger majority than other components (Ackermann, 2000).

The South African Bill of Rights states that 'Everyone has inherent dignity and the right to have their dignity respected and protected' (RSA, $1996 \mathrm{Ch} 2 \mathrm{~s} 10$ ). Writing about the South African Constitution, a constitutional court judge has argued that it is 'a reactive constitution [...] It highlights dignity, equality and freedom, because these are the rights that have suffered so much in the recent past.' (Ackermann, 2000: 539). In particular, he highlights the way in which black people were treated as means to an end during Apartheid, 'an almost complete reversal of the Kantian imperative and concept of priceless inner worth and dignity.' (Ackermann, 2000: 540).

In addition to recognition that the dignity has been compromised in the past, another constitutional court judge has suggested that dignity is still compromised by the high levels of deprivation experienced by many people: Chaskalson writes that:

'As a consequence of our history, structural impediments remain to the achievement of "dignity, equality and freedom". Millions of people are still without houses, 
education and jobs, and there can be little dignity in living under such conditions.' (Chaskalson, 2000: 204).

In spite of the prominence given to dignity in the Constitution ${ }^{28}$, the Constitutional Court has not defined human dignity. It has, however, identified the right to dignity and the right to life as the two most important human rights (Currie and de Waal, 2005). Outside the context of the Constitutional Court, Ackermann has however ventured that:

'Viewed in its historical context I understand dignity in the Constitution to connote innate, priceless and indefeasible human worth.' (Ackermann, 2000: 541). ${ }^{29}$

Whilst recognition of inherent dignity exists as a foundational principle in the Universal Declaration of Human Rights, the South African constitution makes it explicit that everyone has the right to have their dignity respected and protected. Notwithstanding this commitment, very little exploration has been undertaken about what the concept means to people in the context of their own lives.

\subsubsection{Dignity in practice}

Dignity can also be regarded as a sociological and psychological construct, related to individuals and their context. Budowski (2005) describes this as an "embodied", implicit (hierarchical)' notion of dignity and states that:

'hierarchical notions of dignity and honour are pervaded with power as their attribution provides the symbolic legitimization of social positions, their range of action, their codes of conduct, and the respect they are accorded. It is this type of honour and dignity (with its counterparts, humiliation and shame) that structures local, traditional and national social orders.' (Monica Budowski, 2005: 53).

Apart from Budowski's important study, attempts to explore 'dignity in practice' have mainly occurred within the health arena (e.g. Chochinov et al., 1982; Haddock, 1996). In a more recent study on dignity and health of Palestinian refugees, Khatib and Armenian

\footnotetext{
${ }^{28}$ For an account of the role of human dignity in Constitutional Court's human rights jurisprudence, and summary of critiques of the use of dignity as a value in constitutional adjudication see the introduction of Leibenberg (2005).

${ }^{29}$ Ackermann also describes dignity as a distinguishing feature of humanity: 'It is that quality of being human which we gropingly call dignity that distinguishes us from other creatures. Whether one sees fundamental human dignity in purely secular humanist terms, or as the image of some divinity in which humans are created, it was the defiling of human dignity by apartheid that led South Africans to reject apartheid.' (Ackermann, 2000: 556).
} 
(2010) identified four dimensions of dignity: worthiness, self-respect, self-esteem and autonomy. $^{30}$

Experiences of dignity are interpreted and experienced at the psychological level of self-identity and individual subjectivity, which Khatib and Armenian (2010) privilege in their typology, but these experiences are shaped by larger social factors and structural conditions. So although dignity is experienced and lived out at an intra-individual level, larger structures and relations fundamentally pattern it. While these two realms intersect, and the individual is constituted within interactions with the larger social context, neither is reducible to the other.

However individual subjectivity is not solely determined by context nor is it the product of a solipsistic, individual consciousness, hence there is a potential epistemic mismatch in reading one off the other. In other words, it is perilous making analytic inferences about the prevailing social structure exclusively from analysis of individual subjectivity (or, vice versa). This tension is not only a critical one in understanding the determinants of dignity, but the foundational tension between agency and structure within the human sciences (Giddens, 1979). Dignity is therefore located and experienced in relation to individual subjectivity, yet is fundamentally shaped by larger structural conditions and relationships. Sensitive inquiry demands attention to both of these domains. In the present inquiry, understanding the workings of dignity meant that rights-based conceptions of dignity normatively accorded to individuals were an important conceptual and moral 'frame', but for the purpose of the in-depth interviews they were of far less direct analytic interest than the interplay between informant's personal sense of dignity and the manner in which it was mediated by their social context.

\subsection{Dignity and lone mothers: the focus group interviews}

"Yes, dignity touches all aspects of one's life. At home, relations at home, at work, in the community - just everywhere, it's important." (Xesi, FG18)

This Section 4.2 draws from focus group contributions that centred on whether and why dignity is important in South Africa; whether and why dignity is important to South African women in particular; accounts of the impact on dignity of being in paid employment and being unemployed; and examples of why dignity is important in relation to the self, the family, and the wider community (see Annex 3 for the focus group schedule). This classification or taxonomy of dignity proved to be useful as a framework for analysing the focus group interviews and so Sections 4.2.1 to 4.2.4 are structured along these lines.

\footnotetext{
${ }^{30}$ Khatib and Armenian's four dimensions of dignity also resonate with literature on 'Eudemonic' measures of subjective well-being (e.g. Dolan et al., 2011).
} 


\subsubsection{Dignity as worthiness}

One of Khatib and Armenian's dimensions of dignity is 'worthiness', which they describe as including 'the ability to feel important and valuable in relation to others, communicate this to others, and be treated as such by others' (Khatib and Armenian, 2010: 39). Issues relating to worthiness arose very prominently in the focus groups and can be grouped along three themes relating broadly to employment status, sexism and racism.

A very strong impression was conveyed by the participants that they felt 'less worthy' when not in paid employment. ${ }^{31}$

"When you're not working you're not respected within the family. People speak to you any which way and even insult you. But when I have a job I'm treated differently, with respect." (Paarl, FG28)

"Even in our families it does affect us, if there's a family meeting, well those who are working, their words are final. They take decisions." (Alice, FG21)

"We are poor, we don't have jobs - this affects all our relationships especially in the community. There is no dignity." (Dimbaza, FG17)

Many of the participants stressed how their sense of worthiness felt diminished when they were unemployed. The first two examples shown above relate to a sense of value in relation to others within the family: the first participant described how she is treated differently when not working, and the second woman spoke of the way in which her opinions are not taken into account when decisions are made within the family. Many other participants contrasted their experiences of how they are treated by others when they are in work and when they are not in work, referring to the reduced levels of respect within their families and communities. For example:

"When I was working my mother treated me well, she would even do my laundry and I would give her money. Now I am invisible to her, all her respect goes to my brother even though I worked for years before he did." (Dimbaza, FG17)

Secondly, some of the participants spoke of being treated unequally to men. Both of the examples shown here include a reflection that it ought not to be the case. As such,

\footnotetext{
${ }^{31}$ Issues around paid and unpaid work straddle all four of Khatib and Armenian's four dimensions of dignity and are mentioned in each of the respective subsections in this chapter, though see especially the section on 'autonomy'.
} 
sexism is being identified as an affront to dignity, as it is an example of being regarded as less 'worthy' than another person.

"It's very important, really, because it is important to listen to other people's views, especially women. In the old days voices of woman were not heard, only men were allowed to talk and lead but now South Africa has changed, we are all equal, it's supposed to be 50/50, but it does not really happen that way." (Khayelitsha, FG3)

"Well, men's dignity is always being put first, just in society in general. But it's important that our dignity be respected and protected too. We are all human beings, we're not less human." (Butterworth, FG24)

Thirdly, many of the participants highlighted ways in which they felt that their dignity was more protected and respected in present day South Africa than during apartheid. The treatment of black people, and in particular black African people, during Apartheid in many respects epitomises the enforcement of a sense of unworthiness on a group.

"I feel like our dignity as black African people is now being taken into good consideration and respected. If I do some work for someone, they are expected to pay me, it's my right so that I can buy what they also have. It's no longer just white people's dignity that matters anymore." (Centani, FG23)

"Well I think at least the current government takes our dignity into consideration as black people. During apartheid our dignity did not matter to the apartheid government and dignity is very important." (Butterworth, FG24)

"There was a lot of things we couldn't do that time.... You know what I am saying. Lots of our dignity was taken away from us and through the years we had to fight and stand up for our rights ...so that we can do what we doing today." (Mitchells Plain, FG13)

Many of the participants elaborated on the fact that although they feel that their dignity is respected and protected more than it was during the apartheid era, things have only improved 'to a degree'. The following quotations provide examples of women articulating that they are still treated as 'less worthy' than others. In these examples, a number of reasons are given for dignity being compromised, including limitations of government, intraracial inequality, and ongoing racism between population groups.

"I think that since 1994 at least one feels like a human being, you can tell that government is trying to protect our dignity, or at least government knows they are meant to be protecting our dignity. That is their rule. During the apartheid era black 
people had no right to dignity and the apartheid government made sure that we are aware of this fact, no dignity for a black person. The problem now is that the current government has its limitations and we end up with a compromised sense of dignity." (Dimbaza, FG16)

"I think dignity is very important to and for South Africans. Our dignity didn't matter during the apartheid era to the white people that were running this country. But now it matters to a degree, because we're in a democracy.

Facilitator: Why do you say to a degree?

Respondent: Because with inequality there are blacks whose dignity matters more than ours because they are well off, educated and in good positions. At the end of the day though, every human being's dignity matters, it is our humanity and it's important." (Centani, FG23)

"I think it's crucial for people's dignity to be respected because as we sit here, most of us, our dignity is not protected. Apartheid is said to be over according to law, but in practice it's not. White people don't treat us with dignity in this country, there's still a lot of apartheid." (Nyanga, FG1)

\subsubsection{Dignity as self-respect}

Khatib and Armenian's second dimension of dignity is 'self-respect', which they say 'combines respect both for one's self and for others. Self-respect includes being responsible and reliable, a trait that makes a person respected by others' (Khatib and Armenian, 2010: 39).

Self-respect was mentioned very prominently in the focus groups, with women repeatedly making the point that it is necessary to them to respect themselves first, as only then would people treat them with respect: that is, self-respect is seen as a necessary prerequisite for gaining the respect of other people.

"First of all I have to respect myself, because I know who I am and what I'm about. I'm a woman, I'm a mother and I'm somebody's daughter. I have to live my life with dignity and hopefully people will treat me with dignity too." (Paarl, FG28)

"We have to respect ourselves and protect our own dignity, first and foremost, before anybody else can." (Butterworth, FG24)

"I am who I am and at the core of that is my dignity. I have to respect myself and as far as possible, under my control, be dignified. People will easily disrespect you if you disrespect yourself." (Masiphumelele, FG30) 
People also articulated the reverse order of this causal chain, and mentioned that respecting others aids self-respect:

"What I'm trying to say is that it's important for a person's dignity to be protected and respected because if I don't respect others, I am also disrespecting my own humanity." (Dimbaza, FG16)

"It starts with you as a woman, the way you carry yourself, the way you treat others, you can be a woman but not have dignity because of the way you are to people. If you respect others, you'll be able to respect yourself too.." (Alice, FG21)

A second theme to emerge within the dimension of 'self-respect' relates to 'respectable behaviour' which reflects a more conservative and patriarchal worldview and was most prominent in rural areas. A few examples of 'respectable behaviour' were given, including the importance of not gossiping, not drinking in public, and not wearing short skirts:

"Secondly it's important that as a mother and as a woman you stay in your own home with dignity and not go around gossiping about other people in other people's homes and getting in trouble."

(Thafalofefe, FG22)

"I was going to say it's important for women to carry themselves well, and protect their own dignity by not going around getting drunk and things like that." (Qumrha, FG14)

"It's important that a woman leads her own life with dignity, handles herself well and not wear short skirts." (Dimbaza, FG16)

However, in an urban setting there was a debate about clothing and the point was made that being scantily clad did not confer a lack of respectability, but that the interpretation of scanty clothing had changed over time:

"I think it's also important for women to respect themselves and carry themselves with dignity. Times have changed, we live in aggressive and violent times. A scantily dressed woman could walk from one village to another, or in town, without harassment. For that matter, Xhosa traditional-wear for young unmarried women is scanty, not much to it at all and there never used to be a problem. Now, the white man introduces scanty clothing, it conveys a different message and some men get aggressive. In that sense a woman has put herself at risk. We have to change and adapt with the times we live in." (Masiphumelele, FG30) 
Only one participant mentioned the importance of observing traditional ways as a means of retaining dignity:

"Back in the day black people used to slaughter an animal, certain sacrifices, as a way of saying thanks to their ancestors for being employed, since most of us are no longer following our traditional ways we end up not having a way forward in life. Such a person has no dignity" (Langa, FG7)

Lastly - a theme which is revisited later - it was reported that if people are seen to be misusing the Child Support Grant (CSG) e.g. spending it on alcohol, then they are not treated with respect and are seen to lack dignity:

"In most cases we are treated with respect, the thing is most parents have dignity, especially the ones that spend the CSG reasonably and well. You can be a parent and get the grant but not spend it on the children's needs, if it's a grant-day - you enjoy yourself with alcohol. If you're using the grant money people will see that you don't have dignity. (Alice, FG21)

\subsubsection{Dignity as self-esteem}

Khatib and Armenian's third dimension of dignity is 'self-esteem'. They refer to the work of Chochinov et al. (1982), "where they state that dignity refers to internally held qualities that may be based on personal characteristics, attributes, or an acquired world view, including continuity of self, role preservation, legacy, maintenance of pride, hopefulness, a fighting spirit, and other qualities that maintain one's self-respect." (Khatib and Armenian, 2010: 39).

A number of themes arose in the focus groups relating to self-esteem. Of greatest prominence, the point was repeatedly made that the reason why it is important for the dignity of women to be protected and respected is because of their roles of raising children and running homes. As a woman from Butterworth put it: "Dignity is an important part of womanhood and motherhood. They all go together." (Butterworth, FG 25). The following quotations contain examples from the focus group participants of why the protection of their dignity is important, specifically in relation to role preservation:

"It's very important for our dignity to be respected, we contribute to society, we give birth to children." (Khayelitsha, FG3)

"It's crucial to protect women's dignity because women are the main caretakers of homes in our country. It's the mother who bears the burden of the home. For a home to stand with dignity, there must be a woman in it." (Nyanga, FG1) 
"As women we are carrying a huge load. We bear the responsibility of raising children and giving them homes. It's important that our dignity be protected." (Mbekweni, FG27)

"As women we carry families on our shoulders, so we have to have protected dignity" (Qumrha, FG14)

Women distinguished themselves from men whom, they argued, played a smaller caregiving role if present, and found it easier 'to just up and go':

"it's very important that women's dignity be respected and protected. It's huge, what we do. This responsibility we carry of raising children on our own, with very little. The men are nowhere to be found. Sometimes, even if the men are there, they don't meet their responsibilities." (Paarl, FG28)

"It's important, especially for women who are mothers, we as mothers are the caretakers of the next generation. Children look up to us because we tend to spend much more time with them than their fathers. If our dignity is intact as women, it will serve our children well." (Qumrha, FG14)

"It's important because a woman, a mother for example, we care for and look after most of the children in this country. A lot of fathers can just take off and leave their children without consideration, most women can't do that. Our children are like chicks to us, and we are mother hens, we will do anything for them." (Centani, FG23)

Participants spoke of dignity being conferred from the mother to the child ${ }^{32}$ :

"As women if we don't have dignity, then our children also won't have respect for themselves and us. It starts from us as the mother, you have to have the dignity because you pass it over to your child. If we don't have it, then what's the use we raise our kids? So, it's very important for us women." (Mitchells Plain, FG9)

"in my identity as a mother I live my life with dignity so that my children can do the same." (Qumrha, FG14)

Examples were given of the need for a woman's dignity to be protected because children 'look up to' the caregiver, and learn from adults' treatment of one another:

\footnotetext{
${ }^{32}$ This resonates well with Haddock's (1996) operational definition of dignity where she states that 'Context and possession of dignity within oneself affects one's ability to maintain or promote the dignity of another.' (p930).
} 
"You need to have you dignity intact because you cannot raise children without dignity, they have to see that you are dignified." (Alice, FG 21)

"I think it's important because women are pillars in their homes. If a woman is not well treated and her dignity is eroded, when she has no confidence - for example if a husband beats his wife in front of the children, if there's a boy child, the boy will think that's the way to treat a woman or wife, and he himself will end up doing the same. Women must be treated with dignity, it's important." (Qumrha, FG14)

"we are role models to our children, so it's important that our dignity is respected, that we respect ourselves too." (Butterworth, FG25)

Another spoke of the way in which she felt she had to 'stand up and be strong as a parent' in the face of poverty, so as to impart hope in her children:

"We really have to be strong as women who are poor. My children sometimes ask why we don't have a toilet inside the house like their friend's houses or why our house is not plastered properly. You have stand up and be strong as a parent, tell your children it won't always be like this, there's hope. And that they should study hard so that they have better lives. I have to lift myself up and not sink in the mood of feeling a failure as mother." (Qumrha, FG14)

In contrast, a woman from Thafalofefe described how she feels when people can see that her children are well taken care of:

"You feel good and dignified when people can see that your children are well taken care of, that they are clothed like other children and well fed." (Thafalofefe, FG22)

These quotations demonstrate the way in which dignity is depicted as being strongly associated with the ability to fulfil the role of caregiver including meeting the material needs of those being cared for.

Notwithstanding the prominence of the caregiver role, participants additionally ventured to describe dignity in more general terms in relation to their sense of self, rather than in relation to their roles within the family. For example, people repeatedly made the point that their sense of self and their sense of dignity were indivisible:

"my personality is linked to my dignity, it's who I am." (Alice, FG20)

"I'm proud to be South African, to be a woman, to be Xhosa. What holds all those parts of me together is my dignity." (Masiphumelele, FG30) 
"Yes, you cannot separate yourself, your humanity as your individual self, from your dignity. It's one and the same thing, you dignity is the core of your identity."

(Thafalofefe, FG22)

Women provided examples of ways in which external judgement, humiliation, or lack of respect impacts on their dignity in terms of their sense of self:

"I wish people didn't judge us, because that affects our dignity. They should leave us alone so that at least our self-perception remains intact." (Butterworth, FG24)

"If somebody tramples on your dignity, inevitably your self esteem will suffer and go down, and when that happens - your entire life will be dictated by and defined by a low self-esteem." (Qumrha, FG14)

"your dignity cannot be intact if you're not respected, or if you don't feel respected. If somebody humiliates me, for example, it impacts on my dignity, very badly and I end up wondering who I am, what I'm about. I question my own identity as a result." (Masiphumelele, FG30)

Even more starkly, people spoke of how loss of dignity compromises their sense of humanity and (in the third quotation) the humanity of others:

"Without dignity we are nothing, nobody." (Butterworth, FG26)

"When your dignity is compromised you're not whole, as a person." (Dimbaza, FG17)

"Yes, as we said dignity is a core part of a person, without it your humanity is compromised and the humanity of those around you too." (Qumrha, FG15)

In these quotes we see linkages between 'dignity as principle' and 'dignity in practice'. The quotations particularly resonate with the interpretation of dignity provided by Ackermann (2000) as innate human worth.

"A human being without dignity is empty, nothing really." (Xesi, FG18)

"Without dignity, you are not human, there is no human being there if there is no dignity." [...] "Each and every person is born with their own sense of dignity, it does define one." (Butterworth, FG24) 


\subsubsection{Dignity as autonomy}

Khatib and Armenian's fourth dimension of dignity is 'autonomy' which they say 'includes independence, control, ability to make one's own decisions, and functional capacity.' (Khatib and Armenian, 2010: 39). The most prominent issue that emerged in the focus groups relating to autonomy centred on the linkages between dignity and paid work. The causal link is straightforward: paid work yields income which contributes to financial independence and an improved ability to meet the material needs of the family as well as one's own needs, and this not only enhances self-esteem but also a sense of one's autonomy.

This section begins with material that more generally depicts the linkage between paid work and dignity. This emerged most clearly at the end of each focus group, when people were asked what would help to further protect and respect their dignity: most women said 'jobs' and this was the most prominent response in each focus group.

Facilitator: What sort of things would help to respect and protect people's dignity? Respondents: Sisi we need jobs (Khayelitsha, FG5)

Facilitator: I see, so what can be done for people to lead a dignified life? 1st Respondent: More job creation (others agree) at least when you are employed there is that hope of getting paid on month ends, so you don't worry a lot about problems because come month end they'll be sorted. (Langa, FG7)

"We need work. I look at other people my age, they are the ones helping out their parents, not the other way round. It really hurts, it's painful and erodes my dignity that I have to ask relatives for help at my age." (Masiphumelele, FG29)

Recent analysis by Ntshongwana (2010a) also shows that lone mothers value paid work highly, with two-thirds of black African lone mothers stating that a working age lone mother with a child under the age of five should go out to work to support her child, which is interpreted as a response 'to the dire reality of conditions without employment, in the context of no social assistance support.' (Ntshongwana, 2010a: 9). The findings presented here reveal the way in which such attachment to the labour market is linked to a sense of dignity.

Earlier in the focus group, people were asked whether being in or out of paid work impacts on their sense of dignity. People gave examples not only of the negative impact on dignity of unemployment, but also of ways in which their dignity had been compromised when in paid work. ${ }^{33}$

\footnotetext{
${ }^{33}$ Work was generally conceptualized as remunerative work for another person, and not forms of informal self employment.
} 
We begin with the first subgroup, to further demonstrate the negative impact on dignity of unemployment, manifested as a lack of autonomy, and how this has a negative impact in turn on self-esteem:

"Not working takes away your dignity, you end up doing all sorts of things, the children's fathers are nowhere to be found but the children are right there, in front of you, everyday, to be looked after." (Khayelitsha, FG5)

"Not working simply traumatizes my sense of dignity." (Masiphumelele, FG29)

"When you don't have a job you don't have dignity, it's like you're nobody. You have nothing." (Thafalofefe, FG22)

Not working, not having a job lowers my self-esteem. When you don't have a job and feel so low, it's like I was born for poverty and suffering. It's humiliating. I watch people who have jobs and they look dignified. (Mbekweni, FG27)

A number of the women had been in work before, and so contrasted their experiences in relation to dignity from when they were in work and when they no longer had paid work, and stressed the lack of autonomy that they felt when out of work:

"There's a big difference when you are working and when you're not working. When you have a job you can do things for yourself, and when you don't you may even end up stealing out of desperation. Even those thoughts affect your sense of dignity, just being desperate." (Xesi, FG18)

"Not having a job does affect my dignity because I'm used to earning my own money. It's painful, you cannot take care of yourself." (Dimbaza, FG16)

It should be stressed however that work does not automatically guarantee dignity as autonomy. Although most of the focus group participants were not in paid work many of them had experience of having worked previously. Indeed, the in-depth interviews described in what follows (section 8.3.3.), reveal that many lone mothers engage with smaller scale, informal employment. In a focus group in Langa a particularly striking example was given of women's compromised autonomy when in paid work: in an exchange between two women they revealed that due to the fact that their clinic only offers contraception injections during working hours they find themselves choosing between retaining their job and risking becoming pregnant, or avoiding pregnancy by going to the clinic for the injection and risking losing their job ${ }^{34}$ :

\footnotetext{
${ }^{34}$ This example resonates well with Liebenberg's (2005) comment on the Treatment Action Campaign case about the provision of an anti-retroviral drug where she observes that 'For society to deny poor women and
} 
Respondent 6: It's like that everywhere, in clinics and hospitals as well, it's just like that and there's nothing we can do because we're in need. For example at the clinic here, we can only go for the contraceptive injection at 2pm. You can't go before or after, even when you're working. And they know we can't afford to pay the R50 to go to Clicks for the injection. Our dignity is definitely unprotected, it's not seen as important. I don't know about other places but that's what happens here.

Respondent 4: Us too, we have to go for the injection at 2.

Respondent 6: If you want to work you're going to give the injection up because you don't want to lose your job. Then you end up being pregnant! (Langa, FG6)

Indeed, several participants described ways in which their dignity felt so compromised at work, that they decided to leave their jobs. Reasons included being misled about payment levels, poor working conditions when pregnant, and the inability to provide adequate alternative care for one's children:

"My dignity was compromised at work. I was told I'd earn R1 000 (approximately 162 per month), at month end they gave me R800 (£50). I gave up the job." (Xesi, FG18)

"They did not treat me with dignity, the reason I stopped working was the steam, because of the steam. I was pregnant at that time and they did not take that into consideration." (Alice, FG20)

"I used to be a nanny, it used to kill me making breakfast for the children at my workplace, I'd make them muesli and yoghurt. I felt like dying because I knew mine didn't even have a slice of bread at home. I'd watch them go to school, washed, clean and combed by me, while mine are on their own - doing all that for themselves. I was a live in domestic too, my children slept on their own. All that work and l earned R500. It wasn't worth it, I gave it up." (Butterworth, FG24)

\subsection{Dignity and lone mothers: the in-depth interviews}

The in-depth interviews sought to understand dignity by examining it in relation to the lives and social context of the lone mother informants. This required a ground up ('emic') approach in order to consider dignity in a manner attentive to the manner informants negotiate it in relation to the specificity of their own lives and larger social context. The

their newborns access to 'a simple, cheap and potentially lifesaving medical intervention' would clearly indicate a lack of respect for their dignity as human beings entitled to be treated as worthy of respect and concern.' (p 13). In our example, if women find themselves compelled to choose between access to contraception or employment it similarly indicates society's lack of respect for their dignity. 
research approach followed therefore focused attention both on the informant's reporting of their subjectivity and self-identity, and reports of their positioning in relation to the larger social context in which they are embedded.

In order to examine the question of dignity quite generally the research team, at this point, sought to hold in abeyance attention to the specific dynamics related to grant receipt. This was done in order to discern the larger dynamics related to dignity, and avoid fixating on CSG receipt exclusively. While CSG receipt can potentially enhance or detract from dignity, the objective here was to develop some understanding of the in situ workings and sources of dignity, apart from receipt of the CSG. This was an analytic challenge made all the more demanding by the constraints of relatively limited contact (in-depth interview) with each informant.

\subsubsection{Understanding dignity}

Informants explained, in the empirical material that follows, a range of ways in which dignity was created and sustained, and how they positioned themselves relative to it. Dignity was generally described in terms of three constitutive components. Firstly, informants specified that dignity accrued to those women who abstained from disreputable (in social conservative terms) behaviour, such as drinking and smoking. These behaviours detracted from the level of self-respect others accorded them. A second component of dignity entailed maintaining a modest social profile, including confining oneself to one's home during leisure time, and not having too many friends. It entailed eschewing gossip, or avoiding acting in ways as to become a topic of gossip in order to preserve one's respectability. A third component of dignity and dignified behaviour required enacting socially appropriate and validated roles, particularly providing suitable childcare. This would be manifest by, for example, not having one's children wandering around unattended, inadequately clothed or fed. These dimensions are evident in the following extracts.

\section{Extract $1^{35}$}

Informant Siphesande,

Siphesande: How do I see a person with dignity?

S.M: Yes.

Siphesande:

A person with dignity does not go to the streets or gossip about other people. It is better to stay in your house and to not have too many friends, because you're creating dignity for yourself. You mustn't have too many friends because not all friends are always appropriate, so you must carefully choose one good friend. If you go outside and listen to all the gossip,

\footnotetext{
${ }^{35}$ In all the in-depth interview extracts that follow, D.N is the researcher, S.M and V.C are the two fieldworkers who usually conducted the interview and interpreted for D.N.
} 
and go and drink alcohol and not come back home, that is not dignity. If you hear people say, Mrs So and So is having dignity, it is because she stays indoors, takes care of her children and does not go around gossiping.

\section{Extract 2}

Informant Nomkita, in her thirties sharing a house with her own children, her mother, adult siblings and various nephews and nieces.

S.M: Do you think, here at home, they respect this household and is it treated with respect, does it have dignity?

Nomkita: Yes, but you will find out that even me I stay indoors, so they don't know if you are helping me, because we don't want them to know our situation. We [the siblings] help each other, if one of us does not have something we help. Even on the clothes side we mostly buy similar clothes for all the children, so that people don't know our situation. We all do so that they wear the same things, whether expensive or not, especially the little ones. We buy the same items of clothing from the same shop just in different colours.

\section{Extract 3}

Informant Akona, on whether she elicits stigma and gossip:

Akona: No they can't say anything because they get the grant too, besides I'm not drinking or smoking.

D.N: Ja okay.

V.C: So if you were drinking or smoking they will say something?

Akona: Yes they were going to say something.

\section{Extract 4}

Informant Siphesande elaborates with an even more personal, account,

Siphesande: ...I don't want to lie, before I used to drink and smoke a lot, but not anymore. Because I realized that I don't have dignity, and that's why I don't get respect from my younger sister, because I drinking, smoking and go out to my boyfriend in front of her. That's why she doesn't respect me and she is only nineteen years old. By stopping all these things I'm trying to bring my dignity back, and we are visiting each other now. She was here earlier to help me, she washed my baby's clothes and hanged them up.

A final, and complex view of dignity related it to a lack of autonomy, independence and material means: 


\section{Extract 5}

Informant Xoliswa's lucid description of dignity, and reflection on its place in her own life is expanded on and explained in subject of case study vignette 3 presented later in this chapter, but her precise narrative is of interest too.

S.M: What are the characteristics a person with dignity, people will say this person has dignity, do you think you have dignity?

Xoliswa: I don't have dignity.

S.M: Why?

Xoliswa: I am not like other people I'm unique.

S.M: You not like other people in what way?

Xoliswa: People have their own things they have houses but I'm staying in someone's place I can't stand on my own even though I have the grant but I can't stand on my own so that I show myself and develop my dignity.

S.M: When you don't have things like the house and other do you see yourself as someone that is not having dignity?

Xoliswa: When you have nothing and you are staying in your own place you tell yourself that you have dignity because.

S.M: Can you stop. If I follow you correctly you are saying even if you have nothing but staying in your own place then you have dignity?

Xoliswa: Yes and you doing everything for yourself and now you are staying in someone's place whatever he/she says you must jump because you don't have a say he is the owner of the house.

S.M: What are the other characteristics that you see in a person and say this one does not have dignity? I hear you on your point where you say if you don't have your own house you don't have dignity because you have to abide by the rules of the owner of the house, what are the other things that you look and see in a person and say he/she does not have dignity? Xoliswa: You don't have dignity when you don't have a husband, they can look at you when you walk, you don't even have clothes in order for you to live you go and seek help from the people they give clothes to you everyone is taking care of you, they can see your background without they being told so you can never have dignity.

Although there were varying inflections on these three themes, these basic components of the concept of dignity were echoed amongst other informants. They are briefly listed below:

Informant Nomfezikile. Dignity relates to caring for one's children, and not having children wandering about unattended.

Informant Nosomsi. Dignity relates to appearance, deportment and sober/non drinking behaviour. 
Informant Yamkela. Dignity is about having money, because if a person has no money they will not be respected. This is so even if one is behaving appropriately.

Informant Spamandla. Dignity related to looking after ones children appropriately (e.g. suitably laundered nappies).

The above empirical material point to the prevailing socially conservative mores (notably abstaining from smoking and drinking); the decorous deportment and social modest profile required; enacting of socially valued roles (looking after children) and finally having access to resources, identified as necessary for a dignified existence by the research participants. Managing perceptions of outsiders demanded a sartorial egalitarianism in extract 2 , with the purchasing of similar clothes for the children in the household. This enabled the household members to project a common front to the outside world, avoiding gossip from others. In informant Siphesande's confessional account (extract 4) there is the implicit suggestions of her sense of worthiness and even self-esteem, rising with her in concert with her dignity. Furthermore this extract also points to the 'generative' effects of dignity. By regaining her dignity the informant's relationship with her younger sister improved, and she was tangibly able to enlist the younger sisters support in domestic chores. In extract 5 (the subject of a case study vignette later) informant Xoliswa clearly describes dignity in terms of access of resources and secure living arrangements. Their absence very clearly detracts from informant Xoliswa's sense of autonomy, and as she unequivocally indicates, her dignity.

Three additional points can be made in relation to the above material and commentary.

The first is to note that these are not universal prescription for dignity. They are the reported stratagems of the lone mother CSG recipient informants, as they negotiate the demands of forging and sustaining dignity, through bolstering their self-respect, sense of autonomy and self-esteem and worthiness, within their specific social and cultural context.

Secondly, inquiring after the tacit 'rules of dignity' in the interview, unavoidably patterns the responses. The explanations offered up by the informants were the result of discussion framed (at least initially) with reference to CSG receipt. The question therefore elicits accounts expressed in terms of the proscriptions and prohibitions required to sustain dignity, but less adequately captures the productive and proactive dimensions of dignity. So while some informants did describe dignity in terms of their role as mothers, their explanations were partial. They were not able to fully explicate the relationships and elaborate repertoires of behaviour in relation to which dignity is produce and sustained (although informant Siphesande alludes to it, in extract 4). This is significant because dignity is not just accrued through refraining from undesirable behaviour, it is produced by demonstrating one's worthiness, via enacting socially validated acts and identities. Although these, the productive and enactive dimensions of dignity could be partially 
inferred from its prohibitions, they ought to be made far more explicit. The networks of social reciprocity and mutuality on which the impoverished social grant recipients rely are less apparent here but, as will be argued later, significant.

Third and finally, the empirical material presented to this point suggests the commonalities between informants in terms of the workings of dignity, but it also suggests a diverse range of experiences of dignity. Yet asking informants to describe their experience of dignity, or how dignity is generated and sustained in their context, does not adequately capture this range. Instead, the sheer diversity of experiences and dynamics underpinning dignity are usefully described by the counterfactual - cases where informants' dignity was eroded, impaired or otherwise undermined. In other words, understand dignity by paying attention to its negation or absence. This is the focus of the following section.

\subsubsection{Understanding indignity, impaired or eroded dignity}

In what follows a selection of four case study extracts of 'indignity' - eroded or impaired dignity are presented. These are described in order to contrastively examine the workings of dignity. Each requires a short Case Study Vignette in order to intelligibly explain the context and the aspects of the informant's experiences and life that served to undermine their dignity.

\section{Case Study Vignette 1}

Informant Asanda. This informant was a member of one of the most marginalized and vulnerable households visited in the course of the research. Particularly adverse household living conditions, difficulties concerning domestic relationships and membership (a transient, substance-abusing uncle) where further compounded by a co-resident AIDS-ill adult daughter. The informant's tenor was mildly incredulous at questions concerning gossip and indignity in relation to social grant receipt, and disavowed that she had been subject to it. When probed on the occurrence of stigma, gossip and indignity, she ventured perhaps it happened behind her back, or in other villages. Instead the stigma and difficulties of managing AIDS were far more salient to her. But most significantly she identified her lack of dignity in relation to her church; that the household's poverty made her unable to make her weekly church contribution, which she described was very hurtful. This was the setting where she felt her self-respect and worthiness were challenged, and her dignity impaired. 


\section{Case Study Vignette 2}

Informant Zimkita. This informant lived in a former Ciskei homeland village and occupied a large, formal homestead. For several decades her grandparents had been part of the local middle class elite (a nurse and senior teacher) and the family occupied a material strata above many in the village. Their solidly constructed suburban-style house, serviceable vehicle, grandparents state employee pensions, and early ownership of a television set made them amongst the wealthiest and most respected people in the village. However after the grandparents retirement, and grandfather's death, the household's general fortunes, and linkage to formal labour market (via a state employee pension) waned. So while the lone mother informant reported gossip and indignity in relation to social grant receipt (including recipients receiving the misogynistic sobriquet of 'Nogrant'), this was less salient to her that the family's precipitous decline. Far more prominent, she thought, was the local gossip concerning their dilapidated house (in a village where many homes are rudimentary), and the family's humiliating fall from its previous local elite status. What she keenly felt was the family's descent in their material conditions, and loss of erstwhile respect and social status. The opprobrium of CSG receipt was subsumed within this reality.

\section{Case Study Vignette 3}

Informant Xoliswa. This lone mother informant had the deportment and customary attire of a woman who had married formally (significantly, with the payment of bridewealth), and resided at a solid, rural homestead complete with cultivated fields. All of which attested to the traditional cultural script of matrimony and rural household formation. An important cultural ideal, even if it is increasingly elusive. Yet despite this she narrated a wrenching account of her life as precarious and undignified. With particularly unusual candour for a first interview, she tearfully described her lost brother, an older child (prior to her marriage) left with uncaring and neglectful relatives, the experience of being an alienated outsider within the village, and her exclusion from the usual local circuits of social reciprocity and mutual assistance. Her circumstances moreover saw her unable to return to her own family, and rendered her effectively stranded at her marital home. Not only did her mother in law reportedly mistreat her, her ignominies and difficulties where compounded by her husband becoming an 'itshipha' (an urban migrant who absconds, and fails to remit). This was a development that deprived her both materially and socially; of remittances and the social respectability that would normally accrue to a married woman. She relied on the CSG to subsist, but thought her dependence on it was utterly incompatible with dignity. Her explanation of her indignity was therefore articulated in terms of a lack of autonomy ('can't stand on my own' in extract 5), and not having her own place of residence or means of support. It is intertwined with having run out of options, being abandoned and mistreated, and falling outside of the circuits of social support and interdependency. 


\section{Case Study Vignette 4}

Informant Siphesande. This Xhosa lone mother informant received a CSG for her nine-yearold daughter who was temporarily residing elsewhere in the urban township. The informant had a fractious relationship with her own family, and was recuperating post-partum at the rented social-housing apartment of her new Nigerian partner, having recently given birth to his child. Following the birth she had temporarily given up her shack, but felt she was the subject of local gossip and indignity in her current accommodation. The apartments, build around a large central courtyard, were conducive to passive surveillance and local residents routinely assumed she too was a foreign national and gossiped about her. In the context of enduring xenophobia (and widespread homicidal violence in 2008) this was of lingering concern to her. She had variously avoided the gossiping neighbours, and in at least a one case apprised them of their shared ethnic and national origins. The sense of unease induced by her living arrangements, was however greatly exacerbated by contestation between herself and partner concerning the child's surname. Their inability to resolve this had effectively stalled efforts to apply for a CSG. Her partner wanted the infant to bear his surname and mooted marrying her, but he had no South Africa Identity Document. By the respondent's account, he reportedly viewed grant receipt as undesirable and an affront to his status as a paternal provider. However the informant herself was circumspect. She anticipated bureaucratic difficulties in claiming the CSG for a child, with a different surname to her own. While matrimony would strengthen her entitlement to her partner's support, she stated that she feared it would allow him to claim 'custody' of the child or even remove the child abroad. This informant's pressing sense of vulnerability was therefore largely unrelated to CSG receipt. Instead it was bond up with the challenges to her dignity associated with her living arrangements, along with her contested conjugal and (potentially, in her mind) parental status.

The above four case study vignettes sought to examine dignity through its antithesis, namely 'indignity' or the dynamics that erode or diminish dignity. Enquiring after the counterfactual of 'dignity' in this manner offers up a useful sense of the working of dignity in the focal research context. Several broad points are evident here. The first, common across all four case study vignettes, is the manner in which dignity-eroding dynamics, specifically the wearing away of self-respect and worthiness, can be relatively independent of CSG receipt. A second point (evident in relation to Case Study Vignette 3), is that receipt of a CSG by an informant with little autonomy and self-respect can sometimes serve to reinforce the sense of a lack of dignity. (Even though the counterfactual of what her experience would be in the absence of the CSG was not systematically explored). 


\subsubsection{On dignity}

The descriptions of dignity, and exposition of indignity, impaired or eroded dignity, are here synthesized and four points made concerning dignity.

Individual's experiences of dignity are influenced by their experiences of dignity quite globally.

The first point is that the lone mother informants' experiences of dignity are influenced by their experience of dignity in their lives in an accumulative and aggregate sense. In the case studies, this accretive and cumulative quality to dignity appeared to manifest in various ways. In several cases the scale of the adversity and vulnerability recounted by informants was considerable, and appeared overshadowed the potential stigma or opprobrium of CSG receipt. This was evident in the experiences of informant Asanda, where amidst AIDS illness, ultra-destitution and contestation within the household, the experience of CSG receipt per se was reportedly comparatively devoid of stigma, and inconsequential to her sense of dignity. Or informant Siphesande where worries over communal gossip and xenophobia, her insecure living arrangements and potential paternal claims over the child were far more significant in her assessment of her circumstances and dignity.

However the converse can equally apply. For other respondents the vulnerability and adversity that marked their lives and eroded their sense of dignity, was compounded by the difficult dynamics associated with grant receipt. For example, informant Xoliswa understood her lack of independence and autonomy, alienation, conflict, reported mistreatment by her mother-in-law and abandonment by her husband, as all serving to eroded her sense of dignity and social standing. This appeared to be an experience of poverty and vulnerability that was, by her account, exacerbated by the stigma attendant to grant receipt (despite the ameliorative value of the cash itself). Similarly, the loss by informant Zimkitaof her family's material and social status, was aggravated by the gossip and criticism in relation to grant receipt. This suggests that experiences of dignity are profoundly mediated by the totality of respondents' experiences, and that they cannot readily be reduced to a single factor such as CSG receipt.

\section{Manifold factors can serve to erode dignity.}

The factors that potentially serve to erode dignity are numerous, wide-ranging and often very specific. Even the small selection of case study vignettes of impaired dignity presented serve to suggest the plethora of factors that potentially undermine and detract from dignity. In the case study vignettes of impaired dignity above (Case Study Vignettes 1 - 4), these can be enumerated as: health status and an inability to contribute to church collection; a fall in social and economic status; being abandoned by a spouse and finally, the conflict around 
purported 'foreigner' status, and paternal claims. This list can hardly be regarded as exhaustive, it may well expand with a larger sample the inclusion of more case studies. Instead it points to the multi-dimensionality and specificity of the dynamics that serve to undermine dignity. It is beyond the scope of this inquiry to catalogue these dignity-eroding factors in their entirety, for these or all CSG recipients. But what the empirical data does clearly reveal is their fundamental plurality and individual particularity.

\section{The factors that erode dignity are similar to those that create vulnerability}

The third point is that the factors that serve to erode dignity are intertwined with vulnerability more generally. In other words the dynamics that contribute to the erosion of dignity are very similar to those that make individuals vulnerable in the first place. Vulnerability refers to the susceptibility of individuals or systems to adverse events (e.g. environmental, social, economic) from which they are unable to readily recover (Alwang, 2001). The factors that serve to erode informant's dignity (such as ill health, destitution, social alienation, abandonment, social exclusion) are simultaneously those that serve to erode their dignity. In this way experiences of vulnerability are patterned by the overarching realities of deprivation and poverty. Low income and asset levels are omnipresent among respondents (after all they are the criteria that render these individuals eligible for CSG receipt), yet it is analytically useful to think of recipients as simultaneously embedded in larger and far more variegated dynamics of vulnerability. The data suggests the manner in which these manifest themselves differently for various individuals.

\section{Networks of social relationship crucially mediate experiences of dignity}

To this point it has been suggested that individual experiences of indignity, are cumulative, global, multi-dimensional and yet specific. It is suggested here that the social relationships and networks within which individuals are embedded however also significantly shape experiences of dignity. In other words informant's experiences of dignity are mediated by their social relations with others, including the nature of their networks of social support and mutuality on one hand and the dynamics of estrangement, vulnerability and conflict on the other. This is evident in the case of informant Xoliswa (Case Study Vignette 3). Respondents' assessment of these, evident particularly in their biographic and household accounts, serve to reveal much concerning their experiences of dignity. These social relations are key determinants, and mediators, of their reported sense of dignity. 


\subsection{Discussion}

We have explored in detail various ways in which low income lone mothers have described what dignity means to them in the context of their own lives. The focus group data was examined in relation to women's sense of self, their relationships with family members, and their standing in their communities. We used Khatib and Armenian's four 'dimensions' of dignity, as a method for grouping the material as the arising themes corresponded well to their dimensions of worthiness, self-respect, self-esteem and autonomy.

Many of the emerging themes highlight the inherently social aspects of dignity. Liebenberg refers to dignity as a 'relational value' whereby:

'we are interconnected beings. Our sense of self-worth, personal development and well-being is inextricably bound up with the extent to which we are valued by others and by the society at large (Liebenberg, 2005: 11).

In relation to worthiness, women spoke of how they are made to feel less worthy by their families and communities when they are not in work. Examples were given of being insulted, not respected, and not consulted upon in family decision-making processes. Some also gave examples of sexism, when women's views are heeded less than men's, though this was not nearly as prominent as the issues raised around employment. A third theme to arise in relation to worthiness was the comparisons made between the apartheid era and the present day, with most of the participants identifying improvements in terms of their dignity being protected and respected, although many examples were given of how such improvements had been only 'to a degree', with a lot left to be desired. This section demonstrates that within the context of their own lives, the women experience dignity as something that is compromised by unemployment, sexism and racism.

In relation to self-respect, a prominent theme emerged of self-respect being a prerequisite to earning the respect of others (and to a lesser degree, respectful treatment of others aiding self-respect). Another prominent theme related to 'respectable behaviour', with examples given of the need not to gossip, drink in public, and for women to 'carry themselves with dignity', and 'remember that they are mothers'. This dimension manifested itself more as an 'exhortation' to the self.

The dimension of self-esteem contained within it a number of arising themes, most notably that of role preservation as caregiver of children. The main reason why focus group participants said that it was important for women's dignity to be protected and respected was because of their roles as caregivers. Another prominent theme that arose within this dimension was the way in which dignity was expressed by women as intrinsically linked to their sense of humanity, with it being commonly said that loss of dignity results in 'loss of humanity'.

Lastly, the most prominent issue to arise in relation to the dimension of autonomy was the link between dignity and paid work which enables women to meet their own 
material needs, those of their children, and in many cases also enables them to contribute to the needs of their extended families. As we have seen, when people were asked at the end of the focus groups about what would help to respect and protect people's dignity, the vast majority of people replied 'jobs'. Earlier in the focus groups, many women spoke of the negative impact on their dignity of being without paid work, being unable to meet their own and their children's material needs, and being looked down on by people and treated differently. Several examples were given, by women who had experienced being in paid work and were now unemployed, of how this new status badly affects their dignity. The conferment of dignity is by no means automatically associated with paid work, however, and several women spoke of how their dignity was so compromised when in work that they left their jobs.

The focus group material provides striking insights into the complex ways in which 'dignity in practice' is experienced by low income lone mothers. The focus group participants unequivocally identified dignity as something that is indeed important to protect and respect, and cited their roles as caregivers as the main reason. In common with the constitution, they described dignity as being an inherent part of their identity, which resonates well with Ackermann's description of dignity as connoting 'innate [...] human worth' (Ackermann, 2000: 541). However, the vast majority of the women provided examples of ways in which their dignity was compromised or eroded, which contrasts with the notion of dignity being 'priceless, indefeasible human worth' (Ackermann, 2000: 541).

In Section 4.3 the diverse ways in which dignity is created and sustained were examined in relation to the in-depth interview research participants. It was argued that accruing dignity, or being perceived as being dignified, required behaving in modest and socially conservative ways, maintaining a modest deportment and social profile and finally enacting socially validated roles (specifically caring for one's children). These accounts of the workings of dignity within the focal research context were furthermore augmented by examination of its negation or counterfactual; namely sources of indignity, impaired or eroded dignity. A number of specific empirical examples were presented. To sum up it was argued that: individual experiences of dignity are influenced by experiences of dignity quite globally; a large range of factors potentially serve to erode dignity; the erosion of dignity is intertwined with vulnerability more generally; and experiences of dignity are mediated by social relationships.

The issue of the erosion of dignity is explored in greater detail in the following chapter where material is presented on the impact of poverty and inequality on dignity. 


\section{Chapter 5 Lone mothers' experiences of poverty and inequality and their impact on dignity}

Summary: This chapter presents analysis of lone mothers' accounts of the impact of poverty and inequality on dignity. Section 5.2 presents results from the focus groups. The main themes to emerge in relation to the impact of poverty on dignity relate to the ways in which, in the face of extreme poverty, the women struggle to meet their own and their children's material needs; the ways in which they are treated by their families; their standing within their communities; and lastly accounts of the despair expressed by many of the women about their condition. Participants spoke more expansively about poverty than inequality, but section 5.2 .5 summarises the focus group material on the impact of inequality on dignity and of their experiences of living 'at the bitter end of inequality'. Section 5.3 presents results from the in-depth interviews. Section 5.4 presents results from part of the SASAS 2012 module on attitudes to dignity and poverty, comparing the views of lone mother respondents with the wider population.

\subsection{Introduction}

In this chapter we consider lone mothers' accounts of the impact of poverty and inequality on dignity. Section 5.2 draws from the focus group interviews whilst Section 5.3 draws from the in-depth interviews. Section 5.4 presents results from SASAS 2012 on attitudes to dignity and poverty.

\subsection{Focus group interviews}

"Poverty bullies my sense of dignity, it abuses it." (Butterworth FG25)

In the focus groups, participants were asked directly about the ways in which poverty and, separately, inequality impact on their sense of dignity, if at all. In Chapter 4 we saw that dignity is perceived in a number of different ways that can be grouped within the themes of worthiness, self-respect, self-esteem and autonomy. The focus groups also yielded many accounts of the various ways in which poverty impacts on each of these four dimensions of dignity. Rather than presenting the analysis along those four dimensions, the material is presented in relation to four key themes which emerged most prominently across the focus groups; as will become evident, they straddle the various dimensions of dignity discussed in Chapter 4.

The main themes to emerge in relation to the impact of poverty on dignity relate to the ways in which, in the face of extreme poverty, the women struggle to meet their own and their children's material needs; the ways in which they are treated by their families; their standing within their communities; and lastly accounts of the despair expressed by 
many of the women about their condition. The participants spoke more expansively about poverty than inequality, but Section 5.2.5 summarises the focus group data on the impact of inequality on dignity and of their experiences of living 'at the bitter end of inequality'.

\subsubsection{Techniques to survive poverty and their impact on dignity}

\section{Tolerating poor quality paid work}

As we have seen in Chapter 4, the case was strongly made that economic independence through employment was perceived as the primary means by which dignity as autonomy can be protected and respected, but that employment could also erode dignity, and examples were given of women who chose to leave their jobs for reasons linked to dignity. In this section material is presented where women describe ways in which their dignity is compromised at work, and yet how they feel they have no choice but to continue in these unsatisfactory jobs due to the financial pressures which they face. Examples are given of sexual harassment, racism, poor working conditions and poor pay. ${ }^{36}$

Several examples were given of sexual harassment at work. For example, in Masiphumelele two women discussed the impact of such harassment on their sense of dignity:

Respondent 3: It's like what we were saying, some men make sexual advances at us in the work place. It makes things very difficult and it takes away our dignity. Things shouldn't happen like that.

Respondent 7: I really hated it when my former boss, he liked to hit me on my buttocks, at the back at work. It just erodes my dignity, each time it happens. If I say something he treats me badly, shouts at me at work. I had to let him do it. It would be difficult just to get up and go to work. (Masiphumelele, FG29)

In terms of racism, the hierarchies of apartheid continue to be felt. For example:

"Coloured people are favoured in Cape Town. They are treated well, as people at work. We are degraded almost every day. We would be doing the same job as coloured people but they get much better wages than us" (Respondents agree). (Nyanga, FG2)

\footnotetext{
${ }^{36}$ The recent OECD report on Women in Paid and Unpaid Work notes that 'Women still experience systemic barriers in almost every aspect of work, including: whether they have paid work at all (full-time or part-time), the type of work they obtain or are excluded from, their pay and conditions of work, their access to higherpaying 'male' occupations, the insecurity of their jobs, and the unequal division of family responsibilities between women and men within the household.' (OECD, 2012: 4).
} 
Several participants spoke about the negative impact on their dignity of extremely low paid work. For example, a woman in Mitchells Plain said:

"It does affect your dignity because if you work for that amount of money....R12 an hour and then you must take all that money and pay who's looking after your child. So what you working for is nothing." (Mitchells Plain, FG13)

In spite of such conditions, many women explicitly stated that, due to their need for an income, they felt they had no alternative but to tolerate their working conditions. In this first example, the participant explains that the levels of hunger at home cause her to remain at work despite verbal abuse:

"We endure and persevere, what can we do. Our employers are not always polite, they say hurtful things but the problem of hunger back home is much bigger than the pain at work. So I just persevere." (Paarl, FG28)

In this second example, a woman speaks of how her dignity is lost due to the way is which she is treated 'like a slave or a doormat' and yet her situation has to be endured due to the need for the income 'back at home':

"I'll give an example when your employee is way younger than you and lacks communication skills, disrespects you, there is nothing you can do because you are desperate for the job. When you think of your situation back at home you just swallow your pride and keep quiet even though you hate what is going on. You get demeaned, lose dignity because you're treated like a slave or a doormat." (Langa, FG7)

Many examples were given of poor working conditions, with accounts of how this impacts on their sense of worthiness and of dignity. In this first example, the domestic worker never knows when she will next be paid and this makes her feel 'worthless':

"My problem as a domestic worker is that sometimes my white Madam pays me, sometimes she doesn't. I don't know how many months I have not seen my salary. It hurts, you also feel worthless." (Nyanga, FG2)

In this second example, a woman describes her work selling things in the street each day. She states that she feels that even though she has a small business she has no dignity because of the nature of the work:

"I have a small business. Dignity? No, I do not have. I carry a cheap, striped bag on my back and sit in the street the whole day selling things. It's dusty most of the time 
so I'm always sweaty and unclean, people generally undermine me." (Khayelitsha, FG4)

\section{Casual work for neighbours or family}

Some women spoke about more informal types of paid work such as gardening or washing for neighbours. Although they depicted such work as being less demeaning than begging, they nevertheless describe how it impacts negatively on their sense of dignity. In Dimbaza, a very poor rural area in the Eastern Cape, a woman spoke about the humiliation of working in a neighbour's garden:

"you find yourself doing somebody's garden because of poverty. It erodes your dignity, people point at you when they see you doing someone's garden, they talk amongst themselves. It's humiliating, but I need money.." (Dimbaza, FG16)

Several women in various places described the impact on their dignity of doing their neighbour's washing:

"Poverty destroys dignity. I do people's dirty laundry, I have to ask to do it, it's embarrassing because people look down on you even though I'm helping them and helping myself. I don't want to beg, I hate begging for food. Either way, your dignity is eroded."

"And when you do people's laundry, they don't pay when they say they will or give you the agreed amount. You're grovelling all the while until you're paid whatever suits them." (Dimbaza, FG16)

"I do people's laundry for money, in the village. It's humiliating because everyone can see, but I don't have a choice." (Butterworth, FG24)

"You end up doing things like people's washing, which is demeaning. They don't even pay you when they should or how much they'd promised. So yes, my dignity is definitely eroded by not having a job." (Butterworth, FG25)

In a number of instances, people spoke of doing work for neighbours or family and being paid 'in kind' with either alcohol or with food. A discussion took place in Alice about payment with alcohol:

"It happens a lot, you'll find that your neighbour will ask you to do something for her and pay you with alcohol." 
"And when they do that it means they don't have respect for you. Because you are poor they pay you with alcohol. All that means is that they don't have respect for your family."

"There is no dignity in that and they kill them by giving alcohol instead of money." (Alice FG20)

In Butterworth a woman described payment with food whereas she would have preferred money:

"Sometimes they pay you with a plate of food because they know you are hungry.

Meanwhile they are meant to pay you with money." (Butterworth, FG25)

In Mitchell's Plain in Cape Town, women spoke about the negative impact on their dignity of doing domestic work for family members:

"I haven't got a job. I am working at my sister's place, char. I mean your own family....it's taking away your pride."

"It's like what I said, we are like beggars at the end of the day. We have to go knock, we have to ask, we have to stand whatever we have to do. That is taking away our dignity at the end of the day. I mean going to your own family to look for a char so that your children can [inaudible] it's not right because they have it all and you are the one that's struggling. You can't even go to your own family for support... that's your life...you the mother of that children so you must support your children. Now you have to go around and ask for chars and that's also how your dignity is being taken away. Now, like I say... a child is a child.... we cannot blame our children for what [inaudible]. Legally, can they blame us [m] but at the end of the day the child must be fed...the child cannot go to school without anything in his stomach. Because they look at the mother....there's nothing to eat...Mummy...you as mother must go. (Mitchells Plain, FG13)

\section{Begging}

Many of the focus group participants, in both urban and rural areas, spoke of having to beg in order to try to make ends meet. There were frequent accounts of the negative impact of begging on dignity. For example, in rural Xesi in the Eastern Cape, women spoke of how begging takes away one's dignity:

"Begging takes away your dignity."

"When you're not working you're inevitably poor and when you are poor you become a beggar without dignity. No, no, it's terrible." (Xesi, FG18) 
As a woman from Centani describes, begging is to be avoided if dignity is to remain intact:

"I think the best thing for us to do is to stay in our own homes, try our best on our own to support and look after our children, without begging, if we can. So that our dignity remains intact." (Centani, FG23)

However, the point was repeatedly made that at times there was no alternative but to beg. People mostly described begging for food, but also to use others' electricity. In two urban townships in Cape Town, women spoke of having to beg from neighbours. A woman from Nyanga describes how her dignity is eroded by having to ask her neighbour if she can heat water or cook on the neighbour's stove, and how she has to beg for access in order to be able to look after her child:

"I stopped working in January. Not working can be humiliating because you run out of basic things all the time. I run out of electricity all the time. I have to ask my neighbour to use her stove to cook for my child, or to warm up water to bathe my child. She always demeans me and says nasty things, but I have to beg because it's for my child. If it was for me l'd just walk away. It's very bad, your dignity is eroded." (Respondent cries) (Nyanga, FG2)

A woman from Langa describes how she begs for food from her neighbour and how she then feels gossiped about by the neighbour and scrutinised by the community:

"For example in the community, when I go to neighbour that's better off than me, when I go and ask for food, she doesn't just give it to me. She asks me to do her laundry first or clean for her, and then she gives me the food. Even so, she tells people in our community that I have nothing, that I'm dirt poor. So every time I go to her house, which I have to because I always run out of food, everybody knows I'm going there to beg for food. It takes away from your dignity, for sure." (Langa, FG6)

A woman from Centani elaborates on what she goes through when begging for food, and goes so far as to state that 'poverty can kill one's dignity':

"Poverty is humiliating. When you go and beg for food, first of all you're hungry, at that very moment, you're really hungry. You smile and laugh at anything they say even if it's not funny, maybe it's even a jab at you, but because you're begging for survival, you have to act stupid. So yes, poverty can kill one's dignity. You may or may not get food. If you don't you go on to the next house. When you walk out of these houses, you heart is in anguish." (Centani, FG23) 
A number of other respondents make the direct link between poverty and the erosion of dignity when speaking about begging. For example a woman from Butterworth in the Eastern Cape spoke of how poverty results in having to beg and thus 'dignity is forever compromised':

"When you are poor your dignity is forever compromised because you are always begging for one thing or the other..." (Butterworth, FG26)

This is echoed by a woman in Masiphumelele in the Western Cape who spoke of the desperation that causes her to beg from others:

"Well, when you're poor you end up begging from other homes for food, out of desperation. No, there's no dignity in poverty." (Masiphumelele, FG30)

Finally, the desperation of hunger can lead in extremis to stealing, as described by a woman in the Eastern Cape:

"if you go to bed without food enough times you end up stealing the food. Then you get arrested - and there's no dignity, at all." (Dimbaza, FG16)

\section{Transactional sex}

Just as prominently as begging, the focus group participants spoke about how they had to use transactional sex as a method of survival, and of its negative impact on their dignity. A few women spoke in veiled terms but most referred to it directly. In some instances, people described having to have sex in order to secure a new job:

"We're single mothers and need more than the CSG, for example. When we're looking for work sometimes we find ourselves in a position where, if it's men employing, they ask you to sleep with them before you get the job. Desperation can lead to you sleeping with the person." (Masiphumelele, FG29)

"Without a doubt, dignity is eroded. I am young and look even younger, so I go and look for work, men feel me up, they touch me wanting to sleep with me with the promise of a job. Sometimes you give in and get the job, at times you don't. It's terrible." (Dimbaza, FG16).

Many of the participants spoke of having multiple sexual partners in order to acquire income for survival. The theme arose in rural and urban areas, and mainly in relation to obtaining money for food: 
"A lot of women have multiple sexual partners just because they can derive some kind of income from these men - not because they want or desire these partners. At the end of the day, they are living with HIV/AIDS, it's tragic. They throw away their dignity not because they want to, but for survival." (Qumrha, FG15)

"Well, sometimes things get so bad that, you know when we all struggling with hunger, starving, sometimes I go and sell my body so that my family can eat." (Xesi, FG19)

A group of women in Masiphumelele spoke together about transactional sex and its impact on their dignity:

Respondent 4: Yes, you end up selling your body to get money to live on. It's terrible, your life becomes one big nightmare.

Respondent 3: You find yourself hanging around cars, something I thought I would never do, so that I can bring back some food at home.

Facilitator: And that erodes your dignity?

Respondent 3: Yes, definitely. (Masiphumelele, FG30)

A group of women in Nyanga spoke about poverty causing them to enter into relationships for financial security:

"I'm going to be honest, poverty erodes dignity. I have gotten into relationships with a few men because they help me out financially. Not because I love them...(respondent cries).

"It's common, we meet older men and get into relationships with them because we need money for survival."

"Sexually we become easy because we need money to survive." (Nyanga, FG2)

Furthermore, they described how their survival strategies become publicly known:

"Our communities become aware, men know where to go, where it's easy for them and that is ourselves, right here. Nothing is more degrading."

"What happens is that people in the neighbourhood bring you men because they know you need money." (Nyanga, FG2)

One woman describes how the fact that it is known that she will provide sex for income out of desperation means that her dignity is 'finished': 
"Men end up discussing you, they know if they come to you they'll get sex. Your dignity is gone then, finished. It's not that you think it's the right thing to do, it's desperation." (Nyanga, FG2)

A very similar discussion arose in Khayelitsha where women described lack of money causing them to 'sell their bodies':

"It's important for people's dignity to be respected. But we don't have money as mothers. We end up selling our bodies because we don't have money, so it's difficult for our dignity to be protected under such circumstances."

"And not having money, ending up selling your body because of poverty, it takes away your dignity. We have children that look up to us, our dignity is important. The grant is too little, we can't do much with it." (Khayelitsha, FG5)

The discussion concluded with a woman commenting on the lengths that she would go to in order to provide for her children:

"A mother cannot watch her children suffer, we'll do anything so that our children don't suffer, so that they have clothes on their backs, there's electricity in the house and so on." (Khayelitsha, FG5)

Similar discussions took place in Langa, where prostitution was described as a consequence of poverty and hunger:

"Sometimes even though you do not like the idea of having sexual relations with them, you end up doing such because of hunger. People will start perceiving you as a prostitute and that hurts because circumstances forced you to sleep with someone for money and of course you lose your dignity."

"Others do it because they want clothing money and you'd find that half of the time you don't even like the guys that you are sleeping with. This is what I have personally experienced." (Langa, FG7)

A woman in Nyanga describes how some women lack documentation for themselves and their children and therefore cannot claim social security and feel that they can depend only on their bodies for survival:

"Some women can't access the grant because they have no documents whatsoever, no ID for themselves and no birth certificates for their children either. So they sell they bodies because it's all they have." (Nyanga, FG2) 
In addition to these accounts, a few respondents spoke of remaining in abusive relationships because of having no independent means. One woman described how she remains with an abusive boyfriend in order to be able to pay for food:

"Well I have children to feed and I am poor, my children have to eat so I find myself with a boyfriend who beats me up and I tolerate it because he gives R100 a week. I never in my wildest dream thought I'd ever tolerate such." (Butterworth, FG24)

Conversely, one woman spoke of choosing not to have a partner so that her grandchildren would be spared from abuse:

"Poverty, thinking about the poverty. Poverty erodes dignity. That's why I don't live with a man, because he'll probably ill-treat my grandchildren because we are poor, so I chose to live with them alone to protect them." (Dimbaza, FG16)

\subsubsection{Impact of poverty on lone mothers' dignity: strained family relations}

Many of the lone mothers lived with family members or had very close links with family members elsewhere. Based on the accounts, those family members were just as poor, or only slightly less poor than the women themselves. The over-riding issue that emerged regarding the impact of poverty on lone mothers' dignity in terms of their family relations was that poverty puts great strain on those relationships and this in turn has a negative impact on the women's dignity. Specifically, the strain of living in poverty causes family members to treat one another without respect and in some instances abusive behaviour was reported. In their state of poverty, the women were made to feel unworthy of support by their families in many instances; they were regularly insulted for their lack of financial autonomy and made to feel that they are a burden, and this all impacts negatively on their self-esteem.

Two women in Nyanga spoke about the tensions within the home generated by their lack of income. They report being treated badly, and treated without respect and of being excluded from decision-making:

"There's a lot of conflict at home, I'm now treated badly because I have no income. My child sees this, it depresses him. He asks heartbreaking questions. You have no dignity when you're not working. Even the community can see it." "It's the same with me and my family, they treat me with no respect. They make decisions that affect my life without telling me just because I have no income." (Nyanga, FG2) 
The following discussion in Centani, a rural area in the Eastern Cape, sheds light on the direct linkages between income (derived from work) and people's dignity as expressed by one's standing within the family and ability to participate in decision-making:

Respondent 5: You know when we have family meetings, when we are going to have a family function, people say what they are going to contribute. My brother would say a cow, my sister all the vegetables. I sit there with my arms folded because I have nothing to contribute, I'm not working. Not working erodes my dignity.

Respondent 4: My family takes decisions without me because they know I don't have money, nothing to contribute. Where's my dignity in all that?

Respondent 3: Yes its' true, decisions are taken without us. We are like children. You see?

Respondent 7: It's terrible. It affects my health. It feels like I'm being chucked out of my own family. It's very painful when you have nothing to contribute. My heart wants to, but I have nothing. (Centani, FG23)

Participants described how they are made to feel like a burden by members of their family. For example:

"you become a victim to your own family because it's not like they are rich either, so you become a burden on them." (Khayelitsha, FG4)

Several other women spoke of how their mothers make them feel like a burden, and in some instances refuse to provide for the child of the lone mother, whilst others said hurtful things. For example:

"Even when you ask your mother, she says go look for a job, that affects your dignity because it seems as if you choose not to work and you feel like a burden." (Khayelitsha, FG3)

"say for instance you are living by your mothers place...even your mother gets fed up because of looking after you and your child and they nag and they like say things that hurts you and that also takes your dignity as a woman." (Mitchells Plain, FG13)

A woman in Langa describes how she is 'pushed away' from relatives who fear that she will ask them for support, even if that might not be the case:

"our relatives fear that we will want to depend on them, but that's not the case. One goes to see relatives for the love and emotional support. But you're pushed away because you're poor." (Langa, FG8) 
Many of the family tensions and conflicts that were described centred around food. A woman in Paarl describes how her family reminds her that she did not pay for the food that she is eating:

"Even when I'm eating, my heart aches because I didn't buy for the food, or work for it, and my family tells me so too." (Paarl, FG28)

A woman in Langa further describes how she is made to feel to blame when the food runs out at home:

"When you're not working and at home, each time food runs out, people look at you as if you're the one finished the food." (Langa, FG6)

Another woman described the discord that occurs when people are hungry in the family:

"No, listen my cousin and I do not get along at all and the reason behind that is a small, unimportant thing, but as time goes on it escalates into something huge because of hunger. When there is food on our table everybody is happy and gets along very well, there is family love that used to exist when my mother was still alive. I wish it can be like that every day." (Langa, FG7)

In a focus group in Dimbaza a woman described the conflict about food between herself and her sister with whom she lives, whilst another described the withdrawal of her mother's affection when she is unable to provide food for the family:

Respondent 4: I don't have a job and my sister is working. We live in the same house. There's a lot of conflict. She looks down on me because I'm not working. If I eat food from the fridge, she'll ask if I know how much it costs.

Respondent 3: When you've lost your job, like me, things change at home. You're told daily to gather your children and leave. But when you're working, things are different, your mother 'loves' you because she knows you are going to bring home bags full of groceries.

(Dimbaza, FG17)

The direct link between parental affection (towards the lone mother) and income status (in terms of ability to pay for food for the household) was also made in Langa, depicting the way in which poverty reduces the person's standing in the family:

"Even parents prefer 'children' who work because they bring home the groceries..." (Langa, FG7) 
An assumption is sometimes made that people within a family all 'share from the same pot' however in practice, the discord described above shows that this is not necessarily the case as between lone mothers and other family members (see also Mosoetsa, 2011). The following quote provides an example of a cohabiting sibling withholding his income:

"I have a brother who lives at home and is working. He does whatever he wants with his money, doesn't help us much, that's painful." (Dimbaza, FG16)

Women spoke of their discomfort having to ask family members for help with meeting their own material needs:

"I don't want to have to ask my parents to help me out all the time, I'm an adult. Being unemployed is a disadvantage because you end up annoying your parents, asking them to help out all the time and they think that I'm not doing anything to change my situation...[...] You end up feeling small when you want to ask for something." (Langa, FG7)

"I was alright then [i.e. when employed] even though I didn't earn much. I could do the necessary at home every fortnight, I could buy food and electricity, clothe my children. Now, I'm scared to ask my brother for R20 to buy electricity because he has his own problems, so I just sit at home in the dark." (Dimbaza, FG16)

"It begins at home. Your own family does not respect you because you're jobless. You're even scared to ask your own parent for deodorant." (Langa, FG6)

A number of participants spoke about the way that they felt they had no choice but to live with their families, even though they are ill-treated. One woman from Xesi spoke of how she and her children live with her grandmother who ill treats them:

"It definitely affects my children. My oldest child is 8 years old, she takes everything in now and she understands when my grandmother is insulting us. She always asks why we don't go and live in X on our own? I would love to but I can't, the CSG looks after the children, after that I have nothing, we live on the same grandmother who ill treats us." (Xesi, FG18)

A woman in Nyanga described having to live with relatives who treat her and her child very badly:

"This story is too common here, I live under the same circumstances. I have to live with relatives, they treat my child and I very badly. So I sell sweets and caps to survive." (Nyanga, FG2) 
Several of the quotes above contain hints of abuse. More explicit examples of abusive family dynamics included the women being verbally insulted by family members, food being locked away by drunken relatives, and fighting. In the first example, two women share experiences of living with alcoholics who lock food away when they are drunk:

"Not all is well at home, my family has no regard for me. I try to do all I can do, but there's no respect. I'm not working but I try to satisfy my family - I clean the house, I cook, I gather wood. I do all these things but it doesn't seem to make a difference, it's like I'm doing nothing. My grandmother is an alcoholic, she verbally abuses us when she's drunk and locks the food away and we end up not having anything to eat at times. So I'm not happy at home, there's no dignity."

"I'm in the same predicament at home. I don't have a job, the only income I have is the CSG, R270 a month. It's not even enough for my child. My mother is an alcoholic and she's abusive too, she also locks away food when she's drunk. So, no, there's no dignity." (Xesi, FG18)

In Langa, two respondents spoke of how poverty and overcrowding results in expressions of anger and violence towards one another:

"Our home is overcrowded because we are poor and there's no dignity. My sisters, cousins and all our children live together and we do not get along. Sometimes one of us would start a fight out of nothing, because they just need an excuse to express their anger from the overcrowding." (Langa, FG7)

\subsubsection{Impact of poverty on lone mothers' dignity: reduced standing within the community}

The third, prominent theme, in relation to the impact of poverty on lone mothers' dignity, was their accounts of their sense of reduced standing within the community. Women spoke of the way in which they felt that everyone knows that they are poor. There were accounts of being gossiped about, blamed for things going missing, looked down upon, and being overly scrutinised.

The following excerpt from a focus group in Nyanga contains examples of each of these issues:

Respondent 6: Poverty eats away at your dignity, day by day. You're nothing in your community when you're poor, nothing. You have to leave your own home, go to other people's homes and beg for food, for survival. 
Respondent 5: When you're poor, your neighbours know you're poor. They can see your electricity off because you can't pay. When they lose something, like clothing from the washing line, they blame you because you have nothing. Even food in their homes, getting lost, they blame you.

Respondent 4: Because you have nothing, you become nothing. That's how people see us. Nobody will have proof, but you get blamed all the same.

Respondent 6: Sometimes you get given something by a relative, something nice. You'll hear comments like 'where would she get that? she's so poor', nasty comments like that. Because you're poor, people think you are brainless or have some learning disability.

Respondent 1: Sometimes someone gives you something and then talks ill of you, even to your face. They'll say they made you more human, you can't talk back to them. It's degrading. (Nyanga, FG1)

Such experiences were just as prominent in rural areas, where people also spoke of being looked down upon:

"People tend to look down on you when you're poor. You go to somebody's house and already they know you're going to ask for food." (Xesi, FG19)

One woman in Centani spoke of how poverty prevents her from being able to live a dignified life within her community:

"I live my life with dignity but am not living a dignified life overall. Poverty takes away all my dignity. Everybody my community knows that I'm poor, that I'm single struggling with children whose father doesn't care for them. When I walk into somebody's house, already they think I have come to ask for something, for money or food. Even if I'm just visiting and I have not gone to ask for something, already people think I've come to beg. That is humiliating, I tell you." (Centani, FG23)

In Khayelitsha one group spoke of the way in which poverty causes divisions within society, resulting in one woman commenting on its destructive impact within society: "essentially poverty, desperation divides society. We break one another down." (Khayelitsha, FG3)

In another focus group in Khayelitsha a woman spoke about how the whole community will know if she asks someone for food - her poverty becomes public knowledge and she experiences this as an indignity:

"I wanted to go back to the problem of indignity in the community because it's important to me and it affects me. If you go and ask someone for a plate of food or a meal, the whole community will know that you go around asking for food." (Khayelitsha, FG4) 
In Butterworth, women spoke of how children do not treat them with respect because they are poor, and that people are treated even worse for being single and for living in a shack:

Respondent 1: When you are poor, people don't respect you, even children. When you speak as a poor person, people don't respect the words that come out of your mouth. It's a completely different story if you have money and are rich, or course. Respondent 3: It's even worse when you are poor and single, it just makes you that much more vulnerable and people don't even think you have a sense of dignity to be protected.

Respondent 6: People ridicule you for living in a shack. It's humiliating, living in a shack. There's no dignity in poverty, as hard as we may try. (Butterworth, FG26)

Another woman, this time in an urban area, spoke of the way in which single mothers are treated with hostility, but commented that she would not live with a man in order to feel safe as this would erode her dignity further:

"It's tough in our communities, most of us single mothers are treated with hostility. And I'm not going to live with a man just because I want to feel safe. That would just erode my dignity further." (Langa, FG8)

In a focus group in Langa, three women spoke about the jealousy within their community about the fact that they live in brick houses (rather than shacks) and are able to dress their children decently:

Respondent 5: People don't expect us to do well, or at least, let me say at the level that we are at because we are not doing that well here, they don't expect us to survive as we do because we are single parents, on our own. My children dress decently, I see to that, they go to school and we are fortunate enough to have inherited my beloved grandmother's house. So people get jealous in the community, because it's a poor community, and that jealousy can turn into something bitter and sinister. It's the brick houses we live in that make people bitter most of all.

Respondent 3: My children dress decently, and people get jealous of even that. They don't see how I can do it all, some suggest I'm a witch. (Langa, FG8)

To conclude this section, in another focus group in Langa several women spoke about the levels of scrutiny that they face within their community, and although discussed with humour, the 'lose-lose' situation that they find themselves in. If they return home with shopping bags, members of their community speculate as to whether they are working or engaging in transactional sex; if they don't ask neighbours for help this leads to further 
speculation about prostitution; and if they do earn a salary this makes their neighbours jealous and angry.

2nd Respondent: There is nothing that makes a person violent more than poverty (laughs)

Respondents: She is telling the truth.

Respondent: Every time a person goes out carrying a hand bag the neighbours' peek through windows thinking "where is so and so going, to work maybe or to sell her body because she will come back with shopping bags". If you are an unemployed woman who does not ask for any assistance from them they always think you sell sex for cash at Dockson.

3rd Respondent: Also if you are employed and earn a salary that is enough to cover for you and your children's needs they'll have a problem with you, being independent makes them jealous and angry (Laughs) (Langa, FG7)

\subsubsection{Impact of poverty on lone mothers' dignity: the personal toll}

\section{Impeded role as caregiver}

In Part 1 we saw the way in which the focus group participants referred to their roles as caregivers of children as being directly linked to their sense of dignity and self-esteem. When poverty causes them to be unable to meet the material needs of their children, this impacts negatively on their sense of dignity. Many participants spoke about ways in which their inability to provide materially for their children - due to poverty and unemployment eroded or even extinguished their sense of dignity.

For example, a woman in Butterworth described how she feels that she has no dignity, and that she is not regarded as having dignity by her child, as she is unable to provide for his needs:

"As a mother and in relation to my role as a mother, I have no dignity. In my child's eyes I am not dignified because I cannot provide for him. Even in comparison to other mothers, I have no dignity because I can see they can provide for their children much better than I can. My child can see this too." (Butterworth, FG26)

A woman in Mbekweni described her dignity as being 'crushed' when seeing her son watching others play, unable to join in because of his hunger:

"I see my son sitting and watching others play because he does not have the energy to play, he is hungry. You can imagine what that does to my dignity as a mother, it crushes it." (Mbekweni, FG27) 
A woman in Xesi states that her dignity is affected by being unable to support her child herself and having to depend on help from others:

"Even though I get help from home to maintain my child, as her mother, I wish I could support my child myself, that's how my dignity is affected." (Xesi, FG18)

In Paarl, a woman described how her son derides her for being unable to provide for him, even a meagre R1 (6 pence).

"I can't even give my child R1 if he asks for it. He'll say: 'what kind of mother are you, you can't even give me R1?'... Poverty destroys our dignity as mothers." (Paarl, FG28)

Another woman from Masiphumelele spoke of how she feels when she cannot provide things for her child's education:

"I can't get my child the school things he needs. Even crayons. When I go to meetings, school meetings, it's humiliation all the way for me." (Masiphumelele, FG29)

\section{Social isolation}

A number of women spoke of how poverty results in lowered self-esteem and a sense of isolation. For example in Thafalofefe and Butterworth in the Eastern Cape, people spoke of how they feel that they don't 'fit in', how they avoid being with other people, and how others avoid them:

"Poverty affects my self-esteem, it's very low. When you're with people they talk about this and that, buying new furniture and all sorts of things. So I don't fit in because my concerns are about survival. I just get up and go." "Poverty is isolating, I just avoid being with other people because they look down on me. They don't treat me as a human being, it's as if I'm an idiot because I'm poor. That's how it is." (Thafalofefe, FG22)

"People don't even come into your house when you're poor. It's isolating, you end up being on your own most of the time." (Butterworth, FG24)

In Langa, a woman described how she feels unable to contribute towards social gatherings and is excluded which reduces her self-esteem and confidence:

"you can't hang-out with those who are employed [...] even if they plan to have a sitin or party they don't involve you because they know you're not going to be able to 
contribute to make that party happen and that reduces your self-esteem and I end up depressed, feeling hurt. These things, sometimes I don't even have the confidence to look for work." (Langa, FG7)

\section{Despondency through to desperation}

A striking number of women shared information about their mental wellbeing, within the context of the impact of poverty on their sense of dignity. Some described their sense of despondency and defeatedness:

"you try to go forward in life but there's always something coming in the way. You just can't get where you want to be (Lavender Hill, FG10)

"I was born into poverty, I'm poor and my children live in poverty. As much as that is not mentality, it is the way things are in a practical sense. I had no opportunities to develop myself and my children's opportunities are limited too. At the end of the day these things impact on your sense of dignity because you are unable to realize yourself in poverty." (Qumrha, FG14)

"At times, you know I had told myself I would finish matric and go to nursing school because I know my family is struggling, I wanted to help them out, but unfortunately I fell pregnant and everything stopped, my world was turned upside down. My progress stopped and I had to look after my child and ended up living on this grant. Even with matric, I can't get a job, but most of all I want to go to school. There are no government grants for poor people like me who want to continue with their education. I live the way I do and I'm not happy with it, I want to continue with my education. I am now becoming despondent. Maybe it's our lot in my family because this plight started with my elder sisters, they got their matric but could never find a job until they were too discouraged and then too old. I fear my children, whom I am educating, will be in the same plight." (Qumrha, FG15)

In two focus groups people spoke of the strain of being unable to keep clean:

"Well first of all you end up being like a mentally unstable person. You never have proper or decent clothing, if you don't have money for deodorant your arm pits stink amongst other people, people talk about you in a derogatory way, you end up mentally strained." (Dimbaza, FG17)

"For example when I run out of deodorant, I feel bad, it's embarrassing. I can smell myself, it's bad when you don't smell clean in the presence of others... (inaudible)..you don't feel like a human being amongst other people. (Xesi, FG19) 
Alcohol use by the focus group participants themselves was only referred to in two of the focus groups, and on each occasion it was described as a way in which to escape from the daily reality of their lives in poverty. In no instances was alcohol seen as recreational.

"I end up drinking so that I can forget the poverty, so that I don't think about my situation and that takes.. erodes my dignity too." (Butterworth FG24)

"No working class man with a car and a house wants to date a nobody like me who is unemployed and a drunkard, we really end up drinking heavily because of our circumstances, because we have nothing better to do with our time and want to erase the misery or depression that we are going through. [...] Yes that is the kind of life that we live, I don't know maybe we are living in the last days because I always ask myself 'why'?" (Langa, FG7)

Others spoke explicitly of how their state of poverty causes depression, anxiety or anger. For example, a woman from Masiphumelele described her depression:

"It's not right, our mother helping us out, she's too old to be doing that. It affects me, not working. I suffer from depression as a result. I'm on medication for depression, I ended up in [..] hospital because of depression. It's tough, but l'll keep trying." (Masiphumelele, FG29)

As a further example, a woman in Mbekweni described how her poverty causes her to feel stressed and angry and how she takes it out on her children, with negative consequences:

"I end up always snapping at the children because of the stress I feel. I'm always angry that I never have money for anything, I can't provide for my children. I end up taking it out on them and it affects them, they don't perform well at school." (Mbekweni, FG27)

The most extreme examples of mental torment all occurred in focus groups in urban settings in the Western Cape. One woman from Mitchells Plain described how she had felt like ending her life, and went on describe her feeling of depression about living with her parents, supported only by her father's pension:

"As a woman, you get tired of struggling...You get tired of people looking down on you and you feel unworthy. You don't even feel like being around your children anymore because of the way of living...I mean you don't choose that life...It comes to you. Like myself, I also had high hopes for myself... at the end of the day...here I am... I'm back at my mom's place. I'm living from what my father's pension...so for me 
also, sometimes I also feel depressed you know because .... when I see some of my friends. I'm not saying because they better than me or whatever... just when you see some people succeed in life and here you still stuck where you don't want to be...."(Mitchells Plain, FG13)

In Masiphumelele a woman described how she is so under-nourished that she is unable to adequately breast-feed and how this causes her to feel like rejecting the baby:

"When my baby wants to be breast-fed, I feel like throwing her away from me because I have nothing in me to keep me going, no nourishment. I feel like she's sucking the life out of me." (Masiphumelele, FG30)

Similarly, focus group participants in Langa described how their extreme levels of poverty, and inability to provide for their children led them to desperate thoughts of suicide and infanticide:

"And when you are poor you are always depressed, angry and facing problems. When your child asks for food you take out all your problems out on him by insulting or beating him up just because you yourself are defensive about your lack of provision as a parent. Most of the time you end up feeling suicidal and thinking about ways to kill yourself and your children, like bombing my house is a fantasy sometimes. Really because if you only kill yourself who is going to look after your children?"

"let me tell you as I have a two months old baby and when trying to breast feed sometimes the breast milk does not come out because I am malnourished. All the anger I have I just want to take it out on this poor innocent baby by crashing his head on the walls or drowning him but at the same time I think to myself that homicide and suicide is a way out for cowards. I believe that I was brought up to be a stronger person than that so I can't just give up now, but because of starvation and depression you end up thinking and acting like a mentally ill person. Sometimes I go for weeks not having eaten proper food, a full meal, bread and eggs is all you can afford sometimes you don't even have the basics like sugar." (Langa, FG7)

\subsubsection{Impact of inequality on lone mothers' dignity}

As noted earlier, participants spoke more expansively on the subject of poverty than inequality. However, the section of the focus groups that asked about inequality nevertheless did raise some salient points. Some of the focus group participants spoke in quite general terms about inequality, and - in both urban and rural areas - of being 'at the bitter end of inequality', for example: 
"What can we say, we are at the bitter end of inequality in a way that those that are well off cannot imagine. It's hard to break it down further than that." (Qumrha, FG14)

"These things are all connected - poverty and inequality and they both badly affect dignity." (Paarl, FG28)

Although this did not occur in the Western Cape, a small number of people in the Eastern Cape spoke of their acceptance of their position in life, of their lot:

"We shouldn't worry about how wealthy other people are, we should just try to survive in our poverty, it's our lot." (Xesi, FG18)

"I think we have accepted that we are at the bitter side of inequality, it's just like that, no use crying about it." (Butterworth, FG24)

"Well I think we have to work at our hearts in that regard and accept where God has placed us, otherwise stress will kill you. Maybe life will be better for my children. As for me, if my children go to bed with something in their stomachs and they can go to school, every else will come in its own time. I can't compare myself to $X$ who has a glass sliding door otherwise I may end up prostituting myself going after the sliding door that costs $R 1500$ - charging R500 for 3 days to get there. It wouldn't be right, I accept where I am in life." (Qumrha, FG15)

However, most spoke of the unacceptable nature of the state of affairs in relation to the extent of inequality that exists in South Africa:

"Inequality impacts on how we live and our sense of dignity. You heard us talking about basic things like water, toilets, shacks and brick houses. Such things should not be issues in 2011, in South Africa. This country isn't poor, on the whole when you look at it. The country needs to sort all this out. It's probably how I got TB, the mess, the filth, the overcrowdedness of it all. The next thing you get stigmatized because you are ill. People think you're going to pass the disease onto them. All this, these things take away a person's dignity." (Langa, FG8)

The most prominent themes by far to arise out of the focus group interviews in relation to the impact of inequality on dignity related to housing and sanitation. The point was repeatedly made that living in a shack or one-roomed RDP house takes away people's sense of dignity: 
"I live in a shack with 4 children and a grandchild. There is no dignity there, I don't see dignity in such a way of life."(Qumrha, FG15)

"I live in an RDP house. It's just one room. We sleep in it, wash in it and cook in it as a family. There's no dignity or development. What success can come from such an environment? Our relationships are strained in this one-roomed home, it's not easy and there's nothing dignified about it." (Mbekweni, FG27)

"I have four children [...] Do you know I stayed with all of them in one room? So, doesn't that take away my dignity? You don't have privacy. I don't have nothing...I can't move...I can't... how do you breathe in a room like that? Do you know what I am saying. At the end of the day, that does really take away my dignity." (Mitchells Plain, FG13)

Similarly, people - particularly in urban areas - raised the issue of sanitation when asked about the impact of inequality on dignity. ${ }^{37}$ For example, in Nyanga, living in a shack with no toilet was described as the 'lowest end of inequality':

"Where I live there are no toilets. They have these communal plastic toilets that shake when it's windy. Even when you're inside you're afraid because anyone can come and push it to the ground with you inside. When you go there there's always a queue. Imagine, you're desperate to use the toilet and you have to queue. When you go in a house with a proper toilet and ask to use it, people refuse. You have to go back to the queue and wait. That's how we live, people who are better off do not help us poor people. Inequality lowers your dignity."

"I agree with X. We live in shacks, with no toilets. That's the lowest end of inequality." (Nyanga, FG1)

In Cape Town, the lived experience of inequality is particularly stark. Poor people still live in areas that are distinctly separate from prosperous areas and yet are exposed to people whose living standards are amongst the highest in the world. When asked about inequality, people often contrasted their position with others in relation to housing and sanitation. For example, in Nyanga a woman compared her community where there are no flush toilets, with wealthy areas where people from that community work as domestic workers and where there are several flush toilets per house:

"We don't have flush toilets where we live, there are people with 4 toilets in the same house and we clean these toilets for them. It's just not right. Apartheid has not ended

\footnotetext{
${ }^{37}$ A recent study in Kenya about women's experiences of living in the slums of Nairobi similarly identified the prominent theme of the need for adequate sanitation for the protection of dignity (Amnesty International, 2010).
} 
in South Africa, that's the reality for a lot of people. [...]You don't feel free because your dignity is not protected." (Nyanga, FG2)

"It's painful, but the thing is we are not educated, so we have to go and work in suburbs as domestics, we don't have a choice because you want to raise your children. The inequality becomes stark when you compare where you come from and your place of work. Some people don't even have toilets, and some of these houses have 3 or 4, in one house. That's unfair inequality, right there." (Khayelitsha, FG4)

"Yes, inequality is very high here. We've lived in Mbekweni for many years, but we don't even have houses. I signed up for a house in the early 90's, yet I still don't have one. When they build RDP houses for us - it's a one-roomed house yet one has a number of children. You go to town and people live in suburbs, in luxury. When I do piece-jobs in these houses, it does hurt." (Mbekweni, FG27)

Within the Western Cape, people spoke of their negative experiences of living in hostels, sometimes described as being worse than living in shacks:

"Some of us live in X hostel. We use cardboard to divide our homes. It's just one big hall and you hear everything going on in the next home. Toilets are shared, it's bad, that's how deep inequality is in our country. While some have numerous toilets in one house, we have to share with other families and then people wonder why poor South Africans are so angry." (Khayelitsha, FG5)

In rural areas particularly, some women compared themselves to others with whom they had grown up:

"It's hard because there are people we grow up with who have had better fortune than us. They are well to do and we live the way we do, it's humiliating." (Qumrha, FG14)

"It does affect my dignity, for example, in my village there are people of my age group that went to school with me. They are working, driving beautiful cars, so it's embarrassing for me to be so poor." (Alice, FG21)

To conclude this section, this light-hearted but poignant exchange amongst participants in Khayelitsha who had worked in wealthy areas of Cape Town, compared their experience of pregnancy with those of wealthy white women, highlighting the lived experience of inequality: 
Respondent 4: White people, they have money they invest for their children's future from the time a person is pregnant (laughter)

Respondent 2: For us it's very difficult when the baby kicks because of hunger, white people drink spring water and eat lettuce

Respondent 3 : Calamari (laughter)

Respondent 4: We black people eat samp, no beans.

Respondent 1: When they're pregnant they crave for MacDonald's and the husband will go and draw some money and buy MacDonald's, we just crave and go and buy the chicken feet that we can afford. (Khayelitsha, FG3)

\subsection{Lone Mother's practical experience of poverty and inequality, and how these impact on dignity: the in-depth interviews}

In a rights based discourse the deprivation associated with deep poverty, including a lack of access to adequate food, shelter, sanitation is viewed as an affront to human dignity. In the course of the research, many of the informants understood their everyday lives in these terms. Adverse living conditions, material lack and difficulties in providing adequately for their children were difficult to reconcile with, and served to erode, their sense of dignity. They could readily articulate this sentiment in response to questions about their dignity or respectability. The accounts of four research participants are presented below.

\section{Extract 6}

Informant Yamkela, a woman living in the rural Eastern Cape, explained:

Yamkela: I know when she or he is having his/her own things and have a house, livestock when you don't have all those things and don't have money you don't have dignity.

S.M: If you don't have all that you don't have dignity?

Yamkela: You don't have dignity when you don't have livestock, no house and money.

D.N: They got some cattle, they have a garden, I can see they work hard...

V.C: .....and it's beautiful as compared to other gardens.

D.N: Does she think people will respect her more for the fact that she works hard?

S.M: Do you think people respect you even though you don't have money but because you working hard (You're ploughing...), as you plough you work hard, do you think people take note of that?

Yamkela: No people don't respect you even if you work hard, if don't have money. You only get money when you go and work hard in the homes of the others in the community.

V.C: [translating] People don't respect you if you don't have money, you are poor so they don't respect you. 


\section{Extract 7}

Informant Asanda was a member of a rural household that was particularly deprived (amongst the most abject of those visited). She then described their poverty not in terms of the poor quality of their housing, intra-household tensions with a heavy drinking uncle coresident, or even her persistent difficulty feeding in the household - including divert some their income to buy superior quality food for their AIDS-ill adult daughter. Most salient for her, in questions concerning dignity, was her inability to contribute towards the weekly church collection ('yetikiti'). She described this as embarrassing and as detracting from her dignity.

S.M: Mama how do you see a person with dignity, do you think you have dignity, what are the characteristics of a person with dignity?

Asanda: I don't have dignity at church because I am behind in paying the money that is paid, so I get heartache when I don't pay them and I want to pay them. But the grant money is not enough so I usually feel less dignified.

S.M: Is it only in church only that you don't have dignity, what about in the community? V.C: How do people in the community treat you do you think you have dignity?

Asanda: I never heard anything from the community, unless they gossip about me behind my back.

V.C: When you look at them do they respect you?

Asanda: My neighbours do respect me they even help me out at times they even call me without asking to come and take sugar, I don't want to lie they respect me.

D.N: That's interesting so there are places where she feels she does not have dignity, church is one of them. What happens when she is not respected?

V.C: When you are in church how do you feel when you don't pay the 'ticket' money, do they respect you?

Asanda: It worries me because people who have money don't understand, yes I do want to pay the money but I can't afford to. The grant money is not enough.

D.N: The people who have money don't understand why she does not pay the money?

S.M: How do they treat you?

Asanda: Because I am getting the grant they think it's a lot of money.

V.C: How do they treat you?

Asanda: They treat me okay, but I don't feel right when it's time to pay money and I can't pay, I don't feel right.

S.M: Do you feel ashamed?

Asanda: Yes I feel ashamed, and at times I feel like leaving the church because people pay money, and when I'm folding my arms and sitting down its when I know I no longer have dignity. But I just tell myself that it is not by choice that I do not pay the money. 


\section{Extract 8}

Informant Spamandla, was a younger woman living in an urban township, in a house shared with female kin and their children. She was unemployed and reliant on her employed aunt for food. Spamandla, contrasted how she felt before she got the grant, with grant receipt.

S.M: Do you think the grant helps?

Spamandla: It helps a lot, because now that I am getting the grant I am no ashamed to carry my child, I have a bottle for her and go and sit outside with her with other people, I'm no longer ashamed.

\section{Extract 9}

Informant Siphesande describes the mental toll exacted by unemployment and poverty, prior to receiving a grant.

Siphesande: I was so stressed when I was not getting a grant, I ended up taking capsules for depression capsules because my mother is not working, I'm not working too, and I'm fighting with my sister. So there was nothing going right for me (Weeps).

The four extracts give a sense of lone mother's daily experience of poverty and inequality and its impact on their dignity. Evident in each account is the erosion of human dignity inherent in deep and enduring poverty. The first respondent, Yamkela, unequivocally indicates financial resources are intertwined with respectability. She holds this to be so regardless of other assets, and behaviour such as a visible commitment to traditional rural identities and agrarian practices. In her account material resources, but especially money is the source of respectability and dignity. This speaks to her relative lack of autonomy, and accords with Khatib and Armenian's (2010) typology and the lack of worthiness she experiences.

The second informant, Asanda, with great lucidity and specificity located her material inability to contribute to and participate in her church as particularly hurtful and erosive of her dignity. She was noteworthy for the unequivocal manner in with which she did this. Furthermore, despite her multiple other domains of deprivation, she did not think these other domains detracted from her dignity - she explicitly assessed that her neighbour's respect her. So keenly felt was the ignominy of being unable to make her church contribution that it even overshadowed the 'Faustian bargain' (Wood, 2003) that poverty had forced her into - trading the immediate survival of her AIDS-ill adult daughter against the long term nutritional security of her CSG-recipient grandchildren. Her sense of worthiness (Khatib and Armenian, 2010) was impaired in relation to her church contribution.

The third informant, Spamandla, echoed a common sentiment amongst respondents, namely the (pre-grant receipt) embarrassment at their children's deprivation of nutritional comestibles ('bottle'), due to poverty. While, Siphesande, the fourth and final 
informant described the psychological toll of pervasive and enduring poverty. In these cases, their dignity, in terms of the sense of self-esteem and worthiness were undercut by their poverty. These accounts echo several themes from the focus group interviews.

Experiences of poverty and deprivation reflect the specificity of the social context in which they are located. South Africa is a developing country context where the poor have for over a century been incorporated into relationships of market exchange. Racialised legacies of dispossession mean that the occupation and social changes associated with 'deagrarianisation' have long been evident in South Africa (Bryceson \& Jamal, 1997). As a consequence opportunities for subsistence production outside the market and systems of money are scant, even for the rural poor. A dearth of cash resources (described in extracts 6 and 7) is therefore potentially more acutely felt than it might otherwise elsewhere in a low or middle-income country context, with more readily accessible alternate sources of livelihood making and subsistence.

The data points to the manner in which money, and more specifically its absence, is the key domain in which the vulnerability and marginality associated with poverty is manifest. In this way, specific constellations of marginality associated with poverty, notably a lack of access to money in a highly monetized context, shape popular experiences and conceptions of dignity. Conceptions of dignity are often intertwined with the ability to exercise economic agency, through buying, consuming and enter into relationships of monetized exchange.

A further characteristic of the South African context that shapes the lived experience of poverty is inequality. The focus group interviews underscored the often racialised dimensions of this inequality. Contemporary South Africa's extremely high and enduring income inequality, alongside a widespread rhetoric of human rights and history of opposition to the (particularly Apartheid) state all contribute to popular dissatisfaction. Dissatisfaction that is reflected in the regular 'service delivery' protests, fractious industrial relations and other forms of 'insurgent citizenship' (Von Holdt et al., 2011). This feeds into, and underscores, popular conceptions of unjustness, and indignity of enduring poverty and deprivation. These impulses are arguably more prominent in a high inequality, racially divided, post-conflict society such as South Africa, than they might otherwise be in either a less affluent or less unequal society. The contradictions between enduring poverty, amidst inequality and conspicuous consumption were occasionally evident in the empirical material, such as the expensive Italian 'Carvela' shoes exacted by the children of informant Ketiwe. In this way, not even impoverished grant receiving beneficiary children were ignorant of the affluence elsewhere in society, or inured from prevailing aspirations and patterns of consumption.

\subsection{Social attitudes about dignity and poverty}

The South African Attitudes Survey 2012 (SASAS 2012) included four questions that explored attitudes to poverty and inequality, in relation to dignity. Table 5.1 below shows that there was almost unanimous support for the statement that 'It is important that the government 
respects and protects people's dignity ' (Q1), with 94\% of respondents agreeing or strongly agreeing. The vast majority of lone mother respondents also agreed (96\%). Whilst it might be argued that it would be rather perverse to disagree with such a statement, it is nevertheless very striking that it was agreed with so strongly (more strongly than all other questions in this module).

There was general agreement that 'Poverty erodes dignity' (Q2), with around $80 \%$ of all adults and of all lone mothers agreeing or strongly agreeing. Three quarters of the respondents agreed or strongly agreed with the statement that 'The gap between rich and poor people in South Africa undermines the dignity of us all' (Q3), compared with an even higher $80 \%$ of lone mothers. These levels of agreement are arguably very high, as they imply a recognition that inequality is detrimental to the dignity of all people, highlighting the relational nature of not only the reality of inequality but its consequences.

Within a family rather than societal context, the final question highlights the negative impact on dignity of a parent who is unable to provide for their child's basic needs. Over $80 \%$ of all adults, and of lone mothers, agreed or strongly agreed with the statement that 'Being unable to provide for the basic needs of a child erodes the dignity of both parent and child' (Q4). 
Table 5.1

Attitudes about dignity and poverty (SASAS 2012)

\begin{tabular}{|c|c|c|c|c|c|c|c|c|c|c|}
\hline \multirow{2}{*}{$\begin{array}{l}\text { Q: To what extent do you } \\
\text { agree or disagree with } \\
\text { the following } \\
\text { statements? }\end{array}$} & \multicolumn{2}{|c|}{ Strongly agree } & \multicolumn{2}{|c|}{ Agree } & \multicolumn{2}{|c|}{ Neither nor } & \multicolumn{2}{|c|}{ Disagree } & \multicolumn{2}{|c|}{ Strongly disagree } \\
\hline & All & LM & All & LM & All & LM & All & LM & All & LM \\
\hline $\begin{array}{l}\text { Q1 It is important that the } \\
\text { government respects and } \\
\text { protects people's dignity }\end{array}$ & $\begin{array}{r}43.9 \\
(41.3,46.6)\end{array}$ & $\begin{array}{r}46.6 \\
(40.1,53.1)\end{array}$ & $\begin{array}{r}49.9 \\
(47.2,52.6)\end{array}$ & $\begin{array}{r}49.3 \\
(42.8,55.9)\end{array}$ & $\begin{array}{r}2.2 \\
(1.7,3.0)\end{array}$ & $\begin{array}{r}1.4 \\
(0.6,2.9)\end{array}$ & $\begin{array}{r}2.3 \\
(1.6,3.3)\end{array}$ & $\begin{array}{r}2.1 \\
(1.0,4.2)\end{array}$ & $\begin{array}{r}0.7 \\
(0.4,1.2)\end{array}$ & $\begin{array}{r}0.2 \\
(0.0,1.3\end{array}$ \\
\hline Q2 Poverty erodes dignity & $\begin{array}{r}32.7 \\
(30.3,35.2) \\
\end{array}$ & $\begin{array}{r}33.5 \\
(27.8,39.8) \\
\end{array}$ & $\begin{array}{r}48.6 \\
(45.9,51.4) \\
\end{array}$ & $\begin{array}{r}45.8 \\
(39.3,52.5) \\
\end{array}$ & $\begin{array}{r}10.5 \\
(9.0,12.2) \\
\end{array}$ & $\begin{array}{r}12.0 \\
(8.5,16.6) \\
\end{array}$ & $\begin{array}{r}4.6 \\
(3.6,5.7) \\
\end{array}$ & $\begin{array}{r}6.3 \\
(3.8,10.1) \\
\end{array}$ & $\begin{array}{r}1.0 \\
(0.5,1.9) \\
\end{array}$ & $\begin{array}{r}0.7 \\
(0.3,2.1) \\
\end{array}$ \\
\hline $\begin{array}{l}\text { Q3 The gap between rich } \\
\text { and poor people in South } \\
\text { Africa undermines the } \\
\text { dignity of us all }\end{array}$ & $\begin{array}{r}29.0 \\
(2.7,31.4)\end{array}$ & $\begin{array}{r}36.1 \\
(30.0,42.7)\end{array}$ & $\begin{array}{r}45.6 \\
(42.8,48.3)\end{array}$ & $\begin{array}{r}43.4 \\
(37.1,50.0)\end{array}$ & $\begin{array}{r}11.7 \\
(10.2 \\
13.5)\end{array}$ & $\begin{array}{r}8.7 \\
(5.8,12.8)\end{array}$ & $\begin{array}{r}9.2 \\
(7.7,10.9)\end{array}$ & $\begin{array}{r}8.3 \\
(5.3,12.8)\end{array}$ & $\begin{array}{r}1.4 \\
(0.9,2.2)\end{array}$ & $\begin{array}{r}1.9 \\
(0.8,4.3)\end{array}$ \\
\hline $\begin{array}{l}\text { Q4 Being unable to } \\
\text { provide for the basic } \\
\text { needs of a child erodes } \\
\text { the dignity of both parent } \\
\text { and child }\end{array}$ & $\begin{array}{r}32.5 \\
(30.0,35.0)\end{array}$ & $\begin{array}{r}36.3 \\
(30.2,42.9)\end{array}$ & $\begin{array}{r}48.0 \\
(45.3,50.8)\end{array}$ & $\begin{array}{r}45.6 \\
(39.2,52.2)\end{array}$ & $\begin{array}{r}11.3 \\
(9.7,13.1)\end{array}$ & $\begin{array}{r}10.6 \\
(7.3,15.2)\end{array}$ & $\begin{array}{r}5.1 \\
(4.0,6.4)\end{array}$ & $\begin{array}{r}3.7 \\
(2.1,6.2)\end{array}$ & $\begin{array}{r}1.1 \\
(0.7,1.8)\end{array}$ & $\begin{array}{r}2.8 \\
(1.2,6.1)\end{array}$ \\
\hline
\end{tabular}




\subsection{Discussion}

This chapter explored the question of the impact of poverty and inequality on lone mothers' sense of dignity.

In section 5.2 of this chapter, material was presented on the impact of poverty and inequality on dignity, based on the focus group interviews. The results clearly demonstrate that the low income lone mothers who took part in the focus groups regarded poverty and inequality as having a negative impact on dignity.

First, women spoke of the impact on dignity of their techniques to survive poverty. These comprised tolerating poor quality work, undertaking casual work for neighbours and relatives, begging, and transactional sex. People spoke of the humiliation of working for neighbours or relatives, and of the ways in which begging takes away their sense of dignity. In relation to transactional sex people spoke of their dignity not being protected, losing their dignity, and their dignity being destroyed.

Second, extensive accounts were given of the way in which poverty causes there to be strained family relations, with women being treated badly within their families including being insulted, excluded from decision-making, and treated as a burden. People spoke of there being no dignity in poverty, and of their discomfort having to stay in homes where they are ill-treated but cannot afford to leave, and having to depend on others to meet their own material needs. Extreme examples were given of the violence within families seen as being a consequence of poverty.

Third, people spoke extensively about how poverty reduces their standing within the community, and how this negatively impacts on their dignity. People spoke of being looked down upon, and of being over-scrutinised. Vivid examples were given of the extent of jealousy and rivalry within poor communities.

The fourth theme related to the negative impact of poverty on people's self-esteem, ranging from despondency to desperation and despair. Chapter 4 revealed the prominence that women gave to their role as caregivers, and in this section we see the negative impact on dignity when unable to fulfil such roles, with women describing their dignity as 'crushed' and 'destroyed'. Examples were also given of the ways in which poverty breeds social isolation and lowered self-esteem, as well as examples of more extreme thoughts of suicide and infanticide.

In the final part of Section 5.2, findings were presented from the focus group discussions about inequality and dignity. People spoke of living 'at the bitter end of inequality', with a few women in the Eastern Cape expressing acceptance of their lot, though the vast majority across both provinces regarding their plight as unacceptable. People spoke most expansively about the negative impact on their dignity of living in shacks or single-room houses, and of lacking adequate sanitation. Whilst some women compared themselves mainly with people with whom they had grown up, others had a wider reference group particularly if they had worked as domestic workers for wealthy households. 
In Section 5.3 analysis of the material from the in-depth interviews was presented in relation to the effects of poverty on the dignity of the lone mother informants. The recipients generally described poverty and inequality as an affront to their human dignity. Their poverty and deprivation was keenly felt in terms of their difficulties in adequately provide for their children. It was suggested these assessments also reflect the specificity of the South African context, most notably high levels of inequality.

Lastly, in Section 5.4, findings from SASAS 2012 were presented which resonate well with the findings from the qualitative material. There was almost unanimous support for the statement that 'It is important that the government respects and protects people's dignity', a commitment that, as we saw in 5.1, is centre stage in South Africa's constitution.

The following chapters explore the role that social security plays - and could play within this context. 


\section{Chapter 6 Social security for lone mothers in South Africa}

Summary: This chapter considers social security provision for lone mothers in South Africa. Section 6.1 reviews international commitments to social security as a human right. Section 6.2 reviews South African social assistance and social insurance arrangements to highlight the extent to which lone mothers are not currently provided for. Section 6.3 provides examples of other forms of state or state-governed support in the absence of comprehensive social security. Section 6.4 presents analysis of the elite interviews on the extent to which dignity is taken into account in social security design and implementation.

\subsection{International commitments to social security as a human right}

Social security is a human right, and this is made explicit in Article 22 of the 1948 Universal Declaration of Human Rights:

"Everyone, as a member of society, has the right to social security and is entitled to realization, through national effort and international co-operation and in accordance with the organization and resources of each State, of the economic, social and cultural rights indispensable for his dignity and the free development of his personality." (UN, 1948)

Articles $11 \mathrm{e}$ and $14 \mathrm{c}$ of the Convention on the Elimination of all forms of Discrimination against Women reaffirm the right of women to social security (UN, 1979).

In recent years there has been growing emphasis on the importance of social security and the International Labour Organisation has promoted the concept of a social protection floor (ILO and WHO, 2009) which is described as follows:

"The notion of the social protection floor is anchored in shared principles of social justice and in the universal right of everyone to social security and to a standard of living adequate for the health and well-being of themselves and their families, including food, clothing, housing, medical care and necessary social services. It is a rights-based approach and its core idea is that no one should live below a certain income level and everyone should at least be able to have access to basic social services to enhance decent work opportunities." (ILO, 2011: 9).

Within the African Union, there have been a number of initiatives to promote access to social security, and in 2005, a Social Policy Framework for the Southern African Development Community (SADC) was drawn up with the aim of reflecting the aspirations and commitments of the SADC Region (SADC, 2006; Wright and Noble, 2010). The document highlights the importance of social protection stating that it: 
"is important for both vulnerable and non-vulnerable groups, as it has defensive and enabling dimensions. It can reduce their exposure to risks and enhance their capacity to protect themselves against various hazards including loss of income. Social protection instruments, particularly social pensions and social assistance, are priority instruments to expedite poverty reduction, and tools to initiate a positive spiral of aggregate demand in local and national markets. Social protection also has an enabling function as it unlocks human potential to engage in higher productivity and profitability businesses and livelihoods." (SADC, 2006)

Article 10 of the 2003 Charter of Fundamental Social Rights in SADC states that people with no means of subsistence are entitled to social assistance:

"Member States shall create an enabling environment so that every worker in the Region shall have a right to adequate social protection and shall, regardless of status and the type of employment, enjoy adequate social security benefits. Persons who have been unable to either enter or re-enter the labour market and have no means of subsistence shall be entitled to receive sufficient resources and social assistance." (SADC, 2003).

This principle was developed further in the 2007 Code on Social Security in the SADC (SADC, 2007) which was approved by SADC Ministers of Employment and Labour and Social Partners in Lusaka, Zambia and recommended to the Integrated Committee of Ministers in SADC for adoption. This document includes definitions of social protection, social security, social assistance, social insurance and social allowances and clearly outlines the right of everyone in SADC to social security:

\section{"ARTICLE 4: THE RIGHT TO SOCIAL SECURITY}

4.1 Everyone in SADC has the right to social security.

4.2 Every Member State should establish and maintain a system of social security in accordance with the provisions of this Code and Article 10 of the Charter of Fundamental Social Rights in SADC.

4.3 Every Member State should maintain its social security system at a satisfactory level at least equal to that required for ratification of International Labour Organization (ILO) Convention Concerning Minimum Standards of Social Security No. 102 of 1952.

4.4 Every Member State should progressively raise its system of social security to a higher level, which should include achieving the meaningful coverage of everyone under the system, bearing in mind the realities and level of development in the particular Member State." (SADC, 2007) 
To what extent are these high level commitments in evidence in practice in South Africa? And in particular, for the purposes of this project, to what extent are these commitments realized for lone mothers? The following section contains a review of social security provision for lone mothers in South Africa.

\subsection{Social security for lone mothers in South Africa - is there any?}

Social security policy is not value- or gender-neutral and lone mothers as a group place this fact in sharp relief. Whatever the type of provision for lone parents, the policies (or absence of policies) will impact greatly on whether gender equality is being striven towards, as well as the extent to which care is viewed as a social and collective responsibility, and the notion of a work-family balance is taken into consideration (e.g. Chopra et al., 2013; Chzhen and Bradshaw, 2012; Lewis, 2010; OECD, 2012a; UN, 2013). Annex 9 contains a brief review of social security provision for lone parents in other countries.

The South African Constitution's Bill of Rights inter alia stipulates that the state must take 'reasonable legislative and other measures, within its available resources, to achieve the progressive realisation' of the provision of 'access to social security, including, if they are unable to support themselves and their dependants, appropriate social assistance' (RSA, 1996. Ch2 s27).

It is argued in this section that lone mother's access to social security has not yet been progressively realized, and indeed as will be explained below, their access to social assistance has actually deteriorated in certain respects. There are no social allowances (nonmeans-tested universal payments to people in designated categories) of relevance to lone mothers in South Africa and so this section considers social security in relation to social assistance and social insurance only.

\subsubsection{Social assistance for lone mothers in South Africa}

The Code on Social Security in the SADC describes social assistance as provision -

'in cash or in kind to persons who lack the means to support themselves and their dependants. Social assistance is means-tested and is funded from government revenues. Normally, the beneficiaries are those who are not covered by any other form of social security. The objective of social assistance is to alleviate poverty through, amongst other things, the provision of minimum income support.' (SADC, 2007: 1). 
Social assistance in South Africa cost R113Bn in 2013/14, amounting to 3.4\% of GDP, with nearly 16.1 million recipients at the end of 2012/13 (National Treasury, 2013: 84-85). A number of the grants are relevant to lone mothers - as defined broadly for the purposes of this project - and these are summarised in Table 6.1 below (RSA, 2004). Relevant grants comprise the Old Age Grant (OAG) and the Disability Grant (DG) and to a lesser extent the War Veterans Grant (WVG) and Grant-in-Aid (GIA). Applicants for these grants must be resident in South Africa, and must be South Africa citizens or permanent residents or (with the exception of the War Veterans Grant) refugees. The amounts of the grants and the asset and means test thresholds for the grants are listed in Figure 7 below.

Table 6.1: Social Grants for which lone mothers could potentially be eligible

\begin{tabular}{|l|l|l|}
\hline Grant & $\begin{array}{l}\text { Age of } \\
\text { applicant }\end{array}$ & Other criteria (in addition to means test) \\
\hline $\begin{array}{l}\text { Old Age } \\
\text { Grant }\end{array}$ & 60 and over & $\begin{array}{l}\text { Must have an ID document; must not be in receipt of another } \\
\text { grant for herself; must not be maintained or cared for in a State } \\
\text { Institution }\end{array}$ \\
\hline $\begin{array}{l}\text { Disability } \\
\text { Grant }\end{array}$ & $18-59$ & $\begin{array}{l}\text { must submit a medical / assessment report (less than 3m old) } \\
\text { confirming disability; must not be in receipt of another grant for } \\
\text { herself; must not be maintained or cared for in a State } \\
\text { Institution. }\end{array}$ \\
\hline $\begin{array}{l}\text { War } \\
\text { Geterans }\end{array}$ & $\begin{array}{l}60 \text { and over } \\
\text { (or disabled if } \\
\text { younger) }\end{array}$ & $\begin{array}{l}\text { must have fought in the Second World War or the Korean War; } \\
\text { must not be in receipt of another grant for herself; must not be } \\
\text { maintained or cared for in a State Institution. }\end{array}$ \\
\hline $\begin{array}{l}\text { Grant-in- } \\
\text { Aid }\end{array}$ & $\begin{array}{l}18 \text { and over } \\
\text { Must be in receipt of DG, OAG or WVG; must require full time } \\
\text { attendance by another person owing to his/her physical or } \\
\text { mental disabilities; must not be cared for in an institution that } \\
\text { receives subsidy from the State for the care/housing of such } \\
\text { beneficiary }\end{array}$ \\
\hline
\end{tabular}

If lone mothers fall beneath the asset and means-test thresholds they can apply for social assistance in the form of the Disability Grant if they are aged 18-59 and are disabled, or for the Old Age Grant if they are aged 60 and over. ${ }^{38}$ The War Veterans Grant and Grantin-Aid are in practice 'top-up' grants for particular groups - war veterans, and people in need of full time care due to disability respectively.

So, for example, a 45 year old lone mother would be entitled to claim the Disability Grant (R1,260 per month) if she had an income of less than R49,920 per year, had assets worth less than R831,600, and had fulfilled the disability test. There is no social assistance for lone mothers under the age of 60 who are not disabled.

${ }^{38}$ The means test of the OAG is going to be phased out (National Treasury, 2013: 85). 
Figure 7: Asset and income thresholds and amounts of social grants, 2013

\begin{tabular}{|c|c|c|c|}
\hline \multicolumn{4}{|c|}{ Asset And Income Threshold } \\
\hline Asset threshold: & 01 April 2012 & 01 April 2013 & 01 October 2013 \\
\hline \multicolumn{4}{|l|}{$\begin{array}{l}\text { (Grants for older persons, disabled } \\
\text { and war veterans only) }\end{array}$} \\
\hline Single person & R 792 000 & R 831600 & \\
\hline Married person & R 1584000 & R 1663200 & \\
\hline \multicolumn{4}{|c|}{ Income threshold: (Annual amounts) } \\
\hline Single person & R 47400 & R 49920 & \\
\hline Married person & R 94800 & R 99840 & \\
\hline \multicolumn{4}{|l|}{ Child Support Grants: } \\
\hline Single person & R 33600 & R34 800 & R 36000 \\
\hline Married person & R 67200 & R69 600 & R72 000 \\
\hline \multicolumn{4}{|l|}{ Care Dependency Grant } \\
\hline Single person & R 144000 & R 151200 & \\
\hline Married person & $\mathrm{R} 28800$ & R 302400 & \\
\hline \multicolumn{4}{|c|}{ Amounts Of Grants As At 01 April 2013} \\
\hline Grant Type & \begin{tabular}{|l|}
$\begin{array}{l}\text { Amount payable as } \\
\text { from } 1 \text { Appril } 2012\end{array}$ \\
\end{tabular} & $\begin{array}{l}\text { Amount payable as } \\
\text { from } 1 \text { April } 2013\end{array}$ & \begin{tabular}{|l|l|}
5 & $\begin{array}{l}\text { Amount payable as } \\
\text { from 1 October 2013 }\end{array}$
\end{tabular} \\
\hline Older Persons Grant (Old age pension) & R1200.00 & R1260.00 & \\
\hline $\begin{array}{l}\text { Older Persons Grant (Old age pension): } \\
\text { Beneficiary older than } 75 \text { years }\end{array}$ & R 1220.00 & R 1280.00 & \\
\hline Disability grant & R 1200.00 & R 1260.00 & \\
\hline War veterans' grant & R 1220.00 & R 1280.00 & \\
\hline Grant-in-aid & R 280.00 & R 290.00 & R 300.00 \\
\hline Child support grant & R 280.00 & R 290.00 & R 300.00 \\
\hline Foster child grant & R 770.00 & R 800.00 & \\
\hline Care-dependency grant & R 1200.00 & R 1260.00 & \\
\hline
\end{tabular}

Source: SASSA, 2013.

To what extent do lone mothers receive social grants? In the analysis of the GHS in Chapter 3 it was found that - using the definition of lone mothers as explained in that chapter $-12 \%$ of lone mothers aged 16-59 lived in a household that received the DG (though we cannot tell whether the grant was received by the lone mother). Additionally, $90 \%$ of lone mothers aged 60 and over lived in a household that received the OAG (though again this may or may not be being claimed by the lone mother).

Social security for lone mothers has not always been so scantily furnished: South Africa used to have a State Maintenance Grant (SMG) which was introduced in the 1930s. According to Kruger (1998) the focus shifted over time from support for widows (because of the death of an income earner) to support for divorced, abandoned and unmarried mothers (where an absent parent does not contribute to the maintenance of the family). The SMG was paid to parents/guardians (only women until 1992) who were unmarried, divorced, widowed or deserted by their spouse, or who had a spouse who received a social grant, had been declared unfit to work for more than six months, or had been institutionalised (jail, psychiatric hospital) for more than six months (Lund, 2008). The SMG was means tested and the parent/guardian had to prove that $s /$ he had failed to obtain a private maintenance award against the absent parent (Burman and Berger, 1988a and 1988b). ${ }^{39}$ The grant was

\footnotetext{
39 In addition to the burden of proving failure to obtain private maintenance, Burman and Berger's study (1988b) highlights numerous other problematic features of the SMG including: application for the grant could only be made on one day each month; birth certificates (and school certificates for each child of school-going age) had to be provided as well as a social worker's report; only the biological mother could receive the grant,
} 
payable for a maximum of two children (reduced from four in 1992) under the age of 18 (Lund, 2008). In 1996 the value for the parent allowance was in line with the old age pension at R430 per month, while the child allowance was R135 per child (Kruger, 1998).

The SMG was initially introduced for the white population, with coloured and Indian people gradually included in its scope, via racially distinct welfare departments (Burman and Barratt, 1992 and 1993). Black African people were finally included, but there was a great deal of variation in how the system was applied to this group (Lund, 2008). Although the majority of those who received the grant were poor, many of the poorest were excluded due to both the restricted eligibility criteria and the inconsistent administrative procedures. The SMG was phased out from April 1998 to March 2001 (Hunter et al., 2003: 72). Crucially, in an effort to limit the cost of the de-racialisation of the SMG the caregiver component was sacrificed (Kabeer, 2007; Lund, 2008). As a consequence, most lone mothers ceased to be eligible for any form of social assistance for their own material needs. ${ }^{40} \mathrm{~A}$ study of SMG recipients was undertaken while the SMG was being phased out (during which time the SMG payment was reduced to zero over a four year period) and, of particular note for this project, it was observed that:

'Women also report increased levels of conflict in their households due to economic hardship and in general they experience feelings of humiliation and a loss of dignity.' (Vorster, 2000: 16).

Goldblatt observes that there was a failure at the time to highlight the gender implications of the removal of the parent component as part of the transition from the SMG to the CSG. She writes:

'The loss of this aspect of the State Maintenance Grant was a major blow to the struggle for the recognition of women's unpaid caring work in society. There is now no longer any state assistance for the millions of women who contribute to the reproduction of the society by taking care of children. Their unpaid labour [...] is invisible and taken for granted'. (Goldblatt, 2005: 241).

unless evidence was provided that she was sick, dead or had disappeared; approval/refusal letters were only issued in English and Afrikaans; most applications took 3-6 months to be processed; grants could only be obtained for one child 'born of an irregular union'; and the officials used discretion in interpretation of the eligibility criteria. Burman and Barratt (1993) further provide examples of women being obliged to attend a contraceptive class before the grant can be awarded; that young women had to demonstrate that they were looking for work (each day); and that if a job was found for her (in their example, by the 'Department of Manpower' in Cape Town) the woman would be obliged to accept it irrespective of availability of childcare; if her work-seeking performance was deemed unsatisfactory the caregiver component of the SMG would be cancelled.

${ }^{40}$ Lund (2006) calls for a systematic investigation on the effects on women and children of the loss of this source of income. 
Finally, the Social Relief of Distress should be mentioned. This is described as 'temporary provision of assistance intended for persons in such a dire material need that they are unable to meet their families' most basic needs' ${ }^{41} \mathrm{~A}$ discretionary grant, it is provided in the form of a food parcel or food voucher or (in some provinces) as cash. The examples provided on the Government website of potentially eligible people imply that some low income lone mothers could be eligible:

\section{Figure 8: Reasons why people may be eligible for Social Relief of Distress}

- you need help while you wait for your children's grants to be processed

- a crisis or disaster has occurred (e.g. your house has burnt down)

- you do not qualify for a grant, and you are in a desperate situation

- you are unable to work for a period of less than six month because you are medically unfit

- you are unable to get maintenance from the other parent of your child or children

- the breadwinner in the family has died

- the breadwinner has been sent to prison for a short time (less than six months)

- you have been affected by a disaster, but the area or community in which you live has not been declared a disaster area.

Source:

http://www.services.gov.za/services/content/Home/ServicesForPeople/Socialbenefits/socialrelief/en_ZA

The Social Relief of Distress is provided for 3 months with the possibility of extending it for a further 3 months. It is not possible to ascertain the extent to which the Social Relief of Distress is used by lone mothers.

Government has explored options for more comprehensive provision of social security - see for example the Taylor Commission (DSD, 2002). More recently, DSD issued a discussion document entitled Strategic Considerations for a Comprehensive System of Social Security: Discussion Document, in which it acknowledged that one of the shortfalls of the existing programme of social security was that 'caregivers of children in poverty receive no income support' (DSD, 2008: 17). In the section on non-contributory programmes it is stated that the medium-term objective is:

'To expand and develop the non-contributory system to ensure that it receives a balanced share of national resources, and is focused on improving the conditions of the most vulnerable' (DSD, 2008: 24).

In the list of the priority groups that are 'particularly vulnerable' children aged 0-18 are listed first, followed by caregivers of children (DSD, 2008: 24). It is further recommended that income support should be expanded in a sequenced manner, with caregivers of children aged 0-18 again listed as the second most vulnerable group (followed by unemployed youth, youth aged 19-24 in further education, unemployed adults, older people aged 60 and over, people with disabilities of all ages, and severely disabled children). The

${ }^{41}$ http://www.services.gov.za/services/content/Home/ServicesForPeople/Socialbenefits/socialrelief/en_ZA 
section entitled 'Recommended programme for the expansion of social assistance' includes the recommendation that:

'All designated caregivers for child recipients of the CSG should receive a grant (“CCG") at least equal to the value of the CSG' (DSD, 2008: 31). ${ }^{42}$

However, so far, progress has been limited to increasing means test thresholds and grant amounts, extending the upper age limit (up to 17 inclusive) of children eligible for CSG and equalising the age threshold (to 60 and above) for Old Age Grant for men and women, none of which directly impact lone mothers. ${ }^{43}, 44$ In parallel there has been an ongoing debate about the need for more comprehensive provision of income maintenance (e.g. Whitworth and Noble, 2008) including a basic income grant (e.g. Samson et al., 2002; Meth, 2008a) which of course would have a direct impact on lone mothers.

\subsubsection{Social insurance for lone mothers in South Africa}

The Code on Social Security in the SADC describes social insurance as:

'a form of social security designed to protect income-earners and their families against a reduction or loss of income as a result of exposure to risks. These risks impair one's capacity to earn income. Social insurance is contributory with contributions being paid by employers, employees, self-employed persons, or other contributors, depending on the nature of the specific scheme. Social insurance is aimed at achieving a reasonable level of income maintenance.' (SADC, 2007: 1)

Female contributors to the Unemployment Insurance Fund (UIF) can potentially apply for unemployment and maternity benefits. The UIF pays a percentage of the wage/salary that the person earned while contributing to the fund. Unemployment insurance contributions of $2 \%$ of the value of each worker's pay per month to a maximum of R14,872 per month (from 1 October 2012) must be paid to the UIF. The employer and the

\footnotetext{
${ }^{42}$ It was further recommended that the means test should be removed (with a tax claw-back for high income recipients) and that the grant amount should be increased by $2 \%$ in excess of general inflation 'until such time as the grant value equals a designated, officially determined, level of income sufficiency' (DSD, 2008: 31).

${ }^{43}$ In the past there was also a child tax rebate, though this was abolished in 1996, following the recommendation of the Commission of Enquiry into Certain Aspects of the Tax Structure of South Africa (known as the Katz Commission). Parents were eligible for a tax rebate of R100 - R150 per child per year, depending on the number of children. The Katz Commission recommended the abolition of the child rebate because 'it was not substantial enough to make an effective contribution to the upbringing of children and, more importantly, it gave approximately R500 million of relief where it was needed least - to families wealthy enough to pay income tax' (Smith, 2000: 14).

${ }^{44}$ DSD has recently commissioned a study to look at social assistance for pregnant women (Child, 2014). If this was introduced it would provide important support for women during pregnancy, but would not address the absence of social assistance for low income women post-childbirth.
} 
worker each contribute $1 \%$. There are certain categories of worker to whom this does not apply. $^{45}$

Unemployment benefits are available for individuals who contributed to the UIF while in employment. ${ }^{46}$ Workers can claim from the day they stopped working (due to termination of contract, expiry of fixed term contract, or termination of services resulting from employer insolvency) until their benefits are used up or they start working again. Payments are based on remuneration when working. ${ }^{47}$

In relation to maternity benefits, depending on her salary, a woman can claim up to $58 \%$ of her salary for up to 121 days (4 months), subject to the credit days accumulated. ${ }^{48}$ The employer has no obligation to pay an employee during her maternity leave.

South Africa additionally includes domestic workers in its provisions for UIF, one of several groups of employed women that are excluded from protection in some countries (ILO, 2010). However, women will need to have been in formal employment and contributed to the UIF in order to be eligible to apply for it, and so many women are excluded from this provision.

In summary, Figure 9 depicts the way in which most lone mothers mainly fall outside the scope of current social assistance and social insurance provision in South Africa at present.

\footnotetext{
${ }^{45}$ SARS (2012);

http://www.services.gov.za/services/content/Home/ServicesForPeople/Theworldofwork/unemploymentinsur ancefund/unemploymentbenifitsUIF/en ZA; https://www.labour.gov.za/legislation/acts/basic-guides/basicguide-to-uif-unemployment-benefits/

${ }^{46}$ Lund highlights that the maternity and unemployment components of the UIF used to be linked and so the UIF system 'discriminated massively against women, who got reduced entitlements on the unemployment benefit if claiming the maternity benefit' but that the two have now been separated (Lund, 2006: 174). 47

http://www.services.gov.za/services/content/Home/ServicesForPeople/Theworldofwork/unemploymentinsur ancefund/MaternityBenefitsUIF/en_ZA; https://www.labour.gov.za/legislation/acts/basic-guides/basic-guide$\frac{\text { to-uif-maternity-benefits; }}{48}$ http://www.labourguide.co.za/general/unemployment-insurance-fund-uif-838

http://www.services.gov.za/services/content/Home/ServicesForPeople/Theworldofwork/unemploymentinsur ancefund/MaternityBenefitsUIF/en ZA; https://www.labour.gov.za/legislation/acts/basic-guides/basic-guideto-uif-maternity-benefits; http://www.labourguide.co.za/general/unemployment-insurance-fund-uif-838
} 
Figure 9: Summary of Social Security coverage for lone mothers in South Africa

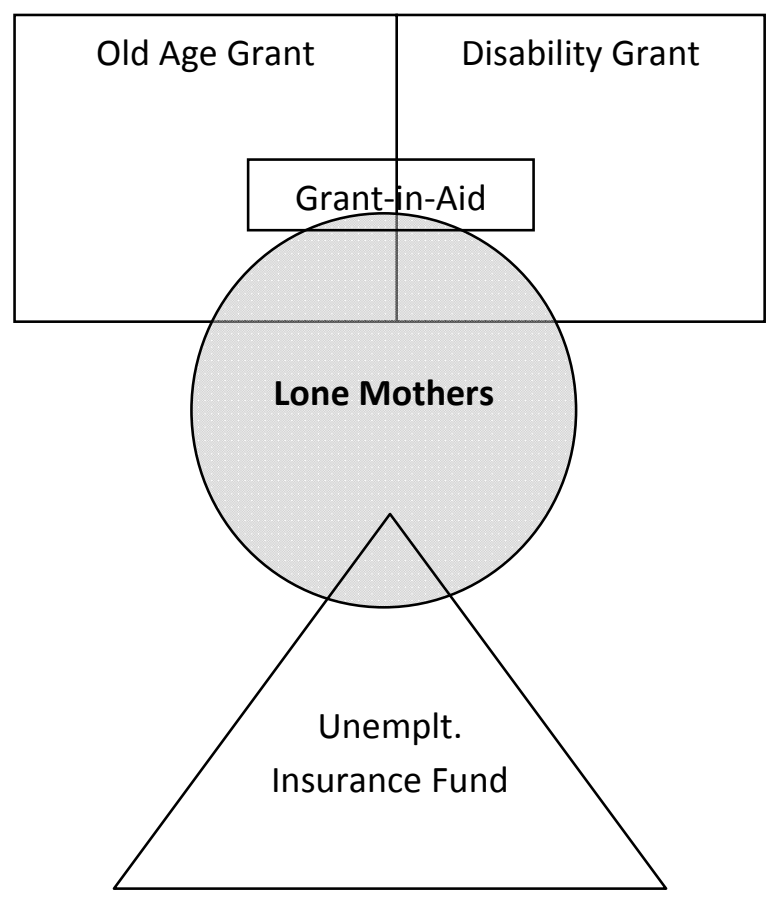

\subsection{Examples of other forms of state or state-governed support in the absence of comprehensive social security}

Given that most lone mothers fall outside the scope of formal social security provision in South Africa, it could be argued that their experience of social security provision in South Africa accords best with Gough and Wood's classification of an informal welfare regime (Gough and Wood, 2004), with heavy reliance placed on social networks and reciprocal exchange (e.g. Du Toit and Neves, 2009).

However, the state does also contribute in a number of other ways to the wellbeing of lone parents, in the form of what is broadly referred to as 'the social wage' which includes provision of healthcare, housing and sanitation, and the local municipality-run indigency policies (see Meth 2008b and in particular pp12-18 for an account of the use of the term in post-1994 South Africa). For example, around three million houses have been provided to low income people since 1994 (Zuma, 2014), though the extent to which the social wage has benefited lone mothers has not been quantified.

There are additionally examples of child-linked state support (or state-governed support) that lone mothers (simply in their capacity as parent) might have access to, some of which are summarised below. 


\subsubsection{Child grants}

There are three grants for children: the Child Support Grant (CSG), the Foster Child Grant (FCG), and the Care Dependency Grant (CDG). In 2013/14 the number of beneficiaries (i.e. children for whom the grant is claimed) were projected to be $11.7 \mathrm{~m}, 0.6 \mathrm{~m}$ and $0.1 \mathrm{~m}$ respectively (National Treasury, 2013: 85). The means tested Child Support Grant (CSG) is paid at R300 per month and is paid per child to the primary caregiver. The age limit of children for whom CSG can be claimed is 18 (i.e. the grant is for children aged 0-17 years inclusive). The FCG, paid at a higher rate (R800 per month), is not means-tested and is paid for children for whom a court order has been issued. The CDG has a much higher means-test threshold and is paid at R1260 per month for children with a permanent, severe disability. Importantly, the child grants do not include a component for the material needs for the caregiver. ${ }^{49}, 50$

\subsubsection{Childcare provision}

A common and significant barrier to employment (both being in paid work and working longer hours) for lone parents is the availability of suitable (good quality and affordable) childcare options. This includes both early years childcare and out of school hours care. Childcare costs have a substantial effect on the take-home pay and labour market behaviour of lone parents (OECD, 2011). For any parent, decisions about modes of childcare - whether parental, informal (relatives and friends) or formal - depend on a variety of factors including 'employment preferences, income, the cost of formal childcare, trust, flexibility, convenience, and also perceptions about child development' (Blackburn, 2006).

While activation policies have placed an obligation internationally on lone parents (amongst others) to seek work, there is a reciprocal obligation for governments to provide realistic childcare options, as well as flexible working practices. The Nordic countries are often cited as having a comprehensive system of childcare with good quality care and on a full-time basis, thus facilitating the return to employment, particularly for lone parents. Some countries, however, see formal childcare as a service that should be paid for in the main by parents and employers (OECD, 2007). Policy measures to lower the costs include subsidies, fee reductions and tax concessions (OECD, 2011). Some countries have subsidies based on family circumstances, including for lone parents, and priority for childcare places can be given to lone parents (Bradshaw and Finch, 2002).

\footnotetext{
${ }^{49}$ In relation to the FCG, Hearle and Ruwanpura write: 'Caregivers are treated simply as intermediaries, with scant attention paid to their rights, roles and responsibilities' ( $p 428$ ).

${ }^{50}$ There is however some ambiguity around the higher-paid CDG and FCG, with some people ascribing to these grants a component for the caregiver. For example Lund describes the CDG as being 'for the caregivers of children with severe physical and mental impairment' and the FCG as being 'aimed to encourage the support by non-kin of children whose parents are unable to care for them' (Lund, 2006: 162), and further that 'the intention behind the [CDG] is that it will obviate the need for a child to be admitted to more expensive fulltime institutional care' (Lund, 2006: 163).
} 
In South Africa Early Childhood Development (ECD) covers children aged 0-9 years. Responsibility for ECD provision rests with various government departments, with the Department of Social Development (DSD) and the Department of Basic Education providing the main sources of government funding and oversight. ${ }^{51}$ The National Integrated Plan for $E C D^{52}$ outlines a range of essential services and approaches to service delivery for children aged 0-4 years. ECD centres (mainly non-profit centres run by community groups and NGOs) are the main form of provision and efforts have been made to increase children's access to these centres (Biersteker, 2012). Subsidies are provided to registered centres by DSD on a per child per day basis for children whose caregivers pass a means test (Giese and Budlender, 2011). However, not all centres are registered, and even where they are and subsidies are provided, fees are usually charged, meaning the poorest children are excluded. There are also age, race and spatial disparities in access (Biersteker, 2012). A major focus in $E C D$ provisioning for children over the age of five has been on Grade $R$, which is offered in both public schools and registered community ECD centres. The Department of Basic Education provides funding for Grade R in schools, and subsidies (either per child or in the form of a salary for a Grade R practitioner) for registered centres (Giese and Budlender, 2011). The funding formula for Grade R provision is said to target the poorest children (Biersteker, 2012; Giese and Budlender, 2011).

\subsubsection{Child support/maintenance from non-resident parents}

Child support is an amount paid to lone parents by the non-resident parent (NRP), which is normally the father. This is a different kind of support that is not provided by the state, although some countries have introduced measures to improve the child support system to ensure that NRPs comply with payment obligations, while others assist further by making advance payments to compensate for late or unpaid payments by NRPs (OECD, 2011). Child support payments can affect the tax of both the NRP and the recipient lone parent, and also other welfare benefits received by the lone parent, depending on how such payments are treated in the tax and benefit system (OECD, 2011).

South Africa's Maintenance Act No. 99 of 1998 requires parents to give their children a 'proper living and upbringing' which includes 'the provision of food, clothing, accommodation, medical care and education, ${ }^{53}, 54$. Parents are regarded as having jointly incurred the obligation to support their child, regardless of 'whether a child is born in or out of wedlock or is born of a first or subsequent marriage'. The share of support each parent is expected to pay is 'apportioned between them according to their respective means', with the amounts determined by a maintenance court (RSA, 1998: 14). However, this legislation is not tightly enforced and in any event, due to the high unemployment rates in South

\footnotetext{
51 http://www.ilifalabantwana.co.za/the-early-childhood-development-sector-in-south-africa/

52 The National Integrated Plan 2005-2010 (RSA, 2005), currently being updated.

${ }^{53}$ For a review of the maintenance system shortly after the new Act had been introduced see Wamhoff (2001).

${ }^{54}$ Parental responsibilities and rights are also set out in the Children's Act No. 38 of 2005.
} 
Africa, a considerable number of non-resident fathers are unable to financially support their children. Additionally, legally setting up child maintenance payments can be timeconsuming and costly, with follow-up procedures for non-paying fathers proving to be even more costly both financially and emotionally (Children's Institute, 2006).

\subsection{4 'Family friendly' employment policy}

Maternity leave (through UIF) has been discussed above, and in some countries there are also arrangements for additional types of leave. These comprise parental leave (leave of absence for employed parents, which is often supplementary to specific maternity/paternity leave periods, and usually follows the period of maternity/paternity leave); home-care leave (leave to care for children until they are about three years old - can be a variation of parental leave, and payments are not restricted to parents with a prior work attachment); and short-term leave to care for sick children (OECD, 2007).

There are a range of other family-friendly measures that help reconcile work and family life, including part-time and flexible hours of work. These measures are generally workplace specific and therefore dependent on the employer, but in some instances countries have introduced legislation which entitles employees to flexible workplace practices (OECD, 2007). The focus of these policies is on the general needs of working parents, particularly mothers (Knijn et al., 2007).

South African legislation (the Basic Conditions of Employment Act No. 75 of 1997, as amended) provides for a paid family responsibility leave of three days per 12 month period that can be used by both parents (see Section 27). Anyone employed for longer than four months and who works at least four days a week for an employer is entitled to take such leave when a child is born (separately from maternity leave) or is sick. ${ }^{55}$

\subsection{Dignity and social security policy design: the elite interviews}

As part of this project, interviews were undertaken with people who had, or had previously been in, senior positions within the Department of Social Development, the South African Social Security Agency, Parliament, and a non-governmental organisation (see Annex 6). As part of the interview, contributors were asked about the extent to which they thought that the concept of dignity plays a role when social security policies are designed. ${ }^{56}$

All of the contributors argued that dignity plays an important role in social security policy design, and that the purpose of social security is to help to protect people's dignity by providing an income to alleviate poverty. For example:

\footnotetext{
${ }^{55}$ Family responsibility leave can also be granted for the death of family members (spouse or life partner, parent, grandparent, child, grandchild or sibling).

${ }^{56}$ Issues about social security policy implementation (rather than social security policy design) are presented in Chapter 7.
} 
"The concept of dignity is quite an important one, especially in the South African context. It is important to the subject of social security as in fact social security is in part aimed at restoring it, rather than taking it away. People who are faced with destitution to a point where they are not able to provide for themselves or their dependents lose their dignity in that sense, and if with the assistance of the state they are able to provide for their dependents, that in a sense helps them restore their dignity as providers, even if the provision they are able to make for their family is through assistance by the state. And more often than not, what we have found, is that people are always on the look-out for opportunities to augment whatever the state makes available for them as social assistance, in order to maximise the potential benefits both for themselves and their dependents. [...]There seems to be a body of thought that by giving more social security you are taking away people's sense of dignity and self-respect, but that is a perspective not shared by many. It's not a perspective I would say enjoys much support" (Mr V. Madonsela, Former Director General of the national Department of Social Development)

Another contributor commented that:

"Social assistance is predominantly about income transfer to poor households and individuals in South Africa. It is really to ensure that they live lives of dignity.

Although one must say that reference to dignity as such is not as strong as reference to social assistance as a right, but the assumption is that the income that is transferred is intended and directed at ensuring that South Africans enjoy a life that is not characterised by abject poverty, by unacceptable levels of want. So I would say that yes policy design does take into consideration the issue of dignity." (Dr W. Magasela, Deputy Director General (Social Policy), national Department of Social Development)

One contributor suggested that although dignity does play a role, it is not overly prominent in policy design; it is considered more prominently around issues of service delivery of social assistance, rather than in terms of the impact of the policy on the dignity of the person. He went on to say:

"I think it does play a role, although I would admit that it's not as prominent a role as it possibly should be. It is something that would be given a bit of thought when various policies are drafted but it usually just gets overtaken by the main gist of whatever the policy is, and it would almost get a backseat and not fully explored." (Mr B. van Vrede, Chief Director (Social Assistance), national Department of Social Development)

When the contributors were asked whether they had encountered any practical difficulties or contradictions in the social security design process that might compromise 
people's sense of dignity, a number of important issues were raised, which will be revisited later in this report. The issues raised related to the CSG means-test, adequacy, contestations over whether social security is an appropriate method for alleviating poverty, pejorative attitudes to CSG beneficiaries, risks of women being stereotyped and controlled (through the use of conditionalities) as caregivers, the over-prioritisation of children over caregivers, and more generally the exclusion of caregivers from the social security system.

First, the CSG means-test was described by several contributors as a feature of the policy design that compromised dignity. For example:

"In part because of our desire to make sure that - even as we extend social security benefits to everyone that's eligible - that we keep out of the system those who do not qualify, that has to some extent necessitated that some of the things we do in the implementation of policy get to be a bit intrusive, purely out of a desire to make sure that people are truly eligible for the benefits." (Mr V. Madonsela, Former Director General of the national Department of Social Development)

Another contributor stressed the difficulty of proving that one falls below the means-test:

“It's very difficult to prove that you don't have money. It's very difficult to prove that you have not worked for the past 6 years. Very, very difficult. Because more often than not for one to prove these things there's got to be supporting documentation. And even at times you would be asked when was the last time that you held a job, what job it was, what was your income then, and what are you living on currently if you are claiming that there is no income that's coming in. So means-testing brings about that kind of issue, where you subject poor people to requirements that are quite strenuous to fulfil." (Dr W. Magasela, Deputy Director General (Social Policy), national Department of Social Development)

He likened the situation to when some poor people postpone visits to the hospital until they can afford the nominal fee rather than undergo the test to ascertain whether they are eligible to receive free care:

"It's an issue of a reluctance to subject yourself to scrutiny, scrutiny of your poverty as a person for you to be able to access services that are free from government, which need proof that you are indeed poor." (Dr W. Magasela, Deputy Director General (Social Policy), national Department of Social Development)

A second example offered by some of the contributors, of instances where social security design compromise dignity, related to the adequacy of the social security provision. For example: 
"At a policy level, particularly when one talks about social protection, I think for me the issue would be really be about the adequacy thereof. The issue for me would be whether the levels of our social protection do meet the minimal requirements for a life lived with dignity. If one is speaking about policy development as such, that for me would really be about that. I could go beyond Social Development, I could go beyond social security, beyond social assistance, beyond the Department of Social Development and maybe look at housing. Some of the housing that has been provided by Government does violate a sense of dignity, in the sense that you are finding families being assigned and allocated single-room houses" (Dr W. Magasela, Deputy Director General (Social Policy), national Department of Social Development)

The issue of adequacy is explored in more detail in Chapter 7 as the inadequacy of the CSG was raised by lone mothers as an issue that compromises their dignity as caregivers.

A third example of policy design compromising dignity that was frequently mentioned was not so much to do with the social security policy design per se as the discourses that surround these policies. As one of the contributors noted:

'there continues to be two lines of thought, or shall I say ideological biases, in South Africa. One where you have people arguing for social security on the basis of access to constitutional rights, assisting people in poverty. On the other hand there are always people who are of the view that we are creating a problem, that this thing is unsustainable, that it creates dependency. So those two lines have always been at loggerheads, and interestingly the major contradiction is that - notwithstanding the argument as well as the balance of power on the side of those against grants - that we've made the success that we have. [...] I think what we are creating is a kind of ambivalent and schizophrenic society when it comes to social grants.' (Mr S. Jehoma, former Deputy Director General (Social Security), national Department of Social Development)

Notably, this same contributor had earlier observed that the social security system was inherited from the apartheid era and that there was no evidence in the literature that dignity had informed social security design prior to 1994. Ironically, though, he argued that due to what he saw as the dominant fear of a welfare state, less progress would have been made in social security provision without the prior existence of this earlier social security system. In his experience dignity would never have provided the basis for a successful argument about social security provision as it would have been regarded as a value judgement and these were discouraged.

A fourth and related issue that was raised was about the disparaging way in which women are referred to in their capacity as CSG recipients. This issue is explored in more detail in Chapters 8 and 9. One contributor in particular expressed concern that women are spoken of in disparaging terms, and accused of 'eating the money and buying booze', and of 
misusing or potentially misusing the money. The contributor had heard such disparaging comments from a range of sources including Parliamentarians, civil servants, clergy, civil society organisations and other members of society.

Related issues that were raised were of women being stereotyped and controlled as caregivers on the one hand, whilst at the same time being excluded from social security support for their own material needs, with an over-emphasis on the needs of children rather than their caregivers. One of the contributors spoke about his concern that the CSG might be regarded by some in government as a replacement of maintenance which was not being paid by the children's fathers, and that the drive to introduce conditionalities revealed a desire to control women. He went on to add that although the SMG was racialised and had its failings, the SMG did at least have a component for the mother whereas the CSG is now overly child-focussed in comparison:

'I'm not saying the reforms to the CSG were bad but the CSG reforms - the way I see it - specifically excluded the mother. It became very child-focussed at the expense of the mother, of the caregiver (not necessarily the mother but $99 \%$ are women) so it almost, and the drive of CSG and the roll-out of the CSG has always has been childfocussed without ever considering the impact that would have on the caregiver." (Mr B. van Vrede, Chief Director (Social Assistance), national Department of Social Development)

This same contributor also highlighted a contradiction inherent in the CSG in practice, whereby it is hailed as empowering the girl child, but the caregivers, who are mainly female, are disempowered by being excluded from the social security provision; this undermines the positive impact of the CSG, as the disempowered caregiver role is witnessed by the girl child and perpetuated:

"often there's a lot of focus on [..] how CSG empowers female children, but if you look at the opposite side because you're disempowering the adult mothers you're actually sending a mixed message. You're proclaiming on the one hand that it empowers girls and you show how more girls access education and so forth, but you're disempowering their caregivers who are females and that role gets get put back by the adult onto the child." (Mr B. van Vrede, Chief Director (Social Assistance), national Department of Social Development)

Other examples of policy design compromising dignity included the introduction of conditionalities when the CSG was first designed (which were soon removed). In contrast, one commentator mentioned that the recent introduction of the conditionality about school attendance was intended to build dignity, although another referred to the resistance to this new conditionality amongst officials and their burdensome impact on caregivers. Mention was also made of how the introduction of further - this time work-seeking - 
conditionalities were under consideration in relation to the CSG, and concern was expressed that this would further compromise women's dignity if forced to undertake poor quality employment.

Another commentator spoke of how - in the context of having no social assistance for her own needs - it dehumanises and undermines women to blame them for using the CSG for their own needs. The point was made that there is a need for social security support for caregivers in their own right.

\subsection{Discussion}

Different social policy approaches have a varying impact on outcomes for lone mothers as a group. A recent study by Brady and Burroway found that: 'the social policy context in which single mothers reside matters as much as or even more than their individual characteristics for poverty' (Brady and Burroway, 2012: 739).

In spite of national, regional and international commitments to provide social security, lone mothers in South Africa are largely excluded from the social security system. Currently the only types of means-tested social assistance that low income lone mothers could apply for are the Disability Grant between the ages of 18 and 59 (if disabled) and thereafter the Old Age Grant. Unless they are disabled, there is therefore no social assistance for lone mothers of working age. In terms of social insurance, lone mothers could claim the UIF for maternity leave and unemployment but this requires them to have been in formal employment and in any event the unemployment insurance payments are for a limited period only. Whilst lone mothers could apply for Social Relief of Distress this is a discretionary form of relief that is made only for a very short period.

The State Maintenance Grant (which contained a paid component for the caregiver) was abolished as part of the process of introducing a non-racially differentiated Child Support Grant: this was a trade-off that yielded vital income for children in low income families but at the same time removed any immediate prospect of social security for lone mothers, or able-bodied low income working age caregivers in general. Although senior policy makers stressed the centrality of dignity in social security design, many examples were given of aspects of the policy design that could compromise dignity and, of primary importance here, there was an acknowledgement amongst some of the contributors of the fact that the lack of social security provision for CSG caregivers would compromise their dignity. In the absence of adequate social security provision, this report explores the question of how the current social security arrangements intersect with lone mothers' accounts of their sense of dignity. 


\section{Chapter 7 Lone mothers' accounts of how applying for and collecting the Child Support Grant intersects with dignity}

Summary: Although we saw in Chapter 6 that South African social security mainly excludes lone mothers (along with most unemployed people of working age), many lone mothers do interact with the social security system in relation to the Child Support Grant. This chapter presents material on accounts of how applying for and collecting the CSG intersect with lone mothers' dignity. Sections $7.2,7.3$ and 7.4 present material from the focus group interviews, the in-depth interviews, and the elite interviews respectively.

\subsection{Introduction}

The previous chapter highlights the absence of social security for lone mothers in South Africa. Many lone mothers do however receive CSG as caregivers of children, and it is relevant to this project to explore lone mothers' accounts of how the CSG intersects with their sense of dignity. Although the CSG is aimed at contributing to the needs of the child and not the caregiver, CSG receipt is intrinsically intertwined with lone mothers' experiences of social security. Goldblatt graphically describes the role of women who claim CSG in their role as caregivers of children:

"Women mediate social assistance and deliver it on behalf of the state. They claim it, collect it and are then expected to turn it into food, shelter, clothing, education, health and other aspects of a child's maintenance through their own labours. [..] Unemployed, improvised women (and some girls) are expected, without any means to feed themselves (or meet any of their other needs), to provide child care services for the society, in exchange for nothing' (Goldblatt, 2005: 242).

The South African Social Security Agency (SASSA) is responsible for processing applications for the CSG. People wishing to apply for the CSG are required to go to the SASSA office nearest to where they live, where the application form is completed in the presence of an official from SASSA (SASSA, 2013: 5).

The qualifying requirements listed by SASSA for CSG are that the primary care giver must be a South African citizen, permanent resident or refugee; both the applicant and the child must reside in South Africa; the applicant must be the primary care giver of the child/children concerned; the child/children must have been born after 31 December 1993; the applicant and spouse must meet the requirements of the means test; people cannot apply for more than six non biological children; the child cannot be cared for in State 
institution; and the child aged between 7 and 18 years must attend school ${ }^{57}$ (SASSA, 2013: 3). Although it used to be necessary for the applicant to have a South African ID book, and to provide a birth certificate for the child for whom the CSG is being claimed, this is no longer a qualifying requirement as alternative forms of identification can be provided (SASSA, 2013a: 4). Once the grant has been awarded, the caregiver and child need to register biometrically with SASSA - all 10 finger-prints are captured along with a voice recording and a photograph (SASSA, 2013b: 1).

Receipt of the CSG is accomplished in a number of ways. It can be collected from paypoints, or can be paid into a bank account, or can be obtained through the new SASSA payment card.

This chapter presents material from the focus groups and in-depth interviews with lone mothers about two different aspects of Child Support Grant (CSG) receipt in relation to dignity. Specifically, we present examples that were given by the participants of ways in which dignity is - positively or negatively - impacted by the application for and receipt of the CSG.

\subsection{Applying for the Child Support Grant: the focus group interviews}

Although SASSA has made great strides in improving access to and take-up of the $\mathrm{CSG}^{58}$, the comments from the focus groups about the application process were overwhelmingly negative. In fact, in 26 of the 30 focus groups participants raised issues about ways in which the application process impacted negatively on their dignity. ${ }^{59} \mathrm{~A}$ number of studies have highlighted problematic features of the application process (e.g. Budlender et al., 2005; Goldblatt et al., 2006). The findings presented here are specifically oriented towards ways in which the issues intersect with lone mothers' sense of dignity and so complement the earlier studies. ${ }^{60}$

\subsubsection{Queuing}

As elaborated in Chapter 4, one of Khatib and Armenian's dimensions of dignity is 'worthiness', which they describe as including 'the ability to feel important and valuable in relation to others, communicate this to others, and be treated as such by others' (Khatib

\footnotetext{
${ }^{57}$ This last qualifying requirement was introduced in January 2010 (RSA, 2009).

${ }^{58}$ For example, Delany et al. (2008) refer to 'the Integrated Community Registration Outreach Programme [...] which brings together a range of stake holders including SASSA, DSD, the South African Police Service (SAPS), and Home Affairs so that applicants are able to access all the required documents in one place. The aim is to provide eligible applicants with a letter approving their application on the day it is made' (p60).

${ }^{59}$ Only a small number of participants said that they had no problems regarding the application process - this point was made by one or more people in five of the 30 focus groups.

${ }^{60}$ It is acknowledged that the timing of the applications will span many years, and we did not obtain details of the date of CSG application about which different focus group participants spoke.
} 
and Armenian, 2010: 39). Focus group participants provided many examples of not being made to feel important and valuable in relation to others. One of the most common points to be made about the way in which the application process intersects with people's sense of dignity was that they have to queue for long periods of time.

"I had to queue, a number of times, from 5 in the morning, applying for the CSG. I'd be in the queue the whole day, I think the last time I was Number 137 in the queue. At 4pm, the SASSA staff just gathered their stuff, took their bags and left. Without explaining or saying anything to us, they simply left when they were meant to. Dignity? Where? Where is it?" (Masiphumelele, FG29)

"With my first child I really didn't have a problem, it was a quick, dignified process. It was not so great with my second child, I queued outside the whole day, in the blazing sun. It was terrible." (Butterworth, FG26)

"The ones working for the Social Developments are the most disrespectful ever, they would let you sit waiting, unattended for the rest of the morning, then around 2 o'clock say they are done working for the day, come back tomorrow. And tomorrow you will not be considered as the first person on the queue." (Langa, FG7)

Mention was made of arriving at the SASSA offices well before they opened so as to ensure that their application would be processed that day:

"The problem is that you have to get up at the crack of dawn to queue. If you're not there by 8am, well in front in the queue, then the day will end without getting any help." (Butterworth, FG25)

In three of the focus groups, women mentioned sleeping in the queues, either arriving the night before or arriving before dawn:

Respondent 6: We sleep in the queue. That's how long the queue for applications are. Respondent 7: We come at 8pm the night before SASSA comes. Sleep in the queue, still, it doesn't mean you'll get the help you need. They'll help 20 that day. You can repeat the same arduous process 3 times.

Respondent 5: You feel like you're losing your mind, it's mad. (Paarl, FG28)

"We shouldn't have to queue up at 4am in order to register for the grant and still get rudely turned away after having risked our safety." (Khayelitsha, FG5)

"When you're there to get application forms, you start queuing at the crack of dawn, for hours. They open, they'll chat and have their tea while you continue to wait. It's 
not right. They say there's no need for us to go and sleep there. But we have to, you see. We can't be there the whole day, we have things to do at home. If you are there the whole day you have to ask people for food too. But if you sleep, you forget about the hunger. They don't care that we are also human beings." (Nyanga, FG1)

The sheer fact of having to queue for long periods is presented as something that erodes dignity, as it conveys the impression to the CSG applicants that SASSA does not consider them or their time to be important and as such this is detrimental to women's sense of worthiness. Queuing was also described as stigmatising:

"Everybody can see that you're poor when you go and queue up for the grant. It's stigmatising." (Khayelitsha, FG5)

Additionally in the urban townships of Langa, Nyanga and Khayelitsha, women spoke of how they felt in physical danger having to travel and queue in the dark:

"It's incredibly difficult to register for the grant. You have to get up when it's still dark, at 3am, and walk in the dark and queue in the dark too. If you don't have everything that's required, you can go through the same process 3 times like I did. So it ends up being dangerous too." (Langa, FG8)

"The worst is when you're going to register for the grant, you have to get up at 2am to go and queue by $4 \mathrm{am}$. It's incredibly dangerous. Some people sleep there overnight and become victims of rape." (Nyanga, FG2)

"When we go and register for the grant we have to leave home at 3 or 4 am. Criminals, rapists are everywhere at that time. They know exactly where to stand to find a vulnerable woman. It injures our sense of dignity because we have to go and register for the grant, we're hungry and desperate." (Khayelitsha, FG5)

\subsubsection{Burdensome and unclear qualifying criteria}

The 1995 White Paper on the Transformation of the Public Service required national and provincial government to develop 'a culture of customer care and of approaches to service delivery that are sensitive to issues of race, gender and disability.' (RSA, 1997: 11). This was further developed in the White Paper on Transforming Public Service Delivery, referred to as the Batho Pele White Paper (RSA, 1997). ${ }^{61}$ As part of the Introduction to this paper it is acknowledged that:

\footnotetext{
${ }^{61}$ Batho Pele means 'People first'.
} 
"Lack of information and complex regulations are also barriers to good service. Too often it is left to the citizen to work out for him- or herself what services are available, and what he or she is entitled to. Too many government forms are complicated and not designed with the user in mind. Too many letters are written in a stilted, impersonal style which is off-putting to the person who receives it. Finding the right person to speak to in a national or provincial department, particularly someone who can give friendly advice can be very trying, leaving the citizen feeling helpless, frustrated and uncertain." (RSA, 1997: 14).

In a section on 'Providing more and better information' the 1997 White Paper states:

"Information is one of the most powerful tools at the customer's $\mathrm{s}^{62}$ disposal in exercising his or her right to good service. National and provincial departments must provide accurate and up-to-date information about the services they provide, and who is entitled to them." (RSA, 1997: 19, original emphasis).

DSD and SASSA have undertaken large numbers of awareness raising exercises to promote the take-up of the grants. Publicity has been particularly prominent during the reregistration period which was implemented to reduce fraud. The grants are promoted on billboards, as special advertisements on television and the radio, and in newspapers. Each of the grants is described in detail on the SASSA website (e.g.

http://www.sassa.gov.za/index.php/social-grants/child-support-grant) and each grant has a booklet that can be downloaded in each of the 11 official languages (e.g.

http://www.sassa.gov.za/index.php/knowledge-centre/grant-booklets). However, it seems that there is still a need for further improvement, based on the accounts from the focus groups.

When asked about how the CSG application process intersects with their sense of dignity, a large number of women raised the issue of the lack of clarity about the qualifying criteria for the grant and the great lengths that they have to go to to provide the necessary documentation. Participants reported that they felt they did not possess sufficiently clear information - prior to going to the SASSSA office to make the application - about which supporting documents they should bring with them. This meant that, after what was often a long wait in a queue, people were often turned away and told to return with additional information, sometimes on multiple occasions, making the application process much more costly in terms of time and in many cases travel costs. The point was repeatedly made that this was detrimental to the applicants' sense of dignity. For example:

Respondent 1: I just don't like the fact that the officials, when you're applying for the CSG send you back and forth, tell you that this or that is missing, come back next time. Why don't they just tell us what is needed once and for all.

\footnotetext{
${ }^{62}$ It is explained earlier in the document that 'customer' and 'citizen' are used interchangeably.
} 
Respondent 4: Yes, and it's costly, very costly going back and forth.

Respondent 7: We wake up early and come and queue the whole day, carrying babies sometimes, it's not right. (Mbekweni, FG27)

"It takes away my dignity."

Facilitator: How so, could you say a bit more?

"When I go to SASSA officials with my ID photo copied, letter from community leaders, affidavit is there, they'll still say something is missing or written incorrectly so that you don't finish in one day, you can even take 3 days applying for the grant." (Alice, FG21)

It's up and down, up and down, going to previous places of employment to fill in forms, you have to go for affidavits... you have to put your dignity aside." (Mitchells Plain, FG9)

"When I went to register for my children to get the grant, to apply for it, I was told to go back and make an affidavit regarding my situation. I had borrowed money from my neighbour and queued for hours before being attended to. When I brought the affidavit the next time, I was told something else is missing. I was not treated with dignity at all, no respect." (Qumrha, FG15)

"To apply for the grant erodes my dignity. First of all, I have to borrow money to go and apply for it, I get there and I'm told this or that is missing I must come back another day when I have those things. Back and forth, I go, with what money? Borrowing over and over again." (Butterworth, FG25)

"When I went to re apply for my child's grant, it took 4 days, 4 times. I wasn't told I have to go to the child's school for proof and also go to the street committee for the stamp - so my dignity was definitely eroded." (Khayelitsha, FG4)

"You are sent from pillar to post, all the while you are starving, hunger written all over your face, where's the dignity in that." (Khayelitsha, FG5)

A woman in Qumrha described that her experience was that the SASSA officials not only provided incomplete information but also applied rules inconsistently:

"It wouldn't be so bad if one got to the SASSA offices and was treated with respect and given the information in a dignified way. What bothers me is, you get to the offices in Qumrha and are told - 'sisi, you are not even meant to be in this town, go to the Bisho offices'. They say this, you are hungry, you borrowed money in order to get to SASSA in Qumrha. The CSG gets finished at the SASSA gates because you 
borrow money for this, money for that. SASSA repeatedly gives us incomplete information each time we're there so that you find yourself going back and forth like an idiot. There's also a problem of inconsistency with SASSA, I can have exactly the same documents as my neighbour but she'll get the grant and I won't, that's a problem because you never know what it is they want from you. Bit by bit, your dignity diminishes." (Qumrha, FG15)

A related point, on rules perceived as being applied inconsistently, was made in Nyanga. Four women spoke of how they felt they had to lie in order to guarantee that their application would be successful - even though if they told the truth they thought they would still be eligible - and that this eroded their dignity. The women were concerned that if they revealed any income at all the grant would be refused, and if they disclosed that they had previously had a job they would be required to provide evidence that they could never obtain:

Respondent 6: We have to lie, if you are honest and say you have piece jobs they take your grant.

Respondent 7: Even if the father of the child helps from time to time, you have to lie and say he isn't, otherwise you lose the grant.

Respondent 4: They ask you if you have ever worked, if you say yes, for example I was a domestic worker, SASSA tells you to get a document from your former employer, they don't care whether they have moved, which was the case for me. My employers moved abroad. It took very long, you end up being forced to lie.

Respondent 3: It erodes our dignity. I had to lie and say the father of my child deserted us because one girl said she gets R200 from the father and she was turned back. She couldn't get the grant. (Nyanga, FG2)

Similarly in Langa a woman spoke - in general terms - of having to lie in the context of being unable to access (or obtain material support from) the father of the child:

"It seems as if the only way of ever getting the money is by telling lies and say the father is dead, or a foreigner who went back home to his country. All of these lies because you can't go looking for the father who is either in jail, unemployed or wants nothing to do with you" (Respondents agree) (Langa, FG7)

\subsubsection{Not being treated with respect}

In Chapter 4 we gave examples of the importance accorded by lone mothers to being treated with respect. There is a commitment within government to treat people with respect. For example, in the foreword of the White Paper on Transforming Public Service Delivery it is stated that: 
"Public servants are expected to treat all citizens with courtesy, respect and dignity." (RSA, 1997: 5).

This is further elaborated in the Paper in a section entitled 'Ensuring courtesy':

"The concept of courtesy goes much wider than asking public servants to give a polite smile and to say 'please' and 'thank you', though these are certainly required. The Code of Conduct for Public Servants issued by the Public Service Commission, makes it clear that courtesy and regard for the public is one of the fundamental duties of public servants, by specifying that public servants treat members of the public "as customers who are entitled to receive the highest standards of service". Many public servants do this instinctively; they joined the public service precisely because they have a genuine desire to serve the public. The Principles of Batho Pele require that the behaviour of all public servants is raised to the level of the best." (RSA, 1997: 18).

More recently the Department of Social Development has produced a Customer Service Charter (DSD, 2013). Amongst other things, the Charter states that people have the right to be treated with dignity in adequate conditions, and to expect friendly and helpful service from respectful, responsible and competent officials.

Many women made the point that the application process was detrimental to their sense of dignity as they were not treated with respect by officials. ${ }^{63}$ For example:

"Well, for example, when you apply for the grant, the SASSA people talk to you any which way they want, it's insulting. This happens so often that if you're not strong, you'll fall apart. If you're going to let your dignity depend on them, you'll fall apart." (Dimbaza, FG17)

"The minute you step your foot there, your dignity is thrown to the ground. Even when you're ill you're treated badly."

\&

"It affects our dignity. They are rude to us, the welfare officers, in front of everyone they'll ridicule you. Maybe it would be better if nobody else could hear." (Nyanga, FG1)

In two of the focus groups reference was made to the way in which SASSA officials behaved as though the grant payments came from their own pockets:

${ }^{63}$ Goldblatt et al. (2006) also report on issues around poor conduct of officials (p14). 
"It takes away our dignity, people from SASSA, they don't respect us. Even if people from SASSA were here, I would tell them the same. They do not know how to talk to people as human beings. They treat us like we're begging for that money, like it's theirs." (Khayelitsha, FG4)

Respondent 4: They tell you it's their tax money, and these are the people who are supposed to be helping and serving you.

Respondent 2: They don't treat us with respect, it would help if they treated us with respect.

Respondent 6: The queue's are long, you have to get up very early, sometimes it's dark, in order to apply. You get there and queue for hours and hours. When you finally get help, the SASSA officials are fed up, it's as if these grants, it's their money. Respondent 3: They ask you questions you simply cannot answer. There's no dignity at all sisi because you're practically begging for the grant. (Butterworth, FG24)

In this respect, as will be discussed further in the concluding chapter, such behaviour serves as an example of social security not being regarded as a social right, nor as a form of social solidarity by the officials. A woman from Langa spoke out in anger about her experience:

"As a public servant you should respect people, they don't even greet us, they just don't care, it's as if they are passing wild animals, they are lazy and incompetent and others are not even qualified for the positions that they are in; others have issues about serving black people even though they are also black... I don't know." (Langa, FG7)

A number of women made the point that they feel unable to defend themselves by challenging the behaviour of the people administering their applications as this might prejudice their application. For example:

"The government officials, they say all sorts of rude things because they know you need the money, you can't do otherwise." (Langa, FG8)

"Well we are basically 'lower' than the people in SASSA, we are below them so they speak anyhow to us. I've experienced that many times but there's nothing I can do because I'm begging for the grant." (Thafalofefe, FG22)

In another focus group in Langa, women were asked if they felt able to defend themselves and replied as follows:

Respondent 3: No you can't, you just can't because we need the grant, we don't want to have difficulty in getting the grant or lose it because we stood up for ourselves. 
Respondent 2: They take note of you, they see who you are and make things difficult. You have to take whatever they dish out with the grant.

Respondent 5: Or they refuse to help you altogether because they tell their colleagues about you, that you think you are better. (Langa, FG6)

Some women spoke of having to be overly deferential to people who did not treat them with respect:

"as the applicant you have to be respectful even though you don't get the respect back because you are in desperate need of the grant, you practically beg and call a consultant who maybe younger than you, with titles like sisi/bhuti, that is desperation."

Facilitator: I see, does that impact on your sense of dignity?

"It does, yes it lowers your dignity." (Langa, FG7)

"They confuse you. And you have to be the least, because you are relying on them for the money. Because if they tell you it's blue and you know it's green, then you have to agree with them and say it's blue. Do you understand? [m] It seems as if the money belongs to them." (Mitchells Plain, FG9)

These examples serve to demonstrate the misuse of power by officials. Far from being public servants adhering to the principles of Batho Pele, the impression is given of them treating applicants as unworthy supplicants.

An important general feature of perceived lack of respect was the absence of consideration for the women's circumstances. Examples given included lack of consideration for the fact that they had had to queue, were tired and hungry:

"Like I say, they don't care if you came in 5am or you sitting there since 4am... How you came there, they don't care. And the way they sometimes speak to us...is like we are nothing. It's almost like they are giving you the money.' (Mitchells Plain, FG13)

"At times they will say they are on lunch, while you woke up early in the morning, on a 6 o'clock bus and you haven't even had lunch." (Alice, FG21)

"We come here because of the pain of hunger at home, not because we want to. We are desperate. Why then is there no compassion as SASSA? Why do they treat us any which way they want?" (Mbekweni, FG27)

"Even when you can't sign the staff look at each other and laugh at you because you do not have a million dollar signature." (Langa, FG7) 


\subsubsection{Pejorative comments from officials}

As well as making general points about being treated without respect, a large number of women gave accounts of receiving pejorative comments in relation to their caregiver or parental or lone parent status.

"From queuing for hours someone still asks you how you can have 3 children without a husband? You can imagine the humiliation." (Butterworth, FG24)

"They asked me how come we always get abandoned by the fathers of our children?" (Nyanga, FG2)

"All they are good at is asking where your baby's father is, he is the one who should be taking care of the child. When you tell them he left and wants nothing to do with neither you or the baby, they tell you to go look for him. They treat us unfairly." (Langa, FG7)

In spite of research that dismisses a link between the introduction of the CSG and teenage fertility rates (Makiwane et al., 2006) there is an ongoing and vibrant discourse within communities and the media that reinforces the notion of there being a link between CSG and choices about reproduction, fostering rumours that women become pregnant in order to receive the CSG as an income stream (see Goldblatt, 2005). Some women described how they were accused by officials of becoming pregnant in order to receive the grant ${ }^{64}$ :

"It's very bad, there's no dignity there, at least for us. People from SASSA will tell you that you become pregnant for the grant, they ask you where the father of the child is?" (Khayelitsha, FG3)

"They swear at us, the government officials, they say we have children to get the grant. We sit there until we get it, we have no choice." (Nyanga, FG2)

"And it's so common that when officials talk to us, the people that register us for the grant, they keep saying that we get pregnant on purpose just to get the grant. They don't realise you can get pregnant by mistake and repeat the same mistake of being pregnant without planning, again. It does and can happen to anyone. I mean, R270, how can anyone fall pregnant for that little money. (Langa, FG6)

Another woman described how the officials said that she was having children for government:

${ }^{64}$ This issue was also identified in a study by Goldblatt (2005). 
"One of the things that affect my dignity the most are the officials from SASSA. When you register, they say all sorts of things. They told me I have children for the government, I give birth for government." (Butterworth, FG24)

Two rural women described how the officials accused them of being too young to have a child:

"Registering for the grant is a problem. The SASSA lady told me a whole lot of nonsense, said I'm too young, why do I have a child. I mean, how is it any of her business? Their attitude stinks and offends our sense of dignity sisi." (Xesi, FG18)

"Sometimes people at SASSA are very rude to us younger mothers. They don't even know how your child came about, some of us were raped walking to school in the rain. Now to have somebody from SASSA saying you're too young to have a child...." (respondent tapers off with emotion).(Butterworth, FG25)

"And now you don't understand them properly, then they say 'don't you listen' then they want to shout at you and belittle you. You can't swear them out. They ask you 'now where's the father, now why don't you go for maintenance, why do you come here and this and that, why don't you report him'. Like that that's how they go on with you....You won't be standing here, if you didn't need it." (Lavender Hill, FG11).

A woman in Xesi described how her application for a second CSG (as caregiver for her sister's child) was refused as the official thought that two CSGs would be too much money:

"Well, you see I look after my sister's child, my sister is in PE. We decided that the grant would come to me, my niece's grant. I have my own child too. When I went to change it the people at SASSA asked what am going to do with 2 CSG's, why don't I just leave it, meanwhile the child lives with me. They just refused." (Xesi, FG19)

In two of the focus groups women spoke about how they experienced intimidation or derogatory treatment when obtaining affidavits at the police station as part of the CSG application process ${ }^{65}$ :

"And if you go to the police station, they intimidate you, they tell you what's on their mind and what's right according to them. It affects you and you ask Lord, why must I go through this process. At the end of the day, you have no choice and are forced to

\footnotetext{
${ }^{65}$ Goldblatt et al. note that applicants do not need to obtain an affidavit from a police station as there are other groups (e.g. public service officers at minimum salary scale level 2 ) who can do this. They found that police involvement was a problematic feature of the CSG administration because 'police time is wasted; police often record the information incorrectly; police are unhelpful; people have to travel to a police station as an added step in the application, which adds time, money and inconvenience to the process.' (p15).
} 
be here for your kids. The application process affects you. It affects you a lot." (Ocean View, FG12).

"And you will go get this affidavit, when you are in the police station they will ask what it is for and when you say it's for the CSG, they'll pass funny remarks like 'you're so old for the grant, you're getting it for you grandchildren'. There is no dignity there." (Alice, FG21)

\subsubsection{Deferring application - an unaffordable option for most}

Three coloured women from areas in the Western Cape described their decisions to defer applying for CSG. A woman in Mitchells Plain described how she walked out of the office when she first went to apply for the CSG as the official was behaving as thought the CSG for which she was applying was her own money (see also section 7.2.3 on being treated without respect):

"The first time, I walked out." Interviewer: Walked out?

"Yes. So I asked the woman at the office, is it her personal money that she is giving to my child, because I feel, the way she was behaving that the money belongs to her. So I said to her, my mother and father also pays tax, and if I work in the retail weekends or whatever, then I also pay tax. Which means I can also receive this money... it is not your money. It's the government's money." (Mitchells Plain, FG9)

A woman from Lavender Hill described how she found the application process for her first child so unpleasant that she has deferred applying for her second child:

"I also have two children and I only get a grant for the one child. And that's the reason why I don't want to go again for the other child because the process is not pleasant. I am going to feel hurt and I am also going to feel shy if I must stand there." (Lavender Hill, FG11).

A woman from Ocean View stated that she waited two years before going through the application process and how she had to 'put her pride in her pocket':

"I had to put my pride in my pocket and I came for the grant. Not for me, but for my child." (Ocean View, FG12).

For many, however, deferral was not an option that they could afford and instead they went to apply as soon as they could. Two women from Thafalofefe spoke of the treatment that 
they received when they applied for the CSG when their children were one week old and three days old respectively:

"The official there was shocked, said I couldn't even wait for the child to be 3 months old before I apply ${ }^{66}$. My question is, what would my child be eating in the meantime? So I asked to tell me the exact age when I can apply for the grant."

Facilitator: What did she say?

"She said since I was already there, she would do it for me. I felt like she was doing me a huge favour." (Thafalofefe, FG22)

"Three days after my baby was born I already had a birth certificate. I went to Centani to apply for the grant." Facilitator: Did you feel strong enough to travel and go through the process? "No, of course not, but there was a greater need at home than my health, my baby. I was in great pain just travelling there in the taxi because the roads are very bad here, bumpy. My breasts were sore as well because they were full. I did not feel well at all. Still that lady there was very rude and wanted to send me back and forth. Fortunately a man, also at SASSA came to my rescue, even reprimanded that lady." (Thafalofefe, FG22)

\subsubsection{Collecting the Child Support Grant: focus group interviews ${ }^{67}$}

Far fewer issues were raised by the focus group participants - positive or negative - about the intersection between their sense of dignity and the process of collecting the CSG, than about the application process. In some focus groups (e.g. Masiphumelele, FG30; Langa, FG8) participants said they had no issues to raise about the process.

Focus group participants raised issues about queues (Mitchells Plain FG9, Lavender Hill FG11, Xesi FG18), fights in queues (Dimbaza FG16, Khayelitsha FG5), and officials speaking roughly, overly loudly or pejoratively (Thafalofefe FG22, Khayelitsha FG3). For example:

"It's just the endless queuing that I find humiliating." (Xesi, FG18)

"They speak so loud as well when they are being rude, the entire hall can hear and people look at you, speaking amongst themselves about you when you leave." (Thafalofefe, FG22)

\footnotetext{
${ }^{66}$ Delany et al (2008) refer to a cultural tradition whereby children should remain at home until they have reached the age of one or three months (p48). It may be that the official was expressing shock for this reason. ${ }^{67}$ During the fieldwork phase the grant payment system changed, with the introduction of a payment card, so most of the material relates to the situation prior to the change.
} 
Perhaps because of the regularity of the payment process - as a monthly activity rather than a once-off process for the application - there was more mention of the issue of public scrutiny.

"If you go to town at the beginning of the month, the first or the third, people always remark that "oh, you're going to get the grant again". It's demeaning and it affects my sense of dignity negatively." (Butterworth, FG26)

"everyone can see that you are getting the grant."

\&

"Same applies if you are getting the grant from the bank, you will still stand in the queue. Unless you are going to wait until the grant dates are over, but you can't because the child is hungry." (Alice, FG20)

"It affects me a lot because if you come here to All-pay all the people stare at you. I didn't know where to look. But I said to myself that we are all here for one reason. [m] I must just keep my head up high and also stare back at them. [m]. I thought that coming earlier I will be quicker helped.... I woke up at 5:30am to be early here, but it's the same as when I came later." (Ocean View, FG12)

"A person stands in the queue and people walk pass you and then they say aloud you are standing in the queue for All-pay and all that stuff saying we don't deserve it." (Lavender Hill, FG10)

“For me, it's like a smack in my face because who's gonna see me. Like you want to hide away. And also, it's not a private thing and it's also not safe to stand and go and fetch this money because there's always little crimaltjies ['Criminals'] that's standing around waiting sometimes to rob you also from your children's money. It's not safe." (Mitchells Plain, FG13)

In Dimbaza, focus group participants spoke of the way in which they were not treated well by SASSA officials when renewing their grant:

Respondent 2: Having to renew the grant is terrible, it's a bad experience, we are not treated with respect or dignity by SASSA.

Respondent 1: Some people are illiterate, they suffer more because they are not assisted adequately, so they go back and forth with money they don't have. Respondents: There is no dignity in the process, sisi (Dimbaza, FG17) 
Whilst in Paarl, there were clearly major problems at the time of the focus group with the new SASSA card payment system with a number of issues raised including money within the system that cannot be accessed, being told to go to different shops to see if the money can be accessed there (payment didn't work at Shoprite so told to try at Edgars), confusion over payment dates, payment of varying amounts, shops requiring people to make purchases before being entitled to the grant (Shoprite and Pep). One woman said she much preferred 'Allpay' (receipt of the CSG at a paypoint):

"With Allpay we would come and get the whole amount, I would be the one choosing what and when I use or do with the money, not Shoprite. This card system is a problem." (Paarl, FG28)

Shops are not allowed to require recipients to purchase items at the shop and so as the card system becomes more established these practices should be stop. It will be important however to explore recipients' views about their experiences of having the card.

\subsection{Lone mothers' experiences of applying for and collecting the CSG and its impact on dignity: the in-depth interviews}

In this section lone mothers' experience of applying for and collecting the CSG and its impact on their dignity is considered with reference to the in-depth interviews. It is examined specifically in relation to their interaction with state-based actors. In other words this section examines dignity in relation to the bureaucratic process of CSG application and receipt, and the interactions with officials and pay point personnel.

Experiences of claiming and collecting the CSG varied quite widely within the small sample of informants who participated in the in-depth interviews. Although there were some notable exceptions, several lone mother recipients described the process as being relatively unproblematic, and with little adverse effect on their dignity. In contrast, a sizeable minority ${ }^{68}$ described aspects of grant application or receipt as being difficult. It was often described as onerous and inconvenient. Within this group who experienced difficulties receiving the grant, a smaller sub-group described the process of grant application and receipt as disrespectful, undignified or dignity-erosive. Impressionistically, informants appeared to describe the community-level gossip or social opprobrium as more trenchant, than the comparable kinds of responses from officials and pay-point personnel. But a caveat must be sounded. Within an in-depth, qualitative inquiry with a small sample it is analytically perilous to attempt to extrapolate the prevalence of a phenomenon. Instead this aspect of the study seeks to understand the determinants and complexity of underlying dynamics. Before this can be done and the evidence presented, three points need to be made.

${ }^{68}$ Approximately half a dozen. 
The first point is that a firm distinction ought to be made between the process of applying for a CSG and the process of monthly grant collection (particularly from a cash pay point). For many informants their original application may have been made several years previously, whereas monthly collection was often more salient and better recollected by many, particularly if they found it dignity impairing. Despite this several informants described the process of initially applying for the CSG as administratively onerous and inconvenient, but for others the recurrent process of monthly collection was reportedly adverse. Informant Zimkita plausibly found receiving her grant in her bank account less onerous that queuing for it monthly, but the sample was overwhelmingly biased towards those that collected the CSG at a pay-point. How these experiences come to interface with informant's sense of dignity, requires careful consideration.

The second point is that it is useful to think of the grant receipt process as involving both human and systemic factors. In response to open-ended questioning about grant receipt, some informants cast it in terms of the quality of the interpersonal interactions with officials and pay-point staff. Other informants described more general, systemic issues (such as onerously early starts, or long queues) that are irreducible the quality of their interpersonal interactions with individual staff. Although both impact on dignity, it is of analytic utility to bear this distinction between interpersonal interactions and systemic issues in mind.

Thirdly and finally, understanding the dynamics concerning CSG application, and receipt and dignity evokes a subtle methodological difficulty. It concerns the normative yardstick by which informants make sense of bureaucratic processes more generally. Quite simply for many impoverished recipients, forms of rudeness, brusqueness and mild indignity may be a familiar feature of their engagement with 'street level bureaucrats'. After all, officials indifference and disrespect are not unknown elsewhere in the frontlines of the state's service delivery, such as health care and education facilities. So while receipt of the CSG might be marked by interactions that are less-than-respectful ${ }^{69}$ or undignified, these may not necessarily be immediately cast as such by informants, particularly if this was not directly elicited. In other words, impoverished and marginalized social assistance recipients' adverse interactions with state functionaries may be relatively common to some extent. Consequently several informants focused on the pragmatic difficulties and inconvenience of application and receipt, but in contrast to the focus groups (where perhaps the presence of others with similar experiences made it easier to articulate such concerns), few informants spontaneously readily cast this in terms of an affront to their dignity. It was just the mundane bureaucratic reality with which they stoically engaged. ${ }^{70}$

In terms of the empirical material, for many of the lone mother informants the processes of CSG application were relatively unproblematic:

\footnotetext{
69 Particularly to a middle class observers who seldom interact with the frontlines of state services.

70 Methodologically, this is a level of interpretation that may be more adeptly accessed by forms of qualitative research that use forms of intersubjective enquiry, such as focus groups.
} 
Extract 10

Informant Spamandla

S.M: Did you struggle when you were applying for the grant or just applied and got it? Spamandla: I did not struggle I went to submit my forms and I got the grant after 3 months.

\section{Extract 11}

Informant Yamkela

Yamkela: No I did not get any difficulties

S.M: How long did the process of applying for the grant take?

Yamkela: It took only one month and I got it in the third month. I didn't go to Social Development offices several times, I went there once and I got the grant on the third month, when I went there I already had the letter from the Ward Councillor and the school letter.

These experiences might be contrasted with experiences which the informants described as difficult or onerous. These included early morning queues:

\section{Extract 12}

\section{Informant Ketiwe}

D.N: Okay was it difficult or easy to get the grant did you have to go back? Ketiwe: It was difficult...

D.N: It was difficult, why was it difficult?

Ketiwe: Because when you go there you have to wake up early in the morning past 3 [am] D.N: Past 3[am]!

Ketiwe: Yes, there are a lot of people in the queue for the grant.

Note too the very specific conundrum early morning queuing for CSG application invokes for post-partum biological mothers. If application is made for the CSG soon after birth, the beneficiary child is a neonate (almost invariably breastfeeding), the child therefore needs to accompany its mother in the early morning hours when both security, the dearth of transport and (particularly in winter) climatic conditions make it difficult to do so. Informant Ketiwe, further encumbered by the demands of post-surgery recuperation, explained the four-month delay between the birth of her child and her CSG application thus: 


\section{Extract 13}

Informant Ketiwe

Ketiwe: Because I gave birth by scissor [caesarean section] so I stayed until I was okay and I applied in July.

Elsewhere, informant Ayanda account echoes on these difficulties, she encounters Social Development officials, who exclude her because they claim their quota has been reached (which may or may not have been the case - but her perceptions are noteworthy).

\section{Extract 14}

D.N: You could have applied when she [the beneficiary child] was much younger, why did the grant only start at 6 months?

Ayanda: I had a difficult time there at Social Workers [Social Development] when I go they will say its full they take this fixed number so I gave up

D.N: The office [allocation] is full?

Ayanda: Yes but sometimes its full, sometimes they don't want to work...

D.N: Okay, and at that stage you were carrying the baby with you because it was too small to leave at home?

Ayanda: Yes

D.N: Okay, you went there and they said its full, you kind of gave up and you went back again?

Ayanda: Yes

Already alluded to, for informant Zimkita, the general adversity of grant collection induced her to switch to having the CSG paid into her bank account

\section{Extract 15}

DN: So you applied for it to go into your bank account?

Zimkita: Yes, because of the queues, we had to queue from 5 o'clock in the morning and get your money at 4 o'clock in the afternoon because of the long queues.

Finally, the onerous long or early morning queues were reported several times, informants generally did not necessarily describe officials as disrespectful or rude. There was therefore a more limited sense, on the part of respondents, of the erosion of dignity in relation to the interpersonal interaction with officials.

Informant Ondela, below was a notable exception. Loquaciously and socially confident, note too her reported retort to the official ('I don't care'). This was one of the few examples of interpersonal rather than systemic slights on dignity. 


\section{Extract 16}

DN: Ja, and how did you feel when you applied for the grant? Were the officials... polite, efficient, rude, or was it just fine?

Ondela: No, there was a rude lady there [an official] because I didn't go there at 8 am or 9 am, I went there after lunch because it was quiet, the hall was not full, and then she said to me 'why are you coming at this time?'. I said it's because I only got a chance now, and then she said 'we almost finished'. I said 'no, its fine, I don't care!'.

More prominent were informants who described the process of application as arduous, and readily attributed this to administrative and systemic factors. This is not unknown in the literature (Goldblatt, 2005; Hall, 2007) These experiences could readily be understood as dignity-erosive. These included:

Informant Ketiwe Being required to bring a letter from the farmer that previously employed her in low paid, seasonal agricultural labour (fruit picking) to attest to the fact that she was no longer employed. This despite the fact that fruit picking is highly seasonal, and some of the lowest-paid and most insecure of work.

Informant Ayanda: (Albeit in order to secure a Foster Care, rather the Child Support Grant) was directed to secure documentary proof that the absent father of her deceased sister's children was in fact dead.

These two examples are consistent with the focus group interview findings of burdensome and unclear qualifying criteria.

Finally in understanding processes of grant receipt it is useful to examine accounts of late or delayed receipt. The three extracts presented in what follows illustrate delays in the process of grant receipt. These include examples where the demands of employment, larger social constraints and ancillary bureaucratic difficulties (particularly in relation to Home Affairs) leading to late CSG application and receipt. These suggest some of the ways in which cases of delayed GSG receipt are not solely caused by issues related to the process of grant application and receipt.

\section{Extract 17}

Informant Akona (described below in Case Study Vignette 10), served a year long internship as a clerk in a government department receiving a monthly stipend of R2400. She applied for a CSG for her child in this time but her application was apparently rejected. Informant Akona explained:

Akona: They said because I'm under government and I sent the amount that I'm earning is not that much, they said as long as you are under government [i.e. employed by the state] you won't get it. 
Her application was therefore reportedly rejected because she was on Persal (the state employees payroll system), for a period 12 months. Once her internship came to an end, she successfully applied for the CSG.

\section{Case Study Vignette 5}

Informant Owami explained how her grandson was three years old before they successfully secured a CSG for him. She explained her daughter was 'naughty' (wayward and misbehaving) as a teenager. Informant Owamiwas not able to apply for a CSG because her grandson's birth had never been registered, so he did not have the requisite birth certificate. This difficulty was further compounded by the fact that his mother (the informant's daughter) had lost her own Identity book. Applying for a CSG therefore required engaging with the preceding steps of reissuing an identity book for her daughter, before applying for a birth certificate for her grandson.

However on applying for the Identity book it emerged the daughter had successfully and changed her forename (to an English name) without the informant's knowledge. More significantly, the daughter's application had seen her processed as a new applicant, and she been accorded a new identity number (although it is unclear, being treated as a 'first time' Identity Document applicant would have spared the daughter a fee). However this duplication meant the entry on the population registration system did not match her daughter's name on her existing birth certificate. This mismatch, and the regulatory prohibition on an individual holding two identity numbers, required an eight month long wait for a query (doubtlessly to the Population Register officials) at Home Affairs in Pretoria. When a reply, and a summoning to the local Home Affairs office finally came, the informant's daughter had left home and was living with elsewhere with her boyfriend. Eventually they made a return visit to Home Affairs, where the informant's daughter was required to select a single name (and identity). With this, the process of having the identity book reissued commenced (Home Affairs had, quite plausibly, invalidated both identity details). Only once reissued, could application be made for the grandchild's birth certificate, and finally the CSG. In this way CSG application required range of preceding administrative steps, which cumulatively introduced a substantial delay.

Finally the case study vignette below of informant Siphesande's account of grant application and receipt that follows, illustrates the interaction between bureaucratic constraints, and the contingency within applicant's lives. 


\section{Case Study Vignette 6}

Informant Siphesande was also the subject of Case Study Vignette 4. Informant

Siphesande's mother had been collecting the CSG for her child since 2003, as she (informant Siphesande) did not have an Identity Book, however when her mother secured a job she terminated the CSG. The informant therefore secured a CSG for her daughter who was several years old already. When the informant moved to the Western Cape from the Eastern Cape she did not believe it possible to transfer her child's CSG to her new province of residence ${ }^{71}$, nor could she make quarterly trips to the Easter Cape to collect it:

Siphesande: She was getting it in Eastern Cape so I decided to just leave it like that so that they stop it, I was reluctant to travel to Eastern Cape and it's when I was already working as a security guard so I did not have days off work.

Siphesande: Yes that's why I didn't want to go to Eastern Cape just for fingerprints [collect the CSG in cash using a biometric scan] I decided to leave it so that they stop it and I reapply.

[She therefore allowed the CSG to lapse with the intention of reapplying for it. However there was a hiatus of almost a year before she reapplied.]

Siphesande: I got the job as a security officer so the people that were doing the grant were only coming on Thursday say, I couldn't do it because at 3 or $2 \mathrm{~h} 30 \mathrm{I} \mathrm{had} \mathrm{to} \mathrm{leave} \mathrm{for} \mathrm{work,} \mathrm{I}$ couldn't do it.

The informant was reportedly unable to reconcile her work commitments with finding an opportunity for CSG application. She subsequently did apply for her older child, but at the time of the interview (2012) had not yet applied for a CSG for her young infant. In light of the contestation over the infant's surname and the future conjugal bond with the child's Nigerian father (discussed in detail in Case Study Vignette 4), it was far from apparent that this issue would be resolved in the near future.

This vignette (Case Study Vignette 6, above) suggests some of the wide determinants on the actual experience of claiming and receiving the CSG. The informant's experiences were influenced both by the social welfare system and a range of factors outside of it. In her account, the relative rigidities of the welfare payment system such as its provincialised nature, difficulties in transferring the grant, small temporal windows for making application, were all cumulative difficulties especially against the backdrop of widespread internal migration and insecure employment. However these dynamics of social grant claiming and receipt where also embedded in range of 'extra-bureaucratic' issues and constraints. In this

\footnotetext{
${ }^{71}$ Whether it is possible or easy to reregister the CSG in another province is less significant here than the recipient's belief that it was not feasible.
} 
particular case contestation surrounding the conjugal relationship and acknowledging the child's paternity (discussed in relation to Case Study Vignette 4) compounded the pragmatic difficulties in accessing the grant.

\subsection{Dignity and social security policy implementation: the elite interviews}

Many of the issues highlighted in this chapter were raised by contributors to the elite interviews. The contributors were asked to comment on the extent to which dignity is taken into account in terms of the implementation of social security policy. Many highlighted the important role of dignity in social security policy implementation. For example:

\footnotetext{
“Dignity plays a very important role. Social security and in particular social assistance, being a right that at present is only exercised by the poor and vulnerable sections of our society has always meant to us that the means by which they access these benefits must be part and parcel of the policy intent to restore the dignity of our people. What that means then is that we in fact designed our processes in such a way that it is by and large trained personnel that entertains applications from applicants. Many who are unable to complete these forms all by themselves are assisted by people who can do so, in the language they understand and speak best, so that they are able to open up on matters that are entirely personal. Matters such as whether or not they have any other source of income and if so how much it is, and the like, or the lack of it." (Mr V. Madonsela, Former Director General of the national Department of Social Development)
}

Another contributor highlighted the way in which 'customer care' is taken seriously:

"So when planning for implementation the issue of dignity, the issue of respect, the issue of creating an environment that is conducive and pleasant really, that it becomes a positive experience, is really there. The Department of Social Development working with SASSA currently speaking, we are engaged and involved in improving what we call 'customer care' which is really the experience when citizens interface with the Department of Social Development, be it SASSA be it welfare services or whatever." (Dr W. Magasela, Deputy Director General (Social Policy), national Department of Social Development)

Several mentioned the recent drive to refurbish and build new offices for SASSA, to ensure that they are better designed to allow privacy and respect for dignity. 
While all spoke of the growing consideration within government of the need to respect people's dignity when providing social security, several examples were given of dignity being compromised, echoing earlier findings in this chapter. For example, in relation to queuing:

'The amount of queuing up, and the risk of the queues being cut, only to return the next day, could make people feel that they are beggars for assistance.' (Mr V. Madonsela, Former Director General of the national Department of Social Development)

Another contributor (from SASSA) highlighted that the application process still has its challenges. Although completed applications now have a turnaround time of 21 days, an applicant may still need to visit the SASSA three or four times in order to be screened for the application, and so the shortening length of time between completion of an application and award, though welcome and important, disguises the fact that there is often a lengthy period from initial contact by the applicant to completion of the application form.

Several of the contributors referred to the way in which officials sometimes treat applicants without respect. The point was made that SASSA has a staff complement of over 8,000 people (servicing 16 million people) which gives challenges to the monitoring of the quality of the service they provide, though there is every intention to improve the situation in this regard. For example:

“Still some of our officials wouldn't necessarily treat people with dignity and respect when they apply for grants, and still have the attitude that they actually doing them a favour. That's still unfortunately an issue that we're trying to get rid of. But on the other hand the positive side is that we do have many officials that would really go out of their way to assist people when they apply for grants, and staff that are really touched by the circumstances of people that are applying for grants." (Dr W.

Terblanche, Head of Western Cape SASSA)

One of the contributors spoke in particular about the disapproval amongst certain officials about young mothers - again reflecting issues raised earlier in this chapter:

"There is evidence that has been collected where the issue of discretion comes in, where certain particular attitudes would prevail with some officials. There is still established quite strongly, specifically within African society, the issue of young girls having children and therefore the exercise of their right to access to social assistance and therefore the kind of treatment that at times does injure their dignity when they present themselves to apply for these. [..] There are recorded instances and cases where this has happened. [..] So there are attitudes that are quite prevalent amongst officials at the local level when it comes to - particularly young girls coming to apply 
for the Child Support Grant particularly as well if maybe it's instances where it's more than one child, there are certain moral overtones that come in, there are certain hardened attitudes that come in." (Dr W. Magasela, Deputy Director General (Social Policy), national Department of Social Development)

A number of the contributors spoke of how they hoped that the new SASSA card would serve to promote beneficiaries' dignity as it provides them with more ways in which to collect the grant payment, which are less stigmatizing, and the card also promotes financial inclusion. The extent to which these good intentions are achieved will need to be monitored in relation to the new SASSA card.

\subsection{Discussion}

Based on the empirical material much of the process of application and (to a lesser extent) monthly grant collection was detrimental to many women's sense of dignity. In the focus group interviews the application process for the CSG was described as particularly adverse in terms of its impact on recipients' dignity. The four themes that emerged most prominently were those of queuing, burdensome and unclear qualifying criteria, not being treated with respect by officials, and being the object of pejorative comments about their caregiver, parental or lone parent status. The issues of queuing and burdensome and unclear qualifying criteria have been identified in previous studies. What is new, however, is that these issues are presented as being detrimental to women's sense of dignity. These issues, as well as the accounts of poor treatment of applicants by officials shifts the issues from the terrain of technocratic efficiency to one of consideration of grant recipients as people who are deserving of treatment with dignity. Although much has been done to improve the application process there is clearly great scope for further improvement. The policy makers who were interviewed were well aware of the importance of respecting dignity in the administration of social security, and the need to continue to treat this as a high priority going forwards.

The process of collecting the CSG on a monthly basis raised fewer issues but perhaps because of the regularity of the process - the most prominent issue to be raised was that of public scrutiny, as well as (what are hopefully only) teething problems in relation to the new payment card.

The in-depth interviews elicited many comparable responses, but also illuminated different aspects of grant application and collection. This is due to the fact that the in-depth interview material enquired more expansively about grant application and collection, and was slightly less explicit in foregrounding dignity in the rubric of the questioning. So unlike the cumulative, intersubjective quality of focus group responses, the in-depth interviews catalogued more specific idiosyncratically 'individual' and contextually grounded accounts of grant receipt and collection. In these accounts experiences of grant receipt were reported as relatively unproblematic for many, but marked by various pragmatic and logistical 
difficulties for a sub-group of informants. Within the latter group, the bureaucratic difficulties of grant application were considerable and included the staples of the onerously long queuing and burdensome and unclear qualifying criteria described in detail in the focus group interviews. Although there were limited reports of dignity-erosive rudeness and brusqueness from officials, these were raised much more prominently within the focus group interviews. What the in-depth interviews did produce is a heuristically useful distinction between the interpersonal and larger systemic dimensions of bureaucratic processes in terms of their impact on recipient's dignity. It also revealed how experiences of CSG receipt and payment was also impacted on by a range of dynamics outside the formal welfare system, in the realm of social dynamics and employment arrangements. The indepth interview data therefore confirms aspects that the formal state-based aspects of grant payment are an important determinant of lone mother's experiences of dignity, but that these are also shaped by interactions with a range of extra-bureaucratic processes. Accounts of late or delayed CSG application are particularly revealing in this regard.

The following chapter considers issues relating to receipt of the CSG as an income stream, and the status of 'being' a CSG recipient in terms of how these intersect with dignity. 


\section{Chapter 8 Lone mothers and how CSG as a source of income, and the status of being a CSG recipient, intersect with dignity}

Summary: This chapter contains analysis of lone mothers' accounts of how the CSG as a source of income, and the status of being a CSG recipient, intersect with their experiences of dignity, drawing on both the focus group and in-depth interviews. Using the focus group interviews, Section 8.2 shows that although the CSG comprises financial support towards lone mothers' role as caregiver, the small sum of the grant sees it have little or no impact on the protection of dignity. Although the CSG provides an important income stream to households, competing priorities often cause its usage to be highly contested both amongst kin, and in relation to members of the wider community. The stigma associated with the grant is an impediment to dignity and caused some recipients to regard it as emblematic of their poverty and lack of paid work. The in-depth interview material (Section 8.3) echoes several of the findings from the focus group interviews, and notes the variability of the CSG's impact on recipient's dignity. This section considers examples of how the CSG can variously protect or erode recipients' dignity. Moreover the in-depth interviews are used to not simply recount reported attitudes, but also explore the pragmatic ways in which the CSG shapes recipient's experiences of dignity. The CSG's dignity-enhancing effects are described in relation to two widespread phenomena: systems of sharing and social reciprocity, and forms of (often) petty, informal employment.

\subsection{Introduction}

The CSG is a type of income maintenance and as such by definition it helps to alleviate poverty. It could be that receipt of it therefore serves to respect and protect people's dignity. However, as has been demonstrated in the previous chapter, many examples were given of the ways in which the process of applying for the CSG erodes the dignity of lone mothers and, to a lesser extent, examples were also given of the detrimental aspects of the collection process. But does the outcome of that application process - the cash in hand, and spending of the cash in hand - serve to help to protect and respect lone mothers' dignity? And in what ways does the status of being labelled as a CSG recipient intersect with dignity?

This chapter presents analysis of the focus group and in-depth interviews to explore these aspects of CSG receipt. 


\subsection{The CSG as a source of income, and the status of being a CSG recipient: the focus group interviews}

"The CSG is like low income, bad pay at work. It has its advantages and disadvantages. It's better than nothing yet it's not much." (Masiphumelele, FG30)

This section explores the ways in which having the CSG as a source of income, and the status of being a CSG recipient intersect with lone mothers' sense of dignity, using the focus group interviews. In Chapter 4, four dimensions of dignity were portrayed in the form of worthiness (as a woman and as a caregiver), respect (for oneself and others), autonomy and self-esteem. Material from the focus groups highlighted that poverty impacted negatively on lone mothers' dignity in relation to all four of the dimensions. Particularly prominent themes in relation to how poverty impacts on lone mothers' senses of dignity were: their impeded role as caregiver, strained family relations, reduced standing in the community, social isolation, despondency through to desperation, and dignity-eroding aspects of techniques to survive poverty (tolerating poor quality paid work, casual work for neighbours or family, begging, and transactional sex).

The points that focus group participants made in relation to these issues were much less consistently expressed than in relation to the application and collecting processes, and in most instances conflicting points were strongly made as outlined below.

\subsubsection{CSG receipt and role as caregiver}

When asked about how receipt of the CSG intersects with their sense of dignity, some women made the point that the CSG helps them in terms of their ability to provide for their children. As seen in Chapter 4, the main reason given by the focus group participants why their dignity should be protected and respected was because of their role as caregiver; and their inability to provide for their children was expressed as very damaging to their sense of dignity. So for example:

"It helps a lot. My eldest child, for example, knows that her grant comes out today and she will have decent meal. It makes a difference, they'll be full and happy. And my baby gets milk." (Qumrha, FG15)

"The CSG helps protect my dignity. It helps my child a lot even though I'm not working. When he's with other children he has some of the things that they have because of the grant." (Centani, FG23) 
"The grant helps us a lot, I use it for clothes for the children and food for us all. I don't know what l'd do if it wasn't there. Now I can go and look for work knowing that I left my kids with food." (Alice, FG20)

"It helps, for example crèche fees are R180. Even if I run out of food myself, at least I know my child will be going to crèche for sure." (Langa, FG6)

A woman in Qumrha linked the CSG to the protection of her child's dignity as it enables her to pay for his school lunches:

"I think the grant helps protect a child's dignity because you can buy the child school lunches so that he doesn't feel left out at school, it helps." (Qumrha, FG15)

It was widely acknowledged that the CSG is a vital source of income:

"The CSG helps protect my dignity because without it I would have nothing, at all." (Butterworth, FG26)

"I was going to say the CSG helps because it's better than nothing. I did not work for the $R 270$ and I rely on it." (Xesi, FG19)

"The CSG has its place. It helps, without it we would even be in deeper trouble. Some homes would be no more if it wasn't for this grant. Yes, it's not much but it's something." (Centani, FG23)

A woman in Nyanga contrasted the money from the CSG with the process of claiming it and explains that it is the latter that erodes her sense of dignity (see previous chapter):

"The CSG itself helps me, it doesn't erode my dignity. It's the process of going to a hall and queuing that erodes my dignity." (Nyanga FG2)

Most comments (still in response to the question about how receipt of the CSG intersects with people's sense of dignity) turned quickly to the question of adequacy of the CSG and in particular its inadequacy for meeting the costs of raising children. The point was repeatedly made that whilst the CSG helps it is not enough, although it is 'better than nothing'. For example, in Qumrha (FG14) a group of women spoke of how the CSG only enables them to feed their children well for part of each month, and how they have to borrow from loan sharks for the second half of the month. A woman in Langa spoke of how the CSG does not cover the cost of nappies and wipes: 
"The CSG is help that we get from government as poor lone mothers, it is not even enough because you only get to buy disposable nappies and wipes at the end of the day from that $R 240$ and you are only left with $R 10$ change which does not even come your way because it all ends there at the store. There is nothing tangible that you can ever claim using the CSG except for the child's nappies which don't even last for the whole month because they are not enough" (Others agree) (Langa, FG7)

Some women went so far as to say that the CSG does not help their sense of dignity at all, as the amount of the grant is so small compared to what they need:

"The CSG does not help my sense of dignity at all. On the day I come to get it, I get very nervous. I'm thinking, I can't afford the baby's milk, my son needs school uniform and I can't buy from the grant. I spend that money on transport for my child to go to school."

\&

"It doesn't help at all, the CSG. All you can buy is milk for the baby, that's it. Even the baby needs more than milk." (Qumrha, FG15)

"What can I do with R270, where's dignity in R270? Can somebody tell me, please?" (Dimbaza, FG16)

"The grant is so little, it doesn't help protect my dignity at all. I have 2 children. The youngest is 6 months, she eats a lot. I spend over $R 300$ on her per month, then I have about R200 left for my son. I just never know what to do, sometimes I want to swallow them." (Butterworth, FG26)

"I'm not disputing what they are saying, but the CSG is a small amount. That's what it boils down to for me. It's certainly not enough for just the child. I sell paraffin so that I can buy my child winter clothes, for example. What I'm saying is that the CSG does not protect my dignity, at all, it's not enough to do that for me or my children." (Langa, FG8)

A woman in Masiphumelele commented that the CSG operates best as an income supplement to cover childcare costs:

"The CSG helps when you have another source of income and you can, for example clothe your child and feed them at home and then use the CSG for crèche fees and crèche lunch. Something like that." (Masiphumelele, FG30)

Two women, from Khayelitsha and Mitchells Plain, reflected on how the State Maintenance Grant was better: 
Respondent 5: In the older days it was much more

Facilitator: Your are talking about the State Maintenance Grant?

Respondent 5: Yes, it was much better. (Khayelitsha FG4)

"I'm speaking in terms of the 1990's when my husband was in prison at that time. I used to get a social grant for my children on the level of a disability or pensioner will get. But in this time now, we not getting that same amount of money that we used to get that time. The children are getting less now...they getting the level of R270 now... but I could afford the things more that time than what I'm affording now. You know what I am saying.. In other countries, they get much more money for... compared to us here in South Africa. And they live comfortable lives.... their children can go to good schools, their school-fees are paid... Here we struggling with putting a plate of food on the table and pay school-fees and depend on your mother's pension. It's hard, and you unemployed at the same time. There's no work here so basically.... We deserve more for the children to give them a better life.... We have to sometimes go out and beg people to help us to survive." (Mitchells Plain, FG13)

In some of the focus groups dissatisfaction and anger was expressed towards government about the level at which it is set, the small payment increases that are made each year for the CSG, and the lower rate that it is paid at compared to the old age grant:

"The CSG only increases by R10 [per month] a year, that's ridiculous considering how expensive things are. Only the elderly people get a decent grant." (Dimbaza, FG17)

"And they raise it with $R 10$ [per month] a year, and for older people with $R 50$. Children are very expensive" (Khayelitsha, FG4)

"When you sit down and consider dignity and social grants - well, the money is too little to, it does not meet the needs of our children. It's like government is looking down on our sense of dignity as poor people. It's our government, we voted them into power. We suffered under the apartheid government, now we continue to suffer because government is not looking well after us as citizens. That's all I want to say." (Nyanga, FG1)

"It does erode one's dignity. I have twins, for example, in Grade 7. They need to go to a school farewell and for them to be able to go I need to pay R300 for each child. The CSG does not even come up to that. Government should really consider giving us more support, it's terrible. Just a school shoe cost R179. You have to take this from the grant. The children still need school lunches. Children go on tours, all this is supposed to come from R260. Government should consider our dignity more government looks down on our sense of dignity. (Nyanga, FG1) 
A woman in Qumrha spoke out about how she struggles to live on the CSG and yet is urged by her child's social worker to save some of the grant and put it in the bank for the child:

"There is dignity in getting the grant because it's intended to help us, but please, if you can pass on the message to government, it's too little. We cannot live on it. We eat the worst kind of food-mealie-meal, sour milk and white samp, but we can't afford even that. We can't live on R270. My child has a social worker who is always telling me to save from the 270 and take some money to the bank for the child. Please tell me how I'm supposed to do this from R270. What is the child going to eat? How am I supposed to meet his school needs. Yes we don't have to pay fees but the school still asks for money for special projects. The social worker comes to all our houses wanting to see the children's back books, all those that get the CSG are expected to save. So please, if you want us to save, raise the grant amount, it's too little." (Qumrha, FG15)

\subsubsection{CSG receipt and family conflict}

One of the main themes to arise in relation to the impact of poverty on lone mothers' dignity in Chapter 5 was how poverty fuelled tension within families. The discussions in the focus groups about the way in which the CSG intersects with their sense of dignity suggests that the CSG functions as 'another log on the fire' that fuels family tensions around limited resources. In some instances the CSG was portrayed as playing a positive role, so for example one woman in Qumrha who, along with her children, lives with her grandmother, said that her grandmother allowed them to stay with her because the cost of feeding the children was covered by the CSG:

"Well as for me my grandmother would have chased me away with my children from her home. At least my children eat from the grant and I'm the only one she feeds." (Qumrha, FG15)

But such positive narratives (albeit in the shadow of the threat of homelessness) were few and far between and instead many examples were given of the negotiations and strife around access to and use of the CSG. A woman from Alice described how tensions arose in her family when she did not spend money on other family members but instead spent it on formula milk when her child was younger:

"It helps a lot when the child is eating food [i.e. on solids] that the rest of the family eats because on the grant date, you can buy $12 \mathrm{~kg}$ mealie meal so that everyone at home can benefit. When the child is on formula you spend the whole money on their 
needs and it's not even enough, that creates tension in the family because they will say you don't even buy meat. The big formula costs R200, I'm left with R70, which I don't know what to do with it." (Alice, FG21)

Delany et al (2008) explored how the CSG money was spent and found that $49 \%$ of caregivers spent it exclusively on the child, whilst $30 \%$ sent a portion on the child and the rest for household expenses, and $21 \%$ pooled the money with other income for household expenses (p.33). In a recent study by Mosoetsa (2011) the expectation that the CSG should be used for the wider family was similarly observed. Referring to this expectation as a 'cultural tradition' Mosoetsa notes that:

'Double standards apply in the home. If a young woman, for example, uses her child support grant for her own or her child's use, she is accused of being selfish and irresponsible. Young men, though, are not expected to contribute to the household expenses in the same way [...] Young women with access to a regular income, such as a child support grant or salary, tend to challenge their parents over the allocation of resources in the household. This has led to strained relations between parents and children in many cases. The growing propensity of young women to retain income for themselves or their children runs contrary to the notion that household members always pool their resources for the benefit of all.' (Mosoetsa, 2011: 65, 70)

A woman in Centani describes how she feels caught between her mother-in-law's and her child's teacher's directives on how the CSG should be spent, with the mother-in-law expecting it to be spent on groceries for the family, and the teacher expecting it to be spent on items for her son at school:

"I live with my mother-in-law. She gets an old age pension and I get R270 for my child. She refuses to buy food because I get the CSG, she tells me to buy the food myself. On the other hand my son comes back from school and says that his teacher says he ought to have certain school things because he gets a grant. He doesn't even have school shoes or a jersey because I buy groceries for the family with his money. So my dignity is not at all protected, it's not secure." (Centani, FG23)

In Nyanga and Langa there was mention of children's fathers wanting a 'cut' from the $\mathrm{CSG}^{72}$ :

"The fathers of the children, they want a part of it as well, they want a share. How can you share such little money?" (Nyanga, FG1)

72 This issue was also identified in a study by Goldblatt (2005). 
"Some baby's daddies chase after this CSG, they even escort you to the pay point to get their share and they claim that if it weren't for them getting you pregnant, you would not be getting the CSG, that is why they want their 50\% share." (Langa, FG7)

People also mentioned that some fathers absolve themselves of any obligation to provide for their children because of the existence of the CSG:

"when you ask him to assist you financially for his child, he would tell you that you get the CSG money, don't bother him. How is $R 250$ going to raise a child in this expensive world?" (Langa, FG7)

"Our children's fathers say we get money from the CSG and refuse to support their children. That's common." (Khayelitsha, FG5)

Though it didn't emerge very prominently, there were a small number of examples of the children themselves demanding sole usage of the CSG. One woman describes what her daughter said when she registered for the CSG:

"She told me when I applied, 'that money is mine, hey, mommy?" (Ocean View, FG12)

This echoes the beneficiary child in the in-depth interviews demanding the premium Carvela shoes (Section 5.3).

\subsubsection{CSG receipt and relations with the community}

In Chapter 5 examples were given of women describing the negative impact of poverty on their sense of dignity in terms of their standing within their communities. In the same way as with the family relations referred to above, the focus group interviews revealed that the CSG operates largely as 'one more log' that fuels the fire of tense communities with scarce resources. These two women describe how when they go to beg or borrow from neighbours they first have to explain to their neighbours how they have spent the CSG:

"You get humiliated, going to a neighbour to borrow money for the children's school needs, the neighbour will ask "Did you not get the CSG just yesterday?" And you have to explain yourself, what you did with the grant and still get nothing from the neighbour anyway." (Dimbaza, FG16)

"Well, say for example yesterday I got the grant and I buy the baby's milk with all the money. So I'll be starving because I have no money for food and I'll end up going to my neighbour for food out of desperation, she'll first want to know what I did with 
the grant money - it's along those lines that the insults about the grant begin." (Mbekweni, FG27)

Several women made the point that their status as CSG recipient erodes their dignity as they become the object of people's prejudices and judgements. This first woman describes how she has to contend with comments that she became pregnant for the grant:

"It lowers your dignity. Even if you're pregnant and you get in a taxi, people pass comments that we get pregnant in order to get the grant. You end up arguing with them that the R250 is not enough even for the child. Please stop saying people fall pregnant for the grant. Even at home they say that."(Nyanga, FG1)

Reflecting a duality explicated in the in-depth interview material, a second woman observes that whilst the CSG helps to protect her dignity as it enables her to help her children, her dignity is also affected negatively by the CSG as her employed peers look down on her for receiving the grant:

"I'm just going to speak as I see it or according to my experience because you said there is no wrong answer. I think it's crucial for people's dignity to be protected, especially women, young and old. For example, the fathers of our children don't support them, that's an indignity. The CSG can both protect and erode your dignity. It helps with the children on the one hand, but there's youth, people my age with jobs, they that do not need the CSG, they tend to undermine one, you know, look down on us. That affects my dignity, negatively." (Nyanga, FG2)

In fact, far from increasing their standing within the community, a number of women went so far as to describe the CSG as being used by people to verbally erode their dignity:

"Even though the grant is intended for good, people use it, verbally, to erode our dignity. (Butterworth, FG26)

"If it wasn't for the grant, I wouldn't be getting all the insults I get. Both in the streets and at home... (respondent breaks down)"

\&

"We need this grant but it comes at a very high cost, it costs us our dignity at the end of the day." (Masiphumelele, FG29)

\subsubsection{CSG receipt and autonomy}

In Chapters 4 and 5 one of the main themes to emerge was the way in which employment was regarded as the key route not only out of poverty but also to the attainment of dignity 
(although many provided examples of dignity-eroding aspects of paid work). For many women, the CSG was expressed not as a move towards greater autonomy but rather as being emblematic of their lack of autonomy, of their lack of employment and lack of an income from paid work. For example:

"I'm going to talk about myself as a grant recipient. I get the grant not because I want to, but because I'm poor. That in itself erodes my dignity because I'm dependent on government. When it suits government I get the grant, when it doesn't suit them, they stop giving it to me. Nobody consults you on anything because you are a poor dependent. It's like people who are uneducated, they are not treated with respect and they have to go around begging. Nobody comes to you, you go to people yourself, begging. People don't treat you with respect when you're poor." (Nyanga, FG1)

A woman in Khayelitsha describes how the receipt of the CSG lowers her sense of dignity as it symbolises the fact that she is not in paid work whereas she feels she ought to be in paid work:

"It affects dignity because if you had money, you wouldn't get a grant, the fact that you go there, your dignity is lowered because you are supposed to work and this money is too little." (Khayelitsha, FG3)

A woman in Ocean View describes how she feels having previously been in work but now claiming the CSG for her 15 year old child:

"All the years I worked for child, now that I am not working...my child is 15 years old and this is the first time that I came for the grant for my child. My dignity is shoved so low that it hurts to come and stand here for money for my child. It is very hurtful because I worked all the years for my child." (Ocean View, FG12)

So too, a woman in Qumrha spoke of there being 'no dignity in receiving this grant' but that in the absence of jobs there was no other way of surviving:

"All I'm trying to say is that there is no dignity in receiving this grant, it's just that we have no other way of survival. We need jobs, we are still young and have strength to work." (Qumrha, FG15) 


\subsection{The CSG as a source of income, and the status of being a CSG recipient: the in-depth interviews}

This section draws on the in-depth interviews and builds on the previous section, to examine closely informants' attitudes towards the CSG, including the extent to which CSG receipt impacts on their sense of dignity. To this end, accounts of CSG receipt as both serving to support, and then alternatively, undermine dignity are presented and critically examined. Following which, the manner in which the CSG is practically used is examined, specifically in terms of its relationship to practices of social reciprocity, and employment.

At the outset it is useful to signpost that discerning perceptions and attitudes to dignity is conceptually complex and difficult task. Despite their intuitive plausibility and wide currency much attitudinal research has been subject to critique. Not only is the presumptions that attitudes represent a stable bedrock of cognition been questioned, so too has the assumption that attitudes correlate with or accurately predict behaviour (Durrheim, 1997; Durrheim \& Dixon, 2004). Much work concerned with attitudes and perceptions relies on a naïve empiricism and is insufficiently attentive to the discursive dimensions of attitudes. In other words, it overlooks the fact that the very act of eliciting or expressing an attitude invariably takes place in a discursive and social context, and which speakers routinely (even unintentionally) tailor their utterances to conversational genres and social contingencies (Potter, 1998).

This critical stance to attitudes therefore challenges the assumption that speakers offer up objective, de-contextual and stable inner truths in response to questions about their attitudes and perceptions. It requires that inquiry into attitudes be reflexive to the roles and discursive 'work' of the utterances that speakers make, and context within which they are made. For this reason, interpretations of empirical data needs to be sensitively done, validated against contextual material, and focus on how the phenomena in question (in this case, the dignity of CSG recipients) plays itself out in everyday life. This interpretative work demands going beyond simply posing the question and uncritically transcribing and presenting informant's illocutions. Instead it underscores the need to consider both CSG receipt and dignity as dynamic forms of social practice, embedded in a larger social and material context. Consequently respondents reported perceptions and larger narratives of CSG receipt in relation to dignity are considered in what follows, by focusing on forms of pragmatic action involving the CSG.

In considering accounts of CSG receipt and its impact on recipient's dignity, there is ostensibly evidence for two diametrically opposed propositions. The first that grant receipt strengthens recipient's dignity; the second that grant receipt potentially undermines recipient's dignity. In what follows evidence for both propositions is presented, evaluated and the relationship between these opposing accounts examined. While the current inquiry explicates these dynamics in detail it does not seek to judge their prevalence. 


\subsubsection{CSG receipt as enhancing dignity}

In response to the enquiry concerning social grant receipt and dignity, a prominent theme amongst informants was that grant receipt served to strengthen and underwrite their dignity. For many informants a dominant experience of CSG was its use as a resource used in a dignity-enhancing manner. Most tangibly, grant receipt served to elevate consumption and ameliorate poverty, allowing recipients to discharge their childcare responsibilities, act in ways congruent with the maternal role and exercise individual agency. Empirical material supporting this is presented in the section below. However grant receipt also impacted on dignity in slightly less direct ways, by strengthening practices of inter-dependency and mutuality between recipients and others. These dimensions relate to the life world and social networks of individual informants, and were less easily captured by the rubric of this question enquiring directly about dignity, or the intersubjectivity of the focus groups. While glimpses of these dynamics emerge here, they are therefore explored in more detail in the sections that follow.

The erosive effects of poverty and deprivation in relation to dignity have already been suggested and are generally widely accepted (Budlender \& Woolard, 2006; Case, Hosegood, and Lund, 2005; Devereux, 2006). The CSG allows recipients to meet some of their children's basic needs, and thereby ameliorate some of the extreme consequences of poverty. Informants readily described grant income being directed to the major categories of food, clothing and schooling related expenses more generally (school lunches; school transport).

\section{Extract 18}

Informant Asanda receives 3 CSGs for grandchildren in her care, and her co-resident daughter receives a single CSG for her youngest child. She explains how it is spent:

S.M: What do you do with the child support grant money that you get?

Asanda: I pay R100 for each child, that is R300 for their transport to school [..]. I pay burial society, which is R100 and then with the rest I buy groceries.

S.M: Do they take lunch box when they go to school?

Asanda: They take lunch to school when there is no gas or electricity at school, because they ... [do not] cook for them at school

S.M: When you buy groceries for the household, so you also look for the things that they will need for lunch?

Asanda: Yes because this money ends [only buys up to] on polony and snacks [for school].

V.C: Where does your daughter get her child support grant?

Asanda: She gets it from Capitec bank. When she was sick she used to give me the card but even since she is better she goes to town herself. Even though she goes to town and get it herself, but she gives me the money to buy huggies [nappies], food and soap, formula milk, 
Nestum (infant cereal), yoghurt for the child. And sometimes the child gets sick and I have to borrow money to take the child to the doctor, and she pays R50 for her burial society

\section{Extract 19}

Informant Ayanda. Ayanda lives with her mother ('Mother' in the extract below), her children and her nephews and nieces. In response to a question about what the grant money is spent on, both women answer in detail.

Mother: These children go to crèche: [Child 1, Child 2 and Child 3] , I pay R120 for their transport [to crèche].

V.C: Each?

Ayanda: No the three of them.

Mother [the mother of informant Ayanda]: No, not each, R120 for them. And at the crèche I pay R10 for each of them, I buy snacks like yoghurt, banana, biscuits and fruit. When they go to crèche there is a time to eat yoghurt, but sometimes I don't give them yoghurt, I give them chips and banana, and I try to buy for the whole month.

D.N: Oh right, for three kids?

Mother: Yes for three kids.

D.N: Alright that's lot of stuff...

Mother: I also buy porridge and groceries for them all and a packet of nappies: huggies.

They use huggies when they go to school they must have 2 huggies - they change them. So I buy all groceries.

The in-depth interviews were well suited to documenting how grant expenditure was also tailored to specific, individual needs. Informant Spamandla has a young infant whom she left in the care of others. She explains that part of her spending of the meagre resources of the CSG is directed to buying disposable nappies (diapers). She explains how these facilitate care arrangements, while she engages in job-seeking.

\section{Extract 20}

Informant Spamandla.

S.M: What do you think it's your reason why you are using the disposable nappies not the cloth nappies? Because he [researcher DN] is saying he is having a baby, and he is using the disposable nappies but he wants to know your reason why you buy the disposable nappies not cloth nappies? Because you just got the grant, why you prefer the disposable nappies? Spamandla: If I go and look for a job the person that is going to look after my child will talk to other people or her neighbour, [saying] these cloth nappies do smell, why is she is not buying the disposable nappies, because she is getting the grant for the child. 
Finally, in the lengthy but particularly revealing extract that follows, rural-resident informant Zimkita explains why she sends the full value of the grant, to her ex-husband in a distant urban centre.

\section{Extract 21}

D.N: ... gets the child support grant, and of your kids who gets it?

Zimkita: [Child 1] and [Child 2]. are getting it.

D.N: Those are the two younger ones?

Zimkita: Yes.

D.N: Ja okay, and then I'm not sure if I asked, your ex-husband is he working now?

Zimkita: No.

D.N: No? How does he manage to take care of the two kids?

Zimkita: With this grant I give him this entire grant, the R540.

D.N: You give him all of this R540?

Zimkita: Yes for the kids.

D.N: Okay, so you collect the money here at the cash pay point?

Zimkita: Yes.

D.N: And then how you give it to him?

Zimkita: I transfer it through Shoprite.

D.N: At Shoprite, okay I see, because you say he is not working, so you send him the grant? Zimkita: Ja.

D.N: So I suppose because he is not working you send him the grants. So he does not pay you any maintenance?

Zimkita: No he is not working.

D.N: Does he pay any maintenance for your daughter who is living with your friend? Zimkita: No. [...] I give it to him and I make sure he buys groceries for the kids. And he knows that he is not working, so he has to have something to eat so that's why... every time I send money he goes to Spar [Supermarket] with them, and buy groceries.

D.N: With the kids?

Zimkita: Yes.

D.N: How do you make sure that he is not misspending the money?

Zimkita: I know, because I usually go there.

D.N: You usually go there?

Zimkita: And my kids will call me, I even want to see the [store sales] slip.

D.N: Oh really! You go there, your kids will call you and you even want to see the slips?

Zimkita: Yes because I'm not doing it for him. I'm doing it for the kids.

D.N: Oh ja, do you tell him he has to keep the slips?

Zimkita: He knows.

D.N: He knows and you said you go there, how often you go there, they come here for holidays but how frequently you do go there? 
Zimkita: I go there once in two months.

D.N: Once in two months.

Zimkita: If there is a meeting in their school or anything, I go.

D.N: Alright. How would you describe your relationship with your ex-husband it sounds good, and there is some co-operation.

Zimkita: Ja it's because of his kids he loves his kids very much even though he doesn't like me. Our relationship was a very abusive relationship, it was not right. We couldn't stand each other. But with his kids... [the relationship is good]

D.N: Okay, so there are conflicts between the two of you but you seem you both being able to work together because of the kids.

Zimkita: Because of the kids, ja.

D.N: Ja.

Zimkita: You know what the reason that they [the kids] are not staying here, it's because they were used to going to English [an English language medium school] school. There are no English school here, and it's very expensive here for you to have a transport to town or wherever. I tried that and it did not work out I decided to send them to P.E [Port Elizabeth]. There you can a bus for R320, and here you have to pay [a school transport] contract of R500 each.

This long extract lucidly details how informant Zimkita is able to use the resources of the grant to support her children's welfare, and enable them to access superior quality schooling in a distant city. Despite a difficult relationship with her ex-husband ('abusive'), to whom she sends the grant, Zimkita is clearly able to exercise over the resources of the grant. Control of these resources enables her to wield considerable personal agency and care over her children, even at a distance. Her control of the resources, arguably also, by her account, enables her to interact with her ex-husband, in a manner that is in the children's best interest.

The above extracts detailed the dignity-enhancing ways in which CSG receipt was used. The resources of the CSG supported basic consumptive expenditure, and were tailored to the demands of the individual's circumstances. Being able to do this was an important source of maternal identity, self-respect, and even self-esteem on the part of informants. Particularly in Zimkita's lengthy extract (extract 21), there was also a sense of grant receipt not simply supporting her children, but empowering her within a (potentially) fractious interpersonal relationship with her ex-husband, thereby bolstering her sense of agency and autonomy. In these ways CSG receipt empowered receipts' to act in ways consistent with the maternal roles and respectability, and to exercise personal agency and autonomy in order to improve the welfare of their children. While informants often expressed this sentiment, the preceding account demonstrates this work in action. The CSG was thus used frequently in ways that underwrote and bolstered recipients' dignity. 


\subsubsection{CSG receipt as undermining dignity}

Much like the focus group interviews questions concerning the CSG also elicited narratives of CSG receipt serving to detract from informant's dignity. By these accounts CSG receipt, to varying degrees, invoked stigma, censure or opprobrium from others, which led to the eroding of the recipients dignity. These narratives are examined in more detail below, but first a caveat needs to be sounded.

One narrative strand from informant's appeared to reject the notion that the CSG positively influenced dignity because, they argued, the CSG was too little to do very much with at all. This echoed a very similar sentiment articulated in the focus group interviews (section 8.2). This type of response ought to be understood against the backdrop of informants rhetorically positioning themselves as worthy subjects of beneficence and assistance. It represents less informants assuming a position between the poles of CSG receipt as either strengthening or undermining dignity, than an argument that more than the paltry CSG is needed. For example:

\section{Extract 22}

Informant Nomfezikile

S.M: When you go and collect the grant what do people in the community say and how you feel when you go and collect the grant?

Nomfezikile: I don't feel right because at times I feel I just go there because we need the grant money and the children need it because it helps and I get heartache because the money is not enough for the needs of the children.

However there was also a clear sense of dignity-eroding opprobrium and disapproval from others.

\section{Extract 23}

Informant Spamandla elaborates:

S.M: How do you feel when carrying that [SASSA payee] card?

Spamandla: Yes people do talk when you carry that card even if you buying stuff for your child and with the change you buy chocolate of R2,50 they will talk and say look at her she is eating the grant money and these people are the older people 
Similarly:

\section{Extract 24}

Informant Nomfezikile reports:

S.M: What do people in the community say about you?

Nomfezikile: People do talk in the community you will hear them say look at her she is going to collect the money and she is going to come back with a plastic bag [shopping packet] with her stuff, not stuff for the children because she spending the money on herself, but they don't even know what you do with the money.

S.M: They assume that you are not going to spend it on children?

Nomfezikile: Yes.

Or, informant Nomkita reports:

\section{Extract 25}

S.M: How does that make you feel?

Nomkita: I don't feel right and even told myself that if I can get a job I will stop the grant because of the way people talk.

Finally, CSG receipt may be dignity eroding, expressed in relation to women's reproductive choices

\section{Extract 26}

Informant Nomkita

S.M: What do men or the fathers of the children say about the grant?

Nomkita: That is the reason that makes them not want to support children, because they say: you are getting the grant.

S.M: What are the things that they say about the grant?

Nomkita: They say we got pregnant for Mbeki and Zuma, they say we must go because we got pregnant for Zuma (laughter)

And similarly, informant Zimkita explains:

\section{Extract 27}

D.N: ... I'm interested to hear about the child support grant, what do people in the community say about other people who get the child support grant? What do other people in the village say about other people that get the child support grant? 
Zimkita: They call them names, saying you just making babies because of this R200 and something even the pregnant woman, if you are pregnant they will tell you that, ja you are pregnant you want more money from the government. They will call people Nogrant ${ }^{73}$, they call them names...

D.N: What kind of names? [Inaudible] You can say that in Xhosa...

S.M: [Clarifies pronunciation] Nogrant.

Zimkita: Nogrant.

To this point informant's varied reports of GSG receipt as dignity enhancing, or alternatively as dignity detracting were presented. This range of responses suggests variations in how informants experience CSG receipt and the consequences of CSG receipt. However the diversity in this range of responses is made even more complex by responses that fit into neither category. Or where the informant acknowledges the existence of dignity-impacting dynamics, but denies they touch her. In other words reported accounts of grant receipt as either negative or positive, but which do not influence the informant's reported selfesteem, sense of worthiness or self-concept. This mismatch, of reported attitudes that are not internalized by informants, is a conceptual tension within attitudinal research.

In the first extract, the informant acknowledges the existence of stigma but indicates she is not particularly subject to it, she is unaffected because of her and her mother's toil. She says the CSG is misspent by many, but not by her.

\section{Extract 28}

\section{Informant Nosomsi}

D.N: What do people say in the village... [turning to V.C. help me with this question]. V.C: How do people in the community treat you and what are the things they say about the grant?

Nosomsi: They just respecting us because they know my mother and I selling, so she is like working they don't comment much about the grant.

D.N: Are there other people in the village that collects the grant? Nosomsi: Yes...

D.N: ....that the people who gossip, say things about?

Nosomsi: Yes like people who get the grant and make lot of debt because of alcohol, so on the first everyone knows it's a payday and the shebeens [informal drinking establishments] are full of young people. Or [speak about] of mothers because usually the grant it's paid on the first of the month. They are the ones who make the grant to be associated with bad behaviour. If they would use the grant properly I don't think they will be much problem. As much as it is small or little, it can make a difference if you use it wisely.

\footnotetext{
${ }^{73}$ In isiXhosa the 'No' prefix, designates a female. Nogrant is therefore a feminine, fabricated name.
} 
In this extract, the informant Nosomsi's assessment of the prevalence of grant misuse or substance abuse is of less analytic interest than her rhetorical position relative to these. She holds that the opprobrium attendant to grant receipt is warranted, but not in relation to her as she is exempt from it.

The second example, extract 29 informant Ondela indicates there is stigma surrounding CSG receipt, and that it is directed to her too. She however disregards it, and feels that she is unaffected by it.

\section{Extract 29}

D.N: The last set of questions, are what other people say about the grant? Like what do other people in the community say about the child support grant, or say about people who are getting the child support grant?

Ondela: It depends on the people that you staying with or around...

D.N: So what do people who are staying around you or here, say about it?

Ondela: The thing is whatever they say they don't come and say it directly to me.

D.N: Okay...

V.C: When you hear other people that are getting the grant what does the community say about the people that are getting the grant besides you, because you never heard anything? Ondela: [To V.C] They say... other people undermine people that are getting the grant. V.C: Did you get that? [directed to D.N]

D.N: No?

Ondela: [Repeats] Some people undermine people that are getting the child support grant. D.N: Ja do you think people say that about you, or said that about you in the past? Ondela: Maybe they do, as I just said to you I'm nobody I'm just living my own life the way I want to live it. I don't care what they say I don't care what they think because I believe if you concerned about someone else's life you not accepting who you are. By accepting yourself you will accept someone else's life, but if you don't you will always be concerned about how she lives her life.

D.N: And you not concerned about what they say?

Ondela: No I'm not [...] That's the way I was raised, I was raised by a single mother she taught how to accept life as it is.

D.N: Ja?

Ondela: Being concerned about someone else's life you just making your life miserable. Ondela: Ja.

Finally, in examining dignity the force with which the lone mother recipients sought to repudiate the opprobrium and stigma of grant receipt, reveals something of their assertion of their dignity. This dynamic is evident in the lengthy extract below: 


\section{Extract 30}

Informant Nothando, is a young rural-resident informant:

S.M: You and the other people that are getting the grant here in the village how do people in the village treat you and what they think of you?

Nothando: They don't treat us well especial the taxpayers they make me angry.

S.M: What did they do? (Laughs)

Nothando: When it is [National] Budget Speech and the grant is increased with R10 you will see on Facebook and Mxit that these things ['ezintwezi'] 'they are sitting in the sun', while we paying tax. 'They eat this money and drink it', I replied to them there on Facebook when this happened this year.

S.M: You responded to them on Facebook?

Nothando: Yes!

S.M: So on Facebook, is it people that are there are your friends, it's people that you know?

Nothando: Yes they are my friends, but at times you get friend requests from people but you don't even know them.

S.M: Are the people that were talking your friends?

Nothando: This is what happened, Ritchie S. is my friend he posted about the grant on Facebook and his friends commented. I am Richie's friend, so I commented back that it's not that we are sitting at home eating the grant. For example I have a diploma that I'm sitting in the sun with [unemployed]. I don't drink the child's grant, that money does nothing for me. I use it for my child I buy [school lunch] snacks for the month for my child. They asked why did I apply, I said I applied because it is there, otherwise me - as Nothando- the grant does nothing for me.

In this extract the lone mother informant Nothando was not a passive subject of the gossip and opprobrium surrounding grant receipt. The informant did not simply acquiesce to other's interpretations of her situation, but engaged in a process of rhetorical claim and contestation on social media (accessed via her cellular phone). The extract attests to her assertion of agency, as she challenged to the aspersions cast on her as a grant recipient. In this exchange the informant positioned herself as not personally benefiting from receipt of the grant, or personal consumption of the income. This extract suggests that experience of grant receipt includes how the impoverished seek to assert their agency, moral entitlement and dignity. In this way experiences of dignity in the face of grant receipt are diverse and dynamic; they can be marked by counter claim, retort and contestation. Grant recipients are not simply passive subjects of stigma and censure.

To this point the empirical material presented suggests that informants' perceptions of the manner in which the CSG impacts on dignity is diverse. Much like the focus group interviews, some in-depth interviewees report grant receipt as dignity enhancing, and others as dignity-detracting. Yet other informants elide this binary, describing themselves as variously unconcerned, unaffected or actively resisting the stigma of grant receipt. From 
this a more nuanced picture of the perceived impact of grant receipt on dignity emerges. It is one where CSG receipt generates dignity enhancing positive effects: enables autonomy, elicits respect and reinforces self-esteem and worthiness. Where use of the CSG is congruent with the maternal role that in turn is a source of social validation and personal satisfaction. Yet simultaneously the CSG can potentially be a source of censure and gossip from others, eating away at respectability, and detracting from dignity. How can these dichotomous poles be reconciled?

How to reconcile this range of responses, specifically accounts of the manner in which the CSG can serve to elevate dignity but also those of it potentially undermine dignity is considered in what follows.

\subsubsection{Examining the experience of social grant use}

In making sense of recipient's experiences and attitudes towards social grant receipt, it is useful to recall the methodological limits of attitudinal research. Interview-based inquiry examining the role that the CSG plays in relation to dignity can therefore take one of two very broad routes. The first entails inquiring after experiences and attitudes towards of grant receipt; the second attention on the dynamics of how grant receipt does its work in practice. While the latter is still contained in the reports of informants, it relies on gleaning narratives of informants' life histories, livelihoods and key social relationships, in order to consider the how the CSG is used in practice. Examining, in fairly specific and concrete terms, the place of the CSG facilitates consideration of its impact on the informant and their experiences of dignity. In the section below these dynamics are examined in relation to two major activities that shape recipients experiences of dignity, the first are practices of social reciprocity and mutuality, the second practices of economic activity, work and selfemployment.

\section{Social grant receipt strengthens systems of social reciprocity}

State cash transfers serve to elevate consumption and have been shown to improve human welfare in a relatively decisive and unambiguous ways (Budlender \& Woolard, 2006; Case, Hosegood \& Lund 2005; Woolard \& Klasen, 2004). However social grants do not simply improve welfare and buttress welfare directly by elevating consumption. They also interface with systems of 'informal social protection' (Bracking and Sachikonye, 2006) by providing material resources, that link into prevailing systems of provisioning and care. They hereby, potentially, strengthen prevailing systems and practices of social reciprocity that in turn support self-respect, self-esteem and a sense of worthiness, thereby serving to underwrite dignity. These systems of social reciprocity and mutuality are discussed in terms of the following three concepts. The first is distributed care work, the second, practices of household-making mobility and migration, the third customs of household resource pooling 
and collectively livelihood-making. These three components of social reciprocity are examined in what follows.

\section{Distributed care work}

Enabled by the resources of the CSG and rooted in relationships of social reciprocity, forms of distributed care work were evident in the empirical material. Care work encompasses the unremunerated labour required for household reproduction, and care of dependents. Although common to all low come households with dependents, the demands of care work are particularly acute in rural households, which often make up the for the care deficit in urban areas. Rural areas are frequently spaces for retirement, recuperation, retreat from urban labour markets, and raising of children (particularly if urban footholds are precarious). In this way, impoverished households, and their care burdens are frequently geographically stretched, across urban and rural sites.

Against this backdrop, complex process of mobility and migration were evident in relation to children. For example rurally-resident informant Zimkita (extract 21) described securing the CSG for her children and transferring the money to her ex-husband in a distant urban centre. The three children were living with him, in order to access superior quality schools, after having initially attended school locally.

A common pattern of childcare provisioning across space was evident in the following vignette.

\section{Case Study Vignette 7}

Informant Yamkela was a rural resident and described elaborate process of child swopping with her urban-resident sister. The informant's 16 year-old daughter was living with her aunt (viz. Yamkela's sister), and attending secondary school in a distant city. In exchange the daughter of Yamkela's sister (viz. Yamkela's niece) was resident with Yamkela, and attending primary school locally. Although Yamkela explained that each dutifully got the CSG for each other's child in accordance with the letter of the regulations, it is quite possible that they agreed that each should simply retain the grant for their own child with the same net result. The resources of the CSG met some of the costs involved and enabled these dispersed patterns of residency, to access superior quality schooling. Finally a third child, another of the informant's nieces was also resident at the rural homestead. The child's parents were rurally resident but lived far from any school therefore the niece lived with Yamkela to access the local school. Her impoverished parents remitted most (but not all), of her CSG (viz. R200) to offset her living expenses. While the local school was inferior to urban schools, it was better than no school at all.

Mobility, migration and flexible mores concerning household membership are all evident in the above extracts. These practices where children of different ages migrated between (often spatially extensive households), are consistent with high levels of internal migration 
and porous household membership that often characterize black African households in South Africa. The pattern of older children residing with a female urban relative and younger children resided with rural kin (typically aunts or grandmothers) is notable. This arrangement allowed older children to access the educational opportunities in town (widely believed to be of higher quality). It also enabled grants recipients to care at a distance or a step removed. Finally the ability to undertake this labour was frequently imbricated with social roles and (gendered) identities. Underpinned by the resources of the grant these practices that position the care work-dispensing women as key agents within the networks of social reciprocity and exchange, that are so crucial to the lives of the impoverished and vulnerable.

\section{Household-making, mobility and migration}

In the empirical material a general pattern was apparent: if the beneficiaries of the CSG where not biological children of the recipient, they frequently occupied a household where an older woman (typically a grandmother, sometimes an older aunt) was resident. In many cases this older woman the de facto household head. In the majority ${ }^{74}$ of the sampled interviews either of these arrangements prevailed. Grandmothers (or an older aunt) of beneficiary children were evident in the interviews with Asanda, Spamandla, Olwethu, Owami, Nomkita, Ketiwe, Zimkita, Xoliswa, Yamkela, Ayanda and Ketiwe. The relatively small value of the CSG, even cumulatively for two or three children, makes independently establishing or sustaining a household difficult in the absence of additional resources. Whereas older women often accessed the Old Age Grant (OAG), or formal sector employment benefits (even if through a spouse). The OAG is a material lynchpin around which impoverished black African households are often constituted (Duflo, 2003). So notable are its effects that there is evidence of it 'attracting' additional household members (Woolard,\& Klasen, 2004). These material realities had implications for household demography, livelihoods, patterns of social reciprocity and grant use. Older women assumed at least partial responsibility for caring for CSG beneficiary children, as was evident in the cases of informants Asanda, Spamandla, Olwethu, Owami and Nomkita. The grandmothers of children born to younger women would frequently be the designated recipients of the CSG, particularly if the younger women were still attending school, or engaged oscillatory job-seeking urban migration. Younger women were in several instances regarded as pragmatically inappropriate recipients of the CSG, as they would need to be locally present to in order apply for and regularly collect the grant. Instead, older, more sedentary female kin were better placed to assume this responsibility.

In this way the CSG enabled women to enact socially validated roles, animated entrenched patterns of care work by grandmothers, and underpinned the 'skipped generation' rural household form (Sagner \& Mtati, 1999). It also provided the material resources to lubricated the spatially extensive systems within which these arrangements are often structured. Finally, this arrangement ultimately facilitated the engagement of

\footnotetext{
${ }^{74}$ Approximately 10 of 16 cases.
} 
younger women with educational or employment opportunities (albeit at the cost of their absence from children).

These dynamics of care work distributed over spatially extensive networks rooted in more of social reciprocity is not a phenomenon exclusive to the South Africa context. Hochschild (2000) has described the transnational global 'care chains', by which women in economically marginalised settings care for the children of kin, or other women, who are economic migrants. Within these spatially extensive networks, resources, care work and even affect - 'emotional surplus value' (Hochschild, 2000) - are therefore distributed. At its lowermost levels care work is often delivered for no or low remuneration, and frequently by kin. They are arrangements that both demand and fortify the interdependencies and patterns of social reciprocity within households.

\section{Household resource pooling}

A final manifestation of social reciprocity was in the practices of household resource pooling, where CSG receipt was directed to common household expenditure (such as groceries for the 'common pot', or the premium for a monthly funeral policy), rather than to the formally defined designated child beneficiary (see also section 8.2.2). The beneficiary recipient child would then typically benefit from sharing and informal transfers elsewhere. This was evident in the following cases:

Informant Ketiwe. Informant Ketiwe's children reside elsewhere (in urban Cape Town) with kin during the week and rely largely on her aunt's state social pension. She explains that she only buys groceries for her aunt's household when she sees something has run out, or if they ask her to buy a item that has been exhausted, or if the date of the next payment is still far into the future and they have run out of all groceries.

Informant Ayanda. Informant Ayandaand her mother receive their social grants in the beginning and middle of the month respectively. This enables them to pool their resources and smooth consumption by alternating between the fortnightly purchasing of groceries.

Informant Nomkita. She occupies a large household with multiple adult siblings, nephews and nieces. She explains how they retain some income for personal expenses, but that the household pools income to purchase groceries collectively.

These collective arrangements once again reflected and reinforced practices of social reciprocity. In this context grant receipt enabled the exercise of care and mutuality, and consequent accruing of respectability, worthiness and self-esteem. This was echoed in the focus group interviews, where the lone mother's sense of self esteem was tightly intertwined with their role as nurturers and caregivers (section 4.2.3). Therefore CSG 
receipt supported livelihoods practices embedded in social roles that were considered to be appropriate and dignified.

\section{CSG receipt and work}

Opprobrium directed to grant recipients on the basis of their receiving 'unearned income' may exist, but its veracity is roundly contradicted by sheer scale of work that recipients undertook. For CSG receipt is not incompatible with labour market engagement either by the adult recipient, or by other working-age household members as part of the household survival strategy.

At least two informants explained long delays (12 months and several years respectively) due to the fact that they were working long or inflexible hours (security, restaurant trade) and unable to collect the grant at the designated time. For example:

\section{Case Study Vignette 8}

Informant Ondela Applied for a CSG when her child was five years old. She explained that she held a succession of jobs in a restaurant industry (including mid level supervisory position), which conferred solid earnings (for a working class woman). However the long hours and nocturnal shifts of the restaurant industry became impossible with the birth of her child five years ago. She explained, the cost of hiring a child minder for each evening would have eroded her earnings from the restaurant too much to make it worthwhile. Instead, she resigned from the restaurant jobs and found employment as a child minder (to a white, middle class family). Despite the lower pay, the regular working hours better accommodated her childcare responsibilities. The job also brought her into circuits of domestic patronage that are not unknown in domestic work, with her new employers funding her own child's crèche fees. It was only after the dissolution of her relationship with the child's father, that she finally applied for a child support grant. Her child was almost five years old at this point.

Other informants readily combined CSG receipt with remunerated work, evident in the following three examples.

\section{Case Study Vignette 9}

Informant Ketiwe. Despite a modest educational background (grade 10) completed in a rural Eastern Cape school, this informant's employment history represented somewhat of an upward trajectory. After migrating to the Western Cape she progressed from seasonal farm work, to a full time, permanent industrial job (at a meat wholesaler), earning approximately R2000 a month [just under the means-test]. She was completing a Saturday morning 'home care' course, which she intended to use as a springboard into a formal nursing qualification. In this way CSG receipt was combined with work and aspirational part-time study. 


\section{Case Study Vignette 10}

Informant Akona. Informant Akona had a tertiary (college) qualification, served a year-long internship in a government department. Failing to secure employment she regularly worked in a restaurant. She had applied for the CSG relatively late, because the small stipend for her internship saw her listed on the Persal (state employee payroll) system, and suspicious officials had rejected her application, despite her stipend being below the means test threshold (R2400 per month). When questioned, she proudly described how well she had fared in her internship, with clients routinely asking for her. She readily described the prospect of employment as far more desirable than grant receipt.

\section{Case Study Vignette 11}

Informant Nomkita. She asserted that if she got a job she would stop collecting the grant because recipients are not respected. Despite this aspiration to full time employment, her working day was fairly busy. She explained she had previously engaged in the hard and poorly remunerated seasonal agricultural labour of fruit picking, but for the last decade she had sold funeral policies for 10 days per month on commission. In addition she sold prepared, cooked food and snacks for learners on most school days. She terminated the interview at midday, in order to go and sell her wares outside the local school gates.

Across the informant's interviewed a commonplace pattern was CSG receipt, paired with other, small-scale economic activity.

Informant Nomfezikile collected bottles for recycling and was a prominent participant in helping with traditional ceremonies for which she was often rewarded in-kind (food etc).

Informant Nosomsi used the grant income to buy groceries, specifically when the household's main income stream (vegetable vending) was disrupted by intermittent breakdowns of their battered bakkie (pick-up truck). But under normal circumstances the CSG was expended on school transport for the beneficiary child. Therefore the CSG indirectly enabled the household to engage in higher value economic activity, in part because it provided a flexible safety net (for food security), when their vending became disrupted. The CSG was being (indirectly) leveraged into higher value activities.

Informant Asanda undertook washing (laundry) by hand, for money, domestic chores and sold airtime (netting R80 profit per month).

Informant Zimkita engaged in informal retail and reared piglets to slaughter and sell pork. 
Informant Xoliswa engaged in some agricultural production and informal vending of prepared food/snacks.

Informant Ayanda was part of a household engaged in multiple activities, including sewing.

In these examples what was noteworthy the extent to which grant recipients combine grant receipt with larger portfolios of livelihood supporting activities, often varieties of informal self-employment. While many of these tasks were diminutive and 'survivalist' in nature, they were often compatible with, or even extensions of tasks required for household reproduction. This is not to suggest this is necessarily sought-after or desirable work. As noted in the focus group interviews 'Tolerating poor quality paid work' (section 5.2.1) much is it is arduous, drudge intensive and poorly paid and felt to be erosive of dignity. But it is to draw attention to the prevalence of such work, which much conventional analysis overlooks due to its small-scale, often intermittent, seasonal and gendered characteristics.

The essential point is that not only do informants report a desire to work rather than collect the CSG, many do work by combining employment or petty self-employment with grant receipt, either simultaneously or sequentially. Furthermore in at least two cases, late application for the CSG - which is a recurrent source of policy and academic concern- was essentially the result of the engagement in remunerative work. In this small selection of cases the stigma of receiving 'unearned income' or fear of social grant receipt creating a 'culture of dependency' or labour disincentives was disproved by the sheer scale and extent of the work that informants undertook.

\subsection{Discussion}

This chapter examined the impact of the CSG on the lone mother informant's dignity by drawing on both the focus group and in-depth interviews. The findings from the focus group interviews (Section 8.2 ) raised contradictory points. On the one hand, women spoke of how the CSG helps to protect their dignity as it enables them to provide better for their children and therefore fulfil their role as caregiver. As seen in Chapters 4 and 5 , this is a primary concern to participants and impacts directly on their maternal identity and sense of dignity. On the other hand, the point was repeatedly made that the CSG is so small a sum that it does little if anything to protect their sense of dignity. Not only is the small amount of the CSG seen as being insufficient to provide for their children's (and their own) material needs, but for some the small size of the grant signifies that the government has little consideration for their dignity, in terms of their worthiness for support.

Many of the focus group participants provided accounts of conflict over the CSG within their households and families (Section 8.2.2). Again, the issue of conflict over access to and use of the CSG is not new (e.g. Mosoetsa, 2011), but what is new is that this was depicted by some as having a detrimental impact on their sense of dignity. Regarding lone 
mothers' standing in the community (Section 8.2.3), accounts were given of having to justify to neighbours how they had used the CSG before being permitted to borrow or even beg, and of being the object of people's prejudices and judgements about having children. As such, some women described CSG receipt being used by community members to erode their dignity. Far from providing them with greater autonomy for some the CSG was paradoxically emblematic of their lack of autonomy and their inability to obtain paid work (Section 8.2.4).

In seeking to understand the role of CSG receipt in the protection of dignity, the indepth interviews captured much of the duality noted in the focus group interviews. Accounts of CSG receipt variously documented dignity-enhancing, and alternatively dignitydetracting effects. The in-depth interviews were well suited to probing the individual specificity of responses, and the above dichotomy was made more complex by a range of responses that fitted into neither category. For instance lone mother participants acknowledged the existence of opprobrium and stigma sometimes attached to grant receipt, but that they either denied that they were subject to it, or that it affected their selfconcept and self-esteem. There was also a sense of the contestation around the negative attributions attached to CSG receipt, with some respondents explicitly resisting the dignitydetracting attributions directed to them. In sum the in-depth interviews confirm the variability in reported attitudes and experiences of grant receipt and thematic continuities between the focus group and in-depth data.

The above findings were augmented with additional data, derived from the in-depth interview data, of the manner in which grant income was actually used in practice. It was found that the resources of the CSG are often used in positive and dignity-enhancing ways. The wide repertoire of grant usage was described with specific reference to practices of social reciprocity and employment. Analytically the contrast is therefore between data showing the diverse and variable impact of the CSG on the lone mother recipients' dignity, and evidence of the pragmatic reality of the CSG frequently used in dignity-enhancing ways.

In seeking to understand the impact of CSG receipt on dignity, a productive distinction to make is between the dynamics and attributions attendant to the informant's status as a CSG recipient, versus how the CSG is actually used in the context of recipient's lives. Adding to this the findings of the preceding chapter, some useful distinctions can be made of the impact of the CSG on dignity. First there is the experience of applying for and collecting the CSG (chapter 7). Second, there is the experience of having the CSG as a source of income which can often be dignity enhancing, although not exclusively so for example when it is subject to familial conflict, social stigma or attributions of misuse. Third, there is the experience of having the status of CSG recipient, either in terms of the attributions of others, or even the recipient's own identity, self-concept and subjectivity.

These distinctions have a number of implications. First, the opprobrium, disapproval or stigma from others associated with being a CSG recipient can be somewhat independent of the ways in which the CSG is used in practice. This accounts for the diverse and even contradictory ways in which recipients experience and report CSG receipt as for instance, 
dignity-enhancing in some respects but erosive in others. Second, dignity-impairing dynamics (such as opprobrium and stigma from others over GSG receipt), may occur alongside potentially dignity-enhancing CSG use - which appeared to be an experience of several informants. Third, for some recipients these dynamics may occur in parallel: they may counterbalance each other, or one might predominate over another. Finally, these findings underscore the complexity of exploring issues around CSG receipt and dignity, and the manner in which the experience of CSG receipt is shaped by the specificity of a given context and individual recipient. 


\section{Chapter 9 Social security, traditional forms of social support and Ubuntu}

Summary: This chapter considers the role that social security plays in relation to traditional forms of social support, as well as the concept of Ubuntu. Drawing from the in-depth interview material, examples are given of intersections between social security and traditional forms of social support which are variously dignity enhancing and dignity eroding (section 9.3). Findings from the focus groups are presented briefly in section 9.4 in terms of the relationship between social security and Ubuntu, and in section 9.5 results from the South African Social Attitudes Surveys 2006 and 2012 are presented on adults' attitudes to state, community and family support for poor people.

\subsection{Introduction}

This chapter examines the relationship between formal social security and traditional forms of social support, including the relationship between dignity, social security and ubuntu. Understanding the nature of the relationship between formal social security and traditional forms of social support, entails firstly defining and clarifying the nature of 'traditional social support'. Following which the relationship of 'traditional social support' to social grant (specifically CSG) receipt, and dignity can be considered.

This chapter is structured as follows: at the outset the concepts of 'traditional social support' and ubuntu are defined and discussed. Following which the relationship between social grant receipt and forms of 'traditional social support' are examined, along with their impact on the dignity of CSG recipients. Evidence on the impact of social grant receipt is then considered, and several of the previously described findings concerning grant receipt supporting, prevailing systems of social reciprocity and mutual support (Chapter 8 ) are reexamined and expanded on. It is argued that formal social security often articulates with systems of 'traditional social support' in complex ways. These are often - although not exclusively - dignity-enhancing. This analysis is then counter-posed with evidence of the dignity-detracting aspects of social grant receipt, including the opprobrium and disapproval occasionally attendant to it. The evidence of this opprobrium is presented and explicated with particular reference to in relation to what, from whom, and why opprobrium and censure occur.

This description of the complexity and social influences that impact on social grant receipt, therefore moves beyond a simple binary of social grants as dignity-enhancing versus dignity-detracting. The concluding discussion critically re-examines the relationship between traditional and formal practices of social security, and notion of 'ubuntu'. 


\section{2 'Traditional social support' and ubuntu}

'Traditional social support' can be understood in various ways, but in the rubric of the question posed in the current research it is cast in terms of the notion of ubuntu. Although there is a considerable overlap between the concepts, it is useful to define each concept and not simply conflate them. 'Traditional social support' typically describes 'horizontal' acts of mutual support and aid between individuals. These practices stand in contrast with 'vertical' relationships, between social security recipients and the state. Forms of traditional social support have been variously described as 'informal social protection' (Bracking and Sachikonye, 2006), proximal social protection (Du Toit and Neves, 2009b), 'non-formal social protection' (Mupedziswa \& Ntseane, 2013) or 'indigenous' welfare practices (Patel et al, 2012) and encapsulate the notion of informal, mutuality and reciprocity between individuals. In the South Africa context, Dekker (2008) makes a coarse distinction between either kinship-based or neighbourhood-based ${ }^{75}$ forms of traditional social support. The former are patterned by relationships between blood relatives, the latter manifest in communal level associational life such as mutual aid schemes, savings and burial societies. Several of these dynamics were brought to the fore in the discussion concerning the dignity-enhancing impact of the CSG (Chapter 8). The notion of traditional social support has moreover been explained with reference to the concept of social capital.

Social capital refers to the shared values and norms, manifest in social networks and relationships, which increase cooperative behaviour and potentially serve as a resource for both individual and public good. Having gained ascendancy in much developmental theory and practice in the last two decades, the notion of social capital has its early origins in the political science and sociologically-orientated work of Putnam (1995), Bourdieu (1986) and Fukuyama (1995). The depth of social relationships, the prevalence of trust, and richness of association life are often taken to be key indicators of social capital in a given context. Commensurately interventions drawing on the notion of social capital typically concentrate on: developing norms of civic engagement and trust, promoting consultative decision making and positive forms of collective action, minimizing negative externalities and diffusing information and knowledge (Maluccio, Haddad May, 2007).

Yet despite its utility, the concept of social capital has been subject to much critical scrutiny. The notion of social capital has been criticized for: its imprecision, the often uneven distribution of its positive effects amongst individuals, its potential to feed into relationships of patronage, cronyism and corruption, and finally the manner in which it may serve to absolve the state of its responsibilities towards marginalized populations (Fine, 1999). All of these describe potential the pitfalls of traditional forms of social security many of the tensions surrounding 'social capital' are equally apparent in relation to the concept of 'traditional social support'.

\footnotetext{
75 Even if the referents of this term are sometimes unclear, in a context with informal settlements and rural villages.
} 
In the South African context social capital, and notions of informal systems of social security as rooted in relational context of mutuality and social reciprocity are frequently cast in the Africanist register of 'ubuntu'. Yet despite its popular parlance ubuntu is marked by diverse usage and theoretical infections. Ubuntu is described as a conceptualization of humanness, which views an individual as both as embedded in, and defined by, relational ties to family, community and society (Kamwangamalu, 1999). It is summed up by the vernacular adages as: umntu ngumnut ngabany' abantu, or, motho ke motho ka batho ba babang (a person is a person through other person), in isiXhosa and seSotho respectively (Mnyaka and Motlhabi, 2005). The concept of ubuntu encompasses the communitarian ethos of traditional black African society, and the values of reciprocity, compassion, sharing and social solidarity. Accounts of ubuntu frequently lay emphasis on its distinctively black African qualities or origins. Within these conceptions of ubuntu, it is easy to overstate or romanticize it, for example:

"ubuntu is.... but the very human essence itself, which 'lures' and enables human being to become abantu or humanized being, living in daily self-expressive works of love and effort to create harmonious relationships in the community and the world beyond" (Mnyandu, 1997).

Yet this valorisation can mask some of the complexity, ambivalences and conceptual tensions within the concept ubuntu: the costs that mutuality and reciprocity exact on individuals, the uneven way in which the benefits of ubuntu are distributed amongst individuals, and its socially conservative qualities and potential to reinforce existing social stratifications, such as gender, lineage or age. A narrow focus on traditional forms of social security, or reification of the concept of ubuntu, may obscure the linkages between formal systems of state cash transfers, and informal practices of social security.

A final conceptual tension inherent in ubuntu concerns the view of personhood it embodies. Within ubuntu the communitarian emphasis is on an individual's dependency on others, within tight networks of social and communal bonds, can be at odds with conventional liberal notions of personhood and citizenship (Whitworth \& Wilkinson, 2013). After all, dependency is typically viewed as the very antithesis of individual freedom to the dominant 'emancipatory liberal mind' (Ferguson, 2013). Within the ontology of liberalism and institutions of modernity the autonomous, detached, 'rights-bearing' individual is the foundational unit. The relational and humanistic view of dependence contained in notions of ubuntu, potentially stands in contrast with the asocial and non-personal relations that characterize the modern bureaucratic state, prevailing conceptions of citizenship and systems of state cash transfers (though see section 9.4 which presents focus group material suggesting that such a tension, if it exists, is not irreconcilable). 


\subsection{Understanding social security and 'traditional social support' : the in- depth interviews}

The notion of 'traditional social support' encompasses several key aspects of the previouslydescribed dynamics, including practices of mutuality and social reciprocity (Chapter 8). As was previously argued, these dynamics and practices have a marked impact on CSG recipient's experiences of dignity. In the present chapter the dynamics and socially embedded nature of dignity is reiterated, before the impact of 'traditional social support' on experiences of dignity are discussed.

Examining the manner in which dignity is forged and sustained underscores the influence of the larger social context in which individuals are located. It was argued that, rather than simply being patterned by social grant receipt, experiences of dignity are global and cumulative, and often crucially mediated by social relationships. Commensurately a wide range of factors can potentially serve to erode dignity, and these dignity-reducing dynamics are intertwined with vulnerability more generally. This view of dignity, suggests the key influence of the overarching social context in which recipients are embedded, in shaping their experiences of CSG receipt.

\subsubsection{Traditional social support and dignity-enhancing dynamics of the CSG}

In seeking to understand the impact of social security on CSG recipients' dignity, recipients' reported attitudes and accounts of the pragmatic effects of grant receipt were examined (Chapter 8). It was argued that use of the CSG frequently occurs in ways embedded in the precepts and practices of social reciprocity. Grant income can resource the social reciprocity evident in acts of distributed care work, household-making, mobility and migration and, finally, household resource pooling (Chapter 8). It is through these mechanisms, and partially enabled by the CSG, that monetary resources, goods in-kind, favours and unremunerated labour are circulated within social networks. It was therefore argued that systems of formal social security link to the larger, and more diffuse, systems of 'traditional social support'.

This is a point that is not always recognized, for instance the assessment that "Currently, informal and formal social security exist as two separate social security networks" (Dekker, 2008 p.119) or they are framed as 'counterparts' (Olivier \& Dekker, 2003 p.562). Whereas in reality, practices and systems of informal and formal social security are often intertwined, with formal transfers supporting and animating informal systems. At present informal systems distribute and leverage formal state cash transfers, even if some commentators suggest more integration between the formal and informal systems to be desirable (Olivier et al, 2008 cited in Mupedziswa \& Ntseane, 2013; RHVP, 2010). These practices also occur in a social context that is dynamic and informal systems are subject to the pressures of urbanization, modernization, and changing cultural mores (Mupedziswa and Ntseane, 2013). 
In what follows the manner in which social grant income is absorbed into complex systems of care and 'informal social support' is reiterated, and expanded on. It is therefore argued that the CSG, in general terms, supports and strengthens 'traditional social support'.

It is here proposed that CSG receipt does not only support acts of social reciprocity, described earlier, the CSG facilitates a optimizing of care and investments in 'human capital'. By way of example, among the research participants the basket of expenditure to which the grant was directed was subtly calibrated upwards in presence of slightly higher levels of resources. Among a stratum of informants, CSG resources were harnessed to access higher quality schooling at former model $\mathrm{C}$ schools. ${ }^{76}$

\section{Extract 31}

Informant Nomkita

S.M: How do you spend the grant money here at home, when you get paid?

Nomkita: We pay transport for our children because they are not schooling here in our township. My child is schooling in [town]. All of them they are paying R250 month and we left with R30 on the grant money. [Child 1, Child 2 and Child 3], they all at [school 1], it's an English school even though the name is Afrikaans. [Child 4] is at [school 2]. [Adult 1] is at [college]. For the lunches each and every one of us [the co-resident adult siblings] see what her child will take to school for lunch

Or, similarly:

\section{Extract 32}

Informant Nosomsi was paying R200 of a R280 child support grant for the daily transport to send her child to a private school, in a nearby town. Her urban resident sister paid the R250 monthly school fee.

Nosomsi: It's a private school at X, that's a lot of money but my sister is assisting me. She is paying school fees each every month, and it's like her responsibility. She's the one who decided to take her to that school and she's willing to pay fees for her. And I pay a transport by using grant money.

The recipients could readily enumerate the advantages of these schools, such as superior sports facilities, or notably improved English and Afrikaans language acquisition. A quality widely (and with justification) believed to confer benefit in terms of future study or employability, for example informant Nomkita elaborated:

\footnotetext{
${ }^{76}$ This was the reality among a stratum of respondents, but this inquiry makes no assessment of how widespread this was. Note research participants were not randomly selected, but may have shared characteristics as they were sampled from a handful of locales.
} 


\section{Extract 33}

Nomkita: I told myself that even though I have nothing I will make sure that my child gets the best education because for us [in a black African township], you find that you have passed grade 12 but you can't even speak English properly. But I can him when he speaks English he knows it although he is in Grade 1, that is why I try so hard for him.

A number of points ought to be made in relation to this data. Although CSG recipients are constrained in terms of their options, and income is typically expended on a fairly narrow basket of basic goods (food, schooling, clothing), there were differences between respondents. In households that were comparatively less poor (albeit still poor in absolute terms), grant income was in more than one case, invested in accessing superior quality schooling. This was particularly evident in less-vulnerable households where other resources were meeting the children's food needs. In this way CSG did not simply underwrite basic consumption, it served as a material foundation for the future-orientated livelihood-making projects and building human capital. It was a resource that facilitated investments by recipients in their children's education, and offered the promise of children's material conditions being better than their own. It thereby contributed to recipients' aspirations, their sense of personal agency, autonomy and worthiness, in their conviction that their children's lives could improve over time. In this way it ultimately contributed to strengthening the human dignity of the recipients.

The flexibility inherent in the fungible cash of the CSG meant that they could be finely calibrated to the context and precise and differentiated needs of recipients. The manner in which CSG receipt can support complex practices of planning and provisioning are evident in the following extract.

\section{Extract 34}

A pensioner (mother, to the index respondent Ayanda) receives a monthly remittance from her formal sector employed son. While the CSG income is allocated to groceries and school transport for the young grandchildren, the grandmother allocates her son's monthly remittance to repay a microloan, which she took in order to refinanced debt (accrued while still working). She is on the cusp of completing the repayments, and explains her future plans.

Mother [Mother of Ayanda]: Like now I have loan from Capitec Bank when I was working I could get loan from Capitec Bank, but now I'm not working that's why I'm saying when he [her son] gives me that money I make sure that I take R500 and pay Capitec. I don't want to be like this look... [she gestures, pressing the inside of her wrists together]

D.N: Handcuffs!

Mother: I don't want (laughs) [she doesn't want to get into trouble for defaulting]. 
D.N: Do you owe Capitec a lot of money, or do you borrow small amount, pay, borrow, pay? [i.e. take revolving credit]

Mother: No I borrowed a long-term loan, it ends in October this year.

D.N: It ends October?

S.M: What was it for? Did you build a house with it?

Mother: No, I had so much debt, so I paid that debt and was left with Capitec [Capitec

repayments].

D.N: Ja after October... or November onwards when finished paying up the loan what are you going to do with extra money? What are your plans with that money? You're going to have R500 extra...

Mother: My plans are I want to take money for these children R100 a month from [Child 1, Child 2, Child 3]. R100 a month and save it at the bank.

D.N: R100 each, or R100 all together?

Mother: Yes, R100 each.

D.N: For four children?

Mother: Yes for four children.

V.C: Is for their education or what?

Mother: And I want it to be in their names and they must get it when they are old.

V.C: For what for their education?

Mother: Just for them to have money that they will get when they are old and not spend all their money.

This lengthy extract not only reveals a strategic engagement with debt and credit markets, it also points the grandmother's aspirations to redirect a substantial portion of the monthly remittance to save on behalf of for her young grandchildren. Not only would these savings constitute a significant resource in the context of poverty, note too that they offer the potential to cement the grandmother's place in future circuits of beneficence. In this way formal social security has entered into complex, and trans-temporal processes of household level resource allocation: it met the children's food and school needs and then secured the space for culturally-inscribed practices of mutual support and trans-generational transfers. The CSG income enabled forms of welfare and dignity enhancing mutuality, care and investment, alongside other resources and imperatives within the household.

\subsubsection{Traditional social support and dignity-eroding dynamics of the CSG}

Having discussed the nature of traditional social support and described its articulation with system of formal social security it was suggested these dynamics can be empowering and dignity enhancing. The present section returns to critically examine instances and accounts of grant receipt as dignity-detracting (initially described in Chapter 8 ). These dynamics are then contextualized in relation to practices of 'traditional social support'. 


\section{Understanding opprobrium: Over what?}

The claims contained in narratives of opprobrium, censure and censure are diverse. Some of the opprobrium was articulated in regular and identifiable memes including: the fiscal burden the CSG places on 'taxpayers' (extract 30), the spectre of its misuse for personal consumption by adult recipients (extracts 23,24 ), the CSG not being appropriately directed to beneficiary children, and finally the CSG leading to childbearing for instrumental or avaricious purposes, to secure the resources of the grant (extract 27). The tropes in which opprobrium is cast are all the more noteworthy because they are generally unsupported by the empirical evidence of the CSG being used, in aggregate terms, in welfare enhancing ways. In what follows opprobrium, stigma and gossip reportedly targeted to CSG recipients are described in terms of: from whom it emanates, followed by discussion of why it occurs.

\section{Understanding opprobrium: From whom?}

This section examines the opprobrium, stigma and gossip sometimes directed to CSG recipients. The basis of this reported opprobrium and censure (i.e. why it exists) is considered in the final section of this chapter, but first the sources (i.e. from whom it originates) are considered in detail.

Stigma reportedly emanates from the comparatively better off or 'rich' (i.e. those employed in 'good jobs').

\section{Extract 35}

Informant Nomkita

Y.S: They say we spending tax money of the people that are working.

S.M: Who are those people that say that?

Nomkita: People that have good jobs.

S.M: It's the people that have good jobs?

Nomkita: But when I go and get the grant I know it's not mine, it's for the transport [for school].

Stigma was reported from those in close proximity, from neighbours:

\section{Extract 36}

Informant Nomfezikile

S.M: The people that gossip in the community who are these people and are they rich or poor people?

Nomfezikile: Its neighbours.

S.M: Neighbours?

Nomfezikile: Yes. 
Or from women, according to informant Siphesande:

\section{Extract 37}

Siphesande: I never heard men gossip its only women that gossip.

V.C: What they say about the grant?

Siphesande: That the child support grant money, what you do with it and what are you wearing.

V.C: (translates for D.N)

D.N: Are they richer people?

V.C: Are the rich people that gossip?

Siphesande: It's the people that are like me they don't even work.

Finally stigma is in some cases emanates from men. In extract 26, informant Nomkita explains that stigma emanates from men who do not want to support their children, and cast aspersions on women, saying they 'got pregnant for Zuma' (i.e. the grant). For example:

\section{Extract 38}

Nomkita: They say we got pregnant for Mbeki and Zuma, they say we must go because we got pregnant for Zuma (laughter)

However the issue of the loci of stigma becomes more complex as the reported accounts of the opprobrium are collated. Reported sources of stigma and gossip include:

Informant Nomkita: The people who have jobs (employed), 'taxpayers' and men Informant Nomfezikile: Neighbours

Informant Siphesande: Women, but not men

Informant Yamkela: Women of all ages (but not men), and those that have jobs and food.

Informant Spamandla: Middle-aged women, and poor people (rather than rich people)

Informant Xoliswa: Those who are tired of supporting poor, the rich, and men. Informant Yamkela: People who have money, but they are asked by grant recipients for assistance when their grant money runs out Informant Ondela: Grant recipients themselves, even those who take their children to the Eastern Cape (and therefore obscure the fact that they themselves are receiving the grant)

Informant Olwethu: Grant recipients themselves.

Informant Nomfezikile: Grant recipients who 'laugh at each other' when others become indebted to moneylenders. 
Informant Asanda: Asanda (denies knowledge or experience of gossip) speculates that it occurs in other villages.

Informant Owami: From children (who overhear adults),

These extracts demonstrate that when asked from whom opprobrium and stigma (in relation to CSG receipt) originates, a diverse set of responses emerge. It variously emanates from: the rich or the poor, the employed 'taxpayers' and impoverished recipients themselves, amongst people in other villages, from proximate neighbours, from men and from women, from women of all ages or specifically middle-aged women, from children, from those embittered CSG recipients indebted to moneylenders, and from nobody at all.

How ought this wide range to be understood? It is important to acknowledge that due to the small sample and variability inherent in semi-structured interviewing, the design of the present study is not well suited to cataloguing the precise demographics of the speakers from whom stigma emanates. It is also useful to bear in mind that individuals' experiences are different, and some variability may reflect their varying social positions (although many described stigma and gossip in fairly generic terms). What is here suggested is that these responses point to the fact that opprobrium is pervasive - even omnipresent - and that those that utter this opprobrium are diverse. The breadth and ubiquity of the opprobrium is all the more remarkable for the fact that in low-income black African communities, CSG-receipt is so widespread as to be the de facto norm.

\section{Understanding opprobrium: Why?}

Having suggested the terms in which opprobrium is articulated, its ubiquity, and the wide group of individuals from which it emerges, this section seeks to explicate why these narratives emerge. The answer to this is explicable in terms of four broad explanations. The first explanation, relates to issues of gender, sexuality and reproductive decision-making. The second involve questions of dependency and work, the third explanation relates to questions surrounding household formation, matrimony and the troubled place of masculinity. The fourth implicates the very workings of traditional social support, ubuntu and social reciprocity.

\section{Gender, sexuality, reproductive decision making}

The first vector of censure and opprobrium relates to the patriarchal anxiety evoked by the prospect of unregulated female sexuality and social reproduction, particularly in the absence of matrimony or co-resident male partners. The gendered concerns embodied in this narrative view lone motherhood as an affront to proper gender relations, and the idealized, normative conjugal family. It is typically directed to (or articulated in reference to) lone mother recipients who are of childbearing age. It may be directed to the non-recipient mothers of the beneficiary children, if their older and more socially respectable female kin 
are the designated CSG recipients. This narrative is often intertwined with concerns regarding childbearing for instrumental purposes, to secure the resources of the grant.

So deep-rooted are these concerns, and tenacious this narrative of censure, that it intermittently surfaces in both official and popular discourse concerning the perverse incentives posed by the child support grant. It is also one that endures, despite the empirical evidence against it (Makiwane et al., 2006). So entrenched are these patriarchal concerns that many female informants understood proper social relationships and gender roles in this way, and some ascribed malign motives to other women. Men therefore did not have a monopoly on the social opprobrium concerning sexuality and reproductive decision-making.

\section{Dependency and work}

Disapproval and opprobrium in relation to CSG receipt, also taps into pervasive and longstanding anxieties of able-bodied adults accessing welfare (in this case the adult recipients of the beneficiary children's grant). This evokes a foundational distinction between deserving or undeserving poor, a tension inherent in the earliest systems of formal welfare, from the 14th Century onwards (the English Statute of Labourers 1351 and subsequent English Poor Laws).

Allied to this are concerns about creating 'dependency' through social security, a recurrent concern in the developed world where welfare benefits can be comparatively large. Although considerably lower benefit levels make these concerns less germane in the South African context, they persist (Noble et al., 2008). Much debate concerning the threat of dependency in relation to state cash transfers overlooks the reality that the vulnerable and economically marginalized are frequently dependent. They are dependent on: other impoverished people, kin, patrons, or even criminal agents, warlords etc. The empirical question ought therefore not to be whether the impoverished are dependent or not, but rather on whom they dependent and on what terms (Meth, 2004). A modest grant delivered by an impersonal, dispassionate state may be a far preferable option to many other forms of dependency.

Apart from concerns about dependency, the stigma of CSG receipt also stems from a pervasive conception of full social citizenship being conferred by an individual's status as a worker. This was commonplace sentiment evident too in the focus group interviews (section 4.2.1 and section 8.2). This 'workerist bias' is buttressed by South Africa's social welfare system, which for a century has been predicated on adult unemployment being a temporary, transient or aberrant phenomenon. Accordingly, as we have discussed in Chapter 6, non-disabled, working age adults have been excluded from means-tested noncontributory systems of state cash transfers (Van der Berg, 1997). This deeply embedded ethos is perhaps reflected in the failure to universalize social security, perhaps most notably and recently in the stillborn proposal for a Basic Income Grant. 
Against this backdrop, CSG recipients generally have weak claims to the status of being a worker, especially the valorised formally-employed variety. This 'workerist bias' positions them in the moral economy of work as the recipients of 'unearned income', and sets them up as targets of opprobrium. This occurs despite the frequent evidence of economic activity on the part of recipients.

Finally, these dynamics are compounded by the manner in which forms of security such as child support grants are targeted. The CSG might be instructively contrasted with the state's old age grant. Most impoverished individuals can imagine themselves ageing, and can hypothetically imagine accessing the OAG, whereas the same cannot be said of the CSG.

\section{Household formation, matrimony and masculinity}

Opprobrium has thus far been explained in terms of its gendered dimensions, and the manner in which worker status and remunerated labour influence it. The link between wage labour and full social membership is most apparent among men in South Africa, where for over a century male wage labour was the route into bridewealth, matrimony and household formation. It was also a route to urban residency and Western-style modernity and consumption. In this way wage labour provided the resources for progress along the pathway into full adult male personhood. Yet in the last four decades this pathway has become disrupted by rising unemployment, especially among unskilled workers. Declining unskilled employment has continuing unabated since 1994, and occurred in parallel with a feminization of the workforce as larger number of low skilled black African woman entered the labour market.

These developments have catalyzed deep changes in traditional social, demographic and conjugal arrangements. Their outcomes are evident in a range of related phenomena, some of which have already been described (Chapter 1), such as: reductions in average household size; the majority of South African children having no contact with their fathers; and mounting concern, both official and academic, with 'masculinities' (Morrell \& Swart, 2005). Men - specifically the fathers of CSG recipient children - are absent from most households. Child-bearing and child-rearing therefore occurs in a context that is disconnected from the idealized traditional practices of matrimony. In this sense CSG receipt is not only an affront to the implicit workerist ideal, but also the patriarchal prerogatives of work, and household headship. After all, for men "social membership and adult masculinity alike have long been aligned to a highly valorised capacity for wage labour" (Ferguson, 2013). These imperatives find expression in - and serve to compound social anxieties and moral panics concerning to women's reproductive decision-making and social independence.

Contemporary, impoverished black African males are consequently confronted with an upturned, upside-down world where men are powerless and superfluous, where women 
raise families with other female kin, and pension-receiving elderly women preside over household's resources. It is therefore unsurprising that fissures and conflicts are often profoundly gendered. They are imbricated with men's misgivings over women's access to resources such as the CSG, and frequently play themselves out at the interpersonal and household levels.

\section{Traditional social support and ubuntu}

The fourth and final reason for the existence of social opprobrium directed to CSG recipients relates to the very workings of traditional forms of social support and ubuntu. While the communitarian values of ubuntu are associated with social solidarity, mutuality and care, they can also serve to fuel opprobrium, censure and stigma. In this way forms and practices of traditional social support are a double-edged sword. They can both serve support dignity, or alternatively diminish it. Furthermore, it is argued here that the reproach and disapproval sometimes directed at CSG recipients is not necessarily the antithesis of traditional forms of social security and ubuntu. Instead, it can be an integral part of these practices. How this works is considered in what follows.

To recapitulate briefly, the focal research context is characterised by a communalistic ethos, and ethic of interdependency and mutuality. It is a context wherein grant income is not only consumed directly by its designated beneficiaries, but rather the resources of the grant circulate within and animate existing systems of social reciprocity. In this way, the benefits of CSG receipt reach both its designated beneficiaries and others. Within the focal research context opprobrium, censure and gossip are frequently the rhetorical strategies and registers by which social mores and conceptions of appropriate behaviour are reiterated and reinforced. Opprobrium is thus not necessarily inimical to the logic of traditional forms of social support, but sometimes an important component of it. The ethos of ubuntu and practices of 'traditional social support' are characterised not only by vaunted values of care, sharing and solidarity, but also potentially also entail opprobrium, censure, chauvinism and a cultural conservativism.

Opprobrium plays itself out at a variety of ways. First, expressions of opprobrium frequently involve an implicit reassertion of socially 'appropriate' resource use, including the social respectability required to appropriately use the grant without reproach. Recipients readily identify that dignified deportment and abstaining from disreputable behaviour were required to successfully enact 'dignity'. Several informants even explicitly identified the modest social profile, and eschewing of a prominent or exuberant social persona this task required.

Second, expressions of opprobrium are frequently intertwined with a social surveillance over the use of resources. This dynamic is not unintelligible in a communalistic context, with deeply entrenched practices of social reciprocity and where personhood is experienced and understood as fundamentally social and relational. In the focus group and 
in-depth interview material various informants readily identified this moral policing and social surveillance as emanating from others. It emanates from kin and distant others including community members, neighbours, distant acquaintances and even interlocutors on social media.

Third, opprobrium functions by posing the prospect of sanction at misuse, or even socially inappropriate grant use. It does this both prospectively and prophylactically, and even in the absence of actual evidence of misuse.

In this way, opprobrium, censure and stigma are a central trope by which entitlements are checked, obligations stressed and socially congruent behaviour policed. It is the register through which individuals (other than the designated recipients or beneficiaries involved) assert claims, duties and scrutiny over these resources.

In sum, traditional forms of social support potentially have a complex and even ambivalent relationship to dignity. These dynamics see that the resources of the CSG interface with prevailing systems and ethics of informal social support; they can be used in a manner that that bolsters dignity, but also in ways that can detract from it. Hence dignity is not an inert or static phenomenon. It is instead dynamically forged in the specificity of the context, the particularity of its use, and in relation to individuals. It is produced in exchange between people, and in relation to their larger social context.

These tensions and contradictions are not always readily understood or recognized, because it is sometimes imagined that ubuntu, 'traditional forms of social support' and the forms of 'social capital' they imply are unmitigated virtues. They are perhaps presumed to offer unadulterated benefit: to confer ceaseless advantage without any cost. This is a view of traditional social support, and 'social capital' that overlooks their potential negatives or downsides.

Traditional forms of social support, and the social capital on which it is rooted, can entail disadvantage and cost. They are for instance, not infrequently marked by coercive interpersonal relationships, violence or the threat of violence. These are evident in the claims of jealousy, and even (potentially devastating for elderly women) of witchcraft (Delius, 1996). In this way the social capital in which traditional forms of social support are rooted is not an unmitigated, inevitable or unqualified good.

Traditional forms of social support and the social capital that underpins the moral calculus of reciprocity serve to distribute resources and risk. Yet they simultaneously exact a pressure to do so. In a context where resources (including the time and energy to do care work) are finite, these transfers that benefit some are invariably costs to others.

\subsection{Social security and ubuntu: the focus group interviews}

When asked whether there was a relationship between social security and ubuntu, participants in the 25 focus groups that were undertaken in isiXhosa overwhelmingly stated that the provision of social security is a form of Ubuntu. The nature of the relationship 
between social security and ubuntu was articulated as the provision of help by the government (in the form of CSG income, or - as in the quote from Masiphumelele FG29 below - in the form of the OAG) for people in need. For example:

'Social security is ubuntu, it's an expression of ubuntu. Where were we going to get the money otherwise?' (Dimbaza, FG17).

"It is ubuntu for us because when we have just given birth we cannot work, there's no way we can work. So at least one can rely on the grant during that time."

(Masiphumelele, FG30)

Respondent 2: It is ubuntu because we haven't worked for the grant. At the end of the day the grant helps us.

Respondent 3: Yes, it is ubuntu

Respondent 6: My mother used to receive the old age pension. I fell pregnant and she continued to support me from her pension, I was able to go back to school. When she died, she died with her pension and I couldn't go back to school. So even her pension was ubuntu, it was ubuntu. (Masiphumelele, FG29)

'It's clear that people live in poverty, so something must be done and it's done in the form of the grants. It is ubuntu.' (Centani, FG23)

"It is Ubuntu because they are helping us to raise our children." (Alice, FG20)

Notwithstanding the intuitive connection that participants seemed to make between social security and the concept of ubuntu, in most of the groups the point was repeated, and often in the same breath, that the grant was still only a small amount (as seen above in section 8.2.1). For example:

"Social grants are ubuntu. They help here and there even though they are so little." (Butterworth, FG25)

Respondent 1: I think it is ubuntu because things would be much worse. At least one can buy nappies and milk from the R270. It's true it's not enough, but it's something. Respondent 2: It's half-ubuntu.

Respondent 3: It's ubuntu all the way, where would one get the milk and the nappies?

Respondent 7: Well, at least we live with the hope that on a certain date I'm going to get R270, it's not like, hopelessness. (Butterworth, FG26)

"Giving social grants to people is ubuntu. Yes it's not much but government still has to consider the elderly and even street kids. At the end of the day this money helps us." \&

"It is ubuntu, but rather measured! (Laughter)" (Khayelitsha, FG5) 


\subsection{Social attitudes towards state, community and family support}

In this final section of Chapter 9, results are presented from the module in the South African Social Attitudes Survey 2012 (SASAS 2012), which was designed especially for this project, with reference back to relevant questions in SASAS 2006.

Eight questions in the SASAS 2012 module focussed on attitudes to state, community and family support for low income people, and the results are presented in the table below. The first column 'All' contains the results for a weighted group of adults that represent all adults in South Africa; this is followed by ' $L M$ ' which contains the results for women identified as lone mothers in SASAS. This enables us to compare how the views of lone mothers in the survey compare to those of the population overall. In fact, there were almost no statistically significant differences between the responses of lone mothers and all adults (and these instances are mentioned below).

There was a high level of support for the statement that 'Employed people should pay tax on their income so government has money to pay for social grants for poor people', with $77 \%$ of respondents agreeing or strongly agreeing (Q1). Furthermore and more expansively, in SASAS 2006 66\% of respondents agreed or strongly agreed with the statement that 'the government should spend more money on social grants for the poor, even if it leads to higher taxes' (Noble et al., 2008: 13). Also, when people were asked in SASAS 2006 specifically about support for raising the level of the CSG, even if it means higher taxes, 71\% supported it being raised (Noble et al., 2008: 13).

Returning to the SASAS 2012 module, 84\% of respondents agreed or strongly agreed to the statement that 'The provision of social grants is an example of society providing support for poor people' (Q6). Although a similar proportion (85\%) of lone mothers agreed or strongly agreed with this statement, their agreement was more emphatic, with $42 \%$ strongly agreeing compared to $32 \%$ of all adults.

A high $71 \%$ of adults agreed or strongly agreed that 'The provision of social grants is consistent with the principles of Ubuntu' (Q8), suggesting not only that South Africans are familiar with the term Ubuntu across the language groups but also that people broadly regarded social security provision as being consistent with the principle. This question also yielded statistically significant differences, with $40 \%$ of lone mothers strongly agreeing, compared to only $31 \%$ of all adults.

In relation to questions on community support, there was only weak support for the statement that 'Poor people should be supported by their community rather than rely on social grants' (Q5), with 19\% agreeing or strongly agreeing, compared to $67 \%$ disagreeing or strongly disagreeing. Also, only $18 \%$ agreed or strongly agreed with the statement that 'The provision of social grants undermines the role of the community in providing support for poor people' (Q7), with 56\% disagreeing or strongly disagreeing, and $14 \%$ neither agreeing nor disagreeing (the highest percent in this category for these particular questions). 
In SASAS 2006, people were asked whether 'payment of social grants by the government encourages people to stop helping each other'. While this view had some support (31\% agreeing or strongly agreeing), a higher percentage (56\%) disagreed or strongly disagreed - remarkably this is the same percentage as for the slightly differently worded question in SASAS 2012 (Noble et al., 2008: 16).

Returning again to SASAS 2012, three of the questions touch on the issue of family support. There was clear support for the role of social security to alleviate the burden on other family members, with $78 \%$ of people disagreeing or strongly disagreeing with the statement that 'People don't need social grants because they should rely on their relatives for support' (Q2): furthermore a high 33\% strongly disagreed overall and (though not significant) an even higher $40 \%$ of lone mothers strongly disagreed. In response to the statement that 'Depending on relatives for housing and food causes tensions within the family' (Q4) more than two-thirds of respondents agreed or strongly agreed, with $16 \%$ disagreeing. Lastly, in response to the statement that 'It is better to receive social grants to avoid extreme poverty than to have to borrow from family and friends' (Q3), a very high $82 \%$ agreed or strongly agreed and only $8 \%$ disagreed in any way. 
Table 9.1: Attitudes towards state, community and family support for poor people (SASAS 2012)

\begin{tabular}{|c|c|c|c|c|c|c|c|c|c|c|}
\hline \multirow{2}{*}{$\begin{array}{l}\text { Q: To what extent do you agree or disagree with the } \\
\text { following statements? }\end{array}$} & \multicolumn{2}{|c|}{ Strongly agree } & \multicolumn{2}{|c|}{ Agree } & \multicolumn{2}{|c|}{ Neither nor } & \multicolumn{2}{|c|}{ Disagree } & \multicolumn{2}{|c|}{ Strongly disagree } \\
\hline & All & LM & All & LM & All & LM & All & LM & All & LM \\
\hline $\begin{array}{l}\text { Q1. Employed people should pay tax on their income so } \\
\text { government has money to pay for social grants for poor people }\end{array}$ & $\begin{array}{r}33.1 \\
(30.7 \\
35.7)\end{array}$ & $\begin{array}{r}39.1 \\
(33.0 \\
45.6)\end{array}$ & $\begin{array}{r}44.3 \\
(41.5 \\
47.0)\end{array}$ & $\begin{array}{r}43.9 \\
(37.5 \\
50.5)\end{array}$ & $\begin{array}{r}7.2 \\
(6.0 \\
8.6)\end{array}$ & $\begin{array}{r}6.8 \\
(4.0 \\
11.3)\end{array}$ & $\begin{array}{r}8.2 \\
(6.8 \\
9.9)\end{array}$ & $\begin{array}{r}5.1 \\
(3.0 \\
8.5)\end{array}$ & $\begin{array}{r}3.2 \\
(2.4 \\
4.2)\end{array}$ & $\begin{array}{r}2.5 \\
(11.5 \\
5.2)\end{array}$ \\
\hline $\begin{array}{l}\text { Q2. People don't need social grants because they should rely } \\
\text { on their relatives for support }\end{array}$ & $\begin{array}{r}3.3 \\
(2.5 \\
4.4) \\
\end{array}$ & $\begin{array}{r}2.8 \\
(12.5 \\
5.9) \\
\end{array}$ & $\begin{array}{r}9.1 \\
(7.8 \\
10.6) \\
\end{array}$ & $\begin{array}{r}9.0 \\
(5.9 \\
13.7) \\
\end{array}$ & $\begin{array}{r}8.8 \\
(7.4 \\
10.4) \\
\end{array}$ & $\begin{array}{r}6.4 \\
(3.7 \\
10.8)\end{array}$ & $\begin{array}{r}44.7 \\
(42.0, \\
47.5)\end{array}$ & $\begin{array}{r}41.6 \\
(35.3 \\
48.3)\end{array}$ & $\begin{array}{r}32.9 \\
(30.5 \\
35.5)\end{array}$ & $\begin{array}{r}39.9 \\
(33.7 \\
46.3) \\
\end{array}$ \\
\hline $\begin{array}{l}\text { Q3. It is better to receive social grants to avoid extreme } \\
\text { poverty than to have to borrow from family or friends }\end{array}$ & $\begin{array}{r}35.4 \\
(32.9, \\
38.0) \\
\end{array}$ & $\begin{array}{r}38.7 \\
(32.6, \\
45.1) \\
\end{array}$ & $\begin{array}{r}47.4 \\
(44.7 \\
50.2) \\
\end{array}$ & $\begin{array}{r}50.3 \\
(43.8, \\
56.8) \\
\end{array}$ & $\begin{array}{r}7.8 \\
(6.2 \\
9.7) \\
\end{array}$ & $\begin{array}{r}5.0 \\
(3.0 \\
8.2) \\
\end{array}$ & $\begin{array}{r}5.4 \\
(4.3 \\
6.6) \\
\end{array}$ & $\begin{array}{r}4.6 \\
(2.7 \\
7.7) \\
\end{array}$ & $\begin{array}{r}2.6 \\
(1.9 \\
3.6) \\
\end{array}$ & $\begin{array}{r}1.0 \\
(0.3 \\
3.2) \\
\end{array}$ \\
\hline $\begin{array}{l}\text { Q4. Depending on relatives for housing and food causes } \\
\text { tensions within the family }\end{array}$ & $\begin{array}{r}28.1 \\
(25.8 \\
30.5)\end{array}$ & $\begin{array}{r}35.1 \\
(29.1 \\
41.7)\end{array}$ & $\begin{array}{r}41.0 \\
(38.3 \\
43.7)\end{array}$ & $\begin{array}{r}39.2 \\
(33.0 \\
45.8)\end{array}$ & $\begin{array}{r}12.6 \\
(11.0, \\
14.5)\end{array}$ & $\begin{array}{c}10.3 \\
(7.0 \\
14.9)\end{array}$ & $\begin{array}{c}11.3 \\
(9.7 \\
13.0)\end{array}$ & $\begin{array}{c}9.2 \\
(6.5 \\
12.9)\end{array}$ & $\begin{array}{r}4.8 \\
(3.8, \\
6.1)\end{array}$ & $\begin{array}{r}5.6 \\
(3.1, \\
9.8)\end{array}$ \\
\hline $\begin{array}{l}\text { Q5. Poor people should be supported by their community } \\
\text { rather than rely on social grants }\end{array}$ & $\begin{array}{r}3.9 \\
(3.1 \\
4.9)\end{array}$ & $\begin{array}{r}5.9 \\
(3.7 \\
9.3) \\
\end{array}$ & $\begin{array}{r}15.2 \\
(13.4, \\
17.2) \\
\end{array}$ & $\begin{array}{r}20.0 \\
(15.1 \\
26.1) \\
\end{array}$ & $\begin{array}{r}13.0 \\
(11.1 \\
15.2) \\
\end{array}$ & $\begin{array}{r}9.0 \\
(6.0 \\
13.1) \\
\end{array}$ & $\begin{array}{r}38.1 \\
(35.5 \\
40.8)\end{array}$ & $\begin{array}{r}33.0 \\
(27.1, \\
39.5)\end{array}$ & $\begin{array}{c}28.4 \\
(26.1, \\
30.8)\end{array}$ & $\begin{array}{r}31.6 \\
(25.9, \\
37.9)\end{array}$ \\
\hline $\begin{array}{l}\text { Q6. The provision of social grants is an example of society } \\
\text { providing support for poor people }\end{array}$ & $\begin{array}{c}31.6 \\
(29.2 \\
34.1) \\
\end{array}$ & $\begin{array}{c}41.6 \\
(35.2 \\
48.2) \\
\end{array}$ & $\begin{array}{r}52.8 \\
(50.1, \\
55.5) \\
\end{array}$ & $\begin{array}{r}43.8 \\
(37.4 \\
50.3) \\
\end{array}$ & $\begin{array}{r}5.6 \\
(4.5 \\
7.0) \\
\end{array}$ & $\begin{array}{r}7.6 \\
(4.6, \\
12.3) \\
\end{array}$ & $\begin{array}{r}5.2 \\
(4.1 \\
6.6) \\
\end{array}$ & $\begin{array}{r}4.2 \\
(2.3 \\
7.7) \\
\end{array}$ & $\begin{array}{c}1.7 \\
(1.1 \\
2.6) \\
\end{array}$ & $\begin{array}{r}0.8 \\
(0.3 \\
2.1) \\
\end{array}$ \\
\hline $\begin{array}{l}\text { Q7. The provision of social grants undermines the role of the } \\
\text { community in providing support for poor people }\end{array}$ & $\begin{array}{c}7.3 \\
(6.1 \\
8.7)\end{array}$ & $\begin{array}{c}10.5 \\
(7.1 \\
15.3)\end{array}$ & $\begin{array}{c}18.0 \\
(16.1 \\
20.0)\end{array}$ & $\begin{array}{r}17.2 \\
(13.0 \\
22.5)\end{array}$ & $\begin{array}{r}14.1 \\
(12.3, \\
16.0)\end{array}$ & $\begin{array}{c}14.7 \\
(10.5 \\
20.2)\end{array}$ & $\begin{array}{r}40.9 \\
(38.2 \\
43.6)\end{array}$ & $\begin{array}{r}36.9 \\
(30.7 \\
43.6)\end{array}$ & $\begin{array}{r}15.3 \\
(13.5 \\
17.2)\end{array}$ & $\begin{array}{r}16.3 \\
(12.3, \\
21.3)\end{array}$ \\
\hline $\begin{array}{l}\text { Q8. The provision of social grants is consistent with the } \\
\text { principles of Ubuntu }\end{array}$ & $\begin{array}{r}31.0 \\
(28.6, \\
33.5)\end{array}$ & $\begin{array}{r}40.2 \\
(34.0, \\
46.6)\end{array}$ & $\begin{array}{r}45.3 \\
(42.6, \\
48.0)\end{array}$ & $\begin{array}{r}43.2 \\
(36.7 \\
49.9)\end{array}$ & $\begin{array}{c}10.2 \\
(8.3 \\
12.3)\end{array}$ & $\begin{array}{r}7.1 \\
(4.4 \\
11.2)\end{array}$ & $\begin{array}{r}5.3 \\
(4.3 \\
6.7)\end{array}$ & $\begin{array}{r}3.5 \\
(1.8 \\
6.7)\end{array}$ & $\begin{array}{r}1.3 \\
(0.8 \\
2.1)\end{array}$ & $\begin{array}{c}11.6 \\
(0.3 \\
3.9)\end{array}$ \\
\hline
\end{tabular}

Notes: 'All' = all adults; 'LM' = lone mother respondents. 


\subsection{Discussion}

This chapter explored the complex relationships between dignity and 'traditional forms of social support' including 'ubuntu'. At the outset definitions of 'traditional social support' and 'ubuntu' were examined in detail. Following which the question of the relationship between these and dignity was considered with reference to data derived from three very different scales: the minutiae of a small selection of in-depth interviews, the wider selection of focus group interviews, and statistical analysis of a nationally representative survey.

The focus group interviews (section 9.4) demonstrated that the isiXhosa-speaking CSG recipients regarded social security as a form of ubuntu. Participants repeatedly made the point that 'social security is ubuntu', and without the CSG their circumstances would be much worse. This suggests that the notion of ubuntu is not limited to manifestations of traditional social support: ubuntu can also be evident in actions of the state, and were identified as such in relation to the CSG. However, many went on to venture that when identifying social security as an example of ubuntu this did not eliminate their concern about the small size of the amount paid out in the form of CSG.

At the national level (section 9.5), data from the South Africa Social Attitudes survey (2012) was used to examine attitudes to the state, community and family support. The statistically representative survey documented broad and popular endorsement of the provision of tax-funded social security provision for low-income people. It revealed that social security was firmly regarded as preferable to reliance on kin (believed by respondents to cause tensions in the family), or having to borrow and obtain resources from family or friends. Accordingly, the survey found South Africans predominantly disagreed with the proposition that the community rather than the state ought to support poor people (i.e. there was strong support for the state's role). Despite this support for state based social security, South Africans did not view it as undermining the role of community support; on the contrary, social security was viewed as a manifestation of society supporting poor and vulnerable people. Therefore social security was firmly believed to be consistent with the commonly-understood principles of Ubuntu. The large-scale survey data therefore confirms strong public support for formal, state-based social security provision, funded through taxation. Social security is generally viewed as neither in opposition to community support of poor people, nor inconsistent with the ethos of ubuntu.

The in-depth interviews (section 9.3) delineated many of these dignity-enhancing dynamics of social security implied in the survey data. These include the manner in which grant receipt bolsters social reciprocity - a key aspect of community support and forms of 'traditional social support'. The specificity and depth of these interviews also facilitated detailed examination of the converse - the dignity-detracting aspects of grant receipt. Opprobrium and stigma in relation to CSG receipt were therefore examined in terms of both from whom, and why it emanates. Opprobrium and stigma were explicable in terms of four dynamics. The first, are popular concerns about gender, female sexuality and reproductive 
decision-making, the second apprehension over the spectre of welfare dependency and receipt of 'unearned' income, the third anxiety over present day household formation, matrimony and the troubled place of contemporary masculinity. The fourth and final source of opprobrium and stigma is potentially the very workings of 'traditional forms of social support' itself. In this final point it was argued that dignity-detracting opprobrium and censure are not discrete and unconnected from the workings of traditional forms of social support, but rather may represent an inherent and integral part of these social practices.

This chapter, and the diverse data presented in it, therefore confirmed the support for and synergies between formal, state-based social security and informal 'traditional social support', but caution that forms of 'traditional social support' and ubuntu also have potentially dignity-detracting qualities for lone mothers. In this way practices of traditional social support are firmly, yet not consistently or unmitigatingly positive in their impact on dignity. 


\section{Chapter 10 Social security for lone mothers - if it existed how might it affect recipients' dignity?}

Summary: This chapter considers the introduction of some form of social security for lone mothers in South Africa. Lone mothers were asked in the focus groups for their thoughts about how such a grant would intersect with their sense of dignity and the findings are presented in section 10.2. The notion was strongly supported. Most participants ventured that it would help to protect their dignity by reducing poverty, as well as helping them to perform their roles as caregivers and to meet their own material needs, although there was an undercurrent of concern about perverse incentives and unintended consequences. A similar question was put to a nationally representative sample of the population in SASAS 2007, presented in 10.3. The survey results resonate well with the focus group material, and reveal support for a new grant not only amongst working age single mothers but also amongst the wider population.

\subsection{Introduction}

Chapter 6 sought to articulate the current lack of social security provision for lone mothers in South Africa. Chapters 7-9 presented analysis of lone mothers' intersection with the current social security system via the CSG which is provided for children. In this chapter we consider the question of the introduction of some form of social security for lone mothers in South Africa, in their own right. In Section 10.2 analysis is presented of focus group interviews in response to a question about a hypothetical grant for the caregivers of the children for whom CSG is claimed. Section 10.3 presents results from SASAS 2007 on attitudes to state support for single parents ${ }^{77}$.

\subsection{Results from the focus groups}

"We would also feel more human, like people with dignity. At least there would be something for our own needs. (Masiphumelele, FG29)

The focus group participants were asked the following question: "If there was a social grant for the adult recipients of CSG in addition to the existing grant (which is intended only for their children's needs) how do you think this would impact on their sense of dignity?"

Details of eligibility were not mentioned in the question, but as it was stated that the grant would be for the carer of the child for whom CSG is received, it can be assumed that the eligibility criteria would be the same, i.e. the grant would be for primary caregivers of

${ }^{77}$ See Section 10.3 for an explanation of the use of the term 'single parent'. 
children, with an income of less than R36,000 per year. The critical detail of the amount of the grant was also not mentioned in the question, but women responded to the question by focusing on the principle of the idea.

The overwhelming response to the question was positive, with people stating that the grant would help to protect their dignity as it would reduce poverty:

"It would help protect our dignity because we are poor." (Nyanga FG1)

"It would protect our dignity because there would be less poverty and suffering." (Dimbaza, FG17)

"It would uplift people's dignity, without a doubt, especially for someone like me who does not have a job. I mean we're really struggling, it's not easy being poor." (Langa, FG6)

One woman commented that she had heard that social security is provided elsewhere for caregivers, observing that:

"I've heard about this, my cousins live with their parents overseas. Apparently there are all sorts of grants, including for mothers like us. I always ask myself why it's not like that here, our dignity would be protected." (Butterworth, FG24)

In Chapter 4, numerous examples were given of the negative ways in which poverty impacts of lone mothers' sense of dignity, and so it makes logical sense that people might regard a grant as helping to protect their dignity. But in what specific ways would it do so, and were there any countervailing comments? The following sub-sections explore the focus group contributions of lone mothers in relation to ways in which the grant would enhance their dignity in two respects: their ability to provide for their children, and their ability to provide for their own material needs. In the final sub-section we present material on some of the lone mothers' concerns about negative or unintended consequences of such a grant. We consider these themes below with reference to the issues identified in Chapters 4 and 5, both in relation to lone mothers' portrayals of dignity and the accounts of ways in which poverty impacts on their sense of dignity.

\subsubsection{Improved ability to provide for children}

In Chapter 4 it was noted that the focus group participants often made a direct link between their sense of dignity and their ability to provide adequately for the needs of their children. The preservation of their role as caregiver was of paramount importance and was cited as the main reason why their dignity should be protected and respected. Their inability to provide for the material needs of their children, due to poverty, was often expressed as 
being detrimental to their sense of dignity. As a woman in Paarl graphically described it: 'Poverty destroys our dignity as mothers' (Paarl, FG28). It should come as no surprise, therefore, that many women's responses to the idea of an adult grant were oriented towards how this would impact on their roles as caregivers and their ability to care for their children.

"It would really help protect our dignity because we would be able to be proper parents and meet our children's needs accordingly." (Nyanga FG1)

Many of the respondents made the point that an adult grant would enable the CSG to be spent on the child rather than being diluted to meet other people's needs, including their own. For example:

"It would be good because we would be able to spend the child's grant on them and not on our needs, that will 'bring back our dignity'. (Alice, FG21)

"It would be good because we would be able to look after ourselves without depending on the CSG, the CSG would be for the child's needs only, I wouldn't use the CSG for groceries." (Alice, FG20)

In fact, many stated that they would use the extra grant to contribute to current unmet material needs of their children:

Respondent 3: It would help a great deal. I would be able to buy school uniform for my child, a school blazer and a jersey.

Facilitator: So you think that you would still use the adult grant on your child? Respondent 3: Definitely! The CSG is not enough. At least my child would be able to eat porridge every morning before going to school. Now he can't concentrate in school because he's hungry all the time. He comes back home from school and there's still no food to eat. So if there were such a grant, I would better be able to provide for my children and my dignity as a mother would be restored.

(Mbekweni, FG27)

"It would help because we don't even have the money to buy the onion and sugar they tell us to use in the clinic [if the child has a cold or flu]. It's pathetic." (Paarl, FG28)

"Even with this grant that is meant to help mothers as well, we will end up using it for the children's benefits and on groceries for the whole family, so that means $80 \%$ of the time you think of your child's needs before yours. I'd rather be the one who is hungry and not my baby." (Respondents agree) (Langa, FG7) 
"Women are generally responsible beings, if we got such a grant we would end up supporting our families with it anyway. We wouldn't just use it for ourselves, no." (Langa, FG6)

In Centani, two women spoke of how the grant would contribute to their ability to look after their children as it would mean that they would no longer need to go in search of paid work which currently results in their children being neglected:

"If there was such a grant I would be able to look after my child properly. Because the CSG is not enough I have to go look for 'piece' jobs in order to provide for the child the best I can. So I end up neglecting my child and not looking after him properly. If there was such a grant, I would take care of my child better and not look for 'piece' jobs all the time." \&

"Sometimes it's cold and I wouldn't be home, I don't even know if my child is warm. Sometimes I can't make food for him because I'm not there. It's not good neglecting your child because of money." (Centani, FG23)

\subsubsection{Improved ability to meet one's own needs}

The majority of the focus group participants' comments about the hypothetical grant comprised examples of how such a grant would help them to meet their own material needs. The point was repeatedly made that a grant aimed at helping them meet their own needs would help to protect their dignity:

"to receive a grant for my personal needs would be helpful and would go a long way in protecting my dignity." (Langa, FG6)

"It would have a drastic positive impact on ones dignity, at least as a mother you would get some sort of income together, for your personal needs." (Langa, FG7)

"Such a grant would be good for my dignity. It would cover areas in my life that are not taken of and are the cause of my humiliation. A grant like that would cover these areas, it would be helpful. (Butterworth, FG26)

"I think our dignity would come back to us if government would increase its support for us unemployed people and give us more money. We are dependent on the children's grants, that's not right. If government does not create jobs, it must support us with more money." (Nyanga, FG1) 
Examples given of the needs that would be met were mainly food, toiletry, clothing and housing. For example:

"If there'd be a grant for mothers like us, at least more needs would be covered. It would help a lot...Toiletry, we never had toiletry. We can't use the CSG to get toiletry" (Khayelitsha, FG5)

"It would help because I would be able to see to my own needs, like buy toiletry and even help at home." (Xesi, FG19)

Two women described how the grant would help them to be able to eat properly so that they could take their ARVs:

"It can help a lot, our dignity would be protected. We can actually have dignity because it would cover so many problems, such as food and other day to day needs. I sleep 3 and 4 days without food and borrow money for bread, French polony and drink pop. When I do that I can't take my ARVs, when I don't eat because it destroys your stomach. But I'm strong because I'm not in an out of hospital. When I get their grant [the CSG] I do the groceries." (Khayelitsha, FG4)

"Yes, also for us people living with AIDS, we would be able to care for ourselves properly, we would buy the nutritious food we need because now, my CD4 count is high, I don't get a disability grant. This kills people because the CD4 count can suddenly drop and my life is in danger. So I need money to support myself." (Dimbaza, FG17)

Another woman commented on how the grant would enable her to eat properly whilst breastfeeding:

"That would really help to protect our dignity. We would, at least, be able to buy food for ourselves. It's not good having to nurse a child, like me, while hungry." (Masiphumelele, FG30)

In relation to housing, women in a focus group in Xesi spoke of how a grant would enable them to live independently from their parents, or at least contribute to the running of a household if they remained with them:

"It would be good because we would be able to have our own homes as adults and not live with our parents like we are children all over again."

\& 
"Even if you remain at home, at least it will be pressure off our parents to support us because we will be contributing and supporting ourselves. It would definitely help protect our sense of dignity."

\&

"If I could just live with my child, just the two of us, my child would be more emotionally stable. Now I have to protect her from my abusive mother who switches off the electricity and locks food away when she's drunk or when I get the grant. These things affect my daughter so if such a grant would come out, it would help my dignity and my child's. (Xesi, FG18)

A woman in Qumrha described how she would spend most of the grant on her children, but would also - brick by brick - build a room of her own and reclaim her sense of dignity as a mother and a woman:

"Well it would still go to the children, that money. But at least they would be well taken care of, unlike now. And at least I wouldn't be sleeping in the same room as my children. I would be able to, even if it's slowly, build an additional room. Even if I buy one brick at a time, ultimately I would have my dignity as a mother and as a woman -having my own room." (Qumrha, FG15)

Examples given of the positive role of the grant were not solely about the ability to afford things. They also related more broadly to the issues of worthiness, self-respect, self-esteem and autonomy that were identified in Chapter 4. For example, a woman in Thafalofefe spoke of how it would protect them from 'the disgrace of poverty' and enable her to regain her sense of common humanity:

"It would protect us from the disgrace of poverty. I'd be like other people too. The CSG would take care of my child, and I'd look after my own needs too. I would even be able to buy furniture like other normal people. I would be able to eat what I want to eat, my child and I. The isolation from other people because of poverty would stop. I too, would be a human being like others." (Thafalofefe FG22)

One woman in Lavender Hill alluded to the way in which the grant would contribute to her sense of worthiness:

"I will feel as if they [i.e. government] are starting to become interested in the mother." (Lavender Hill, FG 10)

Others spoke of how their dignity would be protected as they would be able to be less dependent on their parents:

"It would to contribute towards protecting my dignity as a woman, an adult. I mean I don't want to have to ask my mother for everything but I'm having to because of the 
In Chapter 5 accounts were given of ways in which strategies to avoid poverty (tolerating unsatisfactory working conditions, casual work for neighbours and family, begging, and transactional sex) impacted negatively on women's sense of dignity. A few women commented that a caregiver's grant would reduce their need to undertake demeaning casual work or beg. So for example:

"It would help protect our dignity because then you're not just depending on this R270. We would stop knocking on other people's doors to ask to do their washing, because that's how we end up being treated badly. (Butterworth, FG25)

"It would definitely help protect our sense of dignity because we would stop begging." (Alice, FG21)

However, in relation to how a new grant would impact on strategies to survive poverty that impact negatively on dignity, the most frequent point to be made was that it would reduce the need to use transactional sex as a means of survival for themselves and their children.

"It would help immensely. Mothers prostitute themselves not because they want to but because they have no other way. People look for jobs for ages, in the mean time their children are suffering, one realizes that as a prostitute within a week I can get this much and do that and that for my family. Even though the reason is good, people their dignity is eroded, there is no self respect. The community loses respect for you too once they find out, so such a grant would be a lot of help, it would get us out of many troubles, basically." (Qumrha, FG14)

"It would end up protecting us in many ways, right now we are susceptible to diseases because of the lives we lead, just to survive." (Nyanga, FG2)

"A woman's dignity would be restored in our country. A lot of women have multiple sexual partners just because they can derive some kind of income from these mennot because they want or desire these partners. At the end of the day, they are living with HIV/AIDS, it's tragic. They throw away their dignity not because they want to, but for survival. (Qumrha, FG15)

"We would stop selling ourselves short to men because of poverty, we wouldn't need to rely on them so much. It's very bad. Often you give yourself to a man hoping they'll help you out with money, and they just use you and leave you." (Thafalofefe FG22) 
"We'll stop going out with older men, sugar daddy's, for money"..." know, sugar daddy's give you R250 in one go, to 'buy cool drink', so they say." (Khayelitsha, FG5)

"We won't end up selling ourselves and risking our lives as women, because at least we have something to look to." (Butterworth, FG24)

In addition, others spoke about how the grant would enable them to escape abusive relationships:

"It would also save a lot of women from abuse from men. We stay in relationships because these men give us much needed money, therefore we can't report them when they are abusive, what will we do for money?"

\&

"It can be physical abuse or even sexual abuse. You can even end up with diseases because you need money from the same man who is abusing you, and he knows this so continues the same way because there are no consequences." (Qumrha, FG14)

"We would have dignity. If a guy is messing around with you, we'd be able to tell him to leave your house and not suck up to him because you need his money." \&

"Even the father of the child, if he's mistreating you and you tolerate it because you want him to support your child - well we wouldn't have to withstand the bad treatment with such a grant. If he knew I could look after myself, he won't disrespect me and take my dignity away the way he does now. l'd be able to tell him to leave with the same door he entered." (Thafalofefe FG22)

\subsubsection{Concerns about negative or unintended consequences}

Although the vast majority of women responded very positively to the idea of a grant directed at them as caregivers, there was additionally an undercurrent of concern in some of the focus groups about the potential misuse of the grant and of unintended consequences. This corresponds with previous studies that have explored attitudes towards expanding social security provision (e.g. Surender et al., 2010).

For example one woman said that fear of misuse of the grant would mean that it would never be introduced:

"They won't give it because then there are people who will misuse it." (Lavender Hill, FG 10) 
Examples of misuse included taking the money and leaving the child with its grandmother, ceasing job searching, and having children in order to be entitled to the grant. For example:

"I don't think it would be a good thing because there are mothers who would forget about their children if they had that money. They would just spend it on themselves and be happy away from their children, leaving them with the grandmother." (Xesi, FG19)

"I don't think it will be a good thing for us to get our own grants as mothers, that will make people lazy, they won't go and look for jobs, they will want to depend on the grant." (Alice, FG20)

In most instances, concerns around misuse were met with rebuttals from other members of the group. For example:

Respondent 3: I think such a grant would erode dignity. People would have children just so they can get this grant.

Facilitator: Do you also think people have children just to access the CSG as well? Respondent 3: No, I don't, but with the grant you're talking about, people would because of the extra money.

Respondent 2: But people have children already, anyway, without this grant. Why would things change?

Respondent 4: The money would help, it would go back to supporting the children anyway because the CSG is not enough.

Respondent 5: It would help with childcare needs so that we can work.

(Masiphumelele, FG30)

In a similar rebuttal, following a discussion about the risks of misuse of the grant in Dimbaza, a woman said:

"It would help us a lot. It would protect our dignity, forget about the people that misuse it. We have nothing, we are hungry, we have no jobs, we are humiliated doing people's gardens. It would be a very good thing." (Dimbaza, FG16)

Not all of the concerns focused on misuse of the grant; other concerns related to worries about negative consequences of such a grant including verbal abuse and stigma. ${ }^{78}$ OIn Khayelitsha there was a concern about the stigma of receiving such a grant, particularly if it was called a grant for poor people, and how this would impact negatively on their sense of dignity:

\footnotetext{
${ }^{78}$ For an excellent study of the CSG and stigma in Soweto, see Hochfield and Plagerson (2011).
} 
Respondent 2: It won't protect dignity because the people that will want that money will feel ashamed when going to receive it and yet others won't go and look for work Facilitator: Why would they feel ashamed?

Respondent 2: Because of the insults and attitudes they'll get

Respondent 3: If they call it a grant for poor people, or say it is, it will definitely impact on dignity negatively, those who have jobs will remain with their intact dignity and won't come and get it (Khayelitsha, FG3)

In Qumrha there was a concern that such a grant would result in the caregivers suffering from an increase in verbal abuse:

"It would help I'm sure, but we deal with verbal abuse at times. People will tell you to shut up because you get the grant from their taxes, so how much more when there's a dedicated grant for single mothers like us? (Qumrha, FG14)

In Alice, some women were also worried that it would make things worse for them in terms of their reduced standing in the community, whilst others in the group spoke of being the object of others' envy:

Respondent 5: I think that would make things worse, we would be treated with even less dignity and respect. People attack us for the CSG, imagine if we got yet another grant.

Respondent 1: People will say we are giving birth because we want the mothers' grant. Can I ask, just to be clear, the grant would be for mothers like us.

Facilitator: Yes.

Respondent 1: I think that would make things worse for us in the community.

Respondent 3: I don't think so, because the focus won't be on one person or a certain group of people, every mother would get it.

Respondent 4: They insult us because they are envious of the grant.

Respondent 5: Some are childless and maybe bitter about that. (Alice, FG20)

In Butterworth the facilitator asked whether -as the group had previously reported being on the receiving end of insults from the community as CSG recipients - they thought that an adult grant would cause the same problem. A woman replied agreeing that it might result in insults, but reaffirmed the fact that 'we still have needs and need to survive':

"Probably, but we still have needs and need to survive. Babies are very expensive to maintain and look after. From the R270 I have to feed my baby, clothe her, take her to the doctor, frequently, because she has a problematic chest. So let the people talk, I have needs to take care of." (Butterworth, FG26) 


\subsection{Social attitudes about social security for single mothers}

The South African Social Attitudes Survey (SASAS) 2007 contained a module on Women, Childcare and Work. ${ }^{79}$ SASAS 2007 is representative of the adult population (defined as 16 years and over) in South Africa, with a realised sample size of 3,164 . The module asks a question 'Are you a single parent?' while a question elsewhere in the survey asks 'Are you the parent or caregiver of any children under the age of 18?'. By combining these two questions with questions on gender and age, it was possible to identify single mothers of working age who have children under the age of $18 .^{80}$

Table 10.1 below shows the responses to questions about unemployed single mothers, for all adults ('All'), male respondents ('M'), female respondents (' $F$ '), and working age single mothers ('SM').

Table 10.1: Social attitudes about state support for unemployed single mothers (SASAS 2007)

\begin{tabular}{|c|c|c|c|c|c|c|}
\hline \multirow{2}{*}{$\begin{array}{l}\text { Q: To what extent do you agree or } \\
\text { disagree with the following } \\
\text { statements? }\end{array}$} & \multicolumn{2}{|c|}{ Agree } & \multicolumn{2}{|c|}{ Disagree } & \multicolumn{2}{|c|}{ Neither nor } \\
\hline & All & SM & All & SM & All & SM \\
\hline $\begin{array}{l}\text { Q1 There should be a grant for } \\
\text { unemployed single mothers to meet } \\
\text { their basic needs (in addition to the } \\
\text { Child Support Grant) }\end{array}$ & $\begin{array}{r}77.4 \\
M 74.2 \\
F 80.3\end{array}$ & 85.0 & $\begin{array}{r}13.1 \\
\text { M } 14.7 \\
\text { F } 11.6\end{array}$ & 9.4 & $\begin{array}{r}8.9 \\
M 10.2 \\
F 7.6\end{array}$ & 5.2 \\
\hline $\begin{array}{l}\text { Q2 Unemployed single mothers do } \\
\text { not need any help from the state } \\
\text { and should stand on their own two } \\
\text { feet }\end{array}$ & $\begin{array}{r}22.6 \\
M 23.8 \\
F 21.5\end{array}$ & 19.6 & $\begin{array}{r}63.1 \\
\text { M } 61.5 \\
\text { F } 64.6\end{array}$ & 68.2 & $\begin{array}{r}13.4 \\
M 13.4 \\
\text { F } 13.4\end{array}$ & 11.3 \\
\hline $\begin{array}{l}\text { Q3 Unemployed single mothers } \\
\text { seeking work should have access to } \\
\text { free childcare facilities to aid their } \\
\text { job search }\end{array}$ & $\begin{array}{r}76.3 \\
M 73.2 \\
F 79.2\end{array}$ & 82.4 & $\begin{array}{r}9.2 \\
M 10.4 \\
F 8.0\end{array}$ & 7.1 & $\begin{array}{r}13.3 \\
M 14.8 \\
F 11.8\end{array}$ & 9.2 \\
\hline $\begin{array}{l}\text { Q4 Unemployed single mothers } \\
\text { should have free skills training } \\
\text { provided by the government }\end{array}$ & $\begin{array}{r}84.0 \\
M 81.6 \\
F 86.2\end{array}$ & 86.5 & $\begin{array}{r}4.8 \\
M 5.0 \\
F 4.6\end{array}$ & 4.1 & $\begin{array}{r}10.1 \\
M 11.9 \\
F 8.5\end{array}$ & 8.5 \\
\hline $\begin{array}{l}\text { Q5 Single mothers should not be } \\
\text { expected to work unless free } \\
\text { childcare is available }\end{array}$ & $\begin{array}{r}36.1 \\
M 36.5 \\
F 35.7\end{array}$ & 35.1 & $\begin{array}{r}46.1 \\
M 47.2 \\
\text { F } 45.1\end{array}$ & 47.7 & $\begin{array}{r}16.5 \\
M 14.8 \\
F 18.2\end{array}$ & 15.8 \\
\hline
\end{tabular}

Over three quarters of all adults and single mothers agreed with the statement that 'There should be a grant for unemployed single mothers to meet their basic needs (in addition to

\footnotetext{
${ }^{79}$ Although predating this project, the module was designed by members of the Oxford team.

${ }^{80}$ On this basis, 4.97 million adults were identified as single parents of a child under the age of 18, of which $84 \%$ were female. Of the lone mothers, $88 \%$ were of working age, amounting to $3.68 \mathrm{~m}$. It is not known how respondents treated the question on single parents (and no guidance is given to respondents as to how a single parent should be defined). Therefore the definition of lone mother used in the analysis in this section may not be the same as that employed elsewhere in the report.
} 
the CSG)' (Q1). A higher proportion of women than men agreed with the statement, and single mothers had the highest level of agreement at $85 \%$, with only $9 \%$ disagreeing.

Almost two-thirds of respondents disagreed with the statement that 'Unemployed single mothers do not need any help from the state and should stand on their own two feet' (Q2). Although this leans strongly in favour of support from the state it should be noted that a fifth of the single mothers agreed with this latter statement, possibly reflecting concerns such as were highlighted in section 10.2.3 above.

There was strong support for assistance with free childcare and job searching for unemployed single mothers, with $76 \%$ of respondents agreeing and $82 \%$ of lone mothers agreeing (Q3). There was also strong support for the provision of free skills training by government for unemployed single mothers, with $84 \%$ of respondents agreeing, and a higher $86.5 \%$ of lone mothers (Q4). However, respondents were less attracted to the notion of free childcare being a pre-requisite of lone mothers working, with almost half of all respondents and of lone mothers disagreeing with the statement that 'Single mothers should not be expected to work unless free childcare is available' (Q5).

The following Table shows responses to questions about employed lone mothers.

Table 10.2: Social attitudes about state support for employed single mothers (SASAS 2007)

\begin{tabular}{|c|c|c|c|c|c|c|}
\hline \multirow{2}{*}{$\begin{array}{l}\text { Q: To what extent do you agree or } \\
\text { disagree with the following } \\
\text { statements? }\end{array}$} & \multicolumn{2}{|c|}{ Agree } & \multicolumn{2}{|c|}{ Disagree } & \multicolumn{2}{|c|}{ Neither nor } \\
\hline & All & LM & All & LM & All & LM \\
\hline $\begin{array}{l}\text { Q6 Government should top-up the } \\
\text { wages of single mothers in low paid } \\
\text { work }\end{array}$ & $\begin{array}{r}76.4 \\
M 73.5 \\
F 79.2\end{array}$ & 80.3 & $\begin{array}{r}10.5 \\
\text { M } 11.5 \\
\text { F } 9.7\end{array}$ & 10.7 & $\begin{array}{r}11.8 \\
M 13.4 \\
F 10.3\end{array}$ & 8.6 \\
\hline $\begin{array}{l}\text { Q7 Government should provide } \\
\text { money to help with child care (for } \\
\text { single mother with child under } 5 \\
\text { going out to work) }\end{array}$ & $\begin{array}{r}72.0 \\
M 71.5 \\
F 72.5\end{array}$ & 78.0 & $\begin{array}{r}12.4 \\
M 11.7 \\
F 13.0\end{array}$ & 11.7 & $\begin{array}{r}14.4 \\
M 15.4 \\
F 13.5\end{array}$ & 9.5 \\
\hline
\end{tabular}

More than three-quarters of adults agreed with the statement that 'Government should top-up the wages of single mothers in low paid work' (Q6). More than $80 \%$ of lone mothers agreed with the statement, demonstrating strong support for the notion, with $11 \%$ disagreeing.

There was also support for assistance with child care costs. Almost three-quarters of adults (72\%) agreed with the statement (in relation to employed single mothers with children under 5) that 'Government should provide money to help with child care' (Q7). Again support amongst lone mother respondents was higher (78\%) than for adults overall. 


\subsection{Discussion}

As seen in Chapter 4, the focus group interviews showed that most women regarded paid work as the route to attaining dignity. However, one objective of the project was to explore whether, in the absence of sufficient paid work opportunities, social security could play a role in protecting and respecting people's dignity. In Section 10.2, findings were presented from the focus groups about lone mothers' views about the notion of some form of social security for their own material needs, in terms of how it would impact on their sense of dignity.

The overwhelming response to the idea of a new grant was positive, with lone mothers stating that the grant would help to protect their dignity as it would reduce poverty. The main points they made were that it would enhance their ability to provide for their children (with many stating that they would use the new grant for unmet needs of their children), but also that it would enable them to meet their own needs, with examples given of food, toiletry, clothing and housing. Some women raised concerns about negative or unintended consequences, reflecting back the pejorative ways in which they are regarded as CSG recipients. So for example, some expressed concerns that it would cause women to have more children, or that they would become lazy and cease looking for work, whilst others raised the concern that they would suffer from an increase in verbal abuse in their communities. But the overriding message was that a grant would serve to protect and respect their dignity by acknowledging that they have material needs, and also reducing their need to depend on dignity-eroding survival techniques such as transactional sex and remaining with abusive partners.

Using data from a module contained within SASAS 2007, it was possible to explore how the focus group material compared with the views of a nationally representative sample of South African adults. More than three-quarters of the respondents supported the statement that 'There should be a grant for unemployed single mothers to meet their basic needs (in addition to the Child Support Grant)'. An even higher percentage of working age single mother respondents agreed with the statement (85\%), resonating well with the focus group interviews and demonstrating the extent of widespread support for such a grant amongst the wider population. 


\section{Chapter 11 Conclusions and Recommendations}

\subsection{Summary of findings}

In this report the overarching question that was explored was whether social security serves to protect and respect the dignity of lone mothers in South Africa. A range of methodological approaches were used to explore this issue (described in Chapter 2), including focus groups and in-depth interviews with low income lone mothers which were undertaken in the Eastern Cape and the Western Cape provinces in South Africa, analysis of three rounds of social attitudes survey data, and ten elite interviews with senior policy makers.

In Chapter 3 a working definition of lone motherhood was developed. Lone mothers were defined broadly for the purposes of this project as women who do not live with a spouse or partner and who are primary caregivers of one or more children (whether biologically related or not) aged 0-17 inclusive. Based on this broad definition, but restricting it to those who live with the children (rather than elsewhere), analysis of the 2011 General Household Survey (GHS) revealed that there are over 5 million lone mothers - this figure would increase if lone mothers could be included who live (or mainly live) separately from their children. The lone mothers that were identified in the GHS had a mean age of 37, and on average lived with 2.2 other adults and 2.95 children. The majority of the lone mothers identified in the GHS (79\%) were caring for one or more biological children. ${ }^{81}$ Almost twothirds (63\%) of the lone mothers had a marital status of 'single and have never married or lived together with someone before'.

As a subset of the adult population, lone mothers of working age face many challenges which, although faced by others, are thrown in sharp relief as a consequence of the competing societal expectations that they should not only simultaneously be caregivers and actively participate in the labour force, but that they should also achieve this in a context of high poverty and unemployment. An additional challenge is that low income lone mothers of working age fall outside the social security arrangements unless they are disabled, and yet are regarded by many as benefiting from state provision because of the Child Support Grant (CSG) which is intended for the needs of children. The State Maintenance Grant (which contained a paid component for the caregiver, albeit in a racialised and problematic manner) was abolished as part of the process of introducing a non-racially differentiated Child Support Grant: this was a trade-off that yielded vital income for children in low income families but at the same time removed any immediate prospect of social security for lone mothers, or able-bodied low income working age caregivers in general (Chapter 6).

\footnotetext{
${ }^{81}$ This may be in addition to non-biological children, but the status as a biological mother is prioritised.
} 
Before considering the role of social security arrangements (past, present or prospective), an attempt was made to explore the ways in which dignity is interpreted by lone mothers within the context of their own lives (Chapter 4), followed by an analysis of accounts of the ways in which poverty and inequality impacts on their dignity, if at all (Chapter 5).

In Chapter 4, the focus group data was examined in relation to women's accounts of dignity in relation to their sense of self, their relationships with family members, and their standing in their communities. Khatib and Armenian's four 'dimensions' of dignity were used as a framework for the analysis as the arising themes corresponded well to their dimensions of worthiness, self-respect, self-esteem and autonomy (Khatib and Armenian, 2010). The focus group participants unequivocally identified dignity as something that is indeed important to protect and respect.

In relation to worthiness, women spoke of how they experience dignity as something that is compromised by unemployment, sexism and racism. In relation to self-respect, two prominent themes emerged of self-respect being a pre-requisite to earning the respect of others (and to a lesser degree, respectful treatment of others aiding self-respect), and the importance of 'respectable behaviour'. Most notable within the dimension of self-esteem was the importance of their roles as caregivers of children; indeed, the main reason why focus group participants said that it was important for women's dignity to be protected and respected was because of their roles as caregivers. The most prominent issue to arise in relation to the dimension of autonomy was the link between dignity and paid work which helps women to meet their own material needs, those of their children, and contribute to the needs of extended families. When people were asked at the end of each focus group about what would help to respect and protect people's dignity, the vast majority of people replied 'jobs', although the conferment of dignity is not automatically associated with paid work, with several women mentioning that their dignity was so compromised when in poor quality or exploitative work that they left their jobs.

The diverse ways in which dignity is created and sustained were examined in relation to the in-depth interview research participants in Chapter 4. It was argued that a large range of factors potentially influence and, in some cases erode dignity; the erosion of dignity is intertwined with vulnerability more generally; and experiences of dignity are mediated by social relationships.

Chapter $\mathbf{5}$ explored the question of the impact of poverty and inequality on lone mothers' sense of dignity. The focus group participants regarded poverty and inequality as having a negative impact on dignity in four main respects. First, the techniques to survive poverty (tolerating poor quality work, undertaking casual work for neighbours and relatives, begging, and transactional sex), and thereby to attain autonomy (an important aspect of dignity identified in the previous chapter) in fact had a detrimental impact on their dignity. Second, poverty caused there to be strained family relations, with women providing accounts of being insulted, excluded from decision-making, and treated as a burden. Third, poverty was perceived as having the impact of reducing their standing within the 
community. And fourth, poverty caused damage to self-esteem, ranging from despondency to desperation and despair. People spoke of living 'at the bitter end of inequality', with a few women in the Eastern Cape expressing acceptance of their lot, though the vast majority across both provinces regarding their plight as unacceptable. The in-depth interview participants generally described poverty and inequality as an affront to their human dignity. Their poverty and deprivation was keenly felt in terms of their difficulties in adequately providing for their children. The findings from SASAS 2012 resonated well with the qualitative material.

Although lone mothers are currently largely excluded from social security provision for themselves, they do interact with the system in relation to the CSG. Chapter $\mathbf{7}$ explored how the process of application and monthly grant collection intersects with women's sense of dignity. In the focus group interviews the application process for the CSG was described as particularly adverse in terms of its impact on recipients' dignity. The four themes that emerged most prominently as being detrimental to dignity were those of queuing, burdensome and unclear qualifying criteria, not being treated with respect by officials, and being the object of pejorative comments about their caregiver, parental or lone parent status. The in-depth interviews elicited many comparable responses, and also revealed how experiences of CSG receipt and payment were also impacted on by a range of dynamics outside the formal social security system, in the realm of social dynamics and employment arrangements.

Chapter 8 examined the impact of the CSG on the lone mother informant's dignity in relation to having and using the CSG as a source of income, and the status of being a CSG recipient. The findings from the focus group interviews raised contradictory points. On the one hand, women spoke of how the CSG helps to protect their dignity as it enables them to provide better for their children and therefore fulfil their role as caregiver. On the other hand, the point was repeatedly made that the CSG is so small a sum that it does little if anything to protect their sense of dignity. Not only is the small amount of the CSG seen as being insufficient to provide for their children's (and their own) material needs, but for some the small size of the grant signifies that the government has little consideration for their dignity, in terms of their worthiness for support. Far from providing them with greater autonomy, for some the CSG was paradoxically emblematic of their lack of autonomy and their inability to obtain paid work.

The status of being a CSG recipient was often fraught with challenges. Accounts were given of conflict over access to the CSG within their households, and of being the object of people's prejudices and judgements about having children and claiming the CSG within the community.

This is not for one moment to suggest that the CSG is a 'bad thing'. On the contrary, and has been documented in this report and elsewhere, it plays a vital role in the lives of low income families (e.g. Delany et al., 2008; DSD, SASSA and UNICEF, 2012; Martin, 2014; Neves et al., 2009; Patel et al., 2012 and 2013). Rather, the findings from this study provide an opportunity for wider reflection about its strengths and limitations, in this instance with 
reference to the views of the primary caregiver and how it intersects with their sense of dignity.

In seeking to understand the role of CSG receipt in the protection of dignity, the indepth interviews captured much of the duality noted in the focus groups. Accounts of CSG receipt variously documented dignity-enhancing, and dignity-detracting effects. The findings were augmented with additional data, derived from the in-depth interview data, of the manner in which grant income was actually used in practice. It was found that the resources of the CSG are often used in positive and dignity-enhancing ways. The wide repertoire of grant usage was described with specific reference to practices of social reciprocity and employment.

These distinctions have a number of implications. First, the opprobrium or disapproval from others associated with being a CSG recipient can be somewhat independent of the ways in which the CSG is used in practice. This accounts for the diverse and even contradictory ways in which recipients experience and report CSG receipt as for instance, dignity-enhancing in some respects but erosive in others. These findings underscore the complexity of exploring issues around CSG receipt and dignity, and the manner in which the experience of CSG receipt is shaped by the specificity of a given context and individual recipient.

In Chapter 9 the complex relationships between dignity and 'traditional forms of social support' including 'ubuntu' are explored, using material from the in-depth interviews, the focus groups, and statistical analysis of a nationally representative social attitudes survey.

The focus group interviews demonstrated that the CSG recipients regarded social security as a form of ubuntu. Participants repeatedly made the point that 'social security is ubuntu', and that their circumstances would be much worse without the CSG. This suggests that the notion of ubuntu is not limited to manifestations of traditional social support for those in need: ubuntu can also be evident in actions of the state, and were identified as such in relation to the CSG. However, many went on to venture that when identifying social security as an example of ubuntu this did not eliminate their concern about the small size of the amount paid out in the form of CSG.

Data from the South Africa Social Attitudes Survey was used to examine attitudes to the state, community and family support. The nationally representative survey documented broad and popular endorsement of the provision of tax-funded social security provision for low-income people. It revealed that social security was firmly regarded as preferable to reliance on kin (believed by respondents to cause tensions in the family), or having to borrow and obtain resources from family or friends. Despite this support for state based social security, South Africans did not view it as undermining the role of community support; on the contrary, social security was viewed as a manifestation of society supporting poor people.

The in-depth interviews delineated many of these dignity-enhancing dynamics of social security implied in the survey data. These include the manner in which grant receipt 
bolsters social reciprocity - a key aspect of community support and forms of 'traditional social support'. The specificity and depth of these interviews also facilitated detailed examination of the converse - the dignity-detracting aspects of grant receipt. Further developing the analysis in Chapter 8, opprobrium in relation to CSG receipt were examined in terms of both from whom, and why it emanates. It was suggested that opprobrium was explicable in terms of four dynamics: popular concerns about gender, female sexuality and reproductive decision-making; apprehension over the spectre of welfare dependency and receipt of 'unearned' income; anxiety over present day household formation, matrimony and the troubled place of contemporary masculinity; and finally that opprobrium is actually an integral part of 'traditional forms of social support'. This chapter, and the diverse data presented in it, therefore confirmed the support for and synergies between formal, statebased social security and informal 'traditional social support', but caution that forms of 'traditional social support' and ubuntu also have potentially dignity-detracting qualities for lone mothers.

As highlighted above, most of the focus group participants regarded paid work as the primary route to attaining dignity. However, one objective of the project was to explore whether, in the absence of sufficient paid work opportunities, social security could play a role in protecting and respecting people's dignity, and this was explored in Chapter $\mathbf{1 0}$. The focus group participants were asked for their views about some form of social security for their own material needs, and how it might impact on their sense of dignity.

The overwhelming response to the idea of a new grant was positive, with lone mothers stating that the grant would help to protect their dignity as it would reduce poverty. The main points they made were that it would enhance their ability to provide for their children (with many stating that they would use the new grant for unmet needs of their children), but also that it would enable them to meet their own needs, with examples given of food, toiletry, clothing and housing. Some women raised concerns about negative or unintended consequences, reflecting back the pejorative ways in which they are regarded as CSG recipients. But the overriding message was that a grant would serve to protect and respect their dignity by acknowledging that they have material needs, and also reducing their need to depend on dignity-eroding survival techniques such as transactional sex and remaining with abusive partners. SASAS 2007 provides evidence of widespread support for the introduction of such a grant. 


\subsection{Key findings}

Although there are complex and subtle messages to be found within this study, eleven key findings are highlighted here:

1. Lone mothers make up a sizeable proportion of the population, face multiple challenges and yet are often neglected in the policy arena.

2. Lone mothers fall outside the scope of social assistance provision in South Africa, unless they are disabled or aged 60 or above. Their exclusion reflects the fact that social assistance is not provided to working age adults unless they are disabled. It also reflects the removal of the caregiver component of the (racialised and problematic) State Maintenance Grant when it was converted in the 1990s into the Child Support Grant.

3. As well as being a foundational value in South Africa's Constitution, dignity was understood and experienced as being a very important concept not only by the low income lone mothers who participated in the qualitative research, but also by adults in general as seen in the SASAS analysis.

4. The main reason why lone mothers said that their dignity should be protected and respected was because of their roles as caregivers: they take this role extremely seriously.

5. Poverty was described by lone mothers as eroding of their dignity. It impacted negatively on their sense of self-esteem, worthiness, autonomy, and self-respect. Many of the methods and strategies of surviving poverty were also described by focus group participants as being detrimental to their sense of dignity.

6. The elite interviewees stressed that dignity plays an important role in social security policy design, and that its purpose is to help to protect people's dignity by providing an income to alleviate poverty. Notwithstanding this, several examples were given were the policy design could inadvertently compromise dignity, e.g. the CSG means-test, the exclusion of caregivers from social assistance.

7. The Child Support Grant plays multiple roles in relation to dignity and these are both general and context-specific. To summarise, it plays a vital role in helping lone mothers to provide for their children, yet was also perceived by many as being so small as to have little impact on the protection of their dignity as caregivers. The process of applying for CSG was described by many as being detrimental to dignity, as was the opprobrium associated with their status as CSG recipients. Nevertheless, as demonstrated by the indepth interviews in particular, the use of the CSG as an income stream contributed positively and in dignity-enhancing ways to the lives of many of the informants.

8. Decent paid work was regarded by lone mothers as the main route to attaining dignity.

9. In the absence of sufficient jobs, there was strong support for the introduction of a form of social security for lone mothers, both amongst the participants in the focus groups and more broadly within the social attitudes survey. 
10. There appeared to be a widespread appreciation amongst focus group participants, and respondents to the social attitudes survey, of the provision of formal social security by the state being a manifestation of social solidarity. Notwithstanding this, dignity-eroding aspects of the administration of the CSG by some officials, and the opprobrium accorded to CSG recipients, meant that for many any experience of the spirit of social solidarity was elusive.

11. Whatever the source of social support (state or family) such support plays a vital role for low income people, and yet it is not unmitigatingly positively experienced. Negative aspects of both state support and traditional forms of social support were highlighted. Whilst state support was regarded as preferable, in principle, to dependence on other (usually just as poor or only slightly less so) family members, paid employment was regarded by lone mothers as being far and above the optimal way in which to protect and respect dignity.

\subsection{Recommendations}

There are a number of recommendations that emerge from this study and they are ordered into two main sections. The first set of recommendations are concerned with the larger structural context, the second set are focused on specific aspects of the current grant administration process.

The first set of recommendations include: extending social security provision; recognising and responding to poverty and inequality as threats to human dignity; encouraging public debate about the adequacy of the CSG, challenging the false dichotomy of 'independent self-upliftment' versus passive social grant receipt; and finally, acknowledging and dealing with stigma and the discourse of dependency. The second set of recommendations is narrower and relates to specific aspects of the grant administration process. They include the need to: clearly communicate eligibility criteria to potential applicants, remedy the systemic issues that make grant application and receipt onerous and undignified, retain a firm focus on training and managing officials in an ethos of service, and finally, remove the CSG's means test. All of these are described in detail in what follows.

\section{Extend social security provision}

The main recommendation is that - in parallel with job creation schemes accompanied by free and high quality childcare - social security provision should be extended to include low income lone mothers (and more generally - see below). There is a constitutional commitment to achieve the progressive realisation of access to social security including social assistance for people and their dependants who are unable to support themselves (RSA, 1996. Ch2 s27), hence this is not a recommendation that runs counter to the stated objectives of the constitution. Goldblatt (2005) also argues that there is a case to be made for state welfare provision to actively address the unequal economic position of women in South Africa. 
Internationally it is recognised that poverty rates for lone parents and their children are high, particularly where the parent is not employed (e.g. Brady and Burroway, 2012; Christopher et al., 2002; Chzhen and Bradshaw, 2012; Kilkey, 2000; OECD, 2011; Whiteford and Adema, 2007) and South Africa is not an exception. Social security could be targeted at lone parents (as previously with the State Maintenance Grant, and in the international examples of types of social security provision specifically designed for lone parents presented in Annex 9), or could be implemented in a less targeted way by, for example, providing social assistance for all low income adults of working age adults, or a universal grant such as a variant of the Basic Income Grant. A universal grant (recuperated from higher income recipients via an efficient and progressive tax system) would eliminate, at a stroke, any risk of pejorative association with, or concerns over perverse incentives linked to parental or caregiver status: as such it would achieve even more, in terms of respecting and protecting dignity, than a targeted approach. If a universal approach such as this were unfeasible or politically unpalatable, the second best option would be a means-tested grant for all low-income adults. This option remains attractive because of the particular pressures faced by low-income lone mothers highlighted by this study, and its lower prospects for stigmatising recipients than the current system. (For a costed example of a caregivers grant see Ntshongwana et al., 2010).

\section{Recognise poverty and inequality as threats to human dignity}

There is a need to recognise that much of the threat to grant recipients' dignity inheres in specific dynamics related to the CSG, but also flows from the poverty and inequality more broadly. Dignity-eroding dynamics are therefore intertwined with vulnerability more generally, and policy responses focused on lone mother social grant recipients cannot ignore the challenge of poverty. Policy responses ought accordingly to include the conventional panoply of policy responses to poverty, which are beyond the scope of these recommendations to enumerate. But they should also include interventions to create and strengthen employment, provided that this employment is adequately paid and accompanied by the provision of appropriately high quality but free or inexpensive childcare. However, it should be recognised that a lone parents' caring responsibilities, as a contribution to society, may be at odds with paid work and her choices should be respected and remunerated accordingly through the social security system.

\section{Challenge the false dichotomy of 'independent self-upliftment versus passive social grant} receipt in public discourse

There is a need to consider ways to challenge the false dichotomy of independent selfupliftment versus passive social grant receipt, especially in the popular imaginary. Not only is the notion of passive grant receipt largely unsupported by the evidence, it is a formulation that is erosive of recipient's dignity. A key recommendation is therefore is to consider how to reframe the poles of the public debate concerning social grant receipt. Some of the rhetorical emphasis would indicate the small value of the grant, and that the main 
categories of grant beneficiaries are children, the disabled, and the elderly, groups that are generally not expected to be self-supporting

Some of this rhetorical reframing would entail bring to the fore the prevalence and value of unpaid care work. The care work undertaken by grant recipients is intensely gendered and often invisible, yet crucial to their dependents and society in general. There is also need to challenge the dichotomy of work versus social grant receipt, by making explicit the manner in which grant receipt is frequently combined with repertoires of productive and income-generating activities. Much of the discourse valorising 'independent self upliftment' overlooks both these facts, and the hard realities of a paucity of employment opportunities for unskilled South Africans. Finally there is a need to monitor how these popular understandings interface with emergent developments including the contemporary enthusiasm in policy circles for 'graduation' - with the objective of getting grant recipients to exiting programmes (an inevitability with a child outgrowing their grant anyway). Uncritical appropriation of the rubric of 'graduation' may perversely serve to increase the fantasy of self-upliftment, and therefore the opprobrium directed to grant recipients.

\section{Acknowledge and deal with stigma and the discourse of dependency}

Opprobrium directed at social grant recipients that results in stigma was documented in the course of the research. Although these dynamics are erosive of dignity, they are not always acknowledged by those who research and advocate for state cash transfers. Therefore there is a need to acknowledge that much of the popular (and even on occasion official) discourse concerning the CSG is marked by opprobrium and serves to perpetuate stigma. This discourse is not only socially regressive; it is unsupported by the preponderance of the empirical evidence. Those concerned with state social grants have perhaps not sufficiently informed the debate, in order to dispel the stigma.

The discourse of dependency, following Meth (2004), ought to be reframed beyond the binary of yes or no. The fact is that poor people - and in fact all people - are dependent on others. The question ought not be whether they are dependent, but rather on whom and under what conditions are they dependent. As previously suggested in the research, receipt of a grant is judged by most to be preferable to a reliance on kin, and may well be far preferable to dependency on other forms of patronage, clientelism and illicit authority.

An additional part of a strategy of addressing stigma would be to assert the importance of providing for the material needs of caregivers, who have the same entitlement to human dignity as the children for whom they are caring (Chopra, 2013; Esplen, 2009; Eyben, 2012; Ntshongwana, 2010b; Patel et al., 2013; UN, 2013). Aspects of this debate ought also to be located within the notion of social solidarity, and its Africanist register of Ubuntu. This would also entail tackling that notion that state and informal social support are in opposition, but instead underscore the commonalities and synergies between them. In this way the social solidarity inherent in social grants, would serve to enhance the dignity of their recipients. 
The recommendations that follow relate specifically to the CSG. Although many have been well made by others they are reiterated here because the issues were expressly identified in this study as being detrimental to dignity.

\section{Encourage public discussion about the adequacy of the CSG}

There is a need to encourage public debate on the adequacy of the CSG (see for example Martin (2014): 75-76). The CSG's adequacy affects not only the child but - as seen here - the dignity of the caregiver is compromised if unable to meet the needs of the child (see also Delany et al., 2008; Zembe, 2013). Although the CSG is of vital importance for children and their families, it cannot be expected that child poverty could ever be eliminated if the needs of the family in which they live are not also taken into account; nor for that matter can the care that the children receive be expected to be of high quality if the caregiver cannot meet her own material needs.

As reported in Chapter 9, it would seem that there is already widespread support for raising the CSG: a question in SASAS 2006 specifically asked whether inter alia the CSG should be raised, even if it meant higher taxes, and $71 \%$ said that it should raised a little (31\%) or a lot (40\%) (Noble et al., 2008: 13).

\section{Clearly communicate grant eligibility criteria to CSG applicants}

In the context of current regulations, there is clearly a need for ongoing efforts to raise awareness about the eligibility criteria for CSG so that applicants can apply for the CSG with the supporting documentation already in their possession, and not be sent to-and-fro in search of supporting documentation for their application (see also Delany et al., 2008; Goldblatt et al., $2006^{82}$ ). The point has been well made by others about the detrimental impact - to achieving receipt of the CSG - of the burdensome application process (e.g. Delany et al., 2008; DSD, SASSA and UNICEF, 2012; Goldblatt, 2005; Goldblatt et al., 2006; Martin, 2014). For example Delany et al. (2008) found that the main reason why caregivers with children under the age of two years did not apply for the grant was because they lacked the correct documentation (p60), though it should be noted that their findings about the application process were more positive overall. Although the research suggested some extra-bureaucratic factors that potentially feed into delayed application (such as migration, social and employment related factors), the barriers were overwhelmingly of an administrative nature. It is unnecessary to compound social or employment dynamics with substantial official barriers. Goldblatt et al (2006) observe that 'Onerous requirements on applicants (such as affidavits from former employers) may assist to prove a small number of fraud cases, but generally, will just make access more difficult for most of the genuinely

\footnotetext{
${ }^{82}$ Goldblatt et al (2006) recommend that 'More awareness-raising campaigns need to be launched on local radio stations and via road-shows at different villages, townships, informal settlements etc. These campaigns should clearly state the eligibility requirements for the CSG and the administrative requirements for application.' (p34)
} 
poor applicants who apply.' (p30). Burdensome application processes not only represent an externalising of administrative cost onto applicants, they are detrimental to lone mothers' dignity as they imply that the applicant's time is unimportant and can be spent tracking down and travelling to different places to obtain elusive documentary support, or being told to return on another day. Finally, given the negative accounts about obtaining affidavits from police stations, Goldblatt et al.'s (2006) recommendation should be heeded that a commissioner of oaths should be used on-site at each social security office instead of involving the police.

\section{Remedy the systemic issues that make grant application and receipt onerous and undignified}

The research suggested both systemic and personal-related factors are at play in making the grant application and collection processes onerous and dignity-eroding. In common with other studies, the issue of queuing was raised as being problematic. For example, in a survey of CSG recipients Budlender et al. (2005) found that on average $62 \%$ of the time cost of applying for the CSG was spent queuing (when considering queuing, the application activity itself, travel to and travel from the social security office, but excluding visits to the police) (Budlender et al., 2005: 41). Goldblatt et al. (2006) found that CSG applicants were often turned away during office hours and also reported that in Khayelitsha people arrived at 4 am to be in the front of the queue (p11). Participants in this study echoed these experiences and conveyed accounts of the detrimental impact of queuing on their sense of dignity and worthiness. This recurrent nature of the problem and its impact on dignity suggests keen attention to queues and queuing is warranted.

It is recommended that additional staff are needed at application offices so that waiting times are kept to a minimum (Goldblatt et al (2006). Interventions should be promoted to ensure that there are adequate numbers of staff, and that the inevitable queuing process is managed professionally. These may include the common practice of issuing tickets or tokens for the number of individuals that can be served in a single day, and the opportunity offered to unsuccessful individuals to receive priority the following day. A processing workflow that better matches bureaucratic capacity to queuing would reduce the felt imperative to be first and consequently the hardship, safety concerns and inhibiting effects (especially for post partum mothers) that early morning and long duration queuing entails. It would also powerfully signal that the social security system regards recipients as worthy of dignity and their time as valuable. Finally these pragmatic actions need to be attentive of how that these dynamics may change against the backdrop of a shift in payment modalities towards electronic channels. The uptake of electronic payment channels (bank accounts and ATMs) requires ongoing monitoring to ensure that officials are in the correct places, and that new site payment sites do not simply see onerous queuing conditions displaced to supermarkets, banks or post offices where the process is no longer under the direct control of SASSA. 


\section{Retain a focus on training officials about people-centred service delivery}

There is a general need for officials to be more sensitive to the circumstances of the applicants, who - due to the extent of their poverty - are likely at the very least to be tired and hungry, with particular consideration needed for women with very young children. Goldblatt et al. (2006) recommend that officials should receive further training on conduct and respectful behaviour. Current practices such as the screening of applicants publically ought to be halted, and should be undertaken in private. Accounts of poor treatment of applicants by officials (treating people with little or no respect, and speaking pejoratively) suggests that further in-work training is indeed urgently needed on conduct (see also Martin, 2014) as well as on the principle of social security as a social right of citizenship. In light of the tendency of large systems to develop their own organisational culture and practices, there is a need to consider periodic refresher or retraining for officials to reiterate this ethic. Finally, training is likely to both be of limited utility and dissipate in effectiveness over time, if appropriate supervision and managerial oversight of service provision is absent.

\section{Remove the means test for the CSG}

Lastly, in relation to the CSG, it is recommended that the means test should be removed. As well as there being many well-rehearsed reasons why this would be advantageous for the promotion of take-up (by reducing the number of hurdles in the application process, particularly the considerable burden of providing evidence of no income) and consequent reduction of child poverty and investment in child development (e.g. Delany et al., 2008; Goldblatt et al., 2006; Martin, 2014; OECD, 2011), in the context of this study it is additionally recommended as it would remove at a stroke any association with the caregiver's income or employment status. In so doing the CSG would cease to be emblematic of the caregiver's poverty status or lack of paid work, but instead would only reflect the fact of there being a child in the family. Although in the context of high levels of poverty the CSG would inevitably continue to be an income stream that is competed for within poverty-stricken households and families, the removal of the means-test would reduce the scope for the CSG to be instrumentally harnessed in families and communities to reduce the dignity of recipients by making them the object of scrutiny, opprobrium and pejorative comments. A universal child grant would be better targeted at children in poor families as it would reduce the potential for errors of omission. Such a grant would also represent a positive investment by the state in the lives of all children and provide them all with a better start in life. 


\section{Annex 1: Information and consent form for focus group participants (English, isiXhosa and Afrikaans)}

\section{DEPARTMENT OF SOCIAL POLICY \& INTERVENTION}

Barnett House, 32 Wellington Square, oxford, 0X1 2ER, United Kingdom WWw.spi.ox.ac.uk

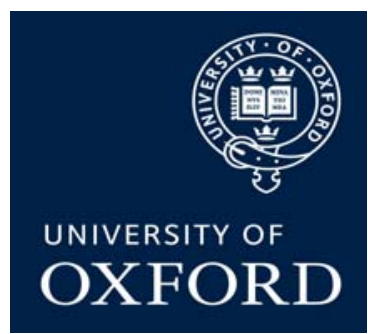

Dear Participant

Being a mother in South Africa: How do the grants affect the ways we feel about ourselves?

Please take time to read this sheet carefully and decide whether you would like to take part in this focus group, which is a group discussion around an issue. If you have trouble reading this, then one of our research team can read it out for you. If you would like a version of this information sheet in your home language then please just ask.

What is this research about? This is a research project about social grants. It is trying to understand how mothers who are bringing up children without the children's father feel about social grants.

Who is doing this research? This project is being done by the Centre for the Analysis of South African Social Policy (CASASP) at the University of Oxford, the Institute of Poverty, Land and Agrarian Studies (PLAAS) at the University of the Western Cape (UWC) and the South African Human Sciences Research Council (HSRC). This research has been approved by a Research Ethics Group at Oxford University.

Do I have to take part? It is up to you to decide whether or not to take part. If you decide not to take part, it will not affect any help you may be getting, or anything to do with your grants. You can stop and leave the interview at any time - it's your choice.

What will this involve? We will have a group interview, which will be recorded. What you say and any information about you will be kept confidential and anonymous. This means that only the research team will know your name, and anything that you say will be quoted under a different name. The focus group discussion will take one hour, and will be in your own home language.

Why should I take part in this study? This study aims to help us understand the effect that social grants have on women's sense of dignity. This is good because we will let the relevant people in government know how the grant affects you and this may help them improve their policies on the grant. We will interview women in the Eastern and Western Cape provinces, and when we have 
finished we will let you know what we have found, in your home language. We will also write a report about the views of women from these provinces.

What if there is a problem? If you have a concern about any aspect of this project, please speak to the researcher concerned (Dr Phakama Ntshongwana on tel: 0836933438 email:

phakama.ntshongwana@spi.ox.ac.uk)who will do her best to answer your query. If you remain unhappy and wish to make a formal complaint, please contact the Research Ethics Committee at the University of Oxford (ethics@socsci.ox.ac.uk; +44 (0)1865 614871; Social Sciences \& Humanities Inter-Divisional Research Ethics Committee, Oxford University, Hayes House, 75 George Street, Oxford, OX1 2BQ, UK).

Thank you for reading this sheet. If you feel comfortable to take part in this discussion, then please sign here.

Yours sincerely

Dr Phakama Ntshongwana

Research Fellow

Centre for the Analysis of South African Social Policy (CASASP)

University of Oxford

Participant's name and address

Participant's signature date 
Mthathi nxaxheba Obekekileyo

\section{Ukuba ngumama eMzantsi Afrika: Ingaba imali yesibonelelo sikarhulumente isichaphazela njani isdima senu? \\ Nceda uthathe ixesha lokufunda eliphetshana ngononophelo uze uthathe isigqibo sokuba ungathanda na ukuthatha inxaxheba kule ngxoxo, njenge QELA ELIJONGENE NOKU (Focus Group) ukushukuxa lo mba. Ukuba unengxaki ukufunda eliphetshana, ukhona omnye weqela labaququzeleli bethu ongakufundelayo. Ukuba ungathanda ukufumana olulwazi ngolwimi Iwakho nceda utsho.}

\section{Ingaba lungantoni oluphando?}

Olu luphando ngesibonelelo sikarhulumente (inkam-nkam). Luzama ukuqonda ukuba oomama abakhulisa abantwana ngaphandle kootata baziva njani ngesisibonelelo.

\section{Ngubani owenza oluphando?}

Oluphando luqhutywa ngabesebe lezophando nzulu mayelana nezentlalo(CASASP) eMzantsi Afrika kwiDyunivesthi yase Oxford, Isebe lemfundo elijongene nezendlala, umhlaba nolimo(PLAAS) kwiYunivesiti yaseNtshona koloni(UWC) kwakunye nesebe lezophando nzulu ngoluntu(HSRC) eMzantsi Afrika. Oluphando luvunyelwe liqumrhu labezophando ngokusemthethweni (Research Ethic Group) eYunivesiti yase Oxford.

\section{Ingaba kunyanzelekile ukuba ndithathe inxaxheba?}

Kuxhomekeke kuwe ukuba uyafuna okanye akufuni ukubayinxalenye yoluphando kusinina, lo nto ayisokuze ichaphazele uncedo onokuthi ulufumane, okanye nayiphi na into edibene nesibonelelo osifumana kurhulumente, ungabinaxhala. Ungayeka naninina ukathatha inxaxheba, uva kuwe.

\section{Oluphando luniphathele ntoni?}

Kuza kubakho ingxoxo yamaqumrhu eyakuthi irekhodwe (ishicelelwe), nayiphina into oyithethayo nencukacha ngawe iyakubayimfihlo. Lonto ithetha ukuba liqela eliququzelelayo kuphela eliyakuba ne negama lakho, yaye nayiphi na into oyakuthi uyithethe iyakukhankanywa phantsi kwegama limbi, hayi elakho. Le ngxoxo iyakuthatha nje ixesha elingange yure enye kuphela, yaye iyakuba ngolwimi Iwakho Iwenkobe.

\section{Kutheni kufuneka ndithathe inxaxheba nje koluphando?}

Oluphando lujongiswe ekuncedeni thina baququzeleli ukuze siqonde ukuba isidima soomama sichaphazeleka njani yimali yesondlo evela kurhulumente. Oku, kuhle, ngoba sizokwazi ukwazisa 
abantu abafanelekiyo abasebenzela urhulumente okokuba isondlo sabantwana sikuchaphazela njani, yaye oku kungakhawulelana ekuphuhlisweni kwemithetho yesondlo sabantwana esivela kurhulumente. Siliqela elijongene nku (Focus Group)sizakuba nengxoxonamabhinqa aseMpuma naseNtshona Koloni, sakugqiba sizakunazisa ngeziphumo ezifumanekileyo ngolwimi Iwenu Iwenkobe. Siyakuthi sibhale nenkcazelo ngezimvo/imbono zala mabhinqa akulamaphondo mabini.

\section{Ukuba kungathi kubenengxaki?}

Ukuba uyasola ngayo nayiphi na into edibene noluphando uyacelwa ukuba uthethe nomququzeleli (Dr Phakama Ntshongwana on tel: 0836933438 email: phakama.ntshongwana@spi.ox.ac.uk) yena wozama ngako -konke okusemandleni akhe ukuphendula imibuzo oyakuthi ubenayo. Ukuba awanelisekanga kwaye ufuna ukufaka isikhalazo ngokusemthethweni nceda uqhagamshelane neResearch Ethics Committee kwiYunivesiti yase Oxford (ethics@socsci.ox.ac.uk; +44 (0)1865 614871; Social Science \& Humanities Inter-Divisional Research Ethics Committee, Oxford University, Hayes House, 75 George Street, Oxford, OX1 2BQ, UK).

Siyabulela ngoku funda eliphepha. Ukuba ungathanda ukuthatha inxaxheba kulengxoxo nceda utyikitye apha ngezantsi.

Ozithobileyo

Dr Phakama Ntshongwana

Research Fellow

Centre for the Analysis of South African Social Policy (CASASP)

University of Oxford

Igama nedilesi zomthathi nxaxheba

usuku/umhla 
Barnett House, 32 Wellington Square, Oxford, OX1 2ER, United Kingdom www.spi.ox.ac.uk

As 'n moeder in Suid Afrika: Hoe affekteur die maatskaplike toelaes (grants) die manier hoe ons oor onself voel?

Neem asseblief ' $n$ bietjie tyd om hierdie informasie deeglik deur te lees, en besluit dan, of u deel wil wees van hierdie fokus groep, wat eintlik ' $\mathrm{n}$ groep bespreking is oor ' $\mathrm{n}$ spesifieke onderwerp. As $\mathrm{u}$ dit ' $n$ bietjie swaar vind om te verstaan, vra asseblief vir een van die navorsers om dit vir $u$ te lees. As u verkies om dit in u huistaal te lees, vra asseblief die navorsers om u een te gee.

Waaroor gaan hierdie navorsing? Hierdie navorsing is ' $n$ projek oor maatskaplike toelaes (grants). Dit probeer verstaan hoe moeders, wat kinders sonder hul pa's grootmaak, voel oor maatskaplike toelaes.

Wie doen die navorsing? Hierdie projek word gedoen deur die Sentrum vir die Ontleding van Suid Afrikaanse Sociale Politiek (CASASP) by die Universiteit Oxford, die Instituut van Armoede, Land en Agrariese Studies (PLAAS) by die Universiteit van die Wes Kaap (UWK) en die Suid Afrikaanse Raad vir Geesteswetenskaplike Navorsing (HSRC). Hierdie navorsing is goedgekeur deur die Navorsings Etiek Groep by Oxford Universiteit.

Moet ek deelneem? Dit is heeltemal $u$ besluite of $u$ deel wil deel neem of nie. As $u$ besluit $u$ wil nie deelneem nie, sal dit nie enige hulp wat u ontvang affekteur nie, dit het ook niks met u toelae te doen nie. $U$ kan enige tyd die onderhoud los, dit is heeltemal u besluite.

Wat behels my betrokkenheid? Ons sal ' $\mathrm{n}$ groep gesprek/onderhoud voer, wat ook dan opgeneem word. Wat $u$ se en enige informasie omtrent $u$ is vertroulik en anonym. Dit beteken dat net die navorsing span u naam sal weet, en enige iets wat gese word onder ' $n$ ander naam geskryf sal word. Die fokus group gesprek sal omtrent ' $n$ uur neem en sal in u huistaal gedoen word.

Hoekom moet ek deelneem in hierdie navorsing? Die doel van hierdie navorsing sal ons help om beter te verstaan wat die affek van die toelaes op ' $n$ vrou se gevoelens van waardigheid is. Dit is goed om dit te verstaan, want die regte mense in die regering sal ook hierdie informasie kry en sal dan beter verstaan hoe die toelaes $u$ affekteur, dit sal dan ook help dat hulle die toelae beleide beter maak. Hierdie navorsing word in die Oos Kaap as ook die Wes Kaap provinsie gedoen, en wanneer ons klaar is, sal ons $u$, in u huistaal, laat weet wat ons uitgevind het. Ons sal ' $n$ report, oor wat die vrouens van hierdie provinsies te se het, ook skryf. 
Wat as daar ' $n$ problem is? Indien u enige problem of kommer het omtrent enige aspek van die navorsing, praat asseblief met die navorser (Dr Phakama Ntshongwana op tel: 0836933438 epos: phakama.ntshongwana@spi.ox.ac.uk) wat haar beste sal doen, om u ' $n$ antwoord te gee. Indien u nogsteeds ontevrede is en graag met iemand anders wil praat, of ' $n$ formele klag wil maak, kontak met graagte, die Navorsings Etiek Raad, by die Universiteit Oxford, (ethics@socsci.ox.ac.uk; +44 (0)1865 614871; Social Sciences \& Humanities Inter-Divisional Research Ethics Committee, Oxford University, Hayes House, 75 George Street, Oxford, OX1 2BQ, UK).

Dankie dat u hierdie informasie gelees het, as u gemaklik voel om deel van die gesprek te wees, teken asseblief hier.

Vriendelike Groete

Dr Phakama Ntshongwana

Navorsings Genoot

Sentrum vir die Ontleding van Suid Afrikaanse Sociale Politiek (CASASP)

Universiteit Oxford

Neelnamer se naam en address 


\section{Annex 2: Demographics Questionnaire for focus group and in-depth interview participants (English, isiXhosa and Afrikaans)}

To be completed for each focus group participant

What is your current marital status?

Single, never been married $(\square)$

Separated $(\square)$

Divorced ( $\square)$

Widowed ( $\square)$

Married - husband lives with me most or all of the time $(X)$

Married - husband lives somewhere else (not with me) most or all of

the time $(\square)$

Living as married- partner lives with me most or all of the time (X)

Living as married - partner lives somewhere else (not with me) most or

all of the time $(\square)$

Are you under 60 ?

Yes $(\square)$

No $(X)$

Are you mainly raising a child/children alone?

Yes

No I have help from someone else - please specify

How many children aged under 17 live with you?

What is your home language?

Xhosa

Afrikaans

English

Other - please specify

What is your employment status?

Unemployed

Employed - for how many hours a week?

Other - please specify

What is your name?

FG Number 
Ingaba sithini isimo sakho somtshato?

Awutshatanga, zange watshata ngaphambili ( $\square$ )

Wahlukene nomyeni $(\square)$

Nohlukene ngokusemthethweni ( $\square)$

Ungumhlolokazi ( $\square$ )

Nditshatile - umyeni uhlala nam amaxesha amaninzi (X)

Nditshatile - umyeni uhlala kwenye indawo ixesha elininzi ( $\square)$

Ndiyahlalisana - Iqabane lihlala nam ixesha elininzi $(X)$

Ndiyahlalisana - Iqabane lihlala kwenye indawo ixesha elininzi ( $\square)$

Ingaba ungaphantsi kweminyaka eyi 60 ubudala?

Ewe ( $\square)$

Hayi

Ingaba unomntana/abantwana om(oba)khulisa uwedwa?

Ewe

Hayi ndifumana uncedo komnye umntu - nceda cacisa

Bangaphi abantwana abangaphansi kweminyaka eyi 17 ubudala abahlala nawe?

Luthini ulwimi Iwakho Iwenkobe (lakuni)?

isiXhosa

Isibhunu

Isingesi

Enye - Nceda ucacise

Sithini isimo sengqesho sakho?

Andiphangeli

Ndiyaphangela - iyure ezingaphi ngeveki?

Enye - nceda ucacise

Ungubani igama lakho?

Inani lequmrhu yengxoxo 
Wat is u huwelik status op hierdie oomblik?

\begin{tabular}{|l|l|}
\hline & Enkel, maar nog nooit getroud nie \\
\hline & Apart/uitmekaar maar nie geskei nie \\
\hline & Geskei \\
\hline & Weduwee \\
\hline & Getroud - Man woon met my mees van die tyd/die heeltyd \\
\hline $\begin{array}{l}\text { Getroud - Man woon erens anders (nie met my nie) mees van die } \\
\text { tyd/die hele tyd }\end{array}$ \\
\hline $\begin{array}{l}\text { Lewe soos getroud - my helpmaat lewe met my mees van die } \\
\text { tyd/die hele tyd }\end{array}$ \\
\hline $\begin{array}{l}\text { Lewe soos getroud - my helpmaat lewe erens anders (nie by my nie) } \\
\text { mees van die tyd/die hele tyd }\end{array}$ \\
\hline
\end{tabular}

Is u onder 60 ?

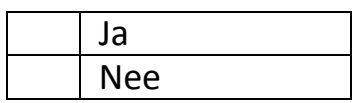

Maak u meestal die kind/kinders alleen groot?

Ja

Nee, ek ontvang hulp van iemand anders - verduidelik asseblief

Hoeveel kinders onder 17 woon saam met u?

Wat is u huistaal?

\begin{tabular}{|l|l|}
\hline & Xhosa \\
\hline & Afrikaans \\
\hline & English \\
\hline & Ander - dui asseblief aan wat dit is \\
\hline
\end{tabular}

Wat is u werks situasie/status?

Werkloos

Werk - vir hoeweel ure per week?

Ander - Verduidelik asseblief

Wat is u naam?

FG Nommer 


\section{Annex 3: Focus group questionnaire (English, isiXhosa and Afrikaans)}

The South African Constitution says:

Human Dignity: "Everyone has inherent dignity and the right to have their dignity respected and protected."

1. What does the word dignity mean to you?

2. (a) With all that South Africa has been through as country, in relation to the apartheid legacy in particular, how important do you think dignity is to South Africans in general?

(b) And to South African women?

3. How do you think poverty impacts on your sense of dignity, if at all?

4. Is there a relationship between your job and your sense of dignity? If you don't have a job does this impact on your sense of dignity? If so, how?

5. South Africa has one of the highest rates of inequality in the world. Does this impact on your sense of dignity? If so, how?

6. What role, if any, does the Child Support Grant (CSG) play in your life in relation to your dignity?

7. If there was a social grant for the adult recipients of CSG in addition to the existing grant (which is intended only for their children's needs) how do you think this would impact on their sense of dignity? [Note: social security protecting dignity versus eroding dignity]

8. How does the actual experience of applying for (at the welfare office) and receiving (at the paypoint) the CSG intersect with your sense of dignity as a lone mother?

9. What is the relationship between social grants and ubuntu?

10. Do you think you are leading a dignified life, in general? What sort of things would help to respect and protect your dignity? 


\section{isiXhosa}

\section{UmGaqo siSeko wase Mzantsi Afrika uthi ngeSidima somntu:}

Isidima somntu: "Wonke ubani unesidima semvelo, kunye nelungelo lokuhlonitshwa nokukhuselwa kwesidima sakhe."

1. Eligama lithi iSidima ingaba lithetha ntoni kuwe?

2. (a) Kuko konke eliliZwe uMzantsi Afrika lithe ladlula kuko, ngakumbi malunga nocalucalulo, ucinga ukuba sibaluleke kangakanani isidima kuluntu?

(b) Kubantu basetyhini beli loMzantsi Afrika bona?

3. Ucinga ukuba galelo lini elibangwa kukuhlupheka kwisidima sakho, ukuba likhona?

4. Ingaba lukhona na unxubelelwano phakathi komsebenzi wakho nesidima sakho? Ukuba awunamsebenzi, ingaba oko kunegalelo ekuhliseni isidima sakho? Ukuba kunjalo, njani?

5. UMzantsi Afrika lelinye lamazwe eliphala phambili kwi yantlukwano ehlabathini. Ingaba leyantlunkekwano iyasichaphazela isidima sakho? Ukuba kunjalo, njani?

6. Nxaxheba ni, ukuba ikhona, isibonelelo sabantwana siyidlalayo ebomini bakho malunga nesidima sakho?

7. Ukuba bekungabakho isibonelelo kubantu abafumana inkxaso ngesibonelelo sabantwana kuRhulumente (esijongene nje neemfuno zabantwana babo kuphela), oku bekungenza galelo lini kwisidima sabo?

8. Ingaba ngokwamava akho, ukususela kucelo Iwesibonelelo (kwii ofisi zentlalo-ntle) nokuyizuza (kwiindawo efumaneka kuzo) le mali yesibonelelo, ezonto zingqamana njani nesidima sakho njengoMama ongena myeni okanye mlingani?

9. Ingaba yintoni na unxubelelwano phakathi kwezibonelelo zoluntu nguRhulumente noBuntu?

10. Ucinga ukuba uphila ubomi obunesidima, nje ngomntu nje? Zintoni ezingaluncedo ukuhlonipha nokukhusela isidima sakho? 


\section{Afrikaans}

Menswaardigheid: "Elkeen het ingebore waardigheid en die reg dat daardie waardigheid gerespekteer en beskerm word."

1. Wat beteken die word menswaardigheid vir u

2. (a) Met alles wat Suid Afrika deurgemaak het as ' $n$ land, veral met apartheid, hoe belangrik dink u is menswaardigheid?

(b) En vir Suid Afrika se vrouens?

3. Hoe dink u affekteur armoede u gevoel van waardigheid, indien dit wel u affekteur?

4. Is daar ' $n$ verhouding tussen u werk en u gevoel van waardigheid? Indien u nie ' $n$ werk het nie, hoe affekteur dit u gevoel van waardigheid? Indien so, hoe?

5. Suid Afrika het een van die hoogste sygers van ongelykheid in die wereld. Affekteur dit u gevoel van waardigheid? Indien so, hoe?

6. Watter rol, indien enige, speel die Kinder Toelae in u lewe in verband met u waardigheid?

7. As daar ' $n$ maatskaplike toelae vir die volwasse ontvangers van die Kinder Toelae was, tesame met die kinder toelae (wat eintlik net vir die kinders se doeleinders bedoel is) hoe dink u dit sal u gevoel van waardigheid impak? [Nota: sociale sekerheid die beskerming van die waardigheid teernoor erodeer waardigheid]

8. Hoe affekteur die eintlike aansoek vir (by die welsyn kantoor) en ontvangs van (by die betaalpunt) die KinderToelae met u menswaardigheid as ' $n$ enkel moeder?

9. Wat is die verhouding tussen maatskaplike toelae en ubuntu?

10. Dink u u lei ' $n$ waardige lewe, oor die algemeen? Wat sou help om u waardigheid te respekteer en u waardigheid te beskerm? 


\section{Annex 4: In-depth interview schedule}

Semi structured interview schedule for in-depth interviews (containing topic areas with indicative questions)

\section{Household orientation}

1. Please list everybody who is part of this household, including their names, ages and genders.

2. Please also tell us about people that are a part of this household, but live somewhere else?

3. What are all the things that people in this household do in order to survive every month?

4. Who outside this household helps it to survive, and who does this household help to survive?

\section{Grant receipt}

5. How long have you been getting a grant / grants?

6. Tell me the story of how you applied for the grant.

7. Was it difficult or easy to get a grant? How did the process of applying for the grant make you feel?

8. Now that you are getting the grant, what kinds of things do you spend grant money on - for instance what do you do with your grant last month?

9. What others kinds of things do you do with the grant money through the year? (e.g. school fees, seasonal inputs, ceremonies)

10. What did you do to survive before you got the grant?

11. Tell me what it is like to go and fetch the grant every month, how does the process make you feel?

\section{Perceptions of grant recipients}

12. How does getting a grant make you feel about yourself? (Prompt if necessary: good, bad, proud, ashamed etc)

13. Do you think people who get grants are respected, or disrespected in this community? Why?

14. What do other people in this community say about people, like yourself, who get grants?

15. How do richer people, who do not qualify for grants because they have jobs, view grant recipients such as yourself?

16. Do men say different things about grant recipients from women? Or do older people view grant recipients different from younger people?

17. If your grant/s had to suddenly stop what would you do in order to survive?

18. What do you think other people would say about you if your grant suddenly stopped? 


\title{
Annex 5: Information and consent form for in-depth interview participants (English and isiXhosa)
}

\author{
Institute for Poverty, Land and Agrarian Studies (PLAAS)
}

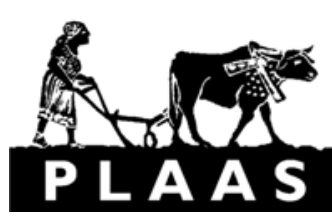

www.plaas.org.za

\author{
School of Government \\ University of the Western Cape \\ Private Bag X17 TEL: +27 219593733 \\ BELLVILLE FAX: +27219593732 \\ 7535 \\ email: plaas@uwc.ac.za
}

Dear Participant

How do women looking after children use, and feel, about social grants?

Please read this sheet carefully, and decide if you would like to take part in this interview around the issue of social grants. If you have trouble reading this, then one of our research team can read it out aloud for you. Please ask if you would like a version of this information sheet in your home language.

What is this research about? This is a research project about social grants. It is trying to understand how mother's, and other women who are looking after children without the children's father, use social grants and how the grants make them feel about themselves.

Who is doing this research? This project is being done by the Centre for the Analysis of South African Social Policy (CASASP) at the University of Oxford, with the Institute of Poverty, Land and Agrarian Studies (PLAAS) at the University of the Western Cape (UWC) and the South African Human Sciences Research Council (HSRC). This research has been approved by a Research Ethics Group at Oxford University.

Do I have to take part? It is your choice to decide whether or not to take part. If you decide not to take part, it will not affect any help you are getting, or affect your grants. The research team is not part of government or any of its agencies giving out grants. You can also stop the interview at any time if you choose.

What will this involve? We will have an interview, which will be recorded. What you say and any information about you will be kept confidential and anonymous. This means that only the research team will know your real name, and anything that you say will be quoted under a different, made-up name. The interview will take about an hour, and will be in your own home language.

Why should I take part in this study? This study aims to help us understand how women use social grants and how they make women feel about themselves and their dignity. This is important 
because we will let the relevant people in government know how the grant affects people like you, and this may help them improve their policies on the grant. We will interview women in the Eastern and Western Cape provinces, and when we have finished we will let you know what we have found, in your home language. We will also write a report about the views of women from these provinces.

What if there is a problem? If you have a concern about any aspect of this project, please speak to the researcher concerned (David Neves on 083 2480120, email: dneves@uwc.ac.za) who will do his best to answer your query. If you remain unhappy and wish to make a formal complaint, please contact the Research Ethics Committee at the University of Oxford (ethics@socsci.ox.ac.uk; +44 (0)1865 614871; Social Sciences \& Humanities Inter-Divisional Research Ethics Committee, Oxford University, Hayes House, 75 George Street, Oxford, OX1 2BQ, UK).

Thank you for reading this sheet. If you feel comfortable to take part in this discussion, then please sign here.

Yours sincerely

David Neves

Institute for Poverty Land and Agrarian Studies (PLAAS)

University of the Western Cape

Cape Town

Participant's name and address 


\section{Institute for Poverty, Land and Agrarian Studies (PLAAS)}

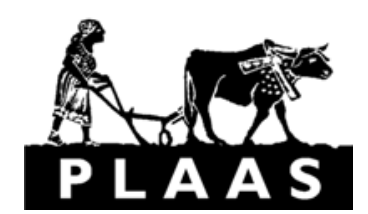

www.plaas.org.za

\begin{tabular}{ll}
\hline School of Government & \\
University of the Western Cape & \\
Private Bag X17 & TEL: +27219593733 \\
BELLVILLE & FAX: +27219593732 \\
7535 & email: plaas@uwc.ac.za
\end{tabular}

Mthathi nxaxheba Obekekileyo

Ukuba ngumama eMzantsi Afrika: Uye uziver njani ngesibonelelo sikarhulumente isichaphazela njani isdima senu?

Nceda uthathe ixesha lokufunda eliphetshana ngononophelo uze uthathe isigqibo sokuba ungathanda na ukuthatha inxaxheba kule ngxoxo. Ukuba unengxaki ukufunda eliphetshana, ukhona omnye weqela labaququzeleli bethu ongakufundelayo. Ukuba ungathanda ukufumana olulwazi ngolwimi Iwakho nceda utsho.

\section{Ingaba lungantoni oluphando?}

Olu luphando ngesibonelelo sikarhulumente (inkam-nkam). Luzama ukuqonda ukuba oomama abakhulisa abantwana ngaphandle kootata baziva njani ngesisibonelelo.

\section{Ngubani owenza oluphando?}

Oluphando luqhutywa ngabesebe lezophando nzulu mayelana nezentlalo (CASASP) eMzantsi Afrika kwiDyunivesthi yase Oxford, Isebe lemfundo elijongene nezendlala, umhlaba nolimo (PLAAS) kwiYunivesiti yaseNtshona koloni(UWC) kwakunye nesebe lezophando nzulu ngoluntu (HSRC) eMzantsi Afrika. Oluphando luvunyelwe liqumrhu labezophando ngokusemthethweni (Research Ethic Group) eYunivesiti yase Oxford.

\section{Ingaba kunyanzelekile ukuba ndithathe inxaxheba?}

Kuxhomekeke kuwe ukuba uyafuna okanye akufuni ukubayinxalenye yoluphando kusinina, lo nto ayisokuze ichaphazele uncedo onokuthi ulufumane, okanye nayiphi na into edibene nesibonelelo osifumana kurhulumente, ungabinaxhala. Ungayeka naninina ukathatha inxaxheba, uva kuwe.

\section{Oluphando luniphathele ntoni?}

Kuza kubakho ingxoxo eyakuthi irekhodwe (ishicelelwe), nayiphina into oyithethayo nencukacha ngawe iyakubayimfihlo. Lonto ithetha ukuba liqela eliququzelelayo kuphela eliyakuba ne negama lakho, yaye nayiphi na into oyakuthi uyithethe iyakukhankanywa phantsi kwegama limbi, hayi elakho. Le ngxoxo iyakuthatha nje ixesha elingange yure enye kuphela, yaye iyakuba ngolwimi Iwakho Iwenkobe. 


\section{Kutheni kufuneka ndithathe inxaxheba nje koluphando?}

Oluphando lujongiswe ekuncedeni thina baququzeleli ukuze siqonde ukuba isidima soomama sichaphazeleka njani yimali yesondlo evela kurhulumente. Oku, kuhle, ngoba sizokwazi ukwazisa abantu abafanelekiyo abasebenzela urhulumente okokuba isondlo sabantwana sikuchaphazela njani, yaye oku kungakhawulelana ekuphuhlisweni kwemithetho yesondlo sabantwana esivela kurhulumente. Sizakuba nengxoxo namabhinqa aseMpuma naseNtshona Koloni, sakugqiba sizakunazisa ngeziphumo ezifumanekileyo ngolwimi Iwenu Iwenkobe. Siyakuthi sibhale nenkcazelo ngezimvo/imbono zala mabhinqa akulamaphondo mabini.

\section{Ukuba kungathi kubenengxaki?}

Ukuba uyasola ngayo nayiphi na into edibene noluphando uyacelwa ukuba uthethe nomququzeleli (David Neves on tel: 0832480120 email: dneves@uwc.ac.za) yena wozama ngako -konke okusemandleni akhe ukuphendula imibuzo oyakuthi ubenayo. Ukuba awanelisekanga kwaye ufuna ukufaka isikhalazo ngokusemthethweni nceda uqhagamshelane neResearch Ethics Committee kwiYunivesiti yase Oxford (ethics@socsci.ox.ac.uk; +44 (0)1865 614871; Social Science \& Humanities Inter-Divisional Research Ethics Committee, Oxford University, Hayes House, 75 George Street, Oxford, OX1 2BQ, UK).

Siyabulela ngoku funda eliphepha. Ukuba ungathanda ukuthatha inxaxheba kulengxoxo nceda utyikitye apha ngezantsi.

Ozithobileyo

David Neves

Researcher

Institute for Poverty, Land and Agrarian Studies

University of the Western Cape (Dyunivesiti yase Ntshona Koloni)

Igama nedilesi zomthathi nxaxheba 


\section{Annex 6: Interview Schedule for elite interviews}

\section{Elite Interview Schedule}

Thank you for agreeing to take part in this interview, we really value your views and are grateful to you for making yourself available to take part. I am going to ask you four questions ( 2 about policy design, 2 about policy implementation), and will then invite you to comment briefly on some of the main emerging themes from the focus group material that we collected last year as part of this same project.

1. The South African constitution includes a commitment to respect and protect people's dignity. Section 27 of the Bill of Rights additionally states that everyone has the right to have access to social security, including, if they are unable to support themselves and their dependants, appropriate social assistance. To what extent does the concept of dignity play a role, if at all, when social security policies are designed, would you say?

2. Have you encountered any practical difficulties or contradictions in the policy design process that might compromise people's sense of dignity?

3. To what extent does the concept of dignity play a role, if it all, when social security policies are implemented, i.e. when people register for and claim for a grant?

4. Have you come across any practical difficulties and or contradictions in the policy implementation process that might compromise people's sense of dignity?

5. I would now like to invite you to comment on two of the emerging themes that have arisen from the focus groups. The lone mothers that we interviewed were very appreciative of the grant and were fully aware that the grant is intended for the child, but they expressed distress about

a) the CSG is insufficient for meeting the needs of the child (does not cover the whole month or the range of needs)

b) the CSG is not intended for the material needs of the mother and so they find themselves in situations that compromise their dignity (e.g. poverty, hunger, abusive relationships with men, prostitution, begging) 


\section{Annex 7: Identifying lone mothers in the GHS 2011}

The GHS series is available to download from the Stats SA website. ${ }^{83}$ The data are available as a person-level file and as a household-level file which can be linked together using the unique household identifier record (Statistics South Africa, 2011:4). The analysis was carried out on the combined household-level and person-level GHS 2011 dataset containing 93,434 individuals. The sampling weights are constructed so that the data can be weighted to represent the entire civilian population of South Africa (Statistics South Africa, 2011:6). According to the GHS 2011 population weights the size of the population in South Africa is 50.3 million.

The GHS does not contain a variable to indicate the lone mothers in the dataset, nor does it contain a variable to indicate a child's main carer. In order to identify lone mothers we first had to identify a child's main female carer (i.e. biological mother or de facto mother) and then identify which of the mothers were caring for their children alone.

It is important to note that the GHS can only be used to identify lone mothers who are resident with their child. It is possible to determine from the data those cases where a mother is absent from the household in which her child lives (using the question which asks whether the individual's biological mother is part of the household). However, it is not possible to establish whether the mother living elsewhere is a lone mother or living with a spouse or partner. Please note that all figures in this annex relate to the unweighted sample.

\section{Identifying main female carers}

The GHS helpfully identifies some of the relationships between the household members, for example biological parents, spouses/partners and all relatives of the household head. For this analysis we were able to identify mothers and fathers living with their biological children and any stepchildren or adopted children of the head of the household. Beyond this it becomes more complicated to identify a child's main carer with the available relationship information.

When there is no existing indication of the child's main carer (i.e. they do not have a biological mother or father and they are not the step or adopted child of the household head) we followed a modified version of the rules used by CASASP for identifying caregivers in the Census for analysis of take up of CSG (Noble et al., 2005) ${ }^{84}$.

We assigned children a 'main female carer' in the following order of preference:

1. Biological mother in the household

\footnotetext{
${ }^{83} \mathrm{http}: / /$ interactive.statssa.gov.za:8282/webview/

${ }^{84}$ See Annex 2 of Noble et al. (2005). This procedure is in turn a modification of a routine developed by Ingrid Woolard for the Department of Social Development.
} 
2. Step or adoptive mother in household (only possible to identify where the step mother is also the head of the household)

3. Oldest working age $(>15<60)$ female in the household

4. Youngest female in the household aged 60 and over

5. Oldest female in the household aged under 16

Steps 3, 4 and 5 are mediated by the presence of an 'obvious' main male carer (i.e. where the child has not been assigned a female carer in steps 1 and 2, and either lives with their biological father or is the stepchild or adopted child of a male head of household, they are not assigned a main female carer).

The mothers identified in step 1 are 'biological mothers', the mothers identified in step 2 are 'step/adoptive mothers') and the mothers identified in steps 3, 4 and 5 are 'de facto mothers'.

Following these steps, the vast majority (95\%) of the dependent children in the dataset are assigned a female carer. The dependent children in the sample who are not assigned a female carer are mainly those children who live with their biological father or those who are the step child or adopted child of a male household head ${ }^{85}$. While many of the remaining cases are children living with a male household member who is neither their biological nor step/adoptive father (i.e. a de facto father) ${ }^{86}$, there are a small number of cases where the child is the oldest in a child headed household (looking after either his/her younger siblings, younger relatives, or own children), or a child living alone. This accounts for just $0.2 \%$ of the sample of children.

Of the dependent children assigned a female carer, $71 \%$ are the biological mother, $1 \%$ are the step/adoptive mother ${ }^{87}$, and $29 \%$ are the de facto mother.

\section{Identifying lone mothers}

Once a female carer has been assigned to each dependent child in the dataset this information is used to flag the lone mothers in the sample.

Each lone mother is only counted once based on the order of preference outlined in the steps above. So a lone mother who is caring for a biological child as well as a nonbiological child will only be counted once (as a 'biological lone mother').

A 'lone' test was applied to all of the mothers identified in steps 1 to 5 based on whether or not the mothers were living with a spouse or partner. This was measured by the

\footnotetext{
${ }^{85} 70 \%$ of these cases are the biological father and $10 \%$ are the step/adoptive father.

${ }^{86} 16 \%$ of the sample of children not assigned a female carer. These de facto fathers are identified using similar rules to those employed in the identification of de facto mothers (i.e. oldest working age $(>15<60)$ male in the household; youngest male in the household aged 60 and over; oldest male in the household aged under 16).

${ }^{87}$ Remember that this could only be determined where the child was the step or adopted child of the head of household.
} 
questions asking whether or not the spouse/partner lives in the household and which household member is the spouse or partner.

Table A7.1 shows the reported marital status of the lone mothers. Two percent of the women identified as lone mothers reported that they were 'living together like husband and wife' (possibly capturing those who live apart due to work or other circumstances and yet regard their status as such, and possibly capturing same sex couples). Ten percent reported that they were 'legally married' (rather than 'separated but still legally married'). Again this is likely to mainly capture women whose spouses are migrant workers: in such a situation a mother might report that she is not living with her spouse and report that she is married. On balance, it seemed more in line with our inclusive approach to defining lone motherhood to look at whether or not a woman reported living with a spouse or partner and to use this as the 'lone' test.

Table A7.1: Marital status of lone mothers

\begin{tabular}{|l|r|}
\hline & $\begin{array}{r}\text { Percentage of } \\
\text { all lone mothers }\end{array}$ \\
\hline Legally married & 10 \\
\hline Living together like husband and wife & 2 \\
\hline Divorced & 3 \\
\hline Separated but still legally married & 2 \\
\hline Widowed & 15 \\
\hline $\begin{array}{l}\text { Single but have lived together with } \\
\text { someone as husband and wife before }\end{array}$ & 3 \\
\hline $\begin{array}{l}\text { Single and have never married or lived } \\
\text { together with someone before }\end{array}$ & 63 \\
\hline Total & 100 \\
\hline N & 10,354 \\
\hline (unweighted) &
\end{tabular}

The majority (76\%) of lone mothers identified using the steps outlined above are the biological mother. Identifying biological lone mothers using the GHS 2011 is a straightforward process using existing variables in the GHS 2011 and so it is reassuring that the majority of lone mothers are identified in step 1 of the process. The identification of step or adoptive lone mothers in step 2 is also unproblematic and uses existing variables. For the lone mothers identified in steps 3,4 and 5 the following caveats should be borne in mind. 
There are two main problems with this method of assigning female carers, which are outlined below.

Problem 1 - overlooking women aged 60 and over

Below is a made up example of a household to illustrate this problem:

\section{Example household 1}

\begin{tabular}{|l|l|l|l|l|l|l|l|l|}
\hline Person & Gender & Age & Rela & Step 1 & Step 2 & Step 3 & Step 4 & Step 5 \\
\hline $\mathbf{1}$ & F & $\mathbf{6 0}$ & $\mathbf{1}$ & $\mathbf{0}$ & $\mathbf{0}$ & $\mathbf{0}$ & $\mathbf{0}$ & $\mathbf{0}$ \\
\hline 2 & F & 25 & 3 & 0 & 0 & 0 & 0 & 0 \\
\hline 3 & F & 14 & 7 & 0 & 0 & 2 & 0 & 0 \\
\hline 4 & F & 7 & 7 & 0 & 0 & 2 & 0 & 0 \\
\hline 5 & M & 5 & 7 & 0 & 0 & 2 & 0 & 0 \\
\hline
\end{tabular}

In this example we see a female headed household (the female head is in bold - she is person 1 ) with three children (those aged under 18 -i.e. persons 3, 4 and 5). The children have not been identified in step 1 as living with their biological mother and they are not the stepchild or adopted child of the head (step 2). In step 3 we can see that person 2 (the 25 year old female) has been identified as the oldest working age female in accordance with the steps outlined above, and is therefore the de facto mother of the three dependent children. This could be the case; however, it is perhaps more likely that the 60 year old female is the main female carer and therefore de facto lone mother of the children. In terms of the relationship variable, the 60 year old woman is the grandmother of the 3 children, and the 25 year old is her daughter/step child/adopted child.

Problem 2 - favouring females over males

Below is a second made up example to illustrate a potential problem:

Example household 2

\begin{tabular}{|l|l|l|l|l|l|l|l|l|}
\hline Person & Gender & Age & Rela & Step 1 & Step 2 & Step 3 & Step 4 & Step 5 \\
\hline $\mathbf{1}$ & $\mathbf{M}$ & $\mathbf{4 5}$ & $\mathbf{1}$ & $\mathbf{0}$ & $\mathbf{0}$ & $\mathbf{0}$ & $\mathbf{0}$ & $\mathbf{0}$ \\
\hline $\mathbf{2}$ & F & 16 & 8 & 0 & 0 & 2 & 0 & 0 \\
\hline 3 & F & 10 & 8 & 0 & 0 & 2 & 0 & 0 \\
\hline 4 & M & 13 & 8 & 0 & 0 & 2 & 0 & 0 \\
\hline
\end{tabular}

In this example we see a household headed by a 45 year old male (in bold). The other members of the household are relatives of the household head (indicated by the 8 in the 
'Rela' column), perhaps nieces and nephews. Because there is no mother (step 1) or female head of household (step 2), the oldest working age female - the 16 year old girl - is assigned the carer status for herself and the other two children. In later steps the 16 year old girl will be assigned non-biological mother status and will be identified as a lone mother due to the fact that she is not living with a partner and is of working age.

A less extreme but still possibly problematic case would be if the female in question was a little older and the other children were under 18 . This female would be assigned the carer status for herself and the other two children, when it is possible that she is their sibling and the carer is actually the male household head.

It is therefore possible that the process used to identify lone mothers may introduce some bias towards an under estimation of lone mothers who are 60 and over and an over estimation of lone mothers aged 16-59 (example 1); and an under estimation of male caregivers (example 2). However, this bias only affects the process from step 3 onwards. . More significantly, probably, the group of migrant worker women who do not live with their children or partner/spouse if they have one are completely omitted from this analysis of the GHS. Notwithstanding these caveats, we feel that the process of identifying lone mothers using the GHS does help to shed some light on the heterogeneous group of women who live with children but not with a spouse or partner. 


\section{Annex 8 Social security for lone mothers elsewhere - some examples}

The provision of social security for lone mothers is a function in part of the overall nature of the welfare state or welfare regime of a country. Goodin (2001) groups countries by the way in which they approach welfare and work in different ways: liberal states which prioritise 'work, not welfare' as the key means out of poverty; corporatist regimes which seek 'welfare through work' and are heavily reliant on a 'male breadwinner model' of contributory social insurance; and social democratic welfare states which support the coexistence of 'welfare and work' and a balance of citizen rights and responsibilities (Goodin, 2001:13).

Overlaying these different ideological approaches towards work and welfare, there has arguably been a change of paradigm in welfare provision generally, from that which was based on the male breadwinner model of the family, where mothers were expected first and foremost to care for their own children, to provision based on the adult worker model of the family, where mothers as well as fathers are now expected to partake in paid work (e.g. Lewis and Giullari, 2005). This can be seen to be part and parcel of the wider sexual revolution and drive for gender equality particularly in the workplace. For women who are mothers this has translated into less financial support for them to stay at home as an unpaid carer and a greater expectation that they will partake in paid work.

In the European context Knijn et al. (2007) have highlighted four commonalities across countries in the welfare provision for lone parents: first, there is an increasing tendency to apply work-related requirements to all benefit recipients including lone parents; second, there is a greater reliance on in-work financial support for those earning low wages; third, there is varying evidence of better support for working parents through policies addressing leave entitlements, flexible working and the provision of childcare facilities; and fourth, there is a growing prevalence for governments to use 'activation' policies with the aim of encouraging lone parents back into the labour market through a range of tailor-made measures, including providing access to further education and training.

Lewis (1998) argues that there are three possible sources of income for lone mothers: the state, wages and fathers. This Annex is primarily concerned with state support in the form of cash benefits and tax breaks, but government policies also impact on the feasibility of employment and thus wage income (e.g. through childcare provision and family friendly policy, and more broadly through labour market policies) and maintenance payments.

A recent $O E C D$ report $(O E C D, 2011)$ identifies five different types of policy measures in support of families: support for mothers-to-be during pregnancy; support for childbirth; longer term financial support for families to cover the direct cost of children; support for parents who are not in paid employment or who stop working to care for young children; and support to help working parents raise their children. These types of policy measure are 
all covered in this Annex but the focus is on the provisions for lone mothers over and above those provided for all families with children, although the review necessarily touches on such issues.

\section{A8.1 Maternity benefits}

Maternity benefits relate to the period during pregnancy and shortly after childbirth. As far as it has been possible to deduce, only one country - Slovakia - has maternity benefits that are specific to lone mothers ${ }^{88}$. It is therefore worth briefly discussing the support that is available to mothers in general.

The International Labour Organization (ILO) has been concerned since its inception with maternity protection, recognising the importance of enabling women 'to successfully combine their reproductive and productive roles, and prevent unequal treatment in employment due to their reproductive role' (ILO, 2010: 1). The ILO's dual concern has been 'to ensure that women's work does not pose risks to the health of the woman and her child and to ensure that women's reproductive roles do not compromise their economic and employment security' (ILO, 2010: v). Maternity protection for women - in the form of prevention of health and safety hazards, rights to paid maternity leave, to return to the job after maternity leave and to breastfeeding breaks, and protection against discrimination based on maternity - contributes to the achievement of the Millennium Development Goals. $^{89}$

A recent study conducted by the ILO (2010) found that internationally only 30 per cent of the ILO member states ${ }^{90}$ fully meet the requirements of ILO Maternity Protection Convention 2000 No. 183. This specifies that states should 'provide for at least 14 weeks of leave at a rate of at least two-thirds of previous earnings, paid by social security, public funds or in a manner determined by national law and practice where the employer is not solely responsible for payment' (ILO, 2010: ix). Requirements for safeguarding employment (non-discrimination and right to return to work) are set out in a number of ILO conventions, including Convention No. 183. The right to health protection for pregnant or nursing women is recognised in Convention No. 183, which includes requirements relating to the arrangement of working time, the avoidance of dangerous and unhealthy work, and the provision of breastfeeding breaks when returning to work after maternity leave. ${ }^{91}$ There are not any ILO standards for other forms of leave, for example paternity or adoption leave, although parental leave is included in the recommendations of a number of Conventions.

\footnotetext{
${ }^{88}$ In Slovakia single mothers are entitled to a greater amount of maternity leave than other mothers (ILO, 2010).

${ }^{89}$ Maternity protection contributes to the health and well-being of mothers and their babies (and thus MDGs 4 and 5 on child mortality and the improvement of the health of mothers) and to women's employment and income security during and after maternity (and thus MDG 3 on gender equality and women's empowerment).

90167 countries were included in the study which was based on 2009 data.

${ }^{91}$ The requirements of Convention No. 183 set out in this paragraph are reinforced in Article 8 of the Code on Social Security in the SADC (SADC, 2007).
} 
Countries vary in terms of the extent to which they fulfill the requirements of Convention No. 183. With regard to maternity leave, all countries provide some maternity leave, but this varies widely and not all meet the requirement of 14 weeks in the Convention. Almost all of the countries in the study provide cash benefits to women during maternity leave ${ }^{92}$. The financing of cash benefits for maternity is typically through one of three main approaches: social security, employer liability or mixed systems. The ILO has advocated the need to reduce the direct cost to the employer through benefits financed by social security, and there has been a shift away from employer liability systems of financing maternity benefits in recent years. Cash benefits can take the form of statutory maternity pay as described above, or maternity allowances (an amount of money paid at intervals for a certain period after a child is born where the mother is not eligible for statutory maternity pay), and/or maternity grants (a one off lump sum amount paid after a child is born to alleviate the costs of new born children).

Table A8.1 shows the key features of maternity provision in selected countries. Certain groups of women (e.g. domestic workers, casual or temporary workers) are explicitly excluded from maternity provision in some countries. Of course, in all countries there remains the question of whether the legislation is effectively implemented so that those eligible actually benefit (ILO, 2010).

\footnotetext{
92 The exceptions are Australia, Lesotho, Papua New Guinea, Swaziland and the United States. These all provide some form of maternity leave but do not have legal provision for cash benefits.
} 
Table A8.1: Examples of maternity support for all mothers

\begin{tabular}{|c|c|c|c|}
\hline Country & Length of leave & Percentage of wages & Source of funding \\
\hline \multicolumn{4}{|c|}{ Selected African } \\
\hline Botswana & 12 weeks & $\begin{array}{l}25 \% \text { or } 50 \% \text { for each } \\
\text { day of absence }\end{array}$ & Employer liability \\
\hline Lesotho & $\begin{array}{l}12 \text { weeks (reportedly } 2 \\
\text { months for public } \\
\text { servants; } 2 \text { weeks for } \\
\text { workers in textile, } \\
\text { clothing and leather } \\
\text { manufacturing } \\
\text { industry }^{93} \text { ) }\end{array}$ & Variable & $\begin{array}{l}\text { Employer liability (but } \\
\text { no obligation for } \\
\text { employers to pay) }\end{array}$ \\
\hline Mozambique & 60 days & $100 \%$ & Employer liability \\
\hline Namibia & 12 weeks & $100 \%$ & Social security \\
\hline South Africa & 4 months & $\begin{array}{l}\text { Up to } 60 \% \text { depending } \\
\text { on income }\end{array}$ & Social security \\
\hline Swaziland & 12 weeks & Unpaid & I \\
\hline Zimbabwe & 98 days & $100 \%$ & Employer liability \\
\hline \multicolumn{4}{|l|}{ Selected other } \\
\hline Australia & 5 weeks & Unpaid & / \\
\hline Brazil & 120 days & $100 \%$ & Social security \\
\hline Mexico & 12 weeks & $100 \%$ & Social security \\
\hline Slovakia & $\begin{array}{l}28 \text { weeks ( } 37 \text { for lone } \\
\text { mothers) }\end{array}$ & $55 \%$ & Social security \\
\hline Sweden & 14 weeks & $80 \%$ & Social security \\
\hline UK & 52 weeks & $\begin{array}{l}6 \text { weeks paid at } 90 \% \text {, } \\
\text { flat rate for weeks } 7- \\
39, \text { weeks } 40-52 \\
\text { unpaid }\end{array}$ & $\begin{array}{l}\text { Mixed (employer } \\
\text { reimbursed for } 92 \% \text { by } \\
\text { the State) }\end{array}$ \\
\hline
\end{tabular}

Source: Adapted from ILO (2010) - information for all 167 countries in study available in report

\section{A8.2 Ongoing financial support for raising a child}

This category of social security refers to both income related (means tested social assistance) and non-income related (universal social allowance) child benefits or family allowances. These are paid to the parents or guardians of children to help with the costs of raising a child. ${ }^{94}$

Child benefits or family allowances, whether income related or non-income related, capture all family types and therefore are not policies specific to lone parents. There are many examples worldwide of both types of child benefit or family allowance. Payments may

\footnotetext{
${ }^{93}$ See Olivier (2013).

${ }^{94}$ For a summary of lone parent tax and benefit schemes in the OECD follow the 'lone-parent benefits' link at http://www.oecd.org/els/benefitsandwagespolicies.htm.
} 
vary by the number of children and the age of the children. In some countries there is extra support for lone parents in the form of an additional payment within the general scheme examples are shown in Table A8.2.

Table A8.2: Examples of additional support specific to lone parents within a general scheme

\begin{tabular}{|l|l|l|l|l|}
\hline Country & $\begin{array}{l}\text { Name of } \\
\text { policy }\end{array}$ & $\begin{array}{l}\text { Means } \\
\text { test }\end{array}$ & $\begin{array}{l}\text { Age } \\
\text { limit }\end{array}$ & Notes \\
\hline Denmark & $\begin{array}{l}\text { Børnetilskud } \\
\text { (child } \\
\text { allowance) }\end{array}$ & No & 18 & $\begin{array}{l}\text { In some cases child allowances are paid in addition } \\
\text { to child benefit. Ordinært børnetilskud (ordinary) is } \\
\text { granted to children of lone parents, amongst } \\
\text { others. } \\
\text { Ekstra børnetilskud (supplementary) is granted to } \\
\text { lone parents whose children receive the ordinært } \\
\text { børnetilskud. Only one ekstra børnetilskud is paid to } \\
\text { the parent, regardless of the number of children. }\end{array}$ \\
\hline Norway & $\begin{array}{l}\text { Barnetrygd } \\
\text { (child benefit) }\end{array}$ & No & 18 & $\begin{array}{l}\text { Lone parents paid for one more child than they } \\
\text { actually have within general scheme (extended } \\
\text { child benefit). } \\
\text { An infant supplement (extra child benefit) is paid to } \\
\text { lone parents with children aged three or under who } \\
\text { receive extended child benefit and full transitional } \\
\text { benefit. }\end{array}$ \\
\hline
\end{tabular}

Sources: Adapted from Bradshaw and Finch (2002) and OECD (2011) with additional information from the following sources:

Denmark - http://ec.europa.eu/employment_social/empl_portal/SSRinEU/

Your\%20social\%20security\%20rights\%20in\%20Denmark_en.pdf (March 2013)

Norway - http://www.nav.no/English/Stay+in+Norway/Barnetrygd.212728.cms (March 2013)

\section{A8.3 Support for low income lone parents}

This section refers to social security in the form of income-related benefits for parents, in particular non-employment benefits (also called 'inactive' benefits) which include all income replacement benefits paid to individuals of working age with few or no work-related conditions attached in order to help them provide for themselves and their families. Insurance benefits are conditional on a record of past contributions to an insurance scheme, while assistance benefits are conditional on current income falling below a certain level (the means test). Some benefits are conditional on both past contributions and a means test (Carcillo and Grubb, 2006).

Certain countries provide financial support for lone parents as a specific group, either as part of a general scheme for unemployed people or those on low incomes (see examples in Table A8.3) or through a separate benefit (see examples in Table A8.4). The support is typically only available until the youngest child reaches a certain age. In some 
instances entitlements to financial support are further limited by a work test (availability for work and/or training - see below), which is linked to the age of the youngest child.

The examples in the tables are all forms of social assistance rather than social insurance, and do not vary by the age of the child.

Table A8.3: Examples of support within a general scheme for lone parents on low incomes

\begin{tabular}{|c|c|c|c|c|}
\hline Country & Name of policy & $\begin{array}{l}\text { Variation by } \\
\text { number }\end{array}$ & $\begin{array}{l}\text { Age } \\
\text { limit }\end{array}$ & Notes \\
\hline Fiji & $\begin{array}{l}\text { Care and } \\
\text { protection } \\
\text { program }\end{array}$ & $\begin{array}{l}\text { No- } \\
\text { amount per } \\
\text { beneficiary }\end{array}$ & 17 & $\begin{array}{l}\text { Allowance for single mothers, deserted } \\
\text { spouses, widows, } \\
\text { prisoner dependants, foster parents/ } \\
\text { guardians. } \\
\text { School age children must be attending school. }\end{array}$ \\
\hline France & $\begin{array}{l}\text { Revenu de } \\
\text { solidarité active } \\
\text { (earned income } \\
\text { supplement) }\end{array}$ & Yes & 20 & $\begin{array}{l}\text { Higher amount if live alone. } \\
\text { Possible extra amount for limited period if live } \\
\text { alone and care for at least one child or are } \\
\text { pregnant. } \\
\text { School age children must be attending school. } \\
\text { Means test on income of children over } 16 .\end{array}$ \\
\hline UK & Income support & No & 5 & $\begin{array}{l}\text { More generous to } 18-24 \text { year old lone parents } \\
\text { than singles. } \\
\text { Extra payment if care for disabled child. }\end{array}$ \\
\hline Yemen & Social welfare fund & Yes & - & $\begin{array}{l}\text { Amount for beneficiary and amount for each } \\
\text { dependant in the household, up to a maximum. } \\
\text { Initially widows and divorced women with } \\
\text { children were targeted but in } 2008 \text { the criteria } \\
\text { were widened to include individuals or } \\
\text { households living below the poverty line, } \\
\text { independently of the categorical criteria. } \\
\text { Further changes include a means test to } \\
\text { exclude the non-poor who are eligible on the } \\
\text { basis of the categorical criteria. }\end{array}$ \\
\hline
\end{tabular}

Sources: Adapted from OECD (2011) with additional information from the following sources:

Fiji - http://www.social-welfare.gov.fi/ (March 2013)

France - https://www.caf.fr/aides-et-services/s-informer-sur-les-aides/solidarite-et-insertion/le-revenu-de-

solidarite-active-rsa (March 2013)

UK - https://www.gov.uk/income-support (March 2013)

Yemen - Bagash et al. (2012) 
Table A8.4: Examples of specific support for lone parents on low incomes

\begin{tabular}{|c|c|c|c|c|}
\hline Country & Name of policy & $\begin{array}{l}\text { Variation by } \\
\text { number }\end{array}$ & Age limit & Notes \\
\hline France & $\begin{array}{l}\text { Allocation de } \\
\text { soutien familial } \\
\text { (family support } \\
\text { allowance) }\end{array}$ & $\begin{array}{l}\text { No-fixed } \\
\text { amount }\end{array}$ & None & $\begin{array}{l}\text { Not guaranteed to all lone parents as it } \\
\text { depends on maintenance payments. } \\
\text { For people bringing up a child alone or } \\
\text { without the support of either parent (i.e. } \\
\text { fostered/adopted) }\end{array}$ \\
\hline Ireland & $\begin{array}{l}\text { One parent family } \\
\text { payment }\end{array}$ & $\begin{array}{l}\text { No-fixed } \\
\text { amount }\end{array}$ & $\begin{array}{l}\text { Gradually } \\
\text { being } \\
\text { reduced to } \\
7\end{array}$ & Personal amount plus amount for child. \\
\hline Japan & $\begin{array}{l}\text { Jido fuyo teate } \\
\text { (child rearing } \\
\text { allowance) }\end{array}$ & Yes & 18 & $\begin{array}{l}\text { Amount varies by number of children. } \\
\text { Income threshold depends on number of } \\
\text { children in a household. }\end{array}$ \\
\hline Norway & $\begin{array}{l}\text { Overgangsst } \varnothing \text { nad } \\
\text { (transitional } \\
\text { benefit) }\end{array}$ & $\begin{array}{l}\text { No-fixed } \\
\text { amount }\end{array}$ & $\begin{array}{l}8 \text { (but see } \\
\text { notes) }\end{array}$ & $\begin{array}{l}\text { Amount varies depending on income. } \\
\text { Once the child is one year old, applicant } \\
\text { must be in activity that constitutes at least } \\
\text { half of a full-time occupation. } \\
\text { Can only receive for up to } 3 \text { years. } \\
\text { If have already been receiving benefit for } 3 \\
\text { years and become sole carer of a new child, } \\
\text { can only receive until the child is entitled to } \\
\text { a place in a day-care institution. } \\
\text { Extension by up to } 2 \text { years if in necessary } \\
\text { education. } \\
\text { Extension by up to } 3 \text { years until youngest } \\
\text { child is } 8 \text { if in necessary education and care } \\
\text { for more than two children, or if became } \\
\text { sole provider before } 18 \text { th birthday. } \\
\text { If become single parent after youngest child } \\
\text { is } 8 \text {, can receive benefit for up to } 2 \text { years } \\
\text { until child is } 10 \text {, subject to activity/ } \\
\text { education requirements. } \\
\text { Possible extension to } 18 \text { if child requires } \\
\text { extra care because of disability, illness or } \\
\text { serious social problems. }\end{array}$ \\
\hline
\end{tabular}

Sources: Adapted from Bradshaw and Finch (2002) and OECD (2011) with additional information from the following sources:

France - http://www.caf.fr/aides-et-services/s-informer-sur-les-aides/solidarite-et-insertion/l-allocation-desoutien-familial-asf (March 2013)

Ireland - http://www.citizensinformation.ie/en/social_welfare/social_welfare_payments/

social_welfare_payments_to_families_and_children/one_parent_family_payment.html (March 2013)

Japan - IPSS (2011)

Norway - http://www.nav.no/English/Stay+in+Norway/805369198.cms (March 2013)

In recent years, in OECD countries at least, there has been a general move towards activation (or active labour market) policies, that is policies to help unemployed people back to work through enforcing work availability and mutual obligation requirements (benefit 
recipients are expected to engage in active job search and to improve their employability, in exchange for receiving efficient employment services and benefit payments) $)^{95}$. This has included policies to reduce expectations of long-term benefit receipt and move nonemployed lone parents off benefits and into work, where before there may have been few work conditions attached to the support they received (OECD, 2011). Examples of activation policies included intensive case management, individual action plans, structured job search assistance, training and education programmes, work experience placements, etc. The introduction of work requirements for lone parents is motivated by the high rates of child poverty in lone parent households and the increasing cost of welfare (Finn and Gloster, 2010) but there are concerns about the detrimental impact of such activation policies (e.g. Cook et al., 2009). Employment is seen as a key route out of poverty for families with children, particularly lone parent families, and yet the issues are complex and require close scrutiny (e.g. in the UK recent DWP-funded studies on lone parents include Coleman and Lanceley, 2011; Finn and Gloster, 2010; Griffiths, 2011; Lane et al., 2011; Sims et al., 2010).

'Work tests' - whereby benefit recipients with children above a certain age are required to be available for work/training - are being introduced at an increasingly early stage to promote labour market re-integration. Table A8.5 provides some examples of work tests for lone parents. There is considerable variation between countries in the age at which the work test is applied, the degree of discretion in deciding whether to impose work requirements and in exemptions to the general rule ${ }^{96}$ (Finn and Gloster, 2010; OECD, 2007; OECD, 2011). Millar (2003: 4) states that with activation policies in general 'there is a great deal of cross-national variation in the degree of compulsion attached to programmes, with different definitions of which lone parents are required to take part in what sort of activities, and significant variation in how strictly this is applied in practice'.

\footnotetext{
${ }^{95}$ http://www.oecd.org/els/employment/almp

${ }^{96}$ Finn and Gloster (2010) give the following examples of exemptions: in France and Norway lone parents are not required to search for work within the first year of becoming a lone parent, whatever the age of the youngest child; in the Netherlands and Australia lone parents are not obliged to accept a job if they are not financially better off in work; and many countries have exemptions for lone parents who have, or have children with, a disability, health problem or special education needs.
} 
Table A8.5: Examples of work tests for lone parents in selected OECD countries

\begin{tabular}{|c|c|c|}
\hline No work test & $\begin{array}{l}\text { Work test applied at discretion of case } \\
\text { managers and/or subject to childcare } \\
\text { availability }\end{array}$ & Work test dependent on child age \\
\hline $\begin{array}{l}\text { Portugal } \\
\text { Spain }\end{array}$ & $\begin{array}{l}\text { Belgium (discretion) } \\
\text { Denmark (subject to childcare) } \\
\text { Finland } \\
\text { Japan (discretion) } \\
\text { Sweden }\end{array}$ & $\begin{array}{l}\text { Ireland (18 or } 22 \text { if child in full-time } \\
\text { education) } \\
\text { New Zealand (16) } \\
\text { UK (5) } \\
\text { Australia (7) } \\
\text { Luxembourg (6) } \\
\text { Canada (varies by state from } 0.5 \text { to 6) } \\
\text { Czech Republic (4) } \\
\text { Austria (3) } \\
\text { France (3) } \\
\text { Germany (3) } \\
\text { Norway (3) } \\
\text { Switzerland (3) } \\
\text { US (varies by state from } 0.25 \text { to } 1 \text { ) } \\
\text { Netherlands (5) }\end{array}$ \\
\hline
\end{tabular}

Source: Adapted from Finn and Gloster (2010). With the exception of the UK the information has not been updated to reflect the current position, which in some cases may be different. For example in Australia the activation policy starts once the youngest child turns 5 (Cook et al., 2009).

These activation policies have been accompanied by the introduction of a range of other provisions aimed at 'making work pay' (financial incentives to work e.g. tax benefits) and 'making work possible' (reducing the barriers to employment and underemployment through e.g. childcare provision and 'family friendly' employment policy).

\section{A8.4 Tax credits}

Strengthening the financial incentives to work has, in some countries, been approached through tax credits and work-conditioned transfers (in-work support), whereby low income families are targeted with an income supplement contingent on work (Brewer et al., 2009). Bradshaw and Finch (2002) distinguish between tax allowances (amounts subtracted from the tax base to arrive at the taxable income) and tax credits (subtracted after gross tax has been assessed).

Eligibility for this form of support depends on family income and often the presence of children, in recognition that there are often higher out-of-work welfare benefits for such families and that the costs of working are higher due to the need for childcare (Brewer et al., 2009). As an example, the aims for tax credits (Child Tax Credit and Working Tax Credit) introduced in the UK in 2003 reveal some of the intentions underpinning this form of support: (i) supporting families with children, recognising the responsibilities that come with parenthood; (ii) tackling child poverty, by offering the greatest help to those most in need, such as low-income families; and (iii) helping to make sure that work pays more than social 
security and that people have incentives to move up the earnings ladder (HM Treasury, 2002 summarised in Millar, 2008).

These policies are often targeted generally at tax-paying adults but there are some examples of support specific to lone parents (variously defined) - see Table A8.6.

Table A8.6: Examples of tax credits for lone parents

\begin{tabular}{|c|c|c|}
\hline Country & Name & Notes \\
\hline Canada & $\begin{array}{l}\text { Eligible dependant } \\
\text { tax credit }\end{array}$ & $\begin{array}{l}\text { For taxpayers without a spouse or common-law partner (or not living } \\
\text { with, supporting, or being supported by such a person) who supported } \\
\text { in their own home a dependant in the year in question. }\end{array}$ \\
\hline Ireland & $\begin{array}{l}\text { One parent family tax } \\
\text { credit }\end{array}$ & $\begin{array}{l}\text { Available to a widowed, separated, deserted or unmarried parent who } \\
\text { is not living together with a partner. The child must live with the } \\
\text { taxpayer and be either: under 18, over } 18 \text { and in full-time education, } \\
\text { or any age if they became permanently incapacitated when under } 21 \\
\text { or in full-time education or training. } \\
\text { Eligibility for the tax credit also entitles the taxpayer to an increase in } \\
\text { the standard rate tax band. }\end{array}$ \\
\hline Netherlands & $\begin{array}{l}\text { (a) Single parent tax } \\
\text { credit } \\
\text { (b) Additional single } \\
\text { parent tax credit }\end{array}$ & $\begin{array}{l}\text { (a) For a single tax payer who: } \\
\text { - is unmarried or lived separated for more than six months } \\
\text { - lives in a household with only his/her own children (including step } \\
\text { children, foster children) who are all under } 27 \\
\text { - contributes to an important extent to the cost of living of at least one } \\
\text { of these children and/or is entitled to child benefit } \\
\text { (b) For a tax payer who: } \\
\text { - is entitled to the single parent tax credit } \\
\text { - has one child younger than } 12 \\
\text { - has income from work outside the household } \\
\text { This tax credit is } 4.3 \% \text { of (taxable) income from work outside the } \\
\text { household, up to a maximum. }\end{array}$ \\
\hline
\end{tabular}

Source: Adapted from Bradshaw and Finch (2002) with additional information from the following sources:

Canada: http://www.cra-arc.gc.ca/tx/ndvdls/tpcs/ncm-tx/rtrn/cmpltng/ddctns/Ins300-350/305/menueng.html (March 2013)

Ireland: http://www.citizensinformation.ie/en/money_and_tax/tax/income_tax_credits_and_reliefs/ one_parent_family_tax_credits_and_reliefs.html (March 2013)

Netherlands: De Vos and De Agostini (2012) 


\section{References}

Ackermann, L. (2000) 'Equality and the South African Constitution: The Role of Dignity', Heidelberg Journal of International Law, 60: 537-556.

Alwang, J., et al. (2001). Vulnerability: A view from different disciplines. Social Protection Discussion Paper Series No. 0115. Washington, D.C., Social Protection Unit, Human Development Network, The World Bank.

Amnesty International (2010) Insecurity and Indignity: women's experiences in the slums of Nairobi, Kenya, London: Amnesty International.

Amoateng, Y., Heaton, T. and Kalule-Sabiti, I. (2007) 'Living arrangements in South Africa' in Y. Amoateng and T. Heaton (eds.) Families and Households in Post-Apartheid South Africa: Socio-Demographic Perspectives, Pretoria: HSRC, pp.43-59.

Bagash, T., Pereznieto, P. and Dubai, K. (2012) Transforming cash transfers: Beneficiary and community perspectives on the Social Welfare Fund in Yemen, London: Overseas Development Institute.

Bak, M. (2008) 'Townships in transition: Women's caring keeps the township together', Journal of Southern African Studies 34(2): 255-268.

Barnes, H., Hall, K. and Wright, G. (2011) Review of Research Evidence on Child Poverty in South Africa, Report for the Monitoring and Learning Facility of the Programme to Support Pro-Poor Policy Development, Office of the Presidency, South Africa.

Biersteker, L. (2012) 'Early childhood development services: Increasing access to benefit the most vulnerable children', in K. Hall, I. Woolard, L. Lake and C. Smith (eds.) South African Child Gauge 2012, Cape Town: Children's Institute, University of Cape Town.

Blackburn, P. (2006) 'The childcare services sector - visions of the future?', European Foundation for the Improvement of Living and Working Conditions.

Bourdieu, P. (1986) The forms of capital. In J. Richardson (Ed.) Handbook of Theory and Research for the Sociology of Education (New York, Greenwood), 241-258.

Bradshaw, J. and Finch, N. (2002) A comparison of child benefit packages in 22 countries, Department for Work and Pensions Research Report No.174, Leeds: Corporate Document Services. 
Bradshaw, J. and Millar, J. (1991) Lone Parent Families in the UK, Department of Social Security Research Report No.6, London: HMSO.

Brady, D. and Burroway, R. (2012) 'Targeting, universalism, and single-mother poverty: A multilevel analysis across 18 affluent democracies', Demography, 49: 719-746.

Brewer, M., Francesconi, M., Gregg, P. And Grogger, J. (2009) 'Feature: In-work benefit reform in a cross-national perspective - Introduction', The Economic Journal, 119 (February): F1-F14.

Budlender, D. (2003) 'The detabe about household headship', Social Dynamics, 29(2): 48-72.

Budlender, D. (2010) 'South Africa: When marriage and the nuclear family are not the norm' in D. Budlender (ed.) Time Use Studies and Unpaid Care Work, London: Routledge Taylor and Francis Group, pp.69-91.

Budlender, D., Rosa, S. and Hall, K. (2005) The cost of the means test for the child support grant, A joint working paper by the Children's Institute and the Centre for Actuarial Research, Cape Town: University of Cape Town.

Budlender, D. and Woolard, I. (2006). The impact of South African Child Support and Old Age grants on children's schooling and work. International Programme on the Elimination of Child Labour. Geneva: International Labour Office.

Bracking, S. and Sachikonye, L. (2006). Remittances, poverty reduction and the informalisation of household well-being in Zimbabwe. GPRG-WPS-045. Global Poverty Research Group. (Available at http://www.gprg.org/pubs/workingpapers/default.htm Bryceson, D.F. and Jamal, V. (eds) (1997). Farewell to farms: De-agrarianisation and employment in Africa. Aldershot: Ashgate

Budowski, M. (2005) Dignity and Daily Practice: The case of lone mothers in Costa Rica, Munster: Lit Verlag.

Burman, S. And Berger, S. (1988) 'When family support fails: the problems of maintenance payments in Apartheid South Africa: Part 1', South African Journal on Human Rights, 4(3), pp. 194-203.

Burman, S. And Berger, S. (1988) 'When family support fails: the problems of maintenance payments in Apartheid South Africa: Part 1', South African Journal on Human Rights, 4(4), pp. 334-354. 
Burman, S. And Barratt, A. (1993) Welfare Law and Bureaucracy in a Changing South Africa: A case study of State Maintenance Grants for the illegitimate, Centre for Applied Legal Studies Working Paper No. 19, Johannesburg: University of the Witwatersrand.

Burman, S. And Barratt, A. (1992) State Maintenance Grants and the Illegitimate: Report for the Black Sash, Socio Legal Research Unit Report No. 1, Cape Town: University of Cape Town.

Carcillo, S. and Grubb, D. (2006) 'From inactivity to work: The role of active labour market policies', OECD Social, Employment and Migration Working Papers No. 36, Paris: OECD Publishing.

Case, A., Hosegood, V. and Lund, F. (2005). The reach and impact of Child Support Grants: evidence from KwaZulu-Natal. Development Southern Africa, 22(4), 267-482.

Chaskalson, A. (2000) 'Human dignity as a Foundational Value of our Constitutional Order', South African Journal of Human Rights, 16: 193-205.

Chochinov, H.M., T. Hack, S. McClement, et al. (1982) 'Dignity in the Terminally III: A Developing Empirical Model', Social Science and Medicine 54: 433-443.

Chopra, D. with Wanjiku Kelbert, A. and Iyer, P. (2013) A feminist political economy analysis of public policies related to care: a thematic review, IDS Evidence Report No.9, Brighton: Institute of Development Studies.

Christopher, C., England, P., Smeeding, T., Phillips, K.R. (2002) 'The gender gap in poverty in modern nations: Single motherhood, the market, and the state', Sociological Perspectives, 45 (3): 219-242.

Clark, S. and Hamplová, D. (no date) 'Single motherhood in sub-Saharan Africa: A life course perspective'.

Cook, K., Davis, E., Smyth, P. and McKenzie, H. (2009) 'The quality of life of single mothers making the transition from welfare to work', Women \& Health, 49: 475-490.

Chzhen, Y. and Bradshaw, J. (2012) 'Lone parents, poverty and policy in the European Union', Journal of European Social Policy, 22 (5): 487-506.

Coleman, N., and Lanceley, L. (2011) Lone Parent Obligations: Supporting the Journey into Work, London: Department for Work and Pensions. 
Currie, I. and De Waal, J. (2005) The Bill of Rights Handbook, Lansdowne: Juta \& Co.

Dawes, A., Biersteker, L. and Hendricks, L. (2010) Western Cape Department of Social Development 2009 Audit of Early Childhood Development Facility Quality, Cape Town: Human Sciences Research Council.

Dekker, A.H. (2008). Mind the gap: Suggestions for bridging the divided between formal and informal social security. Law, Democracy and Development, 12(1), 117-130

Delany, A., Ismail, Z., Graham, L. and Ramkissoon, Y. (2008) Review of the Child Support Grant: Uses, Implementation and Obstacles, A report compiled and produced for the Department of Social Development, the South African Social Security Agency (SASSA) and the United Nations Children's Fund (UNICEF) by the Community Agency for Social Enquiry (CASE), Pretoria: UNICEF.

Delius, P. 1996. A Lion Amongst the Cattle: Reconstruction and Resistance in the Northern Transvaal. Johannesburg: Ravan.

Department for Work and Pensions (2013) Decision Makers' Guide, Available at: http://www.dwp.gov.uk/publications/specialist-guides/decision-makers-guide/\#new). Accessed 03/04/2013.

Department of Social Development (2002) Transforming the Present-Protecting the Future: Report of the Committee of Inquiry into a Comprehensive System of Social Security for South Africa, (Consolidated Report), Pretoria: Department of Social Development

Department of Social Development (2008) Strategic Considerations for a comprehensive system of social security: Discussion Document, Pretoria: Department of Social Development.

Department of Social Development (2013) Department of Social Development Customer Service Charter. Pretoria: Department of Social Development.

DSD, SASSA and UNICEF (2012) The South African Child Support Grant Impact Assessment: Evidence from a survey of children, adolescents and their households, Pretoria: UNICEF, South Africa.

Devereux, S. (2006). Social protection mechanism in southern Africa. IDS Research Report. Brighton Institute of Development Studies, University of Sussex. 
De Vos, K. and De Agostini, P. (2012) EUROMOD Country Report: Netherlands (NL) 20072012, Essex: Institute for Social and Economic Research, University of Essex.

Dinat, N. (2007) 'Restless worlds of work, health and migration: Domestic workers in Johannesburg', Development Southern Africa, 24(1): 186-203.

Dolan, P., Layard, P. and Metcalfe, R. (2011) Subjective Well-being for Public Policy, London: Office for National Statistics.

Duflo, E., 2003. Grandmothers and Granddaughters: Old-age pensions and Intrahousehold Allocation in South Africa. The World Bank Economic Review, 17(1), 1- 25.

Du Toit, A. and D. Neves, 2007. In Search of South Africa's Second Economy. Africanus, 37 (2):145-174.

Du Toit, A. and Neves, D. (2009a) Informal Social Protection in Post-Apartheid Migrant Networks: Vulnerability, Social Networks and Reciprocal Exchange in the Eastern and Western Cape, South Africa, Brooks World Poverty Institute Working Paper No. 74, University of Manchester. (Available at http://www.bwpi.manchester.ac.uk/resources/Working-Papers/index.html)

Du Toit, A. and Neves, D. (2009b) Trading on a Grant: Integrating Formal and Informal Social Protection in Post-Apartheid Migrant Networks, Brooks World Poverty Institute Working Paper No. 75, University of Manchester.

http://www.bwpi.manchester.ac.uk/resources/Working-Papers/index.html)

Dungumaro, E. (2008) 'Gender differentials in household structure and socioeconomic characteristics in South Africa', Journal of Comparative Family Studies, 39(4): 429-451.

Durrheim, K. (1997). Cognition and Ideology: A rhetorical approach to critical theory. Theory \& Psychology, 7, 749-770.

Durrheim, K. \& Dixon, J. (2004) Attitudes in the fiber of everyday life: The discourse of racial evaluation and the lived experience of desegregation. American Psychologist. 59, (7), 626636

Economic and Social Research Council (2012) ESRC Framework for Research Ethics (FRE) 2010 Updated September 2012. Available at http://www.esrc.ac.uk/aboutesrc/information/research-ethics.aspx. 
Esplen, E. (2009) Gender and Care: Overview Report, BRIDGE publication, Brighton: Institute of Development Studies.

Eyben, R. (2012) The hegemony cracked: the power guide to getting care onto the development agenda, IDS Working Paper No.411, Sussex: Institute of Development Studies.

Ferguson, J. (2013). Declarations of dependence: Labour, personhood, and welfare in southern Africa. Journal of the Royal Anthropological Institute, 19, 223-242.

Fine, B. (1999) The Development State is dead - Long live social capital? Development and Change 30(1) 1-19.

Finn D. and Gloster R. (2010) Lone Parent Obligations: A review of recent evidence on the work-related requirements within the benefit systems of different countries, Research Report No. 632, Department for Work and Pensions, London.

Fukuyama (1995). Trust. New York: The Free Press.

Giddens, A. (1979) Central problems in social theory: Action, structure and contradiction in social analysis. Berkley: University of California Press.

Giese, S. and Budlender, D. (2011) Government funding for early childhood development, Learning Brief No. 1 November 2011, Ilifa Labantwana.

Goldblatt, B. (2001) 'Litigating equality - the example of child care', in S. Jagwanth and E. Kalula (eds.) Equality Law - Reflections from South Africa and Elsewhere, Cape Town: Juta.

Goldblatt, B. (2005) 'Gender and Social assistance in the first decade of democracy: a case study of South Africa's child support grant', Politikon, 32: 239-257.

Goldblatt, B., Rosa, S. and Hall, K. (2006) Implementation of the Child Support Grant: a study of four provinces and recommendations for improved service delivery, Cape Town: Children's Institute, University of Cape Town.

Gough, I. and Wood, G. (2004) Insecurity and Welfare Regimes in Asia, Africa and Latin America: Social Policy in Development Context, Cambridge: Cambridge University Press.

Greeff, A.P. and Ritman, I.N. (2005) 'Individual characteristics associated with resilience in single-parent families', Psychological Reports, 96: 36-42. 
Griffiths, R. (2011) Helping More Parents into Work: An Evaluation of the Extension of New Deal Plus for Lone Parents and In Work Credit. Phase 1 Report, London: Department for Work and Pensions.

Haddock, J. (1996) 'Towards Further Clarification of the Concept 'Dignity', Journal of Advanced Nursing, 24: 924-931.

Hall, K. (2007). Where to draw the line? Targeting and leakage in the Child Support Grant. Cape Town: Children's Institute, University of Cape Town.

Hall, K. and Posel, D. (2012) 'Inequalities in children's household contexts: Place, parental presence and migration' in K. Hall, I. Woolard, L. Lake and C. Smith (eds.) South African Child Gauge 2012, Cape Town: University of Cape Town, pp.43-47.

Halman, L. (2001) The European Values Study: A Third Wave, Tilburg: EVS, WORC,Tilburg University.

Hearle, C. and Ruwanpura, K.N. (2009) 'Contentious Care: Foster Care Grants and the Caregiver-Orphan Relationship in KwaZulu-Natal Province, South Africa', Oxford Development Studies 37(4): 423-37

HM Treasury (2002) The child and working tax credits (The modernisation of Britain's tax and benefit system, No. 10), London: HM Treasury.

Hochfield, T. And Graham, L. (2012) 'A feminist reflection on the ethics of social work research', The Social Work Practitioner-Researcher, 24(1), pp.31-47.

Hochfield, T. and Plagerson, S. (2011) 'Dignity and Stigma among South African Female Cash Transfer Recipients', IDS Bulletin 42(6): 53-59. Oxford: Blackwell Publishing Ltd.

Hochschild, A. R. (2000) Global Care Chains and Emotional Surplus Value, in Hutton, W. and Giddens, A. (eds) On The Edge: Living with Global Capitalism. London: Jonathan Cape.

Hoogeveen, J. and Özler, B. (2006) 'Poverty and inequality in post-apartheid South Africa: 1995-2000', in H. Bhorat and R. Kanbur (eds.) Poverty and Policy in Post-Apartheid South Africa, Cape Town: HSRC Press, pp. 59-94.

Hunter N., Hyman I., Krige, D. and Olivier, M., with Dekker, A., Khandhlela, M. and May, J. (2003) South African Social Protection and Expenditure Review. Draft report for Social Protection - Financial, Actuarial and Statistical Services Branch, International Labour Organisation, Geneva. 
International Labour Organisation (2010) Maternity at work: A review of national legislation. Findings from the ILO Database of Conditions of Work and Employment Laws, Second edition, Geneva: International Labour Organization.

International Labour Organization \& WHO (2009). The Social Protection Floor: A joint Crisis Initiative of the UN Chief Executives Board for Co-ordination on the Social Protection Floor. Available at www.un.org/en/ga/second/64/socialprotection.pdf.

International Labour Organisation (2011) Social protection floor for a fair and inclusive globalization: Report of the Advisory Group chaired by Michelle Bachelet Convened by the ILO with the collaboration of the WHO, Geneva: ILO.

IPSS (2011) Social security in Japan 2011, Tokyo: National Institute of Population and Social Security Research.

Kabeer, N. (2007) Mainstreaming Gender in Social Protection for the Informal Economy, London: Commonwealth Secretariat.

Kamwangamalu, M.N. (1999). Ubuntu in South Africa: A socio-linguistic perspective on a Pan-African concept. Critical Arts, 13, 25.

Kankaras, M. and Moors, G. (2009) 'Measurement equivalence in solidarity attitudes in Europe: insights from a multiple-group latent-class factor approach', International Sociology, 24 (4), pp. 557-579.

Khatib, R. and Armenian, H. (2010) 'Developing an Instrument for Measuring Human Dignity and Its Relationship to Health in Palestinian Refugees', World Medical \& Health Policy, 2(2): 35-49.

Kilkey, M. (2000) Lone mothers between paid work and care: The policy regimes in twenty countries, Aldershot: Ashgate.

Knijn, T., Martin, C. and Millar, J. (2007) 'Activation as a common framework for social policies towards lone parents', Social Policy and Administration, 41 (6): 638-652.

Kruger, J. (1998) 'From single parents to poor children: Refocusing South Africa's transfers to poor households with children', Paper presented at ISSA's 2nd International Research Conference on Social Security 'Summing up the evidence: The impact of incentives and targeting on social security', Jerusalem, 25-28 January. 
Kvale, S. (1996). Interviews: An introduction to qualitative research interviewing. London: Sage.

Lane, P., Casebourne, J., Lanceley, L. And Davies, M. (2011) Lone Parent Obligations: work, childcare and the Jobseeker's Allowance regime, DWP Research Report No.782, Sheffield: Department for Work and Pensions.

Lewis, J. (1998) 'Work', 'welfare' and lone mothers', The Political Quarterly, 69 (1): 4-13.

Lewis, J. (2010) Work-Family Balance, Gender and Policy, Cheltenham: Edward Elgar.

Lewis, J. and Giullari, S. (2005) 'The adult worker model family, gender equality and care: the search for new policy principles and the possibilities and problems of a capabilities approach', Economy and Society, 34 (1):76-104.

Liebenberg, S. (2005) 'The value of Human Dignity in Interpreting Socio-Economic Rights', South African Journal of Human Rights, 1: 173-184.

Lund, F. (2006) 'Gender and social security in South Africa'. In V. Padayachee (ed.) The development decade? Economic and social change in South Africa, 1994-2004, Cape Town: Human Sciences Research Council Press, pp. 160-179.

Lund, F. (2008) Changing social policy: The child support grant in South Africa, Pretoria: HSRC Press.

Madhavan, S., Schatz, E., Clark, S. And Collinson, M. (2012) 'Child mobility, maternal status, and household composition in rural South Africa', Demography, 49(2):699-718.

Maluccio, J., Haddad, L. and May, J. (2007). Social Capital and income generation in South Africa 1993-1998. Food consumption and Nutrition Division Discussion Paper no. 71. Washington DC. International Food Policy Research Institute.

Makiwane, M., Desmond, C., Richter, L. and Udjo, E. (2006) Is the Child Support Grant associated with an increase in teenage fertility in South Africa? Evidence from national surveys and administrative data, Pretoria: Human Sciences Research Council.

Martin, P. (2014) 'Children's rights to social assistance: A review of South Africa's Child Support Grant' in P. Proudlock (ed.) South Africa's Progress in Realising Children's Rights: A Law Review. Cape Town: Children's Institute, University of Cape Town \& Save the Children South Africa, pp. 58-83. 
May, V. (2008) 'On being a 'good' mother: the moral presentation of self in written life stories', Sociology, 42: 470-486.

May, V. (2010) 'Lone motherhood as a category of practice', The Sociological Review, 58 (3): 429-443.

McCord, A. (2003) 'An overview of the performance and potential of public works programmes in South Africa', CSSR Working Paper No. 49, Cape Town: Centre for Social Science Research, University of Cape Town.

Meintjes, H., Hall, K., Marera, D. and Boulle, A. (2009) Child-headed Households in South Africa: A Statistical Brief, Cape Town: Children's Institute, University of Cape Town.

Meth, C. (2004). Ideology and Social Policy: 'Handouts' and the spectre of 'dependency', Transformation, 56,1-30.

Meth, C. (2008a) Basic Income Grant: There is no alternative!, School of Development Studies Working Paper No. 54, Durban: University of KwaZulu-Natal.

Meth, C. (2008b) Social Income in South Africa, an economy marred by high unemployment, poverty and extreme inequality, Report for the Human Sciences Research Council.

Millar, J. (2003) 'Employment policies for lone parents', in J. Millar and M. Evans (eds.) Lone parents and employment: International comparisons of what works, Report prepared for the Department for Work and Pensions.

Millar, J. (2008a) 'Making work pay, making tax credits work: An assessment with specific reference to lone-parent employment', International Social Security Review, 61 (2): 2-38.

Millar, J. (2008b) 'Work is Good for You' Lone Mothers, Children, Work and Well-being, Social Security and Health Research Working Paper 60/2008 (2008), Helsinki: Kela, Research Department.

Mnyaka, M. and Motlhabi, M. (2005). The African concept of Ubuntu/Botho and its socialoral significance. Black Theology, 3(2) 215-237.

Mnyandu, M. (1997). Ubuntu as the basis of authentic humanity: An African Christian perspective. Journal of Constructive Theology 3, 81 
Mokomane, Z. (2009) 'Work-family conflict and gender equality in South Africa', paper presented at the $26^{\text {th }}$ IUSSP International Population Conference, Marrakech, Morocco, $27^{\text {th }}$ September $-2^{\text {nd }}$ October 2009.

Moore, E. (2013) 'Transmission and change in South African motherhood: black mothers in three-generational Cape Town families', Journal of Southern African Studies, 39(1): 151-170.

Mosoetsa, S. (2011) Eating from one pot: the dynamics of survival in poor South African households, Johannesburg: Wits University Press.

Moyo, O.N. and Kawewe, S.M. (2009) 'Lone motherhood in Zimbabawe: The Socioeconomic conditions of lone parents and their children', Social Work in Public Health, 24(1-2): 161177.

Mupedziswa, R. and Ntseane, D. (2013). The contribution of non-formal social protection to social development in Botswana. Development Southern Africa, 30(1) 84-97

Morrell, R. and S. Swart, 2005. Men in the Third World: Postcolonial Perspectives on Masculinity. In Handbook of Studies on Men and Masculinities, eds, R.W. Connell, J. Hearn \& M. Kimmel, 90-113. New York/London: Sage.

National Treasury (2013) Budget Review 2013, Pretoria: National Treasury, RSA.

Neves, D., Samson, M., Van Niekerk, I., Hlatshwayo, S. and Du Toit, A. (2009) The use and effectiveness of social grants in South Africa, Working Paper No. 8, Midrand: FinMark Trust.

Noble, M., Barnes, H., Wright, G., McLennan, D., Avenell, D., Whitworth, A., and Roberts, B. (2009) The South African Index of Multiple Deprivation 2001 at Datazone Level, Pretoria: Department of Social Development.

Noble, M., Dibben, C. and Wright, G. (2010) The South African Index of Multiple Deprivation 2007 at Datazone Level (modelled), Pretoria: Department of Social Development.

Noble, M., Ntshongwana, P. and Surender, R. (2008) Attitudes to Work and Social Security in South Africa, Cape Town: HSRC Press.

Noble, M. and Wright, G. (2013a) 'Using indicators of multiple deprivation to demonstrate the spatial legacy of Apartheid in South Africa', Social Indicators Research, 112(1), pp.187201. 
Noble, M. and Wright, G. (2013b) 'Ring of Fire - Socially perceived necessities in informal urban settlements in South Africa', Policy \& Politics, 41(2), pp. 259-277.

Noble, M., Wright, G., Barnes, H., Noble, S., Ntshongwana, P., Gutierrez-Romero, R., McLennan, D. and Avenell, D. (2005) The Child Support Grant: A Sub-Provincial Analysis of Eligibility and Take Up in January 2004, Pretoria: Department of Social Development.

Ntshongwana, P. (2010) Social security provision for lone mothers in South Africa: dependency, independence and dignity, Unpublished doctoral thesis, University of Oxford.

Ntshongwana, P. (2010a) Lone Mothers' Experiences of Employment and Unemployment in South Africa, Pretoria: Department of Social Development.

Ntshongwana, P. (2010b) Childcare Challenges Faced by Lone Mothers in South Africa, Pretoria: Department of Social Development.

Ntshongwana, P., Wright, G. and Noble, M. (2010) Supporting Lone Mothers in South Africa: Towards Comprehensive Social Security, Pretoria: Department of Social Development.

Organisation of African Unity (1999) African Charter on the Rights and Welfare of the Child, entered into force $29^{\text {th }}$ November 1999. Available at http://acerwc.org/wpcontent/uploads/2011/04/ACRWC-EN.pdf.

OECD (2007) Babies and Bosses: Reconciling Work and Family Life. A Synthesis of Findings for OECD Countries, Paris: OECD Publishing.

OECD (2011) Doing Better for Families, Paris: OECD Publishing.

OECD (2012a) Women in Paid and Unpaid Work: Measuring what matters for Gender Equality, Statistics Directorate, Contribution to the Global Thematic Consultation on Addressing Inequalities.

OECD (2012b) OECD Family Database, Paris: OECD (www.oecd.org/social/family/database).

Olivier, M. (2013) 'Social protection in Lesotho: Innovations and reform challenges', Development Southern Africa, 30 (1): 98-110.

Olivier, M., Kaseke, E. and Mpedi, L.G. (2008). Informal social security in Africa: Developing a framework for policy intervention. Conference Paper. International Conference on Social Security. 10-14 March. Cape Town. 
Patel, L., Hochfeld, T. and Moodley, J. (2013) 'Gender and child sensitive social protection in South Africa', Development Southern Africa, 30 (1):69-83.

Patel, L., Hochfeld, T., Moodley, J. And Mutwali, R. (2012) The Gender Dynamics and Impact of the Child Support Grant in Doornkop, Soweto, Centre for Social Development in Africa Research Report, Johannesburg: University of Johannesburg.

Patel, L. Kaseke, E. and Midgley, J. (2012). Indigenous welfare and community based social development: Lessons from African innovation. Journal of Community Practice, 20(1-2), 1231

Payne, J., and Range, M. (1998), Lone Parents' Lives: An Analysis of Partnership, Fertility, Employment and Housing Histories in the 1958 British Birth Cohort, London: Department of Social Security.

Phillips, B.T. (2007) Thoughts on Dignity, Discussion Paper No.1, New Delhi: Programme on Women's Economic, Social and Cultural Rights.

Phillips, B.T. (2011) Dignity and Human Rights: The Missing Dialogue? Report of a Meeting at The Rockefeller Foundation Bellagio Center, Bellagio, Italy, April 7-10, 2009. New Delhi: Programme on Women's Economic, Social and Cultural Rights.

Pillay, U. (2008) 'Urban Policy in Post-Apartheid South Africa: Context, Evolution and Future Directions' Urban Forum, 19 (2): 109-132.

Pillay, U., Roberts, B. and Rule, S. (eds.) (2006) South African Social Attitudes: Changing Times, Diverse Voices, Cape Town: HSRC Press.

Pirouz, F. (2005) Have labour market outcomes affected household structure in South Africa? A descriptive analysis of households, DPRU Working Paper 05/100, Cape Town: University of Cape Town.

Posel, D. (2001a) 'Who are the heads of household, what do they do, and is the concept of headship useful? An analysis of headship in South Africa', Development Southern Africa, 18(5): 651-670.

Posel, D. (2001b) 'How do households work? Migration, the household and remittance behaviour in South Africa', Social Dynamics, 27(1): 165-189.

Posel, D. and Rogan, M. (2012) 'Gendered trends in poverty in the post-apartheid period, 1997-2006', Development Southern Africa, 29(1): 97-113. 
Posel, D., Rudwick, S. and Casale, D. (2011) 'Is marriage a dying institution in South Africa? Exploring changes in marriage in the context of ilobolo payments', Agenda, 87(5): 108-117.

Posel, D. and van der Stoep, G. (2008) 'Co-resident and absent mothers: motherhood and labour force participation in South Africa', Durban: School of Development Studies, University of KwaZulu-Natal.

Putnam, R. (1995). Bowling alone: America's declining social capital. Journal of Democracy. 6(91) 65-78.

Potter, J. and Wetherell, M. (1987). Discourse and social psychology: Beyond attitudes and behavior. London: Sage.

Potter, J. (1998). Discursive social psychology from attitudes to discursive practices. European review of social psychology, 9(1) 233-266

Posel, D. and R. Devey, 2006. The Demographics of Fatherhood in South Africa: An Analysis of Survey Data, 1993-2002. In baba: Men and fatherhood in South Africa, eds, L. Richter and R. Morrell, 38-52. Pretoria: HSRC Press.

Regional Hunger and Vulnerability Programme (RHVP) (2010) Social Protection in Africa: Where are we, and how did we get there? Research Report. RHVP, Johannesburg.

Republic of South Africa (1996) The Constitution of the Republic of South Africa, Section 1 of 1996, Pretoria: Government Printer.

Republic of South Africa (1997) Batho Pele - 'People First': White Paper on Transforming Service Delivery, Department of Public Service and Administration, 18 September 1997, Government Gazette Vol.388, No.18340, $1^{\text {st }}$ October 1997.

Republic of South Africa (1998) Maintenance Act No. 99 of 1998, Government Gazette No. 19513.

Republic of South Africa (2004) Social Assistance Act No. 13 of 2004.

Republic of South Africa (2005) National Integrated Plan for Early Childhood Development in South Africa 2005-2010, Pretoria: Government of Republic of South Africa and UNICEF.

Republic of South Africa (2009) Amendment to the Social Assistance Act 2004, Government Gazette No.32853, Vol.534, pp.3-6. 
Richter, L., Biersteker, L., Burns, J., Desmond, C., Feza, N., Harrison, D., Martin, P., Saloojee, H. And Slemming, W. (2012) Diagnostic Review of Early Childhood Development, $30^{\text {th }}$ May 2012. Pretoria: Presidency Republic of South Africa. Available at: http://www.info.gov.za/view/DownloadFileAction?id=170644.

Roberts, B., Struwig, J., Gordon, S., Ngungu, M. and Jordaan, A. (2013) Family Matters: Family-related Attitudes, Behaviour and Policy Preference in South Africa, Tabulation Report based on the 2012 round of the South African Social Attitudes Survey, Pretoria: HSRC.

Roberts, B., wa Kivilu, M. and Davids, Y.D. (2010) (eds.) South African Social Attitudes: The $2^{\text {nd }}$ Report. Reflections on the Age of Hope, Cape Town: HSRC Press.

Rogan, M. (2012) 'Poverty and headship in post-apartheid South Africa, 1997-2006', Social Indicators Research, DOI 10.1007/s11205-012-0107-8.

Russell, M. (2003a) 'Are urban black families nuclear? A comparative study of black and white South African family norms', 29(2): 153-176.

Russell, M. (2003b) 'Understanding black households: the problem', 29(2): 5-47.

Sagner, A. and R. Mtati, 1999. Politics of Pension Sharing in Urban South Africa. Ageing and Society, 19: 393-416.

SARS (2012) Guide for employers in respect of the Unemployment Insurance Fund, UIF-GEN01-G01, Pretoria: South African Revenue Service.

Samson, M., Babson, O., Haarmann, C., Haarmann, D., Kathi, G., MacQuene, K. and van Niekerk, I. (2002) Research Review on Social Security Reform and the Basic Income Grant for South Africa, EPRI Policy Paper No. 31, Cape Town: Economic Policy Research Institute, University of Cape Town.

Sims, L., Casebourne, J., Bell, L. And Davies, M. (2010) Supporting lone parents' journey off benefits and into work: a qualitative evaluation of the role of In Work Credit, DWP Research Report No.712, Sheffield: Department for Work and Pensions.

Smaling, A. (1992). Varieties of methodological intersubjectivity - the relations with qualitative and quantitative research, and with objectivity. Quality and Quantity, 26, 169180.

Smith, T. (2000) 'Women and tax in South Africa' (available at http://www.fiscalreform.net/index.php?option=com content\&task=view\&id=521\&ltemid=61) 
Social Research Association (2003) Ethical Guidelines, London: SRA.

Social Research Association (2008) Data Protection Act 1998: Guidelines for Social Research, London: SRA.

South African Social Security Agency (2013a) You and Your Grants 2013/14, Available at http://www.sassa.gov.za/Portals/1/Documents/05283ff8-ef75-4869-94b6-c026334269ef.pdf

South African Social Security Agency (2013b) You and Your New SASSA Payment Card:

English, Available at http://www.sassa.gov.za.

Southern African Development Community (2003) Charter of Fundamental Social Rights in SADC, Dar-es-Salaam, 26 August.

Southern African Development Community (2006) Towards an African Regional Social Policy: Johannesburg Draft, Endorsed at the SADC Ministerial Meeting on 24 November 2006 in Johannesburg, South Africa, 2nd Forum of SADC Ministers responsible for social development.

Southern African Development Community (2007) Code on Social Security in the SADC, SADC. (http://www.sadc.int/files/2513/5843/3198/Code on Social Security in SADC.pdf)

Spiegel, A., V. Watson, and P. Wilkinson, 1996. Domestic Diversity and Fluidity Among Some African Households in Greater Cape Town. Social Dynamics, 22(1): 7-30.

Statistics South Africa (2008) Guide to the Quarterly Labour Force Survey, Report number 0211-01, Pretoria: Statistics South Africa.

Statistics South Africa (2011) General Household Survey 2011, Statistics release P0318, Pretoria: Statistics South Africa.

Statistics South Africa (2012a) Census 2011: Metadata, Report No. 03-01-47, Pretoria: Statistics South Africa.

Statistics South Africa (2012b) Social Profile of Vulnerable Groups in South Africa, 2002-2011, Report No. 03-19-00, Pretoria: Statistics South Africa.

Statistics South Africa (2012c) The South Africa I Know, The Home I Understand, Pretoria: Statistics South Africa. 
Surender, R., Noble, M., Wright, G. and Ntshongwana, P. (2010) 'Social assistance and dependency in South Africa: An analysis of attitudes to paid work and social grants', Journal of Social Policy, 39: 203-221.

Surender, R., Ntshongwana, P., Noble, M. and Wright, G. (2007) Employment and Social Security: A Qualitative Study of Attitudes towards the Labour Market and Social Grants, Pretoria: Department of Social Development.

Swartz, S. (2011) "'Going Deep" and "Giving Back" Strategies for Exceeding Ethical Expectations when Researching Amongst Vulnerable Youth', Qualitative Inquiry 11(1): 4768.

United Nations (1948) The Universal Declaration of Human Rights. Adopted and proclaimed by General Assembly resolution 217 A (III) of 10 December 1948. Available at http://www.un.org/en/documents/udhr/

United Nations (1979) Convention on the Elimination of All Forms of Discrimination against Women, adopted in 1979 by the UN General Assembly, available at http://www.un.org/womenwatch/daw/cedaw/.

United Nations (2013) Report of the Special Rapporteur on extreme poverty and human rights, $\mathrm{A} / 68 / 293$. Report on unpaid care work by women.

Van der Berg, S. 1997. South African Social Security under Apartheid and Beyond. Development South Africa, 4(14): 140-164.

Von Holdt, K., Langa, M., Molapo, S., Mogapi, N., Ngubeni, K., Dlamini, J., Kirsten, A., 2011. The smoke that calls: insurgent citizenship, collective violence and the struggle for a place in the new South Africa. Centre for the Study of Violence and Reconciliation; Society Work and Development Institute, Johannesburg.

Vorster, J. (2000) 'Getting social security into gear: reflections on welfare reform in South Africa', paper presented at the International Research Conference on Social Security: 'Social security in the global village', 25-27 September 2000, Helsinki.

Walker, C. (1995) 'Conceptualising motherhood in twentieth century South Africa', Journal of Southern African Studies, 21(3): 417-37.

Wamhoff, S. (2001) South Africa's New Maintenance System: Problems and Suggestions, Centre for Socio Legal Research Report No. 5, Cape Town: University of Cape Town. 
Whiteford, P. and Adema, W. (2007) 'What works best in reducing child poverty: A benefit or work strategy?', OECD Social, Employment and Migration Working Papers No. 52, Paris: OECD Publishing.

Whitworth, A. and Noble, M. (2008) 'A safety net without holes: an argument for a comprehensive income security system for South Africa', Journal of Human Development, 9(2), 247-263.

Whitworth, A. \& Wilkinson, K. (2013). Tackling child poverty in South Africa: Implications of ubuntu for the system of social grants. Development Southern Africa, 30(1) 121-134.

Williams, M. (2007) The Social and Economic Impacts of South Africa's Child Support Grant, EPRI Working Paper No. 40, Cape Town: Economic Policy Research Institute.

Wood, G. (2003) Staying secure, staying poor: The 'Faustian Bargain". World Development, $31(3), 455-471$

Woolard, I and Klasen, S. (2004). Determinants of Income Mobility and Household Poverty Dynamics in South Africa. IZA Discussion Paper No. 1030. Bonn, Germany: Institute for the Study of Labour.

Wright, G., and Noble, M. (2009) The South African Index of Multiple Deprivation 2007 at Municipality Level, Pretoria: Department of Social Development.

Wright, G. and Noble, M. (2010) 'Recent Social Policy Developments in Africa', Global Social Policy, 10(1): 111-119.

Zembe W. (2013) Good but not good enough: the limitations of a social assistance program for children in South Africa -the case of the Child Support Grant. DPhil Thesis. Oxford: Oxford University.

Zuma, J.G. (2014) State of the Nation Address by His Excellency Jacob G. Zuma, President of the Republic of South Africa on the occasion of the Joint Sitting of Parliament, Cape Town, $13^{\text {th }}$ February 2014. 